Florida International University FIU Digital Commons

9-29-2003

\title{
Columbian society in the 1990s : fragmentation, legitimacy, and efficiency
}

Luis Javier Orjuela

Florida International University

DOI: $10.25148 /$ etd.FI15103024

Follow this and additional works at: https://digitalcommons.fiu.edu/etd

Part of the Political Science Commons

\section{Recommended Citation}

Orjuela, Luis Javier, "Columbian society in the 1990s : fragmentation, legitimacy, and efficiency" (2003). FIU Electronic Theses and Dissertations. 2638.

https://digitalcommons.fiu.edu/etd/2638

This work is brought to you for free and open access by the University Graduate School at FIU Digital Commons. It has been accepted for inclusion in FIU Electronic Theses and Dissertations by an authorized administrator of FIU Digital Commons. For more information, please contact dcc@fiu.edu. 


\section{FLORIDA INTERNATIONAL UNIVERSITY}

Miami, Florida

\section{COLOMBIAN SOCIETY IN THE 1990s: \\ FRAGMENTATION, LEGITIMACY, AND EFFICIENCY}

A dissertation submitted in partial fulfillment of the

requirements for the degree of

DOCTOR OF PHILOSOPHY

in

POLITICAL SCIENCE

by

Luis Javier Orjuela

2004 
To: Dean R. Bruce Dunlap

College of Arts and Sciences

This dissertation, written by Luis Javier Orjuela, and entitled Colombian Society in the 1990s: Fragmentation, Legitimacy, and Efficiency, having been approved in respect to style and intellectual content, is referred to you for judgment.

We have read this dissertation and recommend that it be approved.

Brian Nelson

Ronald Cox

Victor M. Uribe

Eduardo Gamarra, Major Professor

Date of Defense: September 29, 2003

The dissertation of Luis Javier Orjuela is approved.

Dean R. Bruce Dunlap College of Arts and Sciences

Dean Douglas Wartzok University Graduate School

Florida International University, 2004 


\author{
ABSTRACT OF THE DISSERTATION \\ COLOMBIAN SOCIETY IN THE 1990s: \\ FRAGMENTATION, LEGITIMACY, AND EFFICIENCY \\ by \\ Luis Javier Orjuela \\ Florida International University, 2004 \\ Miami, Florida \\ Professor Eduardo Gamarra, Major Professor
}

During the nineties, Colombia experienced a two-fold process of restructuring. First, the political system underwent a process of constitutional reform in order to strengthen the state and increase its legitimacy, surpass the exclusionary character of the political regime, and achieve greater equity in the distribution of social resources. Second, the economy made the transition from a Keynesian development strategy to a strategy of "opening" or liberalization and internationalization of the economy, in order to increase the economic efficiency by reducing the "size" of the state and its regulatory role. The purpose of this dissertation is to analyze the interplay and contradictions of economic and political factors in the restructuring of the Colombian politico-economic system.

The main finding of this dissertation is that the simultaneous adoption of a neoliberal economic strategy and of the Political Constitution of 1991, have had a contradictory relationship: while the "political opening" has produced favorable conditions for fostering programs of democratization and social integration, the "economic opening" has counteracted that possibility given that it implies a social 
exclusionary process. This tension has aggravated the problems of political and social integration that have traditionally characterized Colombian society.

This crucial tension has also been characteristic of Latin America in the nineties. However, it has been neglected and undertheorized in most of the democratization studies of American comparative politics. Most of them lack consideration of structural aspects. According to those studies, the cause of regime change is determined by the strategic elections of actors. Contrary to these approaches, I develop a structural perspective. I consider that social phenomena are partly determined by structural factors, and scientific research should assign them decisive importance, since a fundamental basis for social action and transformation is to be found in the dynamics of relationships between individuals and structures and the development of contradictions within structures. 


\section{TABLE OF CONTENTS}

CHAPTER

PAGE

INTRODUCTION

1. LITERATURE REVIEW: A CRITICAL APPRAISAL OF TWO

APPROACHES TO UNDERSTANDING LATIN AMERICAN POLITICS

1.1. The Democratization Approach $\quad 10$

1.2. The Transition to a Market Oriented Economy $\quad 24$

2. THEORETICAL FRAMEWORK: GLOBALIZATION, ECONOMIC LIBERALIZATION, AND THE PROBLEM OF POLITICAL AND SOCIAL INTEGRATION IN LATIN AMERICA

2.1. Social Action: Between the Structural Context and Individual Rationality 46

2.2. Exogenous Factors: Globalization and Neoliberalism 49

2.3. Endogenous Factors $\quad 58$

2.3.1. Society: Cooperation, Conflict, and the Problem of Integration 58

2.3.2. The Weakness of the State $\quad 65$

2.3.3. Social Democracy and Market Economy: Two Social Projects in Conflict 72

2.3.4. The Neoliberal Model and its Effects on the Political Regime 84

$\begin{array}{lr}\text { 2.3.5. Legitimacy Versus Efficiency } & 89\end{array}$

3. STATE, SOCIETY, AND POLITICAL REGIME IN COLOMBIA 93

3.1. The Weakness of the Colombian State 95

3.2. Political Regime as an Amalgam of Premodernity and Modernityand its Limits in a Global World

3.3. The Fragmentation of the Colombian Elite

4. COLOMBIAN SOCIETAL PROYECT I: THE 1991 POLITICAL CONSTITUTION

4.1. The Crisis Leading to the Constitutional Assembly 124

4.2.The Societal Project of the Constitution of 1991: Legitimacy, Democracy and Equity 132

4.2.1. The Quest for Peace

4.2.2. The Introduction of a Social Democracy

4.2.3. Strengthening and Relegitimation of the State and the Political Regime

4.2.4. The Quest for Equity

4.3. The Balance of the New Constitution: A Societal Project without Consensus 
5. COLOMBIAN SOCIETAL PROYECT II: NEOLIBERAL RESTRUCTURING

5.1. Economic Liberalization: An Adequate Societal Project? 161

5.2. The Main Colombian Business Groups 166

5.3. The Early Stage of Economic Liberalization: Ambiguities and Oppositions 171

5.4. The Deepening of the Economic Liberalization 185

5.4.1, Tensions between Anti-Inflation and Liberalization Policies 191

5.4.2. Acceleration of Liberalization $\quad 199$

5.5. From Optimism to Crisis $\quad 204$

5.6. The Effects of the Change of Economic Model on the Political Regime 208

$\begin{array}{ll}\text { 5.6.1. Fragmentation of Economic Elite } & 210\end{array}$

$\begin{array}{ll}\text { 5.6.2. The Breakdown of Labor Agreements } & 217\end{array}$

6. THE CONFLICT BETWEEN PROJECT I AND PROYECT II: LEGITIMACY VERSUS EFFICIENCY $\quad 222$

6.1. Reduction Versus Increased Public Spending 225

6.2. Political Representation Improvement Versus Political Forces Fragmentation $\quad 232$

6.3. Implementation of Neoliberal Economic Model Versus its Unintended Consequences 234

6.4.The Neoliberal Model Versus Economic and Social Heterogeneity 241

6.5. Strengthening of Social Hybridation Social $\quad 251$

6.6. Disagreement over the Criteria for Distributing Social Benefits 256

6.7. The Agreement with the IMF and the Dismounting of the Constitutional Sources of Social Public Spending $\quad 262$

7. CONCLUSIONS WITH SOME HINTS FOR LATIN AMERICA 268

$\begin{array}{ll}\text { BIBLIOGRAPHY } & 280\end{array}$

$\begin{array}{lr}\text { VITA } & 299\end{array}$ 


\section{LIST OF GRAPHS}

GRAPH

PAGE

Graph 1: Central Government Spending by World Regions

Graph 2: The Fall of the Economic Growth Rate

Graph 3: Average Growth Rate of Exports

Graph 4: Evolution of Gini Coefficient

Graph 5: Colombian Foreign Debt 


\section{Introduction}

Colombia, like most Latin American countries, is currently undergoing profound transformations in the state structure, complex processes of economic restructuring, and formidable demographic and cultural transformations. This situation is compounded by disintegrating tendencies produced in recent decades by the convergence of a series of factors such as: a) accelerated, chaotic urbanization caused by industrialization processes that have promoted migration of the rural population to the large cities, as well as by uprooting caused by the múltiple forms of violence that have afflicted the Colombian countryside in recent years; b) tensions and ambiguities in the relationship between processes of economic modernization and democratization; c) persistence of a weak democratic culture, and d) difficulties of identifying the state with the nation. This process of social modernization is related to dynamics that links the country to the present process of economic, political, and cultural globalization that further accentuates problems of social integration.

During the nineties, Colombia experienced a two-fold process of restructuring. In the first place, the political system underwent a process of constitutional reform in order to strengthen the state and increase its legitimacy, surpass the exclusionary character of the political regime, and achieve greater equity in the distribution of social

resources. In the second ! ice. the national economy made the transition from a Keynesian development strategy - imports substitution industrialization - to a strategy of "opening" or liberalization and internationalization of the economy. The objetive of that process was to increase the economic efficiency by reducing the "size" of the state and 
its regulatory role. This two-fold restructuring has deepened Colombia's political and social crisis and has transformed relations between the state, the civil society, and the economy. For this reason, the analytical dimensions in this thesis will revolve around the tensions and contradictions between political and social democratization, the restructuring of the state, and the structural economic adjustment which requires the adoption of a neoliberal development strategy.

A better comprehension of the present political, economic and social processes of Latin America is achieved if one begins with the notion that those processes are a result of the combination of exogenous and endogenous factors. The former consists of globalization and the generalized diffusion of the neoliberal accumulation model. The latter consist of a series of factors present in varying degrees in all Latin American societies, such as the weakness of the state and civil society, the precarious legitimacy of their political regimes, and their social heterogeneity. The result of the conjunction of these exogenous and endogenous factors has been the worsening of the problems of integration that have traditionally characterized the societies of the region.

Thus, from the perspective of this dissertation it is impossible to examine and comprehend the current crisis of the countries of the region without an interdisciplinary view of the way in which the relations among the state, society, and the economy have been estructured in Latin America in general and in Colombia in particular since the early nineties. Any attempt to approach the subject from only one of these angles. would lead to a unilateral and distorted view of of that process. Closed-minded 
"economistic" or "politistic" perspectives limit the construction of models of both analysis and interpretation. This dissertation therefore constitutes an effort to carry out a comprehensive and systematic analysis to show the complexity generated by the interaction of the political and economic phenomena that are determining Colombian reality.

The first chapter of this dissertation consists of a critical review of the bibliography that has been produced by scholars in the United States to analyze both political regime change and structural economic adjustment in Latin America. According to most of the studies reviewed in that chapter, both phenomena are determined by the strategic elections of the actors in the democratization and economic adjustment processes. With the exception of some authors who emphasize international and domestic structural factors in determining the economic restructuring of the Latin American countries, in most of the studies there is a lack of consideration of the structural elements; of the contradictions between the demands of the democratization process and those of neoliberal economic restructuring; of the implications of the change of economic model in the transformation of the political regime; and, of the decisive role of the international factors. The majority of these studies base their explanations of the rise of neoliberal restructuring on the action and the interests of elites in both the public and the private sectors, and the institutional limits within which that action is carried out, or on the basis of the influence, the interests, and the demands of other social actors, such as the organized popular sectors. 
For the above reasons, the second chapter presents an alternative framework that seeks to contribute, from a structural perspective, to a better understanding of the effects that economic and political restructurings have had on Latin American societies. Emphasis will be placed on the sharpening of tendencies toward fragmentation and social disintegration that the transformation of the capital accumulation model has generated.

The main hypothesis of this dissertation is that globalization and adoption of a neoliberal economic strategy as its clearest expression, on the one hand, and simultaneous adoption of the Political Constitution of 1991, on the other, have aggravated the problems of political and social integration that have traditionally characterized Colombian society. The effects of neoliberal strategies on social integration are associated with an increased weakening of the state, the limits it imposes on the continuity of the clientelist political regime, and the the ruling class' inability to elaborate and agree upon a societal project that is broad enough to articulate the diverse social interests involved.

Therefore, the crisis Colombian society has experienced in the past ten years is the result of the convergence of tendencies of political and social disintegration. The former are expressed in the precarious legitimacy of the state due, among other things, to its de-institutionalization, the breaking down of various of its basic functions, the exacerbation of clientelism, the high degrees of violence, and the public's lack of trust in political institutions. The latter are expressed in the ruling classes' inability to elaborate 
and agree upon a societal project broad enough to integrate the diverse social interests; in the fragility of the social fabric; and, in the degradation in the ways in which the social actors assume the conflict, diversity, and disagreement. The analysis of this situation is the objetive of the third chapter.

In the fourth and fifth chapters, it is argued that the crisis of integration in Colombia has been aggravated by the failure to reach a minimum agreement regarding the bases of social order. In this respect, the societal project that arose from the Constitution of 1991 competes with one that is rooted in the neoliberal economic model. While the former was promoted by the progressive forces in the Constitutional Assembly of 1991, the latter has been promoted by the exogenous forces of globalization and by a new technocratic domestic elite. These two projects have advanced in parallel form since 1991, and neither of the two has achieved enough of a consensus to impose its will. In the initial euphoria of democratization caused by the constitutional assembly, Colombian society did not realize the acute contradictions that existed between the two projects, which have since then resulted in the present situation in which it seems impossible to reach an agreement on the fundamental principles of social order.

The effects of the neoliberal development strategy on social integration are also associated with the ruling class' inability to elaborate and agree upon a societal project broad enough to articulate the diverse social interests. That model has generated a division among the economic elites and it is also exclusionary in nature due, among 
other things, to its attempt to reduce work benefits, public social spending and state subsidies, and to the generation of unemployment. Both dimensions of the economic restructuring process limit the elites' possibilities of forming alliances among themselves and with other social sectors, in order to construct democratically the new rules of the game to regulate the relations between the social and political actors. The main objetive of neoliberal economic restructuring has been to develop a market logic in the allocation of resources, the search for fiscal balance, decreased state regulation, and insertion of the Colombian economy into the world market, all imposed by the imperatives of globalization which, among other things, has implied a loss of both the sovereignty and the autonomy of national societies in favor of supra-national regulatory agencies.

Regarding appropriate criteria for allocating social resources, the neoliberal strategy has established that the "laws of economics" and the principles of scarce resources, budget restriction, legal security and supply and demand should govern in these matters. In contrast, the Constitution of 1991 opposed these very principles of commutative justice with the principles of distributive justice, in which the criterion for allocation is not economic but extra-economic, i.e., political. This has a negative effect on neoliberal efforts to reduce public spending, but it was the result of a collective foundational decision in which the criteria and the priorities to be applied in the allocation of social resources were questions that were decided politically. What the confrontation between the two societal projects is showing is that there is no agreement on either the fundamentals of social order or on whether the assignment of liberties, goods and social opportunities should be done on the basis of political criteria and legal 
norms or on the basis of the principles of economic science. The objective of the sixth chapter is to analyze these contradictions.

Finally, it is concluded that if Colombian society wishes to surmount the crisis, it is necessary to generate an agreement on a broader and more inclusive societal project. However, the processes of restructuring the economy associated with the free market and globalization, do not seem to leave room for the social dimension and distributive justice. Nevertheless, the construction of an ethical foundation for agreement regarding a new social order, constitutes the very essence of democracy.

\section{Chapter 1}

\section{Literature Review: \\ A Critical Appraisal of Two Approaches to Understanding Latin American Politics}

The point of departure of this dissertation is that Colombian society has suffered, for several decades, a severe crisis of legitimacy and integration, understood as the weakness of the state, political and economic exclusion, high levels of violence, a lack of trust on the part of the citizens in public and political institutions, and the absence of a ruling class with a project of society strong enough to articulate different social interests.

Institutions are formal and informal rules which structure social life. They constrain social action in order to give political, economic and social relations a 
minimun of covergence. Institutions also facilitate capital acumulation to the extent that they establish property rights and reduce uncertainty, and information and transaction costs (North, 1990). For this reason it is important for society to have an adecuate relation between political and economic institutions. However, in Colombia the simultaneous adoption of a neoliberal economic model and a constitutional reform in the nineties, has deepened problems of political and social integration. To resolve such a crisis, Colombia would need to adopt strong and inclusive political and economic institutions in order to integrate society and mediate its conflicts. But the process of political and economic restructuring of the state and economy have evidenced a contradictory relationship. While the "political opening" has produced favorable conditions for fostering programs of democratization and social integration, the "economic opening" has counteracted that possibility given that it implies a social exclusionary process. This crucial tension between the weak state and the structural constraints of neoliberal economic adjustment has been characteristic of Latin America in the nineties. However it has been neglected and undertheoized in most of the democratization studies.

This double restructuring is the outcome of the confluence of international and national factors. Regarding the international factors, I maintain that the search for democracy and free markets in Latin America in general, and in Colombia in particular, is, in part, the effect of the current worldwide political and economical restructuring toward globalization that reduces the state's room for maneuver in the domestic sphere. This tendency is determining a new relationship between the state, the economy, and 
civil society under the aegis of neoliberalism, producing the emergence of a new situation in Latin America that cannot be analyzed with the traditional democratization approach.

The interplay of economic and political factors in the restructuring of the Colombian politico-economic system, engenders a contradiction between the two pillars of state action: legitimacy and economic efficiency. This contradiction stems from a new constitutional order which claims "more state" as a condition to overcome the legitimacy crisis and integrates society, and a development model which requires "less state" in order to allow the free allocation of society's resources by the market. This contradiction determines the incapacity of the Colombian state and political regime for integrating and orienting society, and redistributing its resources.

Given that the abovementioned tendency is similar in most of the Latin American countries, in this chapter I will discuss my differences with the democratization and political economy approaches that examine political regime change and economic adjustment in the region, neglecting structural political and economic factors. According to most of the studies reviewed in this chapter, the cause of both phenomena is determined by the strategic elections of actors in the democratization and economic restructuring processes. With the exception of some authors who emphazise international and domestic structural factors, in most of studies there is a lack of consideration of structural aspects of the contradictions between the demands of democratization and those of the neoliberal restructuring; of the implications of change 
of the economic model in the transformation of the political regime, and the influence of international factors.

For purposes of analysis, I will identify whether the literature on democratic transition and transition to a market-oriented economy belongs to one or the other of the two major theoretical perspectives in which it can be classified: a) the human agency approach, which in turn, is manifested in two different versions: voluntarism and rational choice theory, and b) the structural approach. The human agency approach places emphasis on the "micro" level, where social phenomena are considered as the result of actors' actions, interests, beliefs, preferences, and choices. The structural approach places emphasis on the "macro" level where social phenomena are explained as the result of transformations in the relationships between political, social or economic conditions, forces and institutions.

It is necessary to highlight these theoretical distinctions in order to establish the framework for the perspective I will maintain in this dissertation, since I consider social relations to consist of the actions of human beings, which are constrained by unintentional forces arising from their actions and interactions.

\subsection{The Democratization Approach}

Owing to the wave of re-democratization that has been sweeping across Latin America since 1980 , the study of the region's political processes has been dominated by the democratization approach for the past two decades. By this I refer to the 
entire area of comparative political studies that aims to analyze different patterns of change from authoritarian regimes to democratic ones and the degree of consolidation of democracy in Latin American countries, as well as the relationship between the actions of different political actors and the kind of democratic institutions that arise therefrom. ${ }^{1}$

Although said studies contributed in part to an understanding of the factors that caused the process of transition from authoritarian to democratic regimes in Latin America and the role performed by the military, political parties, and civil society in these processes, they display serious limitations such as "theoretical denial, voluntarism, barefoot empiricism and intellectual recycling" (Remmer, 1991: 490). From my viewpoint, there are five facts that limit the conceptual and explanatory possibilities of the democratization approach and prevent better understanding of Latin American politics.

First of all, it is not clear that such studies provide "a model of regime change that can be applied around the globe," as asserted by Frances Hagopian (1993:465). Indeed, despite the heterogeneity and complexity of the democratization processes, due to the heterogeneity of socioeconomic conditions and types of regimes that constitute the starting point for democratization, this approach tends to what may be called "south-cone-ization," i.e., it tends to generalize and to apply the

\footnotetext{
${ }^{1}$ The most representative studies within said current of analysis are those by Guillermo O'Donnell, Philippe C. Schmitter, and Laurence Whitehead (1986); James M. Malloy and Mitchell A. Seligson (1987); Larry Diamond, Juan Linz, and Seymour M. Lipset (1989); Dietrich Rueschemeyer, Evelyne Huber Stephens, and John D. Stephens (1992); and James Petras and Fernando I. Leiva (1994).
} 
analysis of the Argentine, Chilean, Uruguayan and Brazilian political processes to all of Latin America. Consciously or unconsciously, such analysis starts from the premise that democracy may only be interrupted by a military or authoritarian regime; that democracy existed before the authoritarian regimes emerged and that it may be resumed through the simple substitution of military regimes by civilian governments. From this perspective, James M. Malloy, in an attempt to elaborate a general framework within which to compare different cases of transition to democracy in Latin America, has had to conclude that the great diversity of national cases prevents the development of general models or theories regarding the shift from authoritarian to democratic regimes in Latin America (1987: 237).

Indeed, since there are cases like Mexico, Costa Rica, Venezuela, and Colombia, in which non-authoritarian civilian regimes - by agreement among the respective political élites - restrict the democratic character of the political system, the transition to democracy approach cannot be applied as a generally valid model. This is especially clear with respect to the Colombian case, which some analysts have asserted is difficult to categorize because,

unlike many of its continental neighbors, Colombia has avoided both military rule and chronic political and economic instability since 1958, when the leaders of the two major parties came together to form the con-sociational National Front (...) The rigid con-sociational practices (relaxed in the post1974 period), combined with other restrictions and have limited the democratic nature of the regime (Hartlyn, 1989: 292-293). 
Secondly, the democratization approach neglects the crucial role that socioeconomic structures play in determining social phenomena. This is a consequence of the theoretical displacement from structuralism to human agency, that has taken place in Latin American political studies in the past decade. One example of this displacement is the change in the theoretical position of O'Donnell (1973), who, after having explained the breakdown of democracy in Latin America in terms of political and economic contradictions engendered by the industrialization process, asserted, along with Schmitter, that "What actors do and do not seems much less tightly determined by "macro" structural during the transitions we study here than during breakdowns of democratic regimes (O'Donnell and Schmitter, 1986: 19).

For these authors, what determines outcomes in the social realm are:

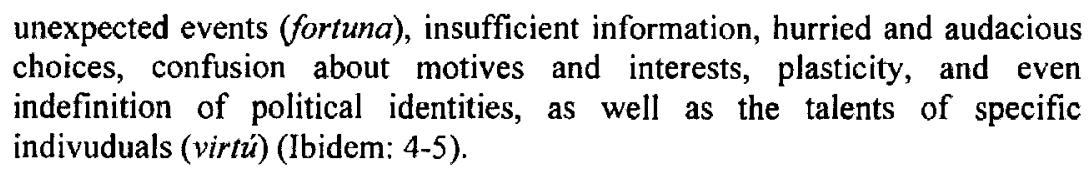
choices, confusion about motives and interests, plasticity, and even indefinition of political identities, as well as the talents of specific indivuduals (virtü) (lbidem: 4-5).

It is theoretically and methodologically incoherent, to say the least, to try to explain the breakdown of democracy as the result of structural factors and its resumption as the result of actors' intentions or human agency. The same is true of Malloy (1987: 239), who, in spite of recognizing that the main structural problem of political economy in Latin America is the contradiction between the need to accumulate capital and the need to achieve political legitimacy by responding to the demands of key social sectors, concludes that the solution to the dilemma lies in the governments' capability to solve key public policy issues. Malloy's adherence to voluntarism appears clearly when he asserts that 
changes in regime are significantly influenced by the decisions of the political leaders who have frequently sought total control of the state. If this assertion is correct, there is obviously a key voluntary dimension to the process that not only makes it difficult to formulate a general theory but also precludes neat deterministic theories based on general laws (ibidem: 237).

These authors' theoretical turns exhibit methodological incoherence, given that a single variable, i.e. regime change, is explained by structural factors in cases of transition to authoritarianism and by human agency in instances of transition to democracy (Remmer, 1991).

Przeworski also develops an approach centered on human agency, in the rational choice version, aimed to highlight the strategic character of democracy. As he points out,

I am convinced that arguments about whether democracies are supported by acting out of values or by strategic pursuit of interests are not resolvable by direct reference to evidence. The two orientations have to and do compete with each other in making sense of the world around us. The only claim I am trying to substantiate is that a theory of democracy based on the assumption of a self-interested strategic compliance is plausible and sufficient (Przeworski, 1991: 24).

Therefore, this author defines democracy in very restrictive terms as a political competition, organized by rules where there are periodic winners and losers and contestation open to participation (ibidem: 10). If there are periodic winners and losers in a democratic system, Przeworski asks himself why political actors accept the rules of the game even when they do not benefit from them in the same way as others? To answer this question, the author develops a preference model to conclude that political actors accept short-term losses in the democratic game if they expect some gains in the future. Thus, democratic consolidation occurs when, despite the 
fact that not all political actors benefit from the democratic arrangements, no one can imagine acting outside the democratic institutions, due to expectations of future winnings, but especially due to the fact the costs of failing to overthrow the democratic regime are higher than those of maintaining it (ibidem: 26).

Przeworski reduces democracy to mere game theortic dynamics, ${ }^{2}$ wherein the democratic character of institutions depends exclusively upon collective actors' rational preferences and choices and on the degree of uncertainty in the correlation of political forces: i.e., the more unknown and uneven the correlation, the more democratic the regime that arises from it will be (ibidem: $81-82$ ). However, this perspective fails to consider two aspects. The first is that individual behavior is ruled not only by rationality but also by norms and institutions embedded in the culture of a given society (Elster, 1992). Secondly, regimes and institutions are also significantly influenced by changes in international politics and economics, class structures, specific historical conjunctures, and crises of consent or legitimacy. This last aspect is expressly rejected by Przeworski who considers that "explanations of regime breakdown in terms of legitimacy are either false or tautological." (ibidem: 54, fn. 2). He considers that legitimacy crises can best be understood as the effect of the organization of "counter-hegemony", but although he recognizes the Gramscian inspiration of this hypothesis, which would therefore seem to have a class character, he rejects the concept of hegemony due to Gramsci's framework

\footnotetext{
${ }^{2}$ Although in these pages I use Przeworski's work as an example of political analysis based on rational choice theory, it is necessary to mention Youssef Cohen's analysis of the breakdown of democracy in Brazil and Chile (1994), and Barbara Gedddes study of state reform in Latin America (1994).
} 
of duality of coercion and consent [which] is not sufficiently specific institutionally to serve as a guide to the problem at hand (ibidem: 55 , fn. 3 ).

Due to its lack of attention to structural factors, the democratization approach also fails to recognize the fact that the transition to democracy in Latin America occurred in a new context: the global processes of internationalization of the economy and the rise of neo-liberalism, which synthesizes an array of structural factors that are reshaping the relationship between the state, politics, economics, and civil society, thus requiring a new theoretical framework to analyze the relationship among them and the problem of fostering democracy. As Remmer points out, every one of the regime transitions that have occurred since the late 1970 s (..) has taken place against a background of major change in the international economy, mounting economic difficulties, and a pro-democratic policy shift on the part of the region's hegemonic power. Studies of democratization, however, have characteristically denigrated the significance of exogenous variables, leaving us with complex and idiosyncratic explanations of individual cases that establish no basis for understanding how and why such a large and heterogeneous collection of authoritarian regimes came to give up power at more or less the same point in time (1991: 486).

Thirdly, for the aforementioned reason, the democratization approach neglects the role of the state as both subject and object of the process of transition to democracy since its explanatory emphasis is placed primarily on the conjunctive analysis of regime change. For some authors of this current of analysis, Latin American politics is seen to be the result of an eternal oscillation between democratic and authoritarian regimes. It is illustrative in this respect to mention Mitchell Seligson, who believes that the whole Latin American region undergoes cyclical periods of democracy and authoritarianism about every twenty years (Seligson, 1987: 
3-4). In a more recent work, Juan Linz and Alfred Stepan have recognized that the democratization approach has paid virtually no attention to the problem of stateness, and they try to fill the gap by showing that no form of democracy is possible without the existence of a sovereign state (Linz and Stepan, 1996: 17).

Three exceptions to this tendency to concentrate exclusively on the rational choices made by agents and regime change are the studies done by Rueschemeyer, Stephens and Stephens (1992), Lipset, Kyoung-Ryung and Torres (1993), and Petras and Leiva (1994), who, with a structural approach, place the emphasis on the interplay between the capitalist economy, the state, social classes, and regime. Rueschemeyer et.al., comparing historical tendencies of democratic development in Latin America, the Caribbean, and Europe, maintain that the possibility of democratization processes is determined by changes in class structure and the autonomy of the state engendered by capitalism. Drawing from Barrington Moore (1966), these authors define class structure as the specific historical articulation of socioeconomic antagonisms that are embodied in different forms of organization and become actors of social and political transformation. However, contrary to Moore, the concept of class of Rueschemeyer et.al. encompasses not only traditional agrarian class relations and landlord-bourgeoisie relations, but urban workers as well, assigning the latter a decisive role in the democratization process (Rueschemeyer et. al., 1992: 58-59 nad 271). Class struggle for participation and distribution of scarce economic and social resources is mediated by the state, which must be autonomous in the face of diverse antagonistic interests. The relative autonomy of the state is 
another central condition for democratic development, which means that the state must have sufficient margin for maneuverability with respect to the dominant classes in order to allow for the expression of other non-dominant but competing interests. As Rueschemeyer, Stephens and Stephens point out,

if the state is simply a tool of the dominant classes, democracy is either impossible or mere form. Such autonomy of the state is in fact but one aspect of the differentiation between political collective decision making and the wider structures of inequality (1992: 64-65).

In synthesis, these authors maintain that capitalist development engenders democracy because it weakens the agrarian dominant class and strengthens organized labor, which in turn, shifts the balance of class power. Indeed, urban workers as a factor of social transformation can explain the democratization process which accompanied the industrialization of Latin America, precisely because the latter process entailed a strengthening of the working class, a key social sector needed by hegemonic classes to set the basis for the new social order, expressed in a "social contract" between politics, capital and labor that gave rise to the welfare state. However, there is a limitation in the framework that Rueschemeyer, Stephens and Stephens propose for explaining the democratization processes of the $1980 \mathrm{~s}$ and 1990 s, since those decades were characterized by the adoption of a neo-liberal development model based on a new relationship between state, economy, and society that redefines the old class-coalitions in which workers played a key role. In the new class arrangements, organized workers are no longer the agents of democratization. Indeed, neo-liberal policies such deregulation of economic process and "flexibilization" of the labor market, weaken workers' ability to respond forcefully and to act collectively and organize in nationwide labor unions. Their negotiating 
power is reduced because it would otherwise interfere with the goal of reduced public spending, which is another pillar of the neo-liberal order.

More than forty years ago, Lipset considered that the level of socioeconomic development determined the degree of democracy. Comparing democratic and nondemocratic countries across four different indices (wealth, industrialization, urbanization, and education), he found that democratic countries had the highest levels in each variable (Lipset, 1959: 80). In 1993 Lipset, along with Kyoung-Ryung and Torres, published the results of a study which basically confirmed Lipset's 1959 conclusion, i.e., "economic development is the single most important predictor of political democracy when controlling for other variables" (Lipset,Kyoung and Torres, 1993: 160). In order to reinforce their findings, these authors argue against O'Donnell's first analysis of the origin of authoritarian regimes in Latin America:

before the wave of transition to democracy beginning in the mid-1970s, some argue that the relationships hypothesized in the 1950s did not hold. But the subsequent record argues for the interconnections between democratic structures and rising levels of income, although economic growth does not determine political democracy by itself (ibidem: 170).

Petras and Leiva depart from the idea that

discussions of political regime, whether electoral-civilian or military, need to refer to the state-class relation upon which they depend. Regimes cannot defend themselves or promote the accumulation process when they act contrary to the state interest (1994:9).

From this structural perspective, they analyze the Chilean transition to democracy taking into account the contradictions that engender the change of ruling élites which must act within a state and economy whose structures were transformed through authoritarian rule. By the "state", these authors mean the permanent institutions that 
exert a monopoly over the means of coercion and those that control the economic levers of the accumulation process, and "the concomitant ensemble of class relations that have been embedded in these same institutions" (Petras and Leiva, 1994: 7). The "regime," on the other hand, is constituted by the political officials who occupy the executive and legislative branches along with the rules that determine the actions of political forces. According to these authors, the new Chilean civil regime inherited an undemocratic staie as a consequence of the authoritarian constitution of 1980, and the adoption of the neo-liberal model of economy. The result was the centralization of capital and "the dramatic growth in social inequalities in income and widespread conditions of poverty, conditions that both broadened and deepened in the process of recovery and economic expansion" (ibidem: 38). Although the conceptual distinction that Leiva and Petras make between "state" and "regime" exhibits methodological problems and requires further theoretical elaboration, it may prove useful in helping to understand the difficulties of fostering democratic development in countries like those of Latin America where states are weak and regimes, owing to their exclusionary and patrimonial character, may counteract such a process.

Fourth, the democratization approach fails to take into account the role played in Latin American polities by societal factors such as the lack of social integration, the weakness of both the state and civil society, and the persistence of pre-modern forms of social and political relations such as clienteslim and 
patrimonialism $^{3}$, and the consequent existence of informal rules and noninstitutionalized forms of behavior (North, 1993; O'Donnell, 1996). In combination, these factors generate hybrid societies and regimes in Latin America that perform in ways notoriously different from what the formal societal norms prescribe, thus affecting the possibility for political and economic reforms to produce the expected results. Due to its neglect of this aspect, the democratization approach cannot provide an adequate explanation, as Hagopian affirms, for "even after rotation of office and partial economic recovery, many of the region's democracies barely manage to limp in an unconsolidated state" ${ }^{4}$ Given this situation, O'Donnell (1996) recognizes the ambiguity of the concept of democratic consolidation and suggests that it should be abandoned in favor of a more realistic approach which takes the persistence of clientelism and other informal rules into account. He therefore resorts to Robert Dahl's concept of polyarchy ${ }^{5}$ in order to identify different types of political institutional agreements in Latin America. Dahl, however, distinguishes between democracy as an ideal type and polyarchy as

the institutional arrangements that have come to be regarded as a kind of imperfect approximation of an ideal, and experience shows, I believe, that when the same term is used for both, needless confusion and essentially irrelevant semantic arguments get in the way of analysis (1971: 9).

In spite of this warning, Dahl's statement has a bearing on democracy studies, generating a true explosion of typologies of democratic regimes which Collier and Levitsky (1997) have termed "democracy with adjectives." Nevertheless, scholars

\footnotetext{
${ }^{3}$ Clientelismo is a political patronage system, whereas patrimonialismo refers to the use of public resources for private purposes.

${ }_{5}^{4}$ Hagopian (1993), p. 465.

${ }^{5}$ As in known, Dahl defines polyarchy as the political order that possesses the following seven attributes: elected officials, free and fair elections, inclusive suffrage, the right to run for office, freedom of expression, alternative information, and associative autonomy (Dahl, 1971: 1; 1989: 220).
} 
do not seem to realize that the use of qualifiers in terms such as "limited-suffrage democracy", "one-party democracy", "illiberal democracy", "tutelary democracy", "delegated democracy", "oligarchic democracy", "restricted democracy", "democracy under siege", and so on, simply permit the creation of euphemisms to refer to the structural social problems of the Third World and its lack of the basic requisites that characterize truly liberal democratic regimes.

Finally, the concept of democracy used in the democratization approach seems very narrow since it is conceived strictly in terms of its political dimension, i.e., as free elections and representative government, while the social and economic dimensions are overlooked precisely at a moment in which neo-liberal restructuring in Latin America is negatively affecting the democratic goal of distribution in the region. To quote just one example, O'Donnell maintains that all the polyarchies he has studied in Latin America "are such because of a simple but crucial fact: elections are institutionalized" (O'Donnell, 1996: 36). This is a minimalist conception of democracy which reduces the task of constructing democracy to mere institutionalization of a political system but which does not take the ethical contents of the resulting institutional order into account. "In this conception, democracy a set of abstract rules, can pose only 'technical' problems of governance and administrative efficacy" (Borón, 1995: 190). However, beyond the electoral politics and instrumental problems of governing are the problems that constitute the very essence of politics: collective deliberation about, among other 
things, the distribution of economic and social goods. Latin American countries underwent (under the authoritarian regimes) or are undergoing (under the civilian ones) a neo-liberal restructuring of their states and economies, which is redefining the concept of democracy and sketching an institutional framework which is determining the conditions in which civilian governments have to act and thereby reducing the spectrum of social and economic policies from which they may choose. Such restructuring is displacing the locus of social justice and distribution from the state to the market, thus affecting the possibilities for the state to pursue a more egalitarian order in societies like those of Latin America which are characterized by extreme inequality.

For the above-mentioned reasons, it is necessary to celebrate the publication of studies with a broader and more critical perspective. Such is the case of the book edited by Agüero and Stark (1998) in which they call on comparative political analysts, in the first place, to elaborate a more complex vision of current Latin American politics, that will take multiple aspects of the normative, historical, cultural, and structural context of Latin American democracy into account, such as gender, ethnicity, administration of justice, "economic reforms, large-scale social restructuring, changes in political practices, and the influence of globalization" (ibidem: ii). In the second place, they are called on to abandon minimalist conceptions of democracy in favor of rethinking the "decoupling between procedural and substantive versions of democracy" (ibidem: 373 ). 


\subsection{The Transition to a Market Oriented Economy}

The 1980 s brought a profound economic crisis to Latin America, characterized by high levels of foreign debt, fiscal deficit, hyperinflation, and low economic growth rates. This situation determined a shift in comparative political studies towards political economy approaches. Initially, these studies, as well as the economic policy measures taken by public policy makers, were of a conjunctural nature, oriented towards generating domestic savings, reducing the fiscal deficit and equilibrating the balance of payments. But reality soon showed that those reforms were due to a process of a structural nature and a new international correlation of forces, expressed in the so-called "Washington consensus" (Williamson, 1990a and 1990b). The result of that process was an actual transition from the model of industrialization through substitution of imports to one of liberalization and internationalization of the economy. This transition required the abandonment of state intervention in the economy along with profound market-oriented reforms. In other words, at the end of the 1980s, Latin America faced a radical transformation in the political, economic and social spheres. Since the mid-1980s this process was articulated with the tendency towards re-democratization of the region, which gave rise to another theoretical approach to analyzing Latin American politics: i.e., that which places emphasis on the transition to a market-oriented economy (the neo-liberal restructuring) and its interplay with the transition to a democratic regime.

Initially, the analysts explored the relation between economic restructuring programs and authoritarian and democratic regimes. Remmer (1990), Haggard 
(1990), Haggard and Kaufman (1992), Bates and Kruger (1993), Przeworski and Limogni (1993), Diamond, Linz and Lipset (1995), and Geddes (1995), all reached the conclusion that, to the contrary of what had been held in the past, authoritarian regimes do not possess any advantage over democratic ones in relation to the performance of the economy and the possibility of adopting policies that altered the economic and social well-being of the diverse social groups. Other analysts explored the relation between that performance and the quality of the bureaucracy and state institutions, and concluded that the role of the public sector was of vital importance for developing successful processes of economic restructuring, for which state autonomy and bureaucratic capacity were required (Evans, 1995; Waterbury, 1992).

Przeworski (1991) examines the interplay between "marketization" and democratization. He develops the argument that the temporary social and economic deterioration caused by market-oriented reform can undermine democratic consolidation or vice versa (ibidem: 137). The costs of economic adjustment will be high for weaker collective actors, especially labor unions. In the face of this situation, governments have two options to carry out the economic adjustment: either to concert and negotiate with the negatively affected groups, which Przeworski considers improbable in developing countries, or to insulate themselves from social pressure, which undermines democracy.

Using rational choice theory, he focuses on the way and the opportunity to make economic adjustments and asserts that political leaders, technocrats and voters all want 
the period of adoption of radical adjustment programs to be as short as possible. This is so because of each actor's pursuit of its rational interest: "people want to eat, technocrats want to succeed, and politicians want to enjoy support" (Przeworski, 1991: 163-164). After having done a complex analysis of different actors' courses of action and their corresponding expectations of maximized utility, Przeworski reaches a conclusion with respect to the sake of the economic reform, which reflects Latin American reality better than other actor-centered analyses do: i.e., given the adoption of radical economic programs

that are eventually slowed or partly reversed, initiated again in a more gradual form with less popular confidence, and again slowed or reversed, until a new government comes in and promises a clean break, and the cycle starts again ... [because political parties reject restructuring while they are in the opposition and pursue it when they are in office], we should expect reforms neither to 'succeed' nor to 'fail', but to proceed in spurts: advancing, stumbling, retreating, and advancing again (ibidem: 179).

However, Przeworski's book does not deal with the question of why politicians in Latin America and Eastern Europe should adopt market-oriented reforms. He takes the economic liberalization programs as a matter of fact, without considering the national and international structural factors that engender the need to make the transition from politically-regulated economic models to market-oriented ones. He does not take into account the existence of an international economic and political system, or global economic changes and transnational forces have produced a worldwide political and economic restructuring, which in turn, internationalizes national decision-making and determines the type of reforms that governments can implement. 
Joan Nelson (1990), and Haggard and Kaufman (1992) also emphasize domestic factors in explaining the adoption of economic restructuring programs and relegate the role of external factors to a second plane, given the variation of national cases of econonic restructuring that can be observed within the framework formed by international factors. However, exogenous factors are among the important constraints that politicians and state agents face in elaborating public policy. The fact that there has been notable coincidence in the adoption of neo-liberal reforms in most Third World countries in recent years, has led some scholars to analyze the role of external factors in determining this policies. Barbara Stallings (1992), among others, analyzes the conditions imposed by international financial agencies such as the International Monetary Fund (IMF) and the World Bank (WB). In doing so, the author is inspired by the relation among three factors used by dependency theory to elaborate its explanatory framework: a) the dependency of Third World exports with respect to international markets of goods and capital, b) the links between the economic élites of the Third World and the interests of international actors, and c) international leverage, understood as the direct use of the power that international financial agencies have over this countries. This approach, however, does not take into account the fact that international markets and actors are also undergoing a profound process of economic and political restructuring. The actions of the international financial agencies in particular are the expression of a new form of economic regulation generated by the globalization process. From this viewpoint, it can be seen that, as structural adjustment deregulates national economies, economic regulation is moved to the international plane, as a consequence of worldwide political, economic and technological transformations that cause production 
and trade to become "planetized", and the regulatory capacity of states to be limited since it was designed to function effectively only within national territories. From this standpoint, the globalization process as a whole, even more than the international financial agencies, acts as a constraint of a truly structural nature.

Gamarra (1994) considers the processes of international restructuring of capital and globalization to be the main forces that have induced economic restructuring in Latin America and reduced the margin of maneuverability on the part of public policy makers, but he does not stop to analyze the relation between the exogenous factors. He concentrates on domestic factors and considers the economic crisis the region suffered to have served as a learning process for the new, democratically elected leaders, based on the errors and experiences of their authoritarian predecessors. This permitted democratically elected rulers to develop more effective and successful policies and to create political coalitions to carry them forward. Therefore, Gamarra (1994: 4-7) argues, solution of the economic crisis was not simply a question of good faith, but also one of political capacity and leadership. Nonetheless, the new democratically elected rulers maintained the exclusionist type of decision making as their authoritarian predecessors. This generated tensions between democratization processes and economic restructuring processes since, on the one hand, Those rulers successfully introduced measures to reduce hyperinflation, for which they had popular support, while on the other hand, they adopted measures that led to deterioration of the social indicators, a fall in per capita income, and an increase in social inequality (ibidem: 6). Thus, the democratization 
and economic restructuring processes not only did not reinforce each other but, instead, the implementation of the latter required strong executives with the capacity to isolate themselves from diverse social demands and pressures which, in turn, entered into contradiction with the need for broad participation and inclusion that are essential to the democratization process. This same idea is expressed by Bresser Perira, Maravall and Przeworski (1994), for whom the stabilization measures not only aggravated the economic crisis but also "generates social costs that make the continuation of reforms politically unpalatable under democratic conditions. Moreover, the technocratic style in which these policies tend to be formulated and implemented undermines the consolidation of democratic institutions (ibidem: 182). Therefore, far from having achieved the consolidation of truly liberal democracies, Latin America in the 1990 s, was characterized by hybrid regimes (ibidem: 6, 12) that combined, and still combine, authoritarian and technocratic decision-making processes with weak democratic legitimization processes and judicial systems (Acuña and Smith, 1994: 18). Acuña and Smith coincide with Gamarra in the idea that economic restructuring led both to the exclusion of the popular sectors from the decision-making process and to concentration of political power in the executive.

In contrast with other simplified concepts of democracy, Gamarra considers that neo-liberal reforms led to two different concepts of democracy in Latin America: a technocratic one, on the part of government officials and international credit and economic regulation agencies, which consider democracy to be simply a question of effective and efficient management of the economy, and another participatory one, 
held by most of the social sectors, for whom democracy means broad access to decision-making processes. From the viewpoint of the former, the legislative and the judicial branches have both proved to be obstacles to the instutionalization of neoliberal adjustment policies since their political demands have endangered fiscal equilibrium (Gamarra, 1994: 11).

The hybrid nature of Latin American political regimes also finds expression in the fact that the new technocratic style of politics induced by the neo-liberal model is articulated with the traditional form of political action in Latin America, i.e., clientelism. According to Gamarra, "many analysts, especially economists, argue that the distribution of patronage undermines the logic of a modern market economy. However, the Latin American record of the late 1980s (and the history of most regions of the world) suggests that patronage was an important instrument in the implementation of neo-liberalism and in securing political stability. It has always been an important tool available to political leaders and the implementation of 'modern' economic reforms did not alter this historical reality" (1994: 7). Although this affirmation is correct, while Latin American clientelism is being used by technocratic decision-makers, it is also beginning to face its limits in economic restructuring and in the new international conditions, as will be seen in the next chapter. Fiscal adjustments and public spending cuts deprive clientelist political action of resources whereas the existence of international agencies like Transparency International creates pressures to reduce political corruption and to establish more direct, rational, impersonal relations between the state and civil society. 
In relation to the support for and the opposition to economic restructuring, Gamarra holds that the former originated in the private sector, which supported the privatization of public enterprises in exchange for beneficial tax reforms (1994: 10), while the latter arose among public employees and social sectors that had previously benefited from public social spending. However, a review of the bibliography on this topic makes it possible to conclude that the participation of business interests has been ambiguous and has not played a very active role in stimulating and orienting economic restructuring policies, whereas the seriously weakened popular sectors are hardly able to oppose the process. Conaghan y Malloy (1994) have expressed themselves in this sense with respect to various countries of the Andean region, as have Sola (1994) with respect to Brazil, and Geddes (1995) who, after analyzing various studies on the subject, holds that

the case studies do not support the stylized view that state policies reflect straightforwardly the desires of interest groups ... one encounters little 'onthe-ground' evidence that groups that have benefited from liberalization or other major changes in economic strategy lobbied for them. Conversely, groups that have borne the costs, especially organized urban labor, have shown less capacity to exert political influence than observers expected (Geddes, 1995: 196).

Mettenheim and Malloy (1998) share the idea that the convergence of democratization and economic restructuring has led to a strengthening of the executive branch in Latin America but, contrary to the authors mentioned previously, they hold that rulers have avoided the extremes of both authoritarianism and liberalısm. To the political capacity of the new democratic leaders already dealt with by Gamarra, Mattenheim and Malloy add 
the factors of creativity and statecraft as crucial to the political, economic and social development of Latin America. The optimism of these two authors contrasts with the realism of other scholars such as Vacs, Ai Camp, Gamarra and Carrion, who collaborated on the edited volume and who point out, on the one hand, the need of those strong executives to isolate themselves from different social sectors in order to successfully implement the neo-liberal policies in open contradiction to the idea of democracy and, on the other hand, the obstacles that political parties and interest groups constitute with respect to the adoption of said policies. Although these "personal characteristics- and human agency-centered approaches" can make important contributions to an understanding of the actors' strategies, they fail to consider the role played by structural factors. Furthermore, it can be argued that strong presidentialism is not something new but rather a traditional characteristic of Latin American political regimes. What is indeed a novelty, introduced by the neo-liberal adjustment process, is the increased power of technocrats and economists, to the detriment of parliamentary and judicial institutions.

The political economy approach presents theoretical and methodological problems that have been analyzed by Acuña and Smith. For these authors, "inferring politics from economics" as well as "divorcing politics from economics" is bad methodology (1994: 23). However, they hold that this relation should not be established on the basis of transformations of the capitalist accumulation model, i.e., the transition from import substitution industrialization to a liberalized market 
economy (ibidem: 56, fn. 6) since, from the political viewpoint, different state institutions, regimes and accords are combined in different ways, with the result that diverse social forces, classes, actors, and groups find diverse ways to further their interests and to achieve their objectives (ibidem: 19).

Despite the fact that these authors recognize that the state, the political regime and the economy can mutually affect each other (Acuña and Smith, 1994: 21), their analysis neglects the structural aspects of that relationship to concentrate on "the logic of support and opposition". For them, the impact of economics on politics occurs in terms of the formation of coalitions that either prevent or facilitate economic restructuring or adjustment. Although it is true that "the same economic policies will determine divergent political outcomes in terms of the level of sociopolitical conflict and opposition to economic reform," (ibidem: 20). Acuña and Smith do not take into account that these divergences conceal profound changes in the relations between social classes, and between social classes and the state. Contrary to what these authors hold, the transformation of these relations follow a similar pattern throughout Latin America since the free-market economic model has structural characteristics which, in articulating the region with the world economy, necessarily lead to a similar redefinition of the relations between the state, the economy, and society. Therefore, in certain historical conjunctures, politics can be inferred from economics and vice versa. 
Contrary to the authors just mentioned, Barbara Geddes recognizes the fact that economic liberalization involves the creation of a new regime. As she points out, because incumbents have gained control over many of the rents created by state intervention in the economy, which in turn plays a central role in attracting political support, the biggest and certainly the most articulate and politically influential losers from structural adjustment in many countries are government officials, cadres of the ruling party and their closest allies. Consequently, regime or government change can increase the likelihood of economic liberalization because it breaks the link between incumbents and the main beneficiaries of statist policies by installing a new set of incumbents (Geddes, 1995: 197). However, it can be argued that the rents and social benefits of the interventionist state not only benefit government officials and cadres of the ruling party but also organized labor, and middle and weaker sectors. The marketoriented reform redefines the relationship between the state, the economy, and civil society. It is precisely this redefinition which implies that incumbents change, which in turn, determines the need to redefine the regime or the rules of the political and economic game. This relationship between state, economic model, and regime will be developed in the next chapter to construct a new framework in order to understand current Latin American politics.

Two reasons impede Acuña and Smith, and Geddes, like many of the authors who adhere to this current of analysis, from placing more emphasis on the structural aspects of the economic, political, and social restructuring of Latin America. In the first place, there is their underlying rational-choice theoretical framework. For these 
authors, the theoretical framework that studies Latin America on the basis of its structural conditions do not permit an understanding of the processes that are presently occuring in the region (Acuña and Smith, 1994: 24). On the contrary, they maintain that

political choices, strategies and contingencies remain central determinants of social and economic processes, and their meaning and consequences perhaps gain even greater relevance in a conjuncture of deep economic crisis and transformations (ibidem: 20).

For these authors, the reasons that generate support or opposition to structural adjustment are rooted in rationality and in the individual interests of the social actors (ibidem: 53). However, economic restructuring not only generates interests, preferences and expectations of the individuals and groups that are affected by it, it also transforms the rules of the game that regulate their social relations. In the second place, Acuña and Smith, like many analysts of Latin American politics, frequently fail to distinguish clearly between the economic crisis of the $1980 \mathrm{~s}$ and the structural transformations of the accumulation model (Acuña and Smith, 1994: 18-24), probably due to the historical sequence and overlapping that existed between the two phenomena. It is therefore necessary to make the following distinction: the debt crisis gave rise to short-term measures oriented to achieving economic stabilization by correcting the negative balance of payments and reducing the fiscal deficit. For this reason, the structural adjustment process has been defined by most analysts as a set of conjunctural measures oriented to promoting long-term economic growth, improving resource allocation, and opening up the national economy to the world market. However, while the policies to confront the economic crisis do not imply a substantial change in the relations between the state, society and the economy, 
economic liberalization does imply it to the degree that it constitutes a structural transformation of the accumulation model. Acuña and Smith both accept the fact that the transformations induced by economic restructuring are not neutral with respect to the class structure and that they can strengthen the power of national and international capitalist interests, to the detriment of other sectors of society. However, this affirmation is not developed in their study. Nonetheless, a profound analysis of the structural transformations of the accumulation model is of great importance at the moment of evaluating the democratic development of Latin America in political and social terms. For this reason, the economic reforms cannot be judged only in terms of resumed growth and consolidation of democracy as maintained by Bresser Pereira, Maravall and Przeworski (1994: 182).

Haggard and Kaufman (1995) also deal with the theoretical framework of political economy studies. Their work constitutes a failed attempt to include the consideration of structural factors in their analysis of the interplay between politics and economics. Their concern is with analyzing the impact of the handling of macroeconomic policy on the withdrawal of authoritarian regimes from power and the consolidation of democratic regimes. The starting point taken by these authors is that the rational choice model used in most studies of the transition to democracy, especially in the aforementioned study by O'Donnell, Schmitter, and Przeworski, has placed an exaggerated emphasis on the actors' decisions. Therefore, it is necessary to take into consideration the social and economic structures that determine who the relevant political actors are and what their preferences are (Haggard and Kaufman: 
1995: 6). These authors begin by analyzing how the transitions from authoritarian rule are produced. The conditions under which an authoritarian regime withdraws is determined by two factors: a) the presence or absence of economic crisis and success or failure in managing economic policy; and b) the degree of cohesion among the ruling élite. From this perspective, the rise of economic crises and deficient management of economic policy on the one hand, and the fragmentation of government coalitions on the other, makes authoritarian regimes unable to establish and control the terms of their withdrawals (a prerogative that might otherwise be feasible) and, consequently, makes it impossible to influence the political process in the democratic regime. In contrast, good economic performance and a cohesive ruling élite can better manage, and even avoid, economic crises, which in turn, redounds in increasing the regime's capacity to withstand political opposition and to determine and control the terms of their withdrawal from power. This enables them to protect themselves and to retain their influence in the democratic regime.

However, despite Haggard and Kaufman's rejection of the preponderant emphasis on actors' strategies and subjective factors to explain democratic transitions, they eventually conclude that the determining factors of changes of regime change are not the structural ones, but rather the personal ability of rulers to manage the economy and to avoid internal divisions within their governments and the coalition that supports them (1995: 12, 37). Haggar and Kaufman are therefore open to the same criticism that they make of authors like O'Donnell, Schmitter, Przeworski and Acuña and Smith: i.e., they neglect the crucial role that 
socioeconomic structures and international factors play in determining social phenomena.

Haggard and Kaufman also analyze the effects of inherited economic conditions in new democracies. Their main argument is that the economic legacies of the authoritarian regimes and of the transition period determine the ability of new democratic rulers to initiate economic "adjustments" and to manage economic policy. For this reason, they distinguish between two types of democratic regimes: a) those that inherit favorable economic conditions and whose task is to maintain the previous economic model, and b) those that inherit an economic crisis situation and must therefore initiate the "economic adjustment" process (1995: 159-163). In the latter case, the initiation of economic reforms requires a powerful, centralized executive, capable of achieving both autonomy and isolation from pressures arising from representative institutions and social sectors negatively affected by such reforms. However, quite to the contrary, the consolidation of economic reform and democracy actually requires the reduction of such autonomy, and a close relationship between the executive and representative institutions since they are crucial in structuring distributive outcomes (ibidem: 335-340).

Two critiques can be made of Haggard and Kaufman. First, their concept of democracy seems very narrow since they consider it to be primarily an instrument to advance the cause of neo-liberal adjustment but not as a means by which to contribute to improving the standard of living of society. As they point out, 
new democratic governments that came to power in the wake of crises had incentives to undertake new policy initiatives, but implementation was difficult precisely because economic problems were more acute and demands for short-term economic relief more widespread. Incoming democratic governments in the non-crisis cases faced a political and policy setting shaped by the fact that authoritarian regimes had already undertaken substantial economic reforms and built a coalition of beneficiaries. In these cases the major question was whether such policies would be sustained under conditions of more open political competition (1995: 153).

Second, Haggard and Kaufman do not provide an explanation of why the new democratic regimes must adopt neo-liberal "economic adjustment," or why its adoption coincides with the emergence of new democracies. To do so would have implied considering structural economic factors from a broader scope rather than focusing only on the short-term horizon of economic performance, as they in fact did (ibidem: 28, 154). The only relationship they establish between economic factors and social transformation is that existing between economic deterioration, social mobilization, and political instability (ibidem: $30-31$ ). This connection can explain a change of regime but it cannot explain the change of economic model. This neglect of macro-structural factors is a characteristic that Haggard and Kaufman's analysis shares with most studies done using the "transition and consolidation to democracy approach." Like most authors of this school, Haggard and Kaufman neglect the fact that the transition to democracy in Latin America occurred within a new context: i.e., the global processes of internationalization of the economy and the rise of neo-liberalism as the structural factors that are reshaping the relationship between the state, politics, the economy, and civil society.

It is possible that this vacuum is being filled by more recent studies on the political economy of Latin America, which show a tendency to reconsider structural 
factors of both an international and a domestic nature. The two books jointly edited by Smith and Korzeniewicz (1996 and 1997) as well as the volume jointly edited by Oxhorn and Ducatenzeiler (1998) all seem to show this trend. The first two authors inspired by Karl Polanyi's holistic view in The Great Transformation - assume a structural, macro-social, and long-lasting perspective of the economic restructuring process in Latin America, which surpasses the view centered on the actor and its agency at the micro-social level in the short term, that Acuna and Smith had posed in 1994. While these authors rejected the relationship between politics and economics in terms of the capital accumulation model at that time, three years later Smith and Korzeniewicz affirmed that

the collision between mobile capital and globalization of production on the one hand, and national and local actors in Latin America on the other, appears to have resulted in a sharp erosion of the capacity of the national state to manage major macroeconomic variables... A more nuanced understanding of the recasting of political power, however, calls attention to new patterns in the relation between political rule and accumulation. From this point of view, the boundaries of political rule and regulation become redefined, as traditional political institutions at the national level increasingly negotiate and coordinate their operations with new agencies of political regulations functioning at a supranational level (1997: 12).

Oxhorn y Ducatenzeiler (1998) start with a double critique of the bibliography on Latin American political economy. In the first place, it tends to ignore the organizations of civil society as an explicative variable, and fails to give due consideration to the fact that civil society has in fact been profoundly affected and weakened by the economic restructuring, especially with respect to the labor movement. In the second place, as has already been mentioned in the case of Haggard and Kaufman, that bibliography "ignores the increasing tendency within Latin America for democratic institutions to become more authoritarian, or confuses 
the institutionalization of authoritarian political practices with democratization" (Oxhorn and Ducatenzeiler, 1998: 7).

Consequently, Oxhorn and Ducatenzeiler hold that insertion into the world economy and the adoption of neo-liberal restructuring policies have led in Latin America to the establishment of "neo-pluralist" regimes, with highly authoritarian features that strengthen the executive and limit the participation of political parties and social organizations. The stability of these regimes is obtained by means of the fragmentation of grassroots organizations (ibidem: 215), which increases the traditional weakness of civil society and affects its ability to pressure for structural changes in its favor (ibidem: 233).

In synthesis, according to most studies under review in this chapter, the cause of both regime change and economic policy making is ultimately determined by the strategic choices of key actors. With the exception of Smith, Acuña and Gamarra (1994), Smith and Korzeniewicz (1997), Agüero and Stark, and Oxhorn and Ducatenzeiler (1998), who emphasize international structural factors in determining the economic restructuring of the Latin American region, most of the studies fail to consider structural elements; the contradictions existing between the requirements of the democratization process and those of neo-liberal economic restructuring; the implications of the change of economic model for the transformation of the political regime; and the decisive role of international factors. Most of the studies explain the rise of neo-liberal restructuring as a result of the action and interests of public or private 
sector élites and of the institutional limits within which said action is carried out, or based on the influence, interests and demands of other social actors, such as organized grass-roots sectors. For this reason, the next chapter seeks to contribute, from a structural perspective, to greater understanding of the effects that economic restructuring has had on Latin American societies. Emphasis will be placed on the intensification of the tendencies toward social fragmentation and disintegration that has resulted from the transformation of the model of accumulation of capital.

\section{Chapter 2}

\section{Theoretical Frame Work: \\ Globalization, Economic Liberalization, and the Problem of Political and Social Integration in Latin America}

Contrary to the approaches of the previous chapter that emphasized the strategic choices of economic and political actors, this chapter will develop a structural perspective. Social phenomena are partly determined by structural factors, and scientific research should assign them decisive importance, since a fundamental basis for social action and transformation is to be found in the dynamics of relationships between individuals and structures and the development of contradictions within structures. In this sense, individual action occurs within frameworks shaped by structural factors and forces generated by individual and collective interactions, and long-term tendencies. 
It is common practice to measure the success or failure of political, economic and social reforms by the degree to which they manage to achieve the purpose and rationality of their authors. Thus, for example, if the stated objective of a given reform was to shrink the size of the state and it was not reduced, it is tipically considered that this failure was due to the deficient or insufficient application of the measure in question. However, in this dissertation I assume a position that goes beyond this type of analysis. I consider that, the dynamics of social processes often surpass actors' intentions, or go even farther beyond, and social actors in conflict for advancing differents societal projects imposes themselves mutual constraints which acts as a structural force. It is the context of forces and social structures in which action is inscribed what determines their destiny. Economic and political reforms, such as the change of accumulation model, or political constitution, are based on postulates of rationality that are not necessarily fulfilled in social reality. It is not possible to anticipate the consequences that a decision will unleash. As Herbert Simon maintains,

in an important sense, all decision is a matter of compromise. The alternative that is finally selected never permits a complete or perfect achievement of objectives, but is merely the best solution that is available under the circumstances. The environmental situation inevitably limits the alternatives that are available, and hence sets a maximum to the level of attainment of purpose that is possible $(1947: 6)$.

Individuals make decisions that may be rational, but society, understood not as the sum of the individuals but as the ensemble of individuals' interactions, generates forces that wind up limiting the individual's field of action. From this perspective, in the Colombian case, the decisions made by actors involved in the economic liberalization policy were constrained by policies concerning the Constitution of 1991, and viceversa. 
At the same time, the structural heterogeneity and fragmentation that characterize Colombian society, coupled with globalization processes in which it is inscribed, affected the course of both societal projects.

Analyses based on rational choice theory are, basically, equilibrium situations carried out in static conditions, from the social point of view (North, 1990: 19). These studies assume that choice situations can arbitrarily be extracted from the historic dynamics of society. However, societies are constituted by continuous and contradictory currents of historic events, and of the assembly of situational consequences which flow from those events. Consequently, actors' choices are always carried out within the current of historic process, determining their options. According to Marx, "men make their own history, but not of their own free will in circumstances they have chosen, but in circumstances they encounter directly, that exist and are a legacy of the past"(1973: 408). The problem with rational choice theory is that it abstracts actors from their historic process. Without the consideration of the impact of historic forces, the analyses of preferences, opportunities, and social action of actors, is inevitably arbitrary. It is impossible to study empirical social processes $a b$ initio, since there is always a prior history that frames any social dynamic. This historic context should be also the subject of analysis. The social process is diachronic. Actors are affected by parallel processes which occur in different levels; there are multiple historic processes and times that elapse in the macro, intermediate, and micro levels of society. Therefore, analyses of the economic and political transformations in America Latina in the 1990s has to take into account that historical context in which those process are inscribed. 
Finally, in an increasingly interconnected and globalized world, analyses of social phenomena should go beyond the relation between action and structure within national societies. It is necessary to take account how the international system and the effects it generates affect domestic domains. It is precisely this complex framework that enables analysts to make generalizations about Latin American politics, since many of the inquiries are very descriptive case studies which lack sound theoretical bases. In the present chapter, I will attempt to develop this interpretative framework.

After examining some theories of social action (2.1), I will outline a theoretical framework for analazing the economic and political reforms in Colombia in the nineties. Examining reforms as the result of the interaction of exogenous and endogenous factors provides a better understanding of the current political, economic and social situation not only of Colombia but also in Latin America. Globalization and the generalized diffusion of the neoliberal accumulation model form the exogenous factors (2.2). Endogenous considerations are present to a greater or lesser degree in all Latin American countries, including the precarious integration of their societies and their social heterogeneity (2.3.1); state weakness (2.3.2); the conflict between political and economic restructurings as a societal projects (2.3.3); the effects of neoliberal restructuring on their political regimes (2.3.4); and finally, the contradiction between the search for legitimacy and efficiency inherent in by both political and economic restructuring (2.3.5). The intersection of exogenous and endogenous factors has 
aggravated of the problems of integration that have historically characterized the region's societies.

\subsection{Social Action: Between the Structural Context and Individual Rationality}

As the previous chapter illustrated, current political science tends to explain social phenomena in terms of the intentional and rational actions of actors. The dominance of rational choice theory and its inscription within methodological individualism accounts for this tendency. This position, take for granted that the central debate in the social sciences is between methodologial individualism and methodological structuralism, where social action is considered a result of a series of constraints imposed by the historic development of society, human interactions, conflict, norms and social institutions, technological development, and environmental and international factors, among others.

In the last two decades, however, a school of thought has emerged that go beyond the agent- structure debate by integrating both positions. Among the most representative authors of this school are Anthony Giddens (1984, 1997), Douglass North (1990), and Jon Elster (1992).

Giddens' point of departure is his criticism of structural functionalism and of structuralism (1997). He criticizes the first perspective for its reduction of human action to a mere interiorization of values, and its use of the concept of structure in purely descriptive terms; the second is accused of structural determinism. For Giddens both 
approaches lead to denying the agency of actors in the constituting society. For this theorist society is in part a result of the capabilities of social actors (1994), and in part a result of the social structures, which enable actors to perform. Drawing on Marx, Giddens affirms that though social actors generate society, they do not do it under conditions of their own election (1997: 127-128), but rather this effort is structurally determined. The structures, nevertheless, should not be understood as mere constraints on human action, but also as the factors that enable agency. Social structures, defined by Giddens as a "recursively organized set of rules and resources" (1984: 25) arise from a succession of repeated actions which through their repetition structure social life. In such a way, actions generate structures and these, in turn, enable individuals to act. Giddens refers to this condition of social structures as both originated and result from human action as the "duality of structure":

"according to the notion of the duality of structure, the structural properties of social systems are both medium and outcome of the practice they recursively organize. Structure is not 'external' to individuals: as memory traces, and as instantiated in social practices, it is in a certain sense more 'internal' that exterior to their activities in a Durkheimian sense. Structure in not to be equated with constraint but is always both constraining and enabling" (1984: 25).

North seeks to develop a institutional framework to oppose the idea of the rational actor upon which the economic theory is based. For North, institutions are the rules of the social game which

"reduce uncertainty by providing a structure to every day life. They are a guide to human interaction, so that when we wish to greet friends on the street, drive an automobile, buy oranges, borrow money, form a business, bury our dead, or whatever, we know (or can learn easily) how to perform this tasks" (North, 1990: 3-4). 
Institutions are thus the framework within which individual action and social interactions are produced. A theory of institutions, argues North, requires the separation of the analysis of the rules of the game from that of actors' strategies (ibidem: 5-6), because institutions have their own logic and relative autonomy. At the same time, however, North affirms that "institutions are a creation of human beings. They evolve and are altered by human beings" (1990: 5). Therefore, there is a relationship of mutual determination between human agency and institutional constraints. By the integrating individual's strategic choices with institutional constraints, North has taken a step toward the unification of theory and methodology in the social sciences. North also transcends the primacy of individual action with his conception of social change, starting from his distinction between formal and informal institutions (1990: 73). Historic change is the result of the interplay between formal institutions which can be modified by the intentional actions of actors, and the resistance opposed by intentional modification by informal norms constituted by the culture, which resists all attempts at intentional modification (ibidem: 16).

Elster (1998) also tries to establish a mutual relation between agent and structure through his criticism of the reduccionism rationalist and normativist approaches. His central concern is the diverse dimensions of social action which is guided by instrumental racionality in certain spheres, and by social norms in others. As Elster has pointed out, human behavior is a result of the tension between homo oeconomicus and homo sociologicus:

The former is supposed to be guided by an instrumental rationality, while the conduct of the latter is dictated by social norms. The former is "pulled" by 
perspectives of future reward, while the latter is "pushed" from behind by quasi-internal forces. The former adapts to changing circumstances ... the latter adheres to prescribed conduct even when new and apparently better options are available to it (Elster, 1992: 119).

The merit of these three perspectives is that they incorporate agency and structure in their analysis of how social institutions are produced. Nonetheless, each of three theorists assume that the social actors converge around a single institutional framework, ignoring that they are, in fact, in permanent conflict whit regard to institucional arrangements. While some actors seek to maintain the statu quo, others seek to reform or to transform social institutions. This conflictual relationship imposes mutual constraints which act as structural determinants of both collective and individual actions. In certain moments structural constraints are even more determinant. Junctures in which social structures are sharply redefined, such as globalization, regime change, or a new model of accumulation, can alter the rules of the game that govern social behavior.

\subsection{Exogenous Factors: Globalization and Neoliberalism}

Political, social and economic problems have traditionally been analyzed from two different perspectives: the nation-state and the international system. This is the legacy of the Westphalian order which consists basically of: a) the principle of state sovereignty, understood as the supreme and exclusive power of the state over the population and the territory, and b) the search for nation-state autonomy in a world characterized by rivalry among states. However, in recent decades a broad spectrum of phenomena are causing globalization, which is altering the so-called Westphalian order. By globalization is meant a broad and complex process that links technological, 
political, economic, cultural and institutional dimensions, by means of which the distances have been made "so much shorter, the movement of ideas, pictures, currencies [goods] and information so much faster, and thus the interdependence of peoples and events so much greater" (Rosenau, 1990: 12). Among the principal causes of globalization is the development of micro-electronics and its application to practically all spheres of human activity, but especially to production and communications. It has generated the progressive interdependence of different national societies, the spatial reorganization of production, the international integration of trade and financial markets, and a profound transformation of the international system. Globalization, however, extends beyond the economic realm and promotes changes in political and cultural concepts and practices as well, and reduces the time and space dimensions of social relations (Mittelman,1996:3). From this perspective, one can say that globalization is characterized by emerging patterns of universal interconnectedness and an increased consciousness of the world as a unitary whole.

In particular, the application of micro-electronic technology to industry and telecommunications has led to the exhaustion of traditional models of production and management such as Taylorism and Fordism. This is expressed, among others things, in the replacement of production of finished goods under one large roof of a single factory, by the production of component parts which may be produced anywhere on the planet and assembled directly in the final markets (Cox, 1987; Lipietz, 1988). From the geographic perspective, these new production systems generate processes of 
flexibilization, decentralization, internationalization and interdependence among national societies which multiply and decentralize the decision-making centers.

This process is also affecting the nation-state's capacity to regulate economy and society for two reasons. First, the interdependence among states is a consequence of the inability of single and independent states, individually considered, to control and regulate phenomena whose origins and effects transcend national borders (Keohane and Nye, 1989). Second, the increased flexibility of industrial production and the internationalization of the economy collides with centralism, normative and institutional complexity, and large public expenditures which are characteristic of such a modality of state action. One important consequence of such a change is that the political and economic arrangements among politics, capital and labor, which gave rise to the welfare state after World War II, have broken down due to the reduction of social policies, the tendency toward the "atomization" of productive units which hinders the organization of workers in national labor unions, and the new scheme for relations between capital and labor which operates on a world scale. As Vacs points out,

taken to its logical conclusion, transnationalization and interdependence would culminate in the creation of an integrated global political economy in which the role of states is severely limited by their growing incapacity to control crucial variables that affect economic, social and political developments within and across national boundaries (1994: 73).

Robert W. Cox affirms that globalization became ideology when it came to be considered a finality or an inevitable culmination of the strong market tendencies at work (1996: 23). Nevertheless, the ideological character of globalization goes beyond its inevitability. Globalization is embodied in neoliberalism as the new concept of the 
relationship between state, economy, and society. If the international system until the 1980s may be characterized as the era of geopolitics in which anti-communist ideology acted as the cohesive factor within the Western nation-states system, in the 1990s the new international scenario may be characterized as the era of geoeconomics in it anticommunism is replaced by neoliberalism as the cohesive factor, for it represents the structural adjustment of national economies and societies which corresponds to the new tendencies of liberalization, flexibility of productive processes, deregulation of economies and integration of local and regional markets ${ }^{6}$. However, in spite of its apparent technocratic neutrality, neoliberalism, with its emphasis on values of freedom and individualism, is in fact the new ideology of the redefinition of the relationship between the state, the economy and civil society. Neoliberalism, as ideology, implies a tendency to replace the logic of politics for the logic of the market as the principal criterion for action in society. In other words, for neoliberals. decisions through public institutions are less democratic than decisions through the market. In the words of one of the most representative ideologues of neoliberalism,

the characteristic feature of action through political channels is that it tends to require or enforce substantial conformity. The great advantage of the market, on the other hand, is that it permits wide diversity. It is, in political terms, a system of proportional representation (Friedman, 1982: 15).

\footnotetext{
${ }^{6}$ I am drawing here from Richard Falk (1995) who characterizes the current restructuring of the world order as a transition from "geopolitics" to "geogovernance", understanding the former as relations among nation-states seeking "balance of power, self-defence, spheres of influence, and alliances", and the latter as a more integrated world in economic, political and cultural terms which weakens sovereign states (pp. 1,2 ,9). But it is important to recall that the ideological confrontation between the eastern and western hemispheres was fundamental in the constitution of a world politics, and in the function of agglutinating states around one of the two poles of world power. Furthermore, given that globalization is basically a globalization of capital and that liberalization of the market and the ideology that accompanies it are its clearest expression, I have decided to change the term "geogovernance" for that "geoeconomics."
} 
For neoliberals, the market reduces the need for political intervention. An important characteristic of political decisions is that they require deliberation, consensus and submission. The market does not. Thus, for neoliberals the market is more democratic than any political regime.

Notwithstanding this, political regulation of the economy is far from disappearing; the economy has become more regulated than it has ever been before. What is happening is that the regulation is undergoing a process of displacement from the nation-state level to the supra-state or global level. This phenomenon has been considered by scholars as a form of "global governance" understood as the emergence of common principles, norms and values to regulate and coordinate political and social relations on a global scale (Rosenau and Czempiel, 1992; Commission on Global Governance, 1995), which constitute global power structures and enhance the scope of political authority and domination. The concept and practice of "global governance" have been fundamental in the constitution of international regimes that demand worldwide observance of principles such as the free market, democracy, and human rights. This is translated into political and economic conditioning that links the granting of loans or development aid to the adoption of structural reforms in the Third World. For this reason, one of the institutional expressions of globalization and global governance of the economy is the strengthening of the role of multilateral financial and trade organizations like the International Monetary Fund (IMF), the World Bank (WB), and the World Trade Organization (WTO). For example, in the past twenty years, the IMF has experienced a process of strengthening, in which it moved from performing 
a relatively low-profile role as coordinator of the international monetary and exchange system, which arose from the Bretton Woods agreements in 1945, to playing the role of a sort of supra-state central bank, some of whose functions are supervision of the global capital market and the demand for adjusting national economies to the principles of globalization and the free market (James, 1996; Scholte, 2000). As Cox has pointed out, “international finance is the preeminent agency of conformity to world-hegemonic order and the principal regulator of the political and productive organization of hegemonic world economy (1987: 267).

Another expression of globalization is the constitution of regional blocs of economic integration such as the European Community, Asean, Nafta, Mercosur, and the Andean Community, which are a sort of supra-national space in favor of which the nation-state is ceding functions in economic matters. In other words, the state is restructuring itself through its participation in the creation of supra-territoriality, i.e., the creation of larger spaces and institutions needed to advance the globalization process. This restructuring implies the broadening of the geographical reference of the state's regulatory capacity. The state is thus undergoing a process of "partial denationalizing of national territory and a partial shift of some components of state sovereignty to other institutions, from supranational entities to the global capital market" (Sassen, 1996: xii).

Simultaneously with the aforementioned process, there has been a process of "rebirth" of civil society which is also undergoing a process of breaking national boundaries and redefining its role. Its protagonism in the international arena stems not 
only from individual and group actions but also from the fact that while the nation-state is still significant as a reference point for the action of groups and individuals, it is no longer the only referent for social action. Their existence has increasingly referred to global processes and institutions. They are in the middle of a competition among different power and decision-centers for their loyalty and support. As Rosenau points out,

individuals have become, both as group members and as citizens, a mayor battleground on which states, governments, sub-national groups, international organizations, regimes, and transnational associations compete for their support and loyalties, thereby posing for them choices that can not be easily ignored and that serve as both a measure of global change and a challenge for global stability (Rosenau, 1990: 213).

However, the rebirth of civil society is a paradoxical process. In spite of the globalization of individual and group frameworks for their actions, and the fact, noted by Rosenau, that the awareness of their insertion in the world and their analytic skills have increased considerably $(1990: 13,64)$, their influence in the national and international agenda and decision-making seems to be more and more reduced. This is due to the fact that while individuals and groups are locally based, the center of power and decisions are moved away from local life due to the process of internationalization. Only a few non-governmental organizations and social movements like Amnesty International and Green Peace, may have the capacity to act transnationally. Most movements and individuals are circumscribed to the limits of local life, thus confirming the irony pointed out by Rosenau that "the abilities of individuals to connect to world politics and cope with its complexity have reached new heights while their sense of control over the complexity has fallen to new lows" (1990: 335). Nonetheless, in the past two years "transnational" social protest movements have begun to arise which, conscious of the 
fact that the decisions of the supranational institutions increasingly affect their living conditions, have begun to question globalization. ${ }^{7}$ Nevertheless, these movements are still very incipient and mainly link groups and individuals from the developed world. The civil societies of the Third World in general, and of Latin America in particular, are still far from being able to effectively influence the global centers of decision-making.

That is the framework in which Latin America must act. The above-mentioned globalization process acts as a constraining force and precludes the possibility of autonomous development. Globalization can explain why some scholars consider it "surprising" that one of the findings of their research "is the degree to which interest groups fail to account for the initiation... of [market-oriented] policy reform" (Bates and Krueger, 1993: 455). This new array of global conditions means that the economic growth and social development of the region's countries depend on their competitive insertion in the world market. As Morley points out, the region is "embedded in a worldwide trading and financial system, from whose rigid rules there was no easy escape" (1995: 5). Besides, in the age of globalization it is not enough to simply export; it is also necessary to increase the technological content of the exported goods and services.

\footnotetext{
${ }^{7}$ I refer to the heterogeeneous ensemble of personalities, political and social movements, and NGOs, of diverse regions of the world, that have raised the banners of antiglobalization, to demand everything from control of multinationals and global protection of the environment, to equitable worldwide distribution of wealth, including the disappearance or democratization of international financial agencies and condoning of the foreign debt of Third World countries. Said groups have directed their protests, often violently, against the summit meeting of the World Trade Organization in Seattle, in December 1999; the Thirtieth World Economic Forum in Davos, Switzerland in January 2000; the joint semi-annual assembly of the World Bank and the International Monetary Fund in Washington, DC in April 2000; the Third Summit of the Americas in Quebec, Canada in April 2001; and the meeting of the G-8 in Genoa, Italy in July 2001.
} 
This situation has led since the 1980s to an exhaustion of the import substitution industrialization model (ISI) which was adopted by Latin American countries in the second postwar period. The type of protected industrialization adopted by Latin America, and the international division of labor that predominated until the 1970s, prevented the region from developing structural conditions for improving its productivity by means of technological development, in order to ensure competitiveness, as of the 1980s, in an increasingly technified and globalized world economy. This situation has expressed itself in a weak interelationship between growth and work productivity. According to the Employment Program for Latin America and the Caribbean, PREALC, in the $1950-1980$ period, Latin American industry expanded at a greater pace
than the average of the OECD and EEC countries; nonetheless, the rate of
increase in work productivity -about $2.9 \%$ - was less than that achicved by
those countries: $4.0 \%$ for the OECD y $4.4 \%$ for the EEC. The productivity
breach is even greater if one compares it with outstanding experiences, such
as the cases of Italy $(5.4 \%)$, France $(5.6 \%)$ or Japan ( $8.1 \%)$. (PREALC,
1990: 7 ). Therefore, according to the WB and the IMF, which are imposing globalization and Neoliberalism in the region, the ISI produced, among other things, a loss of international competitiveness of national industries due to the excessive protectionism it implies. Besides, according to those institutions, this strategy entailed "a serious misallocation of resources, especially because of the central role played by the public sector as an engine of 'growth' " (Fanelli and Frankel, 1994: 102). For those reasons the WB and the IMF are imposing programs of restructuring of the public sector in Latin America, which implies a change in the traditional emphasis of public policy-making in order to achieve a competitive insertion of the region's countries in the world market. Such restructuring 
consists principally of : a) reducing the state's size by reducing public expenditures and privatizing public entreprises; b) decentralizing the state's activity by translating the responsibility of providing public services to local government; c) liberating prices and interest rates from state control, and, in general, deregulating economic activities; d) introducing regressive taxation; e) reducing tariffs and barriers to foreign trade and flexibilizing the exchange rate; f) flexibilizing the labor market and atomizing labor unions and social movements. This policy affects and reduces labor's negotiating power because, otherwise, it could prevent achievement of the goal of reducing public spending.

\subsection{Endogenous Factors}

\subsubsection{Society: Cooperation, Conflict, and the Problem of Integration}

In modern social theory, society has been understood exclusively as conflict (Marx, 1987; Coser, 1964; Dahrendorf, 1973) or as cooperation (Axelrod, 1984; Fukuyama, 1995). However, the purposes of this dissertation demand a concept that will combine both of these dimensions. Therefore, society can be defined as a set of social interactions resulting from the permanent tension between cooperation and conflict. According to Rawls, social cooperation exists since it

makes possible a better life for all than any would have if each were to live solely by his own efforts. There is a conflict of interests since persons are not indifferent as to how the greater benefits produced by their collaboration are distributed, for in order to pursue their ends they each prefer a larger to a lesser share (1971: 4). 
The constitution of the social order has, thus, to do with opposing positions with respect to how the basic structure of society is constructed, i.e., the way in which the principal social institutions are linked in order to permit the allocation of freedoms, goods and social opportunities. From this point of view, politics can be defined as that collective and conflictive action oriented to the construction, maintenance or transformation of a social order. Said confrontation requires society to reach an agreement on the principles of justice that should regulate said construction. It is the conflict, in a context of growing individual and social needs and scarce resources, that obliges the members of society to reach a consensus on the priority in the satisfaction of needs and the distribution of said resources. Therefore, distribution is not only a question of economics but one of politics as well. The re-distributive policies that are carried out in society, are carried out not only through the markets but also through institutions that, in theory, differ substantially from them. It is not possible to understand the nature and the diverse types of economic distribution without understanding, at the same time, the functioning of political institutions and examining the axiological principle on which said distribution is based.

Jürgen Habermas' theory of communicative action can also provide conceptual tools for dealing with the problem of the dual constitution of society and its crises. This author considers society to be simultaneously "system" and "life world", which makes it possible to distinguish between systemic integration and social integration. The "life world" is the concept that makes it possible to observe society from the viewpoint of the constitution of social relations on the basis of recognition of mutual claims of validity 
of the life plans of the actors that intervene in a situation, based on dialogue and argumentation (Habermas, 1987:167 ff). It is on the basis of the life world dynamics that culture and society are generated and the personality of individuals is formed. These elements, which are closely linked in primitive and traditional societies, undergo a process of increasing differentiation in modern and contemporary societies. In synthesis, social integration is produced in the life world and in the ways in which social action is integrated by means of a normatively guaranteed consensus and achieved by means of communication. Society as a system, is constituted by the relations among the different subsystems that compose it (such as the family, the institutions of secondary socialization, the economy, and the State) and the needs for coordination among them from a center of power or "self-government." (Ibidem: $161 \mathrm{ff}$. This need for coordination or "systemic integration" is the result of a historical process of progressive institutional differentiation of society. The factor of systemic integration in traditional societies was the dynastic family, and it is the market and the State in modern and contemporary societies. In synthesis, systemic integration is produced through the exercise of an external control over social actions that are not coordinated intersubjectively.

After having developed said concepts, Habermas points out that "the fundamental problem of social theory lies in finding the way to satisfactorily connect the two conceptual strategies involving the ideas of system and life world" (Ibidem: 151), since a concept of crisis appropriate for the social sciences has to be capable of establishing the connection between social and systemic integration (Habermas, 1989: 
19). This connection can occur in two different ways. In the first place, the progressive complexification and diversification of modern societies has led to a primacy of technical rationality and bureaucratic-organizative aspects to the detriment of communicative rationality, which has been "colonized" by the former. The result is a crisis of legitimacy in which technocracy displaces democracy as a form of coordination and adoption of social decisions. For the purposes of this dissertation, I consider that one of the manifestations of this type of crisis is seen in the way the neoliberal development model was adopted in Latin America in general, and in Colombia in particular. Its technical imperatives required that its adoption be done behind the back of the different social organizations and political institutions of negotiation and articulation of interests. This can be interpreted as a divorce between mechanisms for the generation of consensus and legitimacy and mechanisms for the elaboration and implementation of macro-economic policies. Consequently, by excluding communicative reason and social participation from the sphere of macro-economic decisions, which is precisely where the firm foundations can be laid for a society that is not only democratic but just, a path is being opened in Latin America to a type of instrumental and technocratic rationale that is displacing political legitimacy. But, furthermore, the neoliberal model has contributed to deepening the social inequalities in the region, thus exacerbating the problem of the lack of social integration. In fact, the Gini coefficient in the region rose from 0.54 in 1982 to 0.58 in 1990 (Londoño and Székely, 1997); and despite the moderate resumption of economic growth in the region in the mid-1990s, the number of poor people increased to 210 million, 50 million more than in the critical years of the $1980 \mathrm{~s}$ (Korzeniewicz and Smith, 2000: 15). As Borón points out, an 
enduring legacy of neoliberalism is a society whose social integration has been debilitated by the upsetting impacts of unfettered market dynamics; this weakening has crystallized the tremendous cleavages and inequities that characterize our 'really existing capitalism' (. . .) A 'society' of this type is a mere juxtaposition of 'social universes' and Latin American societies are quickly approaching this. Classes and social groupings may be almost completely disconnected and (...) scarcely adequate for the sustenance of a democratic order (1998: 57-58).

In the second place, from the viewpoint of systemic integration, the State has the responsibility of articulating the economic, political and sociocultural system. However, the development of contemporary societies tends toward progressive autonomization and specialization of the different social systems, especially the economic system that seems to be gaining ground with globalization in relation to the function of coordination and social regulation. Given this tendency to autonomous development of the different systems that make up society,

one can scarcely explain how the political system should be able to integrate society as a whole, even though it is specialized for regulatory activities that are meant not only to rectify disturbances in functional systems but also to achieve an 'environment-friendly' coordination among systems drifting apart (Habermas, 1996: 335-336).

This incapacity of the State to ensure inter-systemic cohesion appears not only as a crisis of legitimacy but of the rationality of society as a whole as well. The crisis of integration also occurs when profound political, economic and social changes, disarticulate the relationships that constitute the societal pattern in such a way that the inter-systemic coordination of society, and the constitution of intersubjectivity and meaning among the actors, is made either difficult or impossible.

Finally, the sociocultural system contributes a "legacy of knowledge" to the integration of society and a set of values and symbols so that the needs of understanding 
and identity of individuals and groups are covered and ties of solidarity and motivations for acting in conformity with social norms are produced, and it becomes possible "to tune individual lives in with the collective forms of life" (Habermas, 1987: 201). Disturbances of the social integration process translate into loss of meaning and identity in the sphere of culture; and into anomie in the sphere of society (Ibidem: 203). These reflections can prove illuminating for an understanding of societies like those of Latin America that have presented tendencies toward social fragmentation since the nineteenth century due to historical problems in the constitution of their social fabric, and to the lack of what Gino Germani denominated "the minimum central prescriptive nucleus sufficient for integration." (Cordera, 1996:22).

In conclusion, every society presents a tendency to a certain degree of disintegration, so that it is never possible to consider it absolutely integrated. Therefore, social integration is a relative concept that has analytical purposes. There will be epochs in which the tendency toward social disintegration will be greater or will affect significant institutional spheres, and others in which said tendency will remain within restricted limits. Accepting that it is a relative concept, an integrated society can be defined as one that presents the following characteristics: a) A State with sufficient capacity to regulate social relations and produce the inter-systemic coordination of society. Politics is thus the form the social conflict assumes and the role of the State is to try to maintain the uneasy balance between cooperation and conflict, providing society with the minimum degree of cohesion required for it to continue to exist. From this perspective, it is possible to speak of the political integration of society. b) A culture 
consisting of a set of values, ideas, symbols and "images of the world", that permit communicaction, intersubjectivity and the attribution of meaning to social life. c) On the basis of said communication and intersubjectivity, a normative structure is produced that is the result of a consensus among its members. This consensus is the source of legitimacy and of the binding force of the norms. The attitudes and expectations of the members of society correspond to the normative structure because they have internalized or socialized it. From this perspective, it is possible to speak of social integration. d) The different elements of state regulation, culture and the normative structure are articulated and there is sufficient compatibility among them to ensure social coordination and the peaceful solution of social conflicts and tensions. Said articulation can be denominated the societal pattern, defined as "a set of relations integrated into the state and the statist historical cycle, and particularly the network of political relations that organizes the style of economic development and the cultural self-understanding of the era and of its social potentialities for change" (Calderón and Dos Santos, 1995: 35).

The concepts of society and social integration have traditionally referred, explicitly or implicitly, to human groups or communities, considered from the cultural viewpoint as nations, settled in spatially delimited territories, and given political cohesion through the Nation-State ${ }^{8}$. Considering this, it is possible to affirm that globalization redefines society and sharpens the tendencies to its disintegration, since it implies a progressive expansion of the forms of social relation and organization, and the

\footnotetext{
${ }^{8}$ Although this is the main meaning that has been given to the term society, $I$ am aware that there are "nation-societies" that struggle to become "nation-states", as in the case of the Palestinian people, or that have no interest in doing so, as in the case of the Gypsy people. However, both cases considered an "exception to the rule".
} 
expansion of the geographic spaces in which they take place. As Giddens states, it is a question of "the intensification of the social relations throughout the world by which distant places are interconnected, in such a way that local events are configured by events that occur at a distance of many kilometers or vice versa" (1993. 68). All this implies, in turn, a crisis of politics, because if this is the form that the cohesion of modern societies assumes, upon expanding the geographical and cultural "coordinates" of society, the possibilities of coordination and regulation of social relations from a spatially delimited political center, are seen to be seriously impaired.

\subsubsection{The Weakness of the State}

As has already been said, society is not only a cooperation network, as Axelrod supposes (1984), but a network of social conflicts and tensions as well, that need to be mediated by a relatively autonomous power, in order to ensure the continued existence and reproduction of the society itself. From this perspective, the role of the State is to maintain the uneasy balance between cooperation and conflict, so that society achieves the minimum degree of cohesion needed for its continuity. As Norbert Lechner states,

politics is a conflict of particularities, and the State is a form of generality. Said distinction does not imply separation or absorption. We cannot think of politics without referring to a form that synthesizes society, nor can we think of the State without referring to a divided society $(1986$, p. 30).

Therefore, the State can be defined as the institution which, by means of a monopoly of the use of legitimate force and of the production of regulations (Weber, 1968), integrates 
both the society and the national territory, mediates social conflicts, and ensures the integration and systemic coordination of society.

Many definitions of the state reduce it to its material expression, i.e., to the state apparatus, to a set of organizations and institutions such as the three branches of government and administrative bureaucracy. However, the state is a specific form assumed by social relations in modern societies; that form of relationship that divides society in both the public and the private sphere. This division, by placing the public sphere above the private sphere, makes possible the cohesin of society. Said social relation crystalizes in specific institutions and organizations that, by means of a monopoly on the legitimate use of force and production of regulations, (Weber, 1968), integrates society and national territory, mediates social conflicts and ensures the integration and systemic coordination of society. This fact generates a political culture that, in general terms, is shared by all members of a cohesioned society (Elias, 1987).

To define the State in this way, i.e., as the cohesive factor in society, does not no necessarily imply ignoring the role of the state in the constitution of social domination, and more specifically in class domination. And it is precisely this domination, made possible, among other things, by the splitting of society into the public and private sphere, that could be considered a specific form assumed by social cohesion. In this respect, it is illustrative to make a brief reference to the Marxist debate about the State. At the risk of simplifying a complex debate, the multiple Marxist concepts of the state ${ }^{9}$ can be reduced to two

\footnotetext{
${ }^{9}$ A good synthesis of these concepts is found in Gold, Clarence and Wright (1975).
} 
major tendencies: a) that which conceives of the state as an instrument of class domination, a reflection of the contradictions originating in the economic structure of society, where classes are pre-constituted as social subjects (Marx, 1973; Lenin, 1978; and Miliband, 1970; among others); b) that which considers the State to be an extraeconomic instance that makes it possible to constitute the economic and political conditions, including among the constitution of classes as social subjects, necessary for the production and reproduction of capital (Poulantzas, 1969; and Offe, 1993; among others). From the former perspective, politics, understood as the State, appears as a mere reflection or epiphenomenon, as an "illusory community", as a product of alienation, of a "false consciousness," that prevents class domination from being perceived as such. From the latter perspective, the State is characterized by its "relative autonomy" with respect to economic relations and as the necessarily political moment of the constitution of class domination. The nature of capitalist production and circulation, and that of the social classes is affected by structural tendencies that impede their reproduction, such as the tendency toward the fragmentation of the dominant class, and toward the unity of the dominated class (Poulantzas, 1979: 152-194), or the tendency toward the "de-mercantilization" of social relations, especially, of the labor force (Offe, 1993: 35-64). Thus the need for State intervention to counteract said tendencies.

To these theoretical concepts of the State can be added the classic liberal and the Hegelian models. For the former, the State arises from the consideration of a pre-social situation, the state of nature, a situation of anarchy and lack of personal security, which justifies the collective configuration of a regulatory power, the legitimacy of which 
originates in a value judgment, according to which individuals accept the authority of the State because it is the most rational institution possible for avoiding a social condition of non-regulated conflict, in which individual liberty, property, and conservation would be impossible (Hobbes, 1987). From an anti-liberal perspective like that of Hegel, the State appears as "the moment of ethicity". That is to say, the State is the institution that returns the individual's collective dimension, social nature, broken by the rise of civil society, i.e., the market economy, and liberal individualism. In this respect Hegel states:

if the State is confused with Civil Society and its determination is placed on the security and protection of property and personal liberty, it is done in the interest of individuals as such, the ultimate end in which they are unified; and in that case, to be a member of the State falls within individual caprice. But the State has a very different relation with the individual; the individual as such has objectivity, truth and ethics only as a member of the State, since the State is objective spirit (Hegel, 1955: 208, § 258).

This brief account of different conceptions of the State, permits us to conclude that since from Hobbes to Hegel to Poulantzas, from the right to the left, the State has been considered an important factor in the constitution and cohesion of society. Something different is the value judgment that each theoretical current makes regarding this function of the State, and from which political strategies tending to its preservation or suppression can be derived.

Now, the State in the Third World in general and in Latin America in particular, it does not have sufficient autonomy to constitute a generic form of society, so as to provide the minimum degree of cohesion and mediate its conflicts, which aggravates the political integration crisis, the expressions of which are violence and anomie. Said 
debility refers to the incapacity of the State to structure the social totality, monopolize the use of violence, constitute social subjects, regulate their relations and mediate their conflicts. With reason Habermas says that

the Third World is composed nowadays of territories where the state infrastructure and the monopoly of violence have been so weakly formed (Somalia) or have crumbled so much (Yugoslavia), where social tensions are so strong and the thresholds of tolerance in the political culture so low that indirect powers of a mafia type [as in Colombia, adds the author of this dissertation] or of a fundamentalist nature shake the internal order. These societies are threatened by national, ethnic or religious processes of decomposition" (1999: 168).

Precisely because of this situation, an extensive bibliography has appeared in the last two decades, stemming mainly but not exclusively from the field of international relations, and dedicated to analyzing the phenomenon of the weakness of the State in the Third World. ${ }^{10}$ Joel S. Migdal, for example, has paradoxically characterized Third World countries as "strong societies", characterized as they are by the persistence of noncapitalistic forms of relation and social control, that have impeded the formation of a centralized state capable of achieving "the successful subordination of people's own inclinations of social behavior or behavior sought by other social organizations in favor of the behavior prescribed by state rules" (1988: 22). The result is a situation of social fragmentation that impedes the rise of "strong states" with sufficient capacity to integrate society and to centralize its regulatory function. Migdal argues that social fragmentation and the primacy of local political bosses in turn impede the development of a rational bureaucracy and facilitate the control of local public institutions by personal interests, which leads to the displacement of general State policies by partial interests of society.

\footnotetext{
${ }^{10}$ A good synthesis of this bibliography can be found in Mason (2001).
} 
Barry Buzan (1991) considers the State to be constituted by the relation among three elements: a) state institutions, composed by law, government, and public administration; b) the idea of the State itself; and c) the physical base, composed of the population, understood as national community, the territory and natural resources. According to Buzan, the strength or weakness of states, depends on the type and degree of cohesion among these elements (Ibidem: 65), which vary from State to State and from region to region. In the countries of the Third World, state institutions lack the necessary capacity to establish legitimate authority and to provide safety and public services for the population. In relation to the idea of the State, Buzan defines it as "what binds the people into a sociopolitical and territorial entity" (Ibidem:70), the main sources of which are found in the nation and the organizing ideologies. However, in Third World countries, the unity of the national community is often affected by ethnic confrontations and the integrity of the territory threatened by secessionist movements or by territorial conflicts with neighboring countries. In synthesis, according to Buzan, weak states are characterized by the incapacity of state institutions to provide safety and welfare for the population, the lack of an identity and national unity; the scarce legitimacy of political authority, and the lack of consensus with respect to the basic norms that regulate the social process (1991: 97-110).

With certain exceptions, concern for the problem of the weakness of the state and civil society in Latin America has been absent from comparative political studies. Nevertheless, in recent studies, this topic has begun to encounter a certain space for reflection. In this respect, Boron points out, 
the problems of governance within new democracies and weak states are compounded in Latin America by the deep, long, and wide 'fault lines' running through the very fabric of their civil societies. As we have seen, democratic states have to face a whole series of problems that in themselves raise serious concerns regarding the possibilities of effective democratic governance. The situation grows worse when these governments have to deal with dual and fragmented civil societies-and with large masses of marginal people unable to be incorporated by the capitalist economy" (1998: 59).

The Latin American State is one whose formative process combined traditional and modern forms and institutions of social relation. This makes it possible to analyze and understand the failures of many of the policies developed by the States of the region, especially those of "Cepal" or of "developmental" inspiration", the purpose of which was to strengthen their interventionist or regulatory capacity to constitute integrated, democratic, rational, and capitalistic societies. From this perspective, it is also possible to understand patrimonialist and clintelist nature of the Latin American states, which has led not only to the lack of autonomy with respect to civil society, but also to its true privatization. Thus, contrary to what many hold today, an urgent task that Latin American societies should undertake, is not so much that of privatizing their states, as one of constituting their public character. In the face of this situation, the neoliberal positions, that maintain that the social and economic problems of the region are due to "a large, pachyidermous state", must be taken with reservations. It is not a question of whether the State should be large or small. The discussion in the region should not revolve around the size of the state but rather the type of state, i.e., a (relatively) autonomous, effective, legitimate State, with the capacity to achieve social cohesion, social and economic development, equity, and democratization of society. However, the margin of maneuver within which to construct such a state in Latin America is limited, if 
one takes into account the fact that the forces arising from the globalization process tend, as already mentioned, to transform the nature, scope, and functions of the state, and to debilitate its capacity to achieve the cohesion of society. Thus the crisis of integration of Latin American societies has tended to worsen with the economic restructuring programs underway since the 1980 s.

\subsubsection{Social Democracy and Market Economy: Two Social Projects in Conflict}

In the past decade Latin America has faced a crisis of political and social integration caused by the impossibility of reaching a consensus on the basic principles of social order, among other things. In this respect, two different societal projects confront each other: one which has arisen from the democratization processes the region has experienced since the 1980 s expressed in a series of constitutional reforms, and another, based on the neoliberal model of opening and internationalizing the economy. There are multiple clashes between these two projects, regarding both conceptualization and implementation that will inevitably lead to crises soon or later.

As a consequence of the democratization processes, many Latin American countries radically reformed their political constitutions: Ecuador did so in 1978, Chile and Brazil in 1989, Colombia in 1991, Paraguay in 1992, Peru and Bolivia in 1993, Argentina, Guatemala and Nicaragua in 1994, and Venezuela in 1999. Although Mexico did not have a radical constitutional reform, it did introduce some notable reforms in its constitution. These constitutional reforms share elements in common, such as the recognition of new social rights; the expansion of political participation and 
the introduction of mechanisms of direct democracy, strengthening of the congress and the systems of checks and balances among the branches of government, reforms of the administration of justice and the central banks, etc. (Gargarella, 1997).

The inclusion of new economic and social rights and the expansion of political participation have been the most significant elements of said reforms. The Brazilian Constitution includes among social and economic rights the establishment of a detailed series of labor rights and guarantees, among which figure unemployment insurance, workers' right to participate in the firm's profits, in determining the workday, etc. The Constitution of Argentina, in addition to expressly establishing a series of economic and social rights, incorporates into its text a series of international treaties signed by this country, such as the Universal Declaration of Human Rights, the American Declaration of the Rights and Duties of Man, and the Convention on the Rights of Children, among others. But according to analysts, Colombia is the country that represents the greatest advance in recognition of social rights (Dugas, 1993: 28). The Colombian Constitution of 1991 not only establishes the traditional or "first generation" civil and political rights, but also considerably increases the number of "second generation" or economic, social, and cultural rights. Among these are the right to protection of the family, to social security, to health services, to decent housing; to education and culture; the rights of women, children, adolescents, the elderly, the handicapped, and workers. It also recognizes collective or "third generation" rights, including the right to a healthy environment, to public space and to quality in services the state offers to the community. Finally, the new constitution established powerful judicial tools to enforce said rights, 
such as the right to judicial tutelage and to popular actions, that have had profound repercussions on the social development of Colombia.

In relation to the system of checks and balances, it is necessary to say that a phenomenon characteristic of Latin American political regimes is their accentuated presidentialism (Linz and Valenzuela, 1994), due not only to a strong centralism inherited from the era of Spanish colonization, but also to the legacy of various decades of authoritarian governments. Therefore, the Constitutional Reforms of recent years were oriented to re-establishing the balance between the executive and the legislative branches of government, reducing the powers of the former and strengthening the political control powers of the latter. With the exception of the constitutional reforms of Ecuador y Peru, where the executive branch was strengthened, various South American countries such as Colombia, Bolivia, Brazil, Paraguay, Argentina and Chile introduced measures that tend to re-establish the balance of powers. In the last country in mention, for example, the president lost many of faculties granted in Pinochet's Constitution. With the constitutional reform of 1989 the Chilean president lost the power to dissolve the parliament, to send whoever opposed the regime into exil, and to restrict liberties and basic civil rights. In fact, even the institutions designed by the dictator to maintain the power and influence of the armed forces after the transition to the democratic regime lost part of their initial force. Likewise, the Constitutional Reform of 1992 in Paraguay reduced the powers attributed to the executive during the dictatorship of General Stroessner. In Colombia, the constitutional reform of 1991, among other things, strengthened the political control function of Congress by introducing the impeachment 
and granting the legislature certain powers of control regarding states of exception, as well as in matters such as the economy. En Argentina, the Constitution of 1994, reduced the presidential term of office from six to four years.

In recent years, some analysts have begun to speak of the "crisis of representativeness" of Latin American parliaments and political parties, due partly to the transformations of civil society and the rise of new social actors and movements and partly to the clientelist nature of the political systems of the region. A study done by Iberobarómetro in 1993 and 1994 and analyzed by the Roper Center for Public Opinion Research of the University of Connecticut, concluded that in most Latin American countries "more than $50 \%$ of the population distrusts the congress (with figures close to $80 \%$ in Colombia); that 8 in 10 Argentines, Colombians, and Peruvians, and 7 out of every 10 Mexicans distrust their political parties" (Gargarella, 1997: 986). For this reason, many of the constitutional reforms in the region introduced a series of dispositions tending to broaden political participation among the population by means of the introduction of mechanisms of direct democracy, the elimination of clientelism and corruption, the improvement of electoral and the representativeness of the congress, and the rationalization and legitimization of the legislative function (Ibidem: 983, 986-987).

Another important constitutional reform topic in Latin America has been improvement of the administration of justice, to ensure its independence and increment its efficacy. The lack of these two characteristics has become an obstacle to full development of democracy in Latin America, since the State is impeded from 
guaranteeing citizens adequate exercise of their constitutional rights (Frühling, 1997). The independence of judicial power had been lost due to the interference of military dictatorships or, in cases like Colombia and Venezuela, due to bipartisan political pacts that, among other things, pre-established a parity-based distribution of judicial posts among the two traditional political parties. For this reason, various countries of the region (among them, Colombia, Peru, Paraguay, Bolivia, Argentina and Mexico) constitutionally established an institution called the Superior Council of the Judicature which constitutes "an intermediate body between judicial power and political power, the main purpose of which is to restrict the executive discretionary power in the selection of new judges" (Gargarella, 1997: 973). In relation to the effectiveness of justice, constitutional reforms in the region introduced the accusatory system through the creation of prosecutors' offices. This has been complemented through the development of a series of programs proposed and financed by international agencies like the World Bank, the Inter-American Development Bank, and the Organization of American States, as well as the adoption of a series of measures to improve access to justice, to facilitate its application and reduce the degrees of impunity (Frühling, 1997: 242).

Finally, another important dimension of the recent constitutional reforms in Latin America has been the creation of independent central banks, i.e., subject neither to the authority of the government nor to the preferences of the voters. Between 1990 and 1995 more than thirty countries in diverse continents carried out constitutional or legal reforms to increase the independence of said entities (Maxfield, 1999). Brazil inititiated the process in Latin America in 1980; Chile followed in 1989, Colombia in 1991, 
Argentina and Venezuela in 1992, and Mexico in 1993. According to Maxfield (1997), this worldwide tendency is due more to the links between the domestic and the international economy than to strictly internal factors, to the extent that increasing flows of international capital have an impact on the public finances and the political and economic stability of these countries which requires centralized control over the basic instruments of macroeconomic policy.

Based on the assumption that institutions are crystallizations of the relations of force among social actors, it can be said that the reforms have had contradictory dynamics to the extent that they represent different interests and societal projects, such as that of social democracy on the one hand and that of neoliberalism on the other. For example, reforms aimed at strengthening the legislative branch and the mechanisms of checks and balances clash in many Latin Americans countries with those concerned with the need to isolate the executive from social and political demands and pressures, in order to implement economic restructuring policies. In the Colombian case, this confrontation, among many others, has occurred between the Constitutional Court which has incarnated the aspirations of social democracy - and the Banco de la República (Colombia's central bank), which epitomizes the tendencies toward an autonomous economic system, and isolation of the technocracy from social pressures and control over macroeconomic policy. As Maxfield, quoting John Freedman, asserts, the current trend toward CBI [central bank independence] 'is antithetical to popular sovereignty' because independent central banks and the owners of mobile capital they essentially 'represent' are usurping national power to 'decide the distribution of power and wealth." "(1999: 290). 
As will be shown below for the Colombian case, the confrontation between the institutions mentioned above, has been one of the most significant expressions of those occurring between the two types of societal projects of contending with each other in Latin America.

Another point of confrontation is presented in relation to the constitutional recognition of economic, social and cultural rights of the population. The effective exercise of these rights does not depend on their simply being mentioned in a constitutional charter, but on the establishment of a social order based on distributive justice, which is opposed by a neoliberal order based on commutative or market-based justice. Thus it seems that the history of the relations between the state, society, and the economy, develop in a pendular movement, in which progressive epochs, of greater displays of public activity in search of a distributive justice, alternates with conservative periods characterized by inhibition of activity of the State, which becomes a mere guardian of order and arbiter of economic activity, so that individuals seek retributive justice for themselves, through the market. In the period between the post-war and the early 1970 s, the Keynesian model which prevailed in the industrialized countries of the west, as has already been mentioned, assumed an increase in public function and in the regulation of the economic process on the part of the State. In contrast, since the mid1970 s, said paradigm entered into a process of crisis, provoked, according to some analysts, by the "excesses" committed by the intervention of the welfare State, the mare magnum of state regulations and bureaucratization inherent to public activity. These factors combined to generate the effect of loss of global efficience of the economy. 
For this reason, another paradigm - the neoliberal one - has arisen recent years. In the economic sphere it postulates reducing state action of by dismounting the institutional and productive apparatuses of the public sector and confiding in the signals of the market to orient private activity and achieve the optimum allocation of resources. Neoliberals thus leave the solution to problems of development and distribution of income and wealth to the free will of the market place. In the political sphere, they pose the need to put limits to the so-called "excesses" of democracy, to the degree in which political participation and democratic demands have generated an "overload" for governments, which have led to an "unbalanced" expansion of public activities to the detriment of private initiative, to a disaggregation of interests, and to the loss of governmental authority (Crozier, Huntington and Watanuki, 1975).

From this perspective, politics is circumscribed to the field of public management, in which the legitimacy of the State is understood, once again, strictly in terms of effectiveness. But it is not enough for state action to be merely effective. For it to be legitimate, it must also be just - in terms of equity. From this it follows, as Van Parijs (1992) maintains, that what makes a society just, is, to a great degree, a matter of distribution: if politics is understood, among other things, as a struggle over the distribution of social resources, the market should give way to deliberation, since what it deals with is the collective and conflictive construction of order. The main problem that said construction has to face, although not the only one, is that of the material reproduction of society and the participation of the diverse actors in the social product; 
"therefore the problem is just that political decision on the economic process. It is precisely that deliberate creation of the development of society that should be the object of a theory of democracy." (Lechner, 1982: 41-42)

To this notion of politics as deliberation, the neoliberals oppose the idea of the market as a factor of social integration, to the extent that society is considered the whole set of acts of exchange, which actually leaves the idea of politics void of content. In fact, in the opinion of the neoliberals, it is not the democratic decision-making process, but the market that guarantees good government. They propose, therefore, to increase the efficience of the system and to substitute politics with economics, or at least to reduce the field of action of the former. In this way, efficience arises from the need to reduce the number of decisions of a collective nature regarding the allocation of resources in society, so that they can instead be made according to the objective and rational principles that are released through the full force of the laws of the market.

The appeal to the virtues of the market as a factor of social cohesion, and the exaltation of economic freedom in opposition to political regulation of the economy, both basic characteristics of neoliberalism that can hardly be conjugated with the idea of a more equitable society, have resurrected the topic of justice as a nodal point of contemporary philosophy and political science. Despite a certain pragmatic trend in economics and political science, the most fundamental concern of neoliberals is not efficience, but freedom. In this respect, it is illustrative to quote Milton Friedman, who affirms that 
what we have spoken of from the beginning is freedom. Although a certain number of my propositions had the immediate effect of improving our economic welfare, this is not, to tell the truth, more than a secondary objective in relation to the preservation of individual liberty (quoted by Van Parijs, 1992: 187).

Thus, in the present discussion regarding redefinition of the concept of the political, a broad range of positions, from the egalitarianism of Rawls (1971) to the anarcho-individualism of Nozick are confronted (1990). The latter, adheres to libertarianism which affirms the supremacy of particular interests of individuals that owe nothing to society, since they are considered separately existing realities (Ibidem: 45), dismissing the fact that what defines society is the interaction among its members. In his attempt to determine how much space individual rights concede to the State, Nozick reached the conclusion that anything more than a minimal State, i.e., anything that goes beyond the simple functions of protection, is an illegitimate State (Ibidem: 287). On the basis of these affirmations and a concept of retributive justice, Nozick rejects outright the political nature of the distribution of social resources and thoroughly disqualifies collective decision-making regarding the material reproduction of society. For Nozick, in society

there is no central distribution, no person or group authorized to control all resources, to jointly decide how they should be distributed. What each one obtains is obtained from others, who give it in exchange for something else or as a gift. In a free society diverse persons control different resources and new ownership of new assets arise from the voluntary actions and exchanges among persons (Ibidem: 153).

Consequently, Nozick does not accept the distributive fiscal policy typical of the welfare state, since for him all taxation is equivalent to a system of forced labor. All distribution that does not adjust to the principle of "to each as he/she chooses and from each as 
chosen" (Ibidem: 163), threatens the freedom of individuals and affects the efficience of the exchange of goods.

Against Nozick and the Neoliberals, it can be argued that the public sphere is not just the ambit of mercantile exchanges, nor is it reduced to the production of security and technical decisions. It is also the space of confrontation of diverse social interests, of state mediation of conflicts arising there and, therefore, of the construction of consensus. The market, per se, does not produce nor does it sustain a social order and, on the contrary, it presumes a policy of ordering.

From the other current, Rawls, in his search for a more egalitarian liberalism, expresses his concern for social and economic inequalities. He maintains that the main objective of justice is to constitute the basic structure of society, with which distributive justice becomes one of the most important objects of political reflection, since it is the first virtue of social institutions, as truth is of systems of thought. A theory, however elegant and economical, must be rejected or revised if it is untrue; likewise, laws and institutions, no matter how efficient and wellarranged, must be reformed or abolished if they are unjust (1971:3).

On the basis of a complex conceptual and methodological apparatus, framed within the contractualist tradition, which is not of interest to us here, Rawls elaborates a notion of justice based on two principles: the first affirms a freedom of equal citizenship for all, and predominates over the second, which should inspire the distribution of the social product. This poses the equality of opportunities and only permits economic and social inequalities to the extent that they are based on institutions established in such a way as to achieve the maximization welfare of the least favored 
From this perspective, contrary to that of Nozick, the political sphere is converted into the space where distinct concepts of man and society "intertwine" to produce a consensus regarding the principles of justice on the basis of which the basic structure of society is constituted or reformed (Rawls, 1993). In this way, citizen participation in the definition of order generates a political concept of justice centered on the problem of the distribution of goods, which constitutes the only possibility that the social organization can signify a rational advantage or good for each of its members.

The above references to the positions of Rawls and Nozick are intended to serve as the basis for showing the present conflict that the introduction of neoliberal models produce in matters of equity. On the one hand, the degree of social development in the region leaves much to be desired and on the other hand, the neoliberals maintain that normative intervention by the State generates inefficiencies and inhibits the exercise of individual liberties. Nonetheless, the construction of a legitimate and democratic State in Latin America requires the introduction of policies aimed at the redistribution of income, for which the neoliberal adjustments leave little margin for maneuver. Paradoxically, together with the implantation of neoliberal models, or because of it, a concern for equity has awakened in the region. The ECLAC, for example, has placed at the consideration of its member countries a proposal for the development of the region in the 1990s, which, given the painful experiences of the previous decade, attempts to conjugate "the transformation of the productive structures of the region within a framework of progressive social equity" (Cepal, 1990: 12). The starting point of said 
proposal is recognition of the fact that the social cost of the neoliberal adjustments dramatically affected the most vulnerable strata of the population and, therefore, the achievement of solid political, economic and social development of Latin America demands fulfillment of minimum requirements of equity (Bóron, 1998; Cepal, 1994). For the Colombian case, the concern for equity appears incorporated in the political Constitution of 1991 (articiles 1 and 334, among others) as one of the principal objetives of public action. Nonetheless, a neoliberal spirit also impregnates large part of the document (articles 333 and 336, among others) as a result of the confrontation between the social democracy and free market models.

\subsubsection{The Neoliberal Model and its Effects on the Political Regime}

The adoption of the neoliberal model of accumulation in Latin America has also implied a recomposition of the relations between social classes. To analyze this phenomenon requires considering this model as something more than a series of macroeconomic policy measures, to consider it as a societal project. By a societal project is meant the concept that the social sectors that aspire to lead the social transformation process have of the relations between the state, civil society and the economy.

This redefinition of the relations between the different social classes, and between them, the State and the economy, implies, in turn, a modification of the political regime. Most comparative political scientists, consider the regime, i.e., as the 
rules of the political game, to be separate and distinct from the rules of the economic game. However, it is possible to consider the regime to be an integral set of rules that regulate the relations between the state, society, and the economy. The economy and politics are both social institutions, sets of rules of the game, as North defines them (1990: 3-4), that shape social interaction, provide a structure for daily life and, therefore, define and limit the range of actions and choices open to individuals. Profound changes in the economy or in politics may induce mutual transformations that profoundly alter social relations and therefore require new rules to regulate them. Changes in the accumulation model transform the political regime and generate new rules of the game that produce societal transformations and redefine the social actors, their relationships, and their fields of action and choice.

Traditionally, the political regime has been defined, in strict terms, as the set of rules and institutions that regulate the type and number of political actors (generally political parties), the forms of access to political power (generally competitive elections), the relations among the branches of government (system of checks and balances), and the process of binding public decision-making (Munck, 1996: 3-4). This definition excludes elements such as non-partisan actors, social classes, economic interests, and the ideologies of the actors. Furthermore, it does not pay sufficient attention to the "rules of the game", i.e., the negotiations or alliances between the actors and the conditions that facilitate or impede them. Munck excludes, explicitly, from the concept of regime this type of considerations and rejects alternative definitions, like that of Michael Mann, that considers the regime as having originated in "an alliance of the 
actors of ideological, economic and military power, coordinated by the rulers of the state" (Mann, 1993: 18-19). Definitions like the above are reductionist, maintains Munck, because they conceive of the regime "in terms of its actors and deal with the institutional rules as epiphenomena." (1996: 20).

The concept of regime used in thisw dissertation is closer to that of Mann, since I consider the rules to originate in an alliance not only among political actors but with social and economic actors as well. Therefore, I define the political regime as the set of rules that regulate the relations between social classes and their organizational expressions and among these and the political parties and the State. The principal function of the political regime is to act as a junction between the State and the economic model, in order to constitute an organizing principle of society, i.e., to act as a base for undertaking alliances between different social sectors in order to provide orientation for the social process. The idea of the accumulation model as societal project and as the set of rules that regulates the relations between social classes and political actors, produces consequences for the concept of "autonomy of the State." As traditionally conceived (Poulantzas, 1969; Skocpol, 1985), said autonomy has been understood as the capacity of the State to distance itself with respect to the partial interests of civil society. On the contrary, the existence of a societal project requires that state action be the result of a combination of the internal strength of state institutions and their articulation with key sectors of civil society that aspire to lead the process of social transformation (Evans, 1995). In this sense, the political regime is the link of union 
between the State and the economic development model, and makes it possible either to undertake the latter as a societal project or to impede its implementation.

To elaborate said conception of the political regime as an organizing principle of society, it is necessary to draw from Antonio Gramsci's concept of hegemony. From his perspective, the ruling class not only exercises domination but also "moral and intellectual leadership" in society (1971: 57), i.e., it is a question of exercising domination not only by means of force but also by consensus. The contributions of Max Weber (1968) also help to structure the concept of political regime proposed here, to the degree that, for said author, the processes of capitalist accumulation require a series of cultural conditions relating to the existemce of an ethic of the ruling class, without which no development is possible. Said leadership and consensus should be obtained through commitments and reforms in which the interests of different social groups should be taken into account.

The political regime and the model of accumulation are mutually conditioned. For this reason, the type of economic model is not neutral with respect to democracy and respect to the type and the participation of political and economic actors. The model itself possesses characteristics which generate inclusionary or exclusionary processes. The ISI was an inclusionary model since it required suitable working and middle classes not only with technical skills but also with increasing purchasing capacity. For this reason the institutional expression of such a model was the inclusivionary welfare state that acted through a series of distributive policies like: a) public health system, b) the 
unemployment insurance system, c) the provision of financial aid to low-income families with dependent children, and d) government promotion of trade union organization, among other things. It might be said that these and other related measures constituted a "social contract" among capital, the State, workers and other social movements, over wages, working conditions, social benefits and political participation. To the contrary, the neoliberal model is exclusionary, since it makes it more difficult to devise and enact a distributive policy. Those tendencies undermine the possibility for the action of workers and other organized social actors. Their participation in the economic process and in the distribution of its benefits progressively loses legitimacy.

The change of economic model invalidates the old agreements between the elites and the social classes that sustain and make possible the functioning of the above model of industrialization by substitution of imports, and imposes the need to generate new agreements to fit the new correlation of social forces. Nonetheless, the neoliberal model limits or prevents the possibility of achieving these new agreements among the different social actors or establishing the leadership of the economic and political elites. This contradictory dynamics between the lack of functionality of the old agreements and the structual impossibility of achieving new ones, aggravates the society's tendency towards disintegration. This is due to two reasons. In the first place, to the division among the economic elites due to the opening and internationalization of the economy. The elites are divided into those who have incorporated technological advances and have connected to the world's productive and financial circuits, and those less competitive ones that act on the basis of the national market. While the former advocate free trade 
and the internationalization of the economy, the latter advocate protectionism or gradual liberalization of the economy. In the second place, it is to the exclusion of subordinate social sectors because, among other reasons, of the reduction of public social spending and state subsidies and the generation of unemployment. Both dimensions of the economic restructuring process limit the possibilities of the elites to form alliances among themselves and with other social sectors, in order to democratically construct new rules of the game to regulate the relations among the economic, social, and political actors.

\subsubsection{Legitimacy Versus Efficiency}

The simultaneous processes of democratization and change of the accumulation model in Latin America engenders a contradiction between legitimacy and economic efficiency. Indeed, legitimacy and efficiency are the most important factors of state activity (O'Connor, 1973; Offe, 1993) and they determine its capacity to integrate society and distribute its resources. The contradiction lies in the fact that the state must try simultaneously to fulfill

$$
\begin{aligned}
& \text { the conditions in which profitable capital accumulation is possible [and] to } \\
& \text { maintain or create the conditions for social harmony. A capitalist state that } \\
& \text { openly uses its coercive forces to help one class accumulate capital at the } \\
& \text { expense of the other classes loses its legitimacy and hence undermines the } \\
& \text { basis of its loyalty and support. But a state that ignores the necessity of } \\
& \text { assisting the process of capital accumulation risks drying up the source of its } \\
& \text { own power, the economy's surplus production capacity and the taxes drawn } \\
& \text { for this surplus (Ibidem: } 6 \text { ). }
\end{aligned}
$$

Legitimacy and efficiency determine also the twofold nature of the state's expenditures, which may be divided into social capital and social expenses: the former is constituted 
for expenditures required for profitable private accumulation while the latter is constituted for projects and services

which are required to maintain social harmony to fulfill the state's 'legitimization' function. (. . .) Because of the dual and contradictory character of the capitalist state, nearly every state agency is involved in the accumulation and legitimization functions, and nearly every state expenditure has this twofold character (Ibidem: 7).

Adapting O'Connor's premises to the Latin American case, the contradiction between legitimacy and efficiency stems from a democratization process and a new constitutional order which claims "more state" as a condition to overcome the legitimacy crisis, and an accumulation model which requires "less state" in order to allow the free allocation of society's resources by the market. While neoliberal governments privatize public enterprises and reduce the public expenditures, the new constitutions increased the number of public institutions and erected fairness and redistribution as the cornerstones of the new political and economic order. However, the final balance affected this last objective owing to the greater importance attributed to the policy of recovering the legitimate monopoly on force by the state. Additionally, an alternative diagnosis of the efficiency of the Latin American state lies in the fact that, no matter what its size, its inefficiency originates in the politicians' tendency to take possession of public resources and offices for their own benefit, owing to the clientelist and patrimonialist character of the political regime. Rather than be privatized, the Latin American state should be become "public".

The contradiction between legitimacy and efficiency is also expressed in the tension between fiscal policy and social policy, which has the following dynamics: the 
neoliberal adjustments pursue the efficiency of the state for achieving macroeconomic equilibrium, specifically for reducing inflation and the fiscal deficit. The search for those goals implies, among other things, the decrease of public expenditures, the introduction of regressive taxation, and the reduction of the real wage. With these policies the distributive function of the state is severely affected which also affects its capacity to conciliate the interests of different social actors. This situation engenders a struggle over distribution and a increasing social polarization of the population. The state, with diminished resources, has less capacity to respond to pressure which leads to the loss of the state's legitimacy and the need to resort to repression and authoritarianism. Thus, the abandonment of the interventionist concept in Latin America has occurred at the expense of civil rights and democratic warranties. For this reason,

current political-economic trends have heightened the importance of the socioeconomic components of the equation -market structures- over the political ones-democratic procedures. This raises the possibility of conflictive situations where the preservation of market structures is secured at the expense of democratic procedures (Vacs, 1994: 68).

In synthesis, I have developed a structural perspective in this chapter. I have maintained that rational choice theory assumes that choice situations can be extracted from the historical dynamics of society. Consequently, actors' choices are always implemented within the context of historic processes which determine their options. Therefore, analyses of economic and political transformations in America Latina in the 1990s have to take into account the historical context in which those processes are embedded. 
I also have maintained that although there is a mutual interaction between agent and structure at certain junctures the dynamics of social processes surpass actors' intentions, and that social actors seeking to advance differents societal projects imposes upon themselves mutual constraints which act as a structural force. From this perspective, I showed that in Latin America the decisions made by actors involved in the economic liberalization policy were constrained by decisions concerning democratization policies, and vice versa. At the same time, the structural heterogeneity and fragmentation that characterize Latin American societies, coupled with globalization processes in which it is inscribed, affected the course of both societal projects.

I have argued that the structural context of political and economic reforms is shaped by the interaction of exogenous and endogenous factors. Globalization and the generalized diffusion of the neoliberal accumulation model were analyzed as exogenous factors. As endogenous factors, the precarious integration of the Latin American societies was analyzed, along with their social heterogeneity, state weakness, the conflict between political and economic restructurings as a societal projects, the effects of neoliberal restructuring on their political regimes and finally, the contradiction between the search for legitimacy and efficiency inherent in both political and economic restructuring. The interaction of exogenous and endogenous factors has aggravated the problems of integration that have historically characterized the region's societies. 
In the following chapters I will apply such a structural framework to the Colombian case for analyzing the contradictory dynamics of political and economic reforms in the 1990s.

\section{Chapter 3}

\section{State, Society, and Political Regime in Colombia}

Colombia, like most Latin American countries, is characterized by a weak state and a fragmented civil society. These historical traits have become even more pronounced during the 1990s as a consequence of political and economic transformations in the country. On the one hand, the political system experienced a traumatic process of constitutional reform designed both to strengthen the state and increase its legitimacy, as well as to overcome the exclusionary nature of the political regime. On the other hand, the national economy also made the transition from an import substitution model of industrialization to a neoliberal model of economic opening and internationalization of the economy. The aim of this process was to increase economic efficiency by reducing the size of the state and its regulatory function. Regarding this restructuring process, it is worth asking whether the adoption of the neoliberal has deepened the fragmentation of 
the Colombian society and whether reducing the scope of its intervention works against the objectives of strengthening and legitimizing the state.

This two-track restructuring is based upon a contradictory relationship. While "political opening," as a result of the adoption of a new Constitution, has produced favorable conditions for fostering policies of democratization and social integration, "economic opening" has counteracted that possibility. This economic process is exclusionary in social terms, owing to the privatization of state enterprises; bankruptcy of private enterprises that cannot compete in the international arena; unemployment; and, the reduction of public social expenditures, among other things. Furthermore, these two structural political and economic reform processes, constitute, in turn, two societal projects promoted by diverse actors and interests. These two societal projects have confronted each other in Colombia since the early nineties, and neither of the two has achieved legitimacy and the political agreements needed to impose themselves and to promote diverse social interests.

The economic and political restructuring has been accompanied by the severe crisis of legitimacy and hegemony the Colombian political system has suffered in the last three decades, as manifested by high levels of violence, a lack of trust in public and political institutions, and the lack of a ruling class with a societal project comprehensive enough to integrate the national territory and different social interests. This situation stems from three factors: the weakness of the state (3.1), a political regime that 
amalgamates premodernity and modernity, which confronts domestic and external forces towards its full modemizations (3.2), and the fragmentation of the Colombian elite (3.3).

\subsection{The Weakness of the Colombian State}

Colombia's current political crisis is a consequence, among other things, of the weakness of the state, which can be traced to its historical inability to integrate territory, establish a legitimate monopoly of force and production of regulations. If the state is, as defined in the theoretical framework presented above, the main cohesive factor of society, it can be said that the Colombian state has failed both to monopolize the use of force and to integrate the nation's society and territory, thus reducing its possibilities for mediating and channeling social conflicts and tensions. Said conflicts are therefore resolved at the margins of public institutions, a situation which gives rise to parainstitutional expressions of power such as paramilitary groups, drug-trafficking mafias, and guerrilla movements.

As has been established in the theoretical framework, the state is a social relationship that divides society into a public and a private sphere. Said division is what makes it possible to establish and exercise domination in society. In turn, a system of domination presupposes a material basis (territory and economy), an institutional base (state apparatus), and a symbolic base (national culture). This triple base forms a structure capable of building and reproducing the network of modern social relationships. 
The equivalent of the symbolic element, the concept of the nation, in classic and traditional societies was the ethnic group. Nevertheless, the modern concept of the nation links ethnic elements to the idea of a political community whose unity is based on the integrating function of an internal market as well as on basic social solidarity. The modern concept of the nation also supposes the existence of a ruling class that needs to organize its preponderant role in society on a universal plane, i.e., it has to give its domination a general form, which implies articulating its own interests with those of other subordinated social sectors, which is what Gramsci (1971) denominates hegemony.

Historically, the formation of the state has been a gradual process of construction or acquisition of the above-mentioned attributes, in order to exercise domination over society and the territory in which it is setttled. These attributes generate the state's capacity to integrate regions and populations and to create and reproduce certain patterns of social relations.

This process of state formation has not been free from violence. Nevertheless, it is necessary to distinguish between two types of violence: that which is exercised in the process of constituting the state, and that which arises from precarious constitution of the state or from the absence of the same in different regions of the national territory. In relation to the former, authors like Tilly (1992) and Elias (1998) have pointed out that the process of integrating territories and societies necessarily passes through a periods of 
exercising rough coercion and violence. Elias holds that the processes of formation of the state and construction of the nation show that

every effort towards greater interdependence, towards closer integration of previously independent or less reciprocally dependent human groups, undergoes a series of specific conflicts and tensions of integration, of balances. of power struggles that are not accidental but structural concomitants of these efforts to achieve greater functional interdependence of the 'parts' within the whole (Elias, 1998: 106-107).

The integration achieved by the State (which is basically the triumph of a strong power over its rivals and the imposition of its own legality as the victor's legality) absorbs violence or the power to use violence to solve social conflicts, that was diffuse in the society, and creates an institutionalized, legitimized, centralized and legally regulated power. Thus there arose a public space that serves as a form of mediation and resolution of social conflicts and tensions. Failure to firmly constitute this integration, or to legitimate it, leaves power in the private sphere, which means that members of society may resort to the use of force and violence for the solution of conflicts, to the detriment of basic social cohesion.

In general terms, this has been the process of constitution of the state as an "ideal type", based on the European experience of historic formation of the nation-state (Tilly, 1992). Although the formation of the state in Latin America in general, and in Colombia in particular, has followed a similar pattern, the process has been conditioned by three factors. In the first place, the legacy of a colonial past marked by Spanish influence. From the cultural point of view, this legacy is expressed in the survival of particularism, localism, nepotism and generally anti-capitalistic values and codes of behavior (Oslak, 1981), i.e., a legacy associated with the survival of a traditional political and social 
order. The successive processes of capitalist modernization that developed after independence and until well into the twentieth century became hybridized with these traditional institutions. In the second place, the process of settlement that originated in the colony, characterized by the development of enclave economies which made it possible to link each population to the metropolis through commerce but also resulted in isolation and the lack of a communications infrastructure among them. Thus, when the links to the metropolis were interrupted after independence, territorial fragmentation became even more acute and further hindered the formation of a national market. The weakness of the Colombian state is partially due to its limited territorial integration that, even today, characterizes various regions of the country. Thirdly, the lack of articulation among the different sectors of the ruling class, i.e., their inability to constitute a hegemony. This aspect will be dealt with in section 3.2.1

The regional, political, and social fragmentation of the ruling clase has impeded the structuring of an effective system of power and has been one of the causes of its weak centralization. But this fragmentation has especially contributed to the lack of leadership and capacity of the elites to "envision" an integrated society, territory, and economy, i.e., to construct a real nation-state. This situation is manifest, among other things, in the elite's incapacity to elaborate a policy of broadening the internal market, by means of colonization processes that integrate marginal territories and populations that, unfortunately, constitute more than half the country. Those marginal territories, colonization zones of the agricultural frontier, are concentrated in the region of Orinoquia in the eastern part of the country, with an extension of $310,000 \mathrm{~km}^{2}$, and in 
the region of Amazonia, in the southeast, with an extension of $315,000 \mathrm{~km}^{2}$. These regions are characterized by low agricultural productivity, lack of infrastructure in terms of roads and basic services, no integration into national or regional markets, and a precarious presence of the state. The towns of these regions have a population of less than 10,000 inhabitants each and less than one-third reside in the municipal seat. Of the population of these regions, $75 \%$ live in poverty and $40 \%$ of the same live in conditions of misery. The two regions add up to a total extension of $625,000 \mathrm{~km}^{2}$, i.e., $54.7 \%$ of the nation's $1.141 .748 \mathrm{~km}^{2}$ surface area. If other minor zones of internal colonization, situated in the central and northern regions of the country, are added, it is no exaggeration to say that almost $60 \%$ of Colombian territory is composed of zones that are either not integrated or precariously integrated into the economic, political and social development of the country (Instituto Geográfico Agustín Coddazzi, 1996; Echandia Castilla, 1999).

As one author has pointed out, "Colombia is a country of permanent colonization" (Bolivar, 1999:34), but in the twentieth century this has been more the result of spontaneous uprooting of populations from the different regions, for political or economic reasons, than the product of any deliberate territorial and socioeconomic development policy on the part of the state and the ruling class. It is precisely this circumstance and the failure to carry out an agrarian reform, which has been postponed ever since 1936 because of the lack of political will among the elites, that have generated "empty spaces" in Colombia. These prove to be fertile ground for armed violence, since within them 
there exists a population ready to resort to armed opposition, produced by a flood of heterogeneous colonization in which very different regional and ethnic groups converge (...) that constitute very diverse subcultures. Furthermore, the presence of the state is precarious and almost entirely limited to repressive control of conflicts due to the fact that the traditional bipartisan system never managed to monopolize the expression of political and social struggles in these areas as it did elsewhere. On the contrary, these regions have been the scenario of a tradition of protest dating back to the beginning of the $20^{\text {th }}$ century that has led the population to identify with groups that confront both the State and the traditional bipartisan system. (González, Fernán, 1997:93).

The lack of effective institutional presence of the state in the different regions of the country contradicts the vision of the Colombian state as a monolithic entity, the product "of a globalizing and totalizing national history, whose validity collapses when one takes into account the particularity of a regional life" (Uribe de Hincapié and Alvarez, 1987: 13). As an indicator of such a lack of state presence, it can be mentioned that $86 \%$ of total public expenditures in 1995 was spent by the central government and only $14 \%$ by departmental and local governments. Of the total amount spent by the central government, more than $38 \%$ was invested in Bogota and only $5.8 \%$ in Orinoquía and Amazonia (Fundación Social, 1998, p. 155), which are colonization areas that are totally marginalized from socioeconomic development efforts and plagued by social conflict and by a high degree of guerrilla, paramilitary and drug-trafficking activities. In addition, one might note that $39 \%$ of the Colombian population inhabits 808 municipalities which represent $77 \%$ of the total number of Colombian municipalities, and are in turn classified from a socioeconomic development point of view, as precarious, fragile or incipient (Ibidem, p. 395).

The incapacity of the present ruling class to carry out a policy of national integration contrasts with the successful processes of territorial integration and social 
cohesion developed during the second half of the $19^{\text {th }}$ and beginning of the $20^{\text {th }}$ century, as a product of a vision of the elite. I refer to the Antioqueño colonization that was fundamental in the constitution of the culture and the economy of the coffee-growing region which, until just recently, was the motor force of the Colombian economy since it permitted the accumulation of capital needed for the industrialization of the country. In the mid- $19^{\text {th }}$ century, the present coffee-growing region was an uncultivated jungle area in the southwestern portion of the country. Although its colonization was not free of violence and unexpected events, the decided support of the Antioquia's commercial and political elite, facilitated a significant agricultural, commercial and demographic development of the coffee-growing region (Brew, 1977; Palacios, 1980b). In the second half of the nineteenth century, the merchants of Medellin (the state of Antioquia's capital) acquired large extensions of land in the southwestern part of the state, fomented immigration, and donated lands to those who were willing to work on the construction of roads to connect this region with the capital of the department, to work in agriculture and mining, or to found settlements (Brew, 1977: 176-177).

The leadership of the elite and the importance that coffee acquired as an export product made this one of the most highly integrated regions of the country from the economic, political, and social points of view. This integration was expressed in a series of organizations and institutions, such as the coffee-growers committees that coordinated and promoted coffee-growing activity at the local, departmental and national levels through the powerful Federación Nacional de Cafeteros. This integration established ties of solidarity, symbols and ways of life that produced the 
"coffee culture," which has played a key role in creating a sense of a Colombian nationality (the national pride associated with the idea that Colombia produces the best coffee in the world, the internationally projected image of the Colombian peasant in the figure of "Juan Valdés"). However, it is necessary to say that this integration has begun to erode recently because of the crisis of the coffee economy induced by the opening of the economy and the global economic conditions. These developments no longer favor worldwide pacts and producers' cartels regarding the commercialization of primary products, which had been crucial to the success of Colombian coffee-growing activity. That crisis has eroded the quality of life of coffee-growing peasants and coffee-growers institutions' chances of maintaining this model of integration. This situation has expelled peasants towards the current areas of spontaneous colonization, where social cohesion is either lax or non-existent and plantations of coca and poppy abound in a generally illegal economy.

If the state is defined as a social relationship and as a set of institutions and mechanisms that make it possible, one could say that to a certain extent the Federación de Cafeteros and its coffee-society project has been a state. In fact, there are authors who consider it to be a para-state (Escobar, 1995). Although there are those who adduce that precisely because of this the Federacion de Cafeteros has helped to impede the formation of a true state in Colombia, the purpose of these reflections is to illustrate how the current ruling class has failed to construct a nation-state in the current colonization zones, due to its lack of long-term vision and its inability to integrate society and territory. 
The Colombian bipartisan regime has also contributed to the weakness of the state. In this respect, Fernán González (1997) maintains that the weakness of the Colombian state is due to the early rise of traditional political parties at the end of the first half of the $19^{\text {th }}$ century ${ }^{11}$, a very difficult initial period in the process of forming the Colombian state. Parties, the Conservative and Liberal, acted as a factor of social integration at that time and promoted the formation of social identity on the basis of patronage and personal loyalties, thus preventing the establishment of a direct relationship between state and citizens. The weakness of the state became even more visible during the second half of the twentieth century, as a result of the crisis of parties and the erosion of their central role in Colombia's political and social life after the end of the National Front ${ }^{12}$ (1958-1974).

Paul Oquist (1978) maintained that throughout the nineteenth century the Colombian state was very weak and social integration was achieved through strong noncapitalistic social structures and non-state forms of social control. This situation changed during the first four decades of the twentieth century when, according to Oquist, the Colombian state achieved a considerable degree of strength and ability to integrate and regulate society. However, during the 1940 s and 1950 s, the political struggle between Liberals and Conservatives for control of exclusive access to state power, along with profound changes in the structure of classes and emergence of social

\footnotetext{
1 The Liberal and Conservatives parties were founded in Colombia in 1848 y 1849 respectively

${ }^{12}$ The National Front was an agreement made in 1957 between the Liberal and Conservative parties to bring an end to a long period of extremely violent confrontations (1946-1957) for the control of the state apparatus. The agreement provided for the two parties' alternation in power and equal distribution of government jobs between them over a period of sixteen years. See Hartlyn, 1988; Leal, 1986).
} 
conflicts, generated a situation of violence which undermined the previous strengthening of the state to the point of partial collapse, especially in regions with the most acute social contradictions.

Contrary to Oquist, Bejarano and Segura (1996) consider that the state underwent selective strengthening during the National Front period due to increased public spending in three sectors of the executive branch. The average percentage of total public spending from 1957 to 1974 was $28.6 \%$ in the social sector, $25.9 \%$ in justice and security, $20.3 \%$ in infrastructure, and $20.88 \%$ in public administration (Ibidem: 14). According to those authors, the process consolidated the executive branch and public administration at the expense of the legislative branch, whose functions and controls were clearly diminished vis $\grave{a}$ vis the former. Nonetheless, this selective strengthening does not seem so clear, as these same authors recognize, if various aspects are taken into account. In the first place, the growth of social spending (education, health, housing, and agriculture), contrasts with the marginality and extreme poverty of large sectors of the Colombian population during the period considered, as pointed out by various analysts (Urrutia, 1984). At the same time, that increase coincided with increased social protests during the National Front, which rose from 46 in 1958 to a total of 295 in 1974, with a notorious rise to 539 in 1971 (Archila, 1997:16). This would suggest that the increased spending was due more to the pressure exerted by these social struggles than to a deliberate policy oriented to strengthen the state and social integration, or that social spending was diverted to other sectors, inefficiently allocated or that it "did not grow at 
the rhythm of the social needs of a country that was growing and becoming transformed at dizzying speed" (Bejarano and Segura, 1997: 16). In the second place, increased public spending in the areas of justice and security does not seem to have been as clear as the authors hold, since public spending in those sectors declined from $28 \%$ in 1958 to $20.57 \%$ in 1974 . The administration of justice was the "Cinderella" of the state for a long time, a fact that has contributed significantly to the deterioration of public order ever since the National Front period. This situation is reflected in an increased rate of impunity that rose from $84 \%$ en 1975 to $95 \%$ in 1992 (Montenegro, Posada y Piraquive, 2000: 99). Investment in justice only began to increase in the early nineties when aggravated violence and profound deterioration of public order made it imperative to do so. In the third place, public spending on infrastructure does not seem to sustain the idea of selective strengthening of the state. That spending also diminished throughout the period studies by Bejarano and Segura, since it fell from $28.3 \%$ in 1958 to $13.12 \%$ in 1974. This situation is grave if one considers the fact that Colombia is a country with serious deficiencies regarding the integration of its territory and its national market, precisely because of the weakness of the state.

Although there is no sound empirical evidence for Bejarano and Segura's argument and despite the fact that they do not consider other important dimensions of the concept of the state such as the cultural, political, economic, and territorial ones, one can accept for the sake of the discussion that a certain increase in public spending and rationalization of public administration implies a partial strengthening of the state. 
Indeed, during the 1960 s and 1970 s the National Front governments revitalized the policies of modemization and rationalization of state and public administration which had been interrupted during the violent period of the 1940s and 1950s. However, this process was undermined by a series of other factors such as the exacerbation of clientelism and patrimonialism as a consequence of the exclusionary power-sharing arrangement between the Liberal and Conservative parties, the rise and entrenchment of drug-trafficking, the strengthening of guerrilla groups and organized crime, the growth of informality and illegal forms of capital accumulation, and increasing colonization of agricultural and economic frontier zones without due planning, orientation and integation into the national market and institutions. Therefore, the relative advances achieved in terms of the state's capacity to regulate society, and to mobilize and allocate resources practically collapsed during the $1980 \mathrm{~s}$ and $1990 \mathrm{~s}$.

In addition to the Colombian state's inability to integrate the territory, another important aspect of its weakness is its inability to administer justice and provide security for its citizens. The judicial system's capacity to resolve conflicts among citizens is very limited. According to the Colombian Department of Planning the rate of impunity in 1994 was $97 \%$, while a criminal court judge produces only 15 sentences per year, i.e. little more than one a month (Montenegro, 1994: 38). That year there was a backlog of $2,000,000$ cases in criminal matters and 1,800,000 cases in civil and economic matters without solution (ibidem). For the same year, there were 196 police for every 100,000 inhabitants in Colombia, while smaller countries like Uruguay and Peru had 767 and 350 respectively (Ibidem: 41). Social conflicts thus tend to be solved at the margin of public 
institutions by the guerrilla, paramilitaries, drug trafficking mafias and other forms of private justice and defense.

Economic studies have appeared recently on the situation of justice and violence in Colombia, that reject the weakness of the state as an explanatory variable, considering it a vague concept that does not withstand "either a serious empirical analysis or a minimimum contrast with reality" (Montenegro, Posada and Piraquive, 2000: 85 and 93). Instead, they consider the causes of violence in Colombia to be associated with the rise and strengthening of drug-trafficking and organized crime, the expansion of the illegal economy, and the existence of areas of colonization with abundant economic resources such as oil, bananas, gold, and emeralds. All of this made possible and increased criminality, which, in turn, led to the collapse of criminal justice (Gaitán, 1995; Rubio, 1999; Montenergo, et. al., 2000). Although these authors are correct in pointing to the above-mentioned factors as causes of violence, the strictly quantitative view of the phenomenon, typical of the economic bias, leads them to underestimate the institutional, political and cultural dimensions. They do not consider the fact that the administration of justice is a function of the state that has traditionally been neglected in Colombia, and that the economic and social exclusion, the lack of territorial integration and development of the internal market (fundamental elements of the state), propitiate processes of spontaneous and disordered colonization, with uprooted populations, in which the exploitation of natural resources foments and strengthens criminality. 
By and large, the development of para-institutionality is a result of the weakness of the state that is facilitated by geographic complexity of territory; scarce or nonexistent communication, transportation, education and health infrastructure, and the limited presence of administrative, police and judicial authorities. The gap left by the state is filled by clientelism, drug-trafficking mafias, guerrilla movements, and groups dedicated to private justice and defense. The last of these constitute an interesting symbiosis of social relations: powerful regional interests in search of the security the state fails to provide as protection against delinquency or guerrilla excesses, ally themselves with some sectors of the military and drug-traffickers to fight a common enemy. It is the guerrilla itself and its supposed sympathizers or supporters which are defined ambiguously to encompass intellectuals, teachers and professors, human rights defenders, and civic leaders. Such a strategic alliance has engendered a spiral of war, terror, massacres and social uprooting, and a "culture" of intolerance, violence and exclusion. This "culture" pervades the ways in which the population of a weak state and a fragmented civil society solves its conflicts.

Since the 1980s all those factors have created a situation of social anomie characterized by violence and the systematic violation of almost all norms of social coexistence. As I have argued (Orjuela, 1990), the catalyst of this crisis has been drugtrafficking, which has exacerbated all its dimensions. The weakness of the state and the absence of public authorities and development policies in much of Colombian territory have spurred the expansion of the drug-trafficking cartels. Supported by unlawful forms of capital accumulation, they challenge the precariou s institutional order and 
through corruption and violence they seek political, economic, and social insertion into Colombian society. In their struggle against legality they contribute to the decomposition of the state and society.

The incapacity of the elites to integrate the national territory and to assume leadership in society, the state's inability to administer justice, the increasing weight of the economy and illegal activities in Colombian society and culture, the anomie and deterioration of the social fabric, have given certain authors grounds on which to characterize Colombian culture as a "mafia culture" (Garay, 1999). This culture has displaced the culture of work and productive investment, which has led to the "deindustrialización" of the country. According to Gómez Buendía, one of the characteristics of Colombian society is the weakness of public rationality, which is topped by private rationality, understood as

individual creativity, diversity, imagination, ingenuity, the inexhaustible tenacity of Colombians; but also their difficulty in organizing themselves to undertake collective projects so as to resolve the most essential public problems. (beginning with peaceful coexistence and respect for the country's institutions - first and foremost, the law-) (1999: 19).

\subsection{Political Regime as an Amalgam of Premodernity and Modernity and its Limits in a Global World}

According to Weber, historically the development of the modern state began at the moment in which the prince expropriated the bearers of administrative, fiscal and war mechanisms and concentrated all power in himself (1997: 1059-1060). If, as Weber says, a characteristic of political modernity is the separation of state officials from the resources with which they administer society, then we can say that in the Third World in 
general, and in Colombia in particular, that separation and, therefore, modemity, has only been produced partially and, in any case, not fully produced. This can lead as to affirm that patrimonialism and clientelism are typical of Third World regimes.

Furthermore, as mentioned above in the theoretical framework, the legacy of "the colonial and traditional past in Third World societies reinforced non-capitalistic forms of social control and socio-political relations, impeding the formation of a centralized state able to achieve "successful subordination of the people's own inclinations of social behavior . . in favor of behavior prescribed . . by rules" (Migdal, 1988: 22). The result is a social fragmentation that impedes the emergence of "strong states" with sufficient capability to integrate society and centralize its regulatory function. This social fragmentation and the political primacy of local and regional strongmen prevent, in turn, the development of a rational bureaucracy and facilitate the control of local institutions by personal interests, which leads to the displacement of general state policies by partial interests. From this perspective, it can be said that Colombia's armed conflict has to do, in large part, with the state's incapacity to predominate over local interests in order to address historical problems related to the redistribution of land an the integration of territory. These ideas from Migdal must be complemented with those of Gamarra (1994), who has referred to the contemporary Latin American regime as a hybrid given that it combines, on the one hand, democracy and authoritarianism, and on the other hand, neo-liberal technocracy and "patronage" in the decision-making process.

Drawing on Weber, Migdal, and Gamarra, one can say that the modernization of Colombian society can be viewed as an unfinished process if one takes into account that 
both the legacy of social and territorial fragmentation of the colonial past (Palacios, 1986; Pecaut. 1987), the process of industrialization that occurred during the first half of the twentieth century, and the National Front pact from 1958 to 1974, generated a social and political hybrid of modernity and premodernity. Indeed, the old and bloody struggle over hegemony from the 1940 s to 1950 s, between the conservative agrarian-based faction of the elite, and the liberal pro-modernization faction, was solved by means of a mutually beneficial covenant that appeased both sides. Although priority was given to the modernization and industrialization of Colombian society, the traditional sector was able to maintain some privileges based on a partial continuity of traditional society. That situation helps to explain the persistent failure of attempts at agrarian reform, why the large rural landowners have paid low taxes, and why many of the political relationships in Colombia have a clientelistic character. Politically, the pact included the alternation of Liberal and Conservative Parties in government, and equal distribution of positions in the legislative, executive, and judicial branches (Leal, 1984). The arrangement has consequently been labeled as a "consociational regime" (Hartlyn, 1988). Although the National Front marked an end to the political violence of the 1940s and 1950 s, and for some years promoted stability of the political regime, it established the basis for yet another crisis whose principal effects were: a) exclusion of new social and political forces which arose due to the process of modernization and industrialization, b) exacerbation of clientelism, c) blurring of ideological and programmatic boundaries between the two parties, d) incapacity to implement social reforms, e) lack of representation, and d) rupture between political and economic elites. 
Clientelism is the premodern legacy of an agrarian and traditional society that has served as a cohesive force for socio-political integration for a large portion of the Colombian population, especially the rural one. Indeed, the lack of both a broad and effective infrastructural and social policy and of a state presence in a large portion of the national territory is the essence of clientelism. Clientelism is a personalized and hierarchical system of socio-political relations, and a sort of private social security system, in which regional and local politicians (electoral barons, in the Colombian jargon) substitute for the state action. They satisfy the particular needs of their clients by means of the private use of state resources and funds, and controlling access to public services, in exchange for their clients' political loyalty. This undermines the state's effectiveness in providing Colombians with adequate public services in matters that encompass everything from water and sewerage to the administration of justice.

The exacerbation of clientelism and patrimonialism has reduced the relative autonomy of the state in Colombia and negatively affected its legitimacy for two reasons. First, the private use of public resources impedes state efforts to direct such resources towards state priorities or the common good. Second, political relations based on personal loyalties impede the state's capacity to act as a general cohesive factor of society that, in turn, limits its possibilities for leading the modernization process. Therefore, the Colombian political crisis engenders, among other reasons, the delegitimation of the state due to the lack of generalization of the benefits derived from its action. 
According to some authors, clientelism has proved functional for the different social classes, the political system, and the economy in general, since it has provided stability and integration for Colombian society (Leal and Dávila, 1991: 97). However, one must to accept this affirmation with some reservations, since the political stability has been very fragile and social integration has been partial at best. However, clientelism, patrimonialism, and hybridation that have characterized the Colombian political regime until now have begun to find their limits and have ceased to be functional to Colombian society.

One of the limitations confronted by the Colombian hybrid political regime is the current national and international concern for corruption. This has been defined, from a moral and juridical perspective, as the undue and illegal appropriation of public money or goods for private ends. However, for the purposes of my analysis, I will approach the issue of corruption from a Weberian sociological perspective. From this point of view, corruption is one of the expressions of clientelism and patrimonialism that, in turn, are expressions of a premodern political culture. According to Weber, patrimonialism is a traditional form of domination, in which political control is exercised by means of a bureaucratic apparatus integrated by the sovereign's friends or favorites. When such domination is exercised in polities it is called patrimonial state, and its form is similar to the domination established in the domestic community (Weber, 1997: 184-187). The types of retribution of the "patrimonial servants" are called by Weber "prebends", which consist of the sovereign's personal patrimony assignments in money, goods, granting of land or of incomes, rights or tributes. Weber calls "prebendary" the existence of a public 
administration maintained in such a way (ibidem: 187-189). This form of patrimonial exercise of authority implies a political relationship based primarily on personal loyalty, which represents a strong obstacle for the rise of economic and political modern rationality (ibidem: 191). This, as mentioned above, impedes the complete separation of the private and public spheres, and the appearance of the rational legality. As Weber points out, "the patrimonial state assures that the sphere of favors granted by the sovereign can be converted in to a mechanism for the formation of fortunes, and clears the path (. . .) to the enrichment of the sovereign himself, of his favorites, courteous officials, governors, mandarins, taxgatherers, state attornies, sellers of all kinds of graces, large merchants and capitalists. . ." (Ibidem: 837).

According to this Weberian characterization, it can be said that in Latina America, patrimonialist political domination manifests itself in two institutions: clientelism and prebendarianism. From this perspective, corruption is not a moral deviation of behavior but a form of prebendary relationship, which characterizes Latin America's political regimes. Corruption thus be understood as a remnant of patrimonialism hybridized with the modern bureaucratic rationality. Patrimonial regimes constantly generate clientelist and prebendary relations, reproducing a traditional political culture. In such regimes those practices are not only apparent in pre-electoral periods (although they intensify in such periods) but also constitute the fundamental and core praxis that generates stable bonds of domination which, in turn, reproduce practical clientelist and prebendary relations. Practices of this kind include: the delivery of money in exchange for votes or recommendations to obtain official posts ; favoritism in 
granting public contracts; monopolies offered to friends of the state; tolerance of the infractions of the law, incompatible accumulations of officials posts, etc. All of these cases refer to political practices that blur the crucial distinction between the public and private spheres.

The new limits confronted by the Colombian hybrid political regime are thus manifested in greater national and international concern regarding corruption and they are being replaced by the new public institutions that arose from the new political Constitution of 1991, which will be analyzed below, and by the globalization process. Both these phenomena are forcing full modernization of social relations, in the sense of the establishment of more rationalized and transparent relations between the state and civil society, in order to make the economy more effective. But it is not simply a question of seeking greater transparency and effectiveness in the allocation of social resources at the national level, but also of seeking greater security for capital at the international level, threatened by the insecurity of the regulative framework of Third World societies and the fragility of the new electronic technologies of transmission of information at the global level. In this respect, Wang and Rosenau point out that

as growing numbers of companies from northern industrialized countries expand their operations into developing countries, where the monitoring and regulative framework tends to be less developed, they are subject to greater temptations to engage in practices not allowed at home. The digitalization of international finance and the proliferation of strategic business alliances accompanying globalization are other reasons why corruption may be increasing: it is technically much easier than ever before to launder and dispose of the gains harvested through corrupt practices (2001: 30).

Furthermore, the international political changes have contributed to generating a new anti-corruption environment, since with the end of the Cold War, the collapse of the 


\section{Soviet Union and crisis of communism, the great economic powers are no longer willing}

to support and tolerate corrupt, undemocratic governments or those that do not respect human rights.

Thus, corruption has become a topic on the new international agenda. The new sensitivity in the face of this phenomenon and the need to design new policies to combat it have been warned by various international analysts. In this respect, Glym, Kobrin, and Naím say the following:

in less than a half-decade, the worldwide backlash against corruption has swept like a firestorm across the global political landscape. Governments have fallen. Longtime ruling parties have been hounded from office. Presidents, prime ministers, parliamentarians, and once mighty corporate chieftains have been grilled by prosecutors and herded into the docket. Italy, France, Japan, South Korea, India, Mexico, Colombia, Brazil, South Africa: no region, and hardly any country, has been immune (quoted by Wang and Rosenau, 2001: 27).

The new global anti-corruption attitude has also been expressed in countless international conferences and institutions. Among them, it is worth mentioning the International Anti-corruption Conference, IACC, which has been meeting every two years since 1983. In its ninth meeting, held in 1999 in Durban, Surafrica, the IACC considered that corruption is "one of the most debilitating legacies of the twentieth century" (Ibidem). International multilateral organizations like the United Nations, the World Bank, the International have also redoubled their efforts in the struggle against corruption. In 1999 James Wolfesohn, president of the World Bank, emphasized the importance of the policy of combating the phenomenon in the following way:

while building an effective government framework is difficult, it will become impossible if there is corruption which is the single most corrosive aspect of development and must be fought systematically at all levels. Particularly it must start with a vigorous commitment from the leadership to fight 
corruption on all levels, with initiative both to prevent it from happening and a system for finding and punishing wrongdoers where corruption exists. The lead must come from the top and efforts must be persistent and unyielding (Wang and Rosenau, 2001: 28).

But perhaps the maximum expression of the new global order against corruption has been the rise of "Transparency International", founded in 1993 as a nongovernmental organization, specialized in anti- corruption matters. Transparency International states that its mission is "to curb corruption by mobilizing a global coalition to promote and strengthen international and national integrity systems" (Galtung and Pope,1999: 260; emphasis added). This NGO is constituted by a general secretariat, located in Berlin, and a large number of national chapters, which have increased from 50 in 1995 to 100 in 2000 (Ibidem). In 1996, the Latin American chapters constituted a regional chapter to strengthen cooperation in the struggle against corruption.

In Colombia, it can also be said that the sensitivity of civil society in the face of corruption has increased. A survey done in the year 2000 by the Confederation of Chambers of Commerce and the Fundación Corona on the perception of Colombian entrepreneurs regarding the phenomenon, showed that the majority believes that corruption has increased. Of those who have contracts with the state, $95 \%$ recognize that they have accepted paying a percentage of the total amount of the contract to functionaries of the state entity that should ganted it; and $37.8 \%$ affirm that they know the amount of the bribe that they must pay in advance, $44.2 \%$ affirm the bribe is solicited by the public official (Confecámaras, Fundación Corona y Cipe, 2000: 21 and 29). According to the business sector the more corrupt state entities are the Congress, 
the Social Security System, the Public Finance System, and the Public Sector Unions. The entrepreneurs think the Colombian Government should consider the fight againts corruption as one of its more important priorities (ibidem: 44).

The Colombian General Comptroller's Office was strengthened by the 1991 Constitution. In consequence, in the last years its investigations have increased notoriously, from less than 1000 in 1990 , to 1229 in 1998 , and 1751 in 1999 . Moreover, in the last decade in Colombia there has been a proliferation of civil society's organizations known as veedurias ciudadanas, a kind of citizens's comptrollerships whose function is to oversee politicians and public employees' behavior, as well as the correct allocation of state funds and the execution of public works. These organizations have created a network in order to coordinate their actions.

In synthesis, at the beginning of the 1990s, "global coalition" arose against corruption as an expression of global governance." This fact, along with the political changes occurring in Colombia during the same period, have contributed to the generation a domestic public conciousness against corruption and the development of national and international strategies for fighting it. In turn, the above processes have created a pressure toward rationalizing and increasing transparency in the allocation of state resources that constitute a force against the continuity of clientelism and the hybrid nature of the Colombian political regime. 


\subsection{The Fragmentation of the Colombian Elite}

The clientelistic socio-political relations, that are one of the characteristics of the Colombian political regime, are articulated with another of its characteristics that, as has already been mentioned, is the ruling class' inability to integrate its different sectors. This has been one of the traits of the Colombian elite from the era of independence to the present day (Palacios, 1980a).

During the nineteenth century, this incapacity of the ruling class to organize its interests on the general plane of society, appears as disarticulation among the landowners, and between them and the commercial sector. During the first half of the twentieth century, this disarticulation appeared as a confrontation among the rural landholding elite, and the industrial urban elite, which became clearer after 1930, when the liberal governments assumed power and laid the political and institutional bases for the process and the formation of a working class (Pecaut, 1987). At the end of the twentieth century and the beginning of the twenty-first, this fragmentation is manifested in over-representation of the rural sector in the Congress ${ }^{13}$, in disarticulation between the political elite and the economic elite ${ }^{14}$, and in fragmentation of the latter between the sector that produces mainly for the internal market, and that which, by taking advantage

\footnotetext{
${ }^{13}$ This over-representation persists despite the fact that the latest census, done in 1993, showed substantial changes in the composition of the Colombian population, including the fact that $74 \%$ of the population lives in urban areas, while $26 \%$ lives in rural areas. Nevertheless, that census has not been approved by Congress, adducing supposed technical defects in its execution, since representation of the regions in this institution, and the political interests linked to rural areas, would be affected.

${ }^{14}$ Despite this historic situation of fragmentation of the ruling class, there have been three failed attempts in Colombia to link and harmonize the different sectors of that class and to develop the nation-state on this basis. These were the governments of Rafae] Nuñez (1884-1886), Alfonso López Pumarejo (1934 1938), Carlos Lleras Restrepo (1966-1970).
} 
of economic "opening", has managed to become articularted into the global economy. This last aspect will be analyzed in Chapter 5 .

This rupture between political and economic elites has led to an institutional fragmentation of the state: the political elites express themselves and act through the Congress and other non-technical institutions, while the economic elites pursue their interests through institutions responsible for economic policy, such as the Central Bank, the National Planning Department and the Finance Ministry. This fragmentation becomes apparent in three ways: First, the primacy of economists over lawyers and politicians in public policy making. Second, concern over the excessive clientelist influence on economic policy which led to administrative reforms aimed at insulating state institutions responsible for economic policy; and, third, the new role that the Consejo Gremial Nacional (a federation of the principal business organizations) has played in Colombia's political life in recent years.

In relation to the first aspect, until the fifties politicians and lawyers exercised a privileged management of state institutions and economic policy. Political activity and membership in political parties were also mechanisms of prestige and social mobility at that time. However, adopting Palacio's hypothesis, it seems plausible to affirm that since 1948 "militance in political parties was no longer a channel of social mobility, especially for professionals, who began to seek public office through distinct mechanisms" (2001: 115). 
In the 1960 s, the process of industrialization and "semi-modernization" was consolidated in the country, and the economic functions of the state increased and became more complex. This coincided with the development of economics as a science and a university career. Economists began to replace lawyers and politicians, who remained as representatives of the traditional social relations and political culture (Palacios, 2001: 115). The number of schools or departments of economics in Colombian universities increased from 3 in 1952, to 9 in 1960 , to 35 in the 1980 s, and to 48 in the 1990s. Consequently, the number of graduates in economics grew from 60 in 1960 to 1449 in 1980, and descended to 812 in 1997 (Palacios, 2001: 111). It can be said that, as of the $1960 \mathrm{~s}$, the economists began to replace to humanists and lawyers as the primary "organic intellectuals" of Colombian society. As Gramsci points out, "each social group, upon emerging from the original base of an essential function in the productive sphere, creates at the same time, organically, one or more layers of intellectuals that give that group homogeneity and consciousness of its own function in the economic field: the capitalist businessman creates with himself the economist, the scientist of the political economy. In addition, the businessman is also an intellectual" (Gramsci, 1981; 187)

In Colombia, the tecnocratic economists, have formed a closed social circle based upon its commmon social class identity, its academic formation in few universities, especially Los Andes University (Bogotá), a elite University; its professional fulfillment in the same institutions in the public and private sectors, especially, the Ministerio de Hacienda, the Departamento Nacional de Planeación, the 
Banco de la República, and the Asociación Nacional de Instituciones Financieras, ANIF; in research centers such as CEDE and FEDESARROLLO, and in international multilateral organizations such as ECLA, Inter American Development Bank, and the World Bank. Between 1958 and 2000, 62 people have occupied ministerial posts, director of the Departmento Nacional de Planeacion, and director or codirector of the Banco de la Republica, and the great majority of them have been economists. Of these 62 officials, 32 are Los Andes University alumni (Palacios, 2001: 128). Of the all Colombian economists, 164 have carried out doctoral studies at foreign universities, especially in the United States; and $80 \%$ are Los Andes University graduates (ibidem: 121). Additionally, $70 \%$ of the scholarships offered by the Banco de la Republica to conduct doctoral studies outside the country have been offered to Los Andes University alumni (ibidem: 122). In consequence, the economics school of this University has been the alma mater of the main decision makers of Colombian economic development policies during the last four decades. According to Palacios, in the context of Colombian economics schools, Los Andes University "has better complied with the two requirements consistent with the values of the practical ideal: it has been more apolitical and tecnically oriented in all aspects, and more open to internationalization" (Palacios, 2001: 118)

In regards to the Consejo Gremial, this organization has filled the political gap left by the traditional parties since they abandoned the function of channeling, debating, and proposing solutions to general interest issues. The Consejo Gremial has replaced political parties on issues such as conflict and peace, erosion of the social fabric, and 
citizen security. It is illustrative in this respect to quote Cesar González, former president of the Consejo Gremial:

business institutions should perform a cultural role in the formation of public opinion and strengthening of citizenship. It should be this way because of the weakness our society exhibits in performing a real public action aimed at solving our fundamental problems. The concept of "public action" refers not only to the administration and control of state power and instruments but also to civil society's ability to obtain general interest goals. Peace, cultural modernity, an identity worthy of Colombia in the international community, and sustainable economic growth are our fundamental interests" (González, Cesar, 1997: 75-76).

As will be shown below, this fragmentation of elites and state institutions has affected the regime's effectiveness, i.e., its capacity to lead society, especially in the context of the changing economic model. The situation is reinforced by the neoliberal nature of such a model, whose exclusionary character limits the possibility for elites to make alliances with other social sectors.

In synthesis, I have argued in this chapter that Colombia has suffered a crisis of legitimacy and hegemony, which originated in the interaction of four factors: a) the weakness of the state; b) the hybrid character of the political regime, resulting from the combination of premodern and modern political cultures; c) the limits imposed by new political and economic conditions at the national and international levels upon the continuation of such a hibridization; and d) the fragmentation of the political and economic elite. This crisis becomes more acute due to the confrontation between two conflicting societal projects that have struggled for recognition since the early $1990 \mathrm{~s}$ : that which arises from the 1991 Constitution, and that which arises from the neoliberal 
economic model. The development of these ideas is the objective of the next three chapters.

\section{Chapter 4}

\section{Colombian Societal Project I: The 1991 Political Constitution}

As shown in the theoretical framework, many of the countries of Latin American suffered a series of constitutional reforms during the eighties and nineties that, as Gargarella has affirmed (1997), share common elements. These constitutional reforms were the result of three factors. First, the need to institutionalize the transition to the democratic regime, in the second place; second, the concern among different political and social forces over the institutional deterioration and social inequality, and third, the pressure of international economic agencies and of technocratic national elites to institutionalize the neoliberal economic restructuring. Colombia has become inscribed within this general tendency in Latin America. However, it is necessary to point out that the adoption of a new constitution in Colombia was also determined by the need to find a solution to a long and profound political crisis.

\subsection{The Crisis Leading to the Constitutional Assembly}

In the previous chapter we analyzed the weakness of the Colombian state, its incapacity to integrate the territory and the society, the fragmentation of the ruling class, and its 
incapacity to constitute a hegemony. To have a complete picture of the Colombian crisis in decade of the nineties, three more elements must be added to the situation described above. In the first place, the long crisis of the political regime that had been developing since the seventies, based on the negative effects of the bipartisanship agreement of the National Front. These effects are the exacerbation of clientelism, the fading of the parties' ideology and programs, their inability to carry out the necessary social reforms in a Country which had suffered an accelerated modernization, and the fragmentation of the parties to the point that in practice each member of the party organizes its own political movement for personal ends, as a result of which the representation of the general interests of society becomes impossible. But perhaps the most perverse effect of the National Front was the exclusion of the new social forces that arose as the product of industrialization, urbanization and the relative modernization of the country that occurred in the second half of the twentieth century. This more diversified and complex Colombian society faced a

blockade, quite diversified in its methods, of almost all the emerging forms of political participation. Everything that did not pass through the bipartisan filter received a systematic treatment, whether subtle or barefaced, of annulment" (Leal, 1987: 77).

This exclusion was the cause of the rise of guerrilla movements like April $19^{\text {th }}$ Movement, M19. Future members of this group, united in a dissident nationalist political party named ANAPO saw their hopes of coming to power legitimately frustrated in $1970^{15}$, which obliged them to radicalize and to confront the regime illegally. However, in 1990, this guerrilla movement became reincorporated into life in

\footnotetext{
${ }^{15}$ Due to the fact that the government of that time manipulated the electoral results to prevent the populist political movement Alianza Nacional Popular, ANAPO, from assuming power. If that had occurred, the bipartisan political regime would have come to its end.
} 
civil society to participate in the Constitutional Assembly, obtaining a high number of votes.

In the second place, the deterioration of public order, due to the increase in common delinquency, the violence of guerrilla and paramilitary groups and, above all, since the mid-eighties, of drug-trafficking mafias that declared war on the weak Colombian state in order to prevent their extradition to the United States.

Finally, the tendency of the Colombian economic structure to generate severe inequalities in the income distribution and high levels of poverty, is reinforced by the political regime's scarce receptivity to any reform of the social structure. This is manifested in social instability, as a result of the aggravation of the class conflicts and the increase in social protests.

Thus, adoption of the 1991 Constitution was an attempt to overcome the crisis of the political regime and its legal expression, the old Constitution of 1886 . But to understand the political meaning of this Assembly, it is necessary to review the failed attempts at reform that preceded it, which illustrate the rigidity of the power structure in Colombia and the incapacity of the political regime to respond to the necessities of democratization and social reform of an increasingly differentiated and complex society.

The idea of convoking a constitutional assembly as a solution to the crisis of the regime, dates back to the Liberal government of López Michelsen (1974-1978), who 
proposed to reform the administration of justice and to restructure the political-territorial division of the country (Cepeda, 1987), given that the political, administrative and fiscal centralism started to show signs of exhaustion at that time and to generate a series of protests called paros civicos on the part of the different municipalities and regions throughout the country. These protests were due to the precarious level of socioeconomic and infrastructural development of the municipalities. The progressive increase in the number of paros civicos is illustrative in this respect: between 1958 and 1966 there were 16 paros civicos, between 1971 and 1981 there were 138 , and between 1982 and 1989 there were 218 (Orjuela, 1992). However, the idea of undertaking this reform was declared unconstitutional by the Supreme Court of Justice, due to the fact that the constitution in force at that time did not permit amendments to be made outside of the Congress, as president López had proposed.

During the Liberal government of Turbay Ayala (1978-1982), the increase in the guerrilla activities of the M19 coincided with the popular protests of the subordinate social sectors, that were a constant phenomenon throughout the period of the National Front (Archila, 1997). For this reason, the ruling class diagnosed the crisis as the result of problems of public order. Consequently, the policies of Turbay Ayala were directed to preventing and criminalizing the popular protest by means of the so-called "security statute" (Reyes, et. al., 1978). At the same time, he revived the previous government's idea of carrying out a constitutional reform of the administration of justice, through the creation of a general Prosecutor office that would be in charge of the functions of 
investigation and accusation in criminal matters. Nevertheless, this reform was also declared unconstitutional, for the same reason mentioned above.

During the presidential period of Conservative Belisario Betancur (1982-1986), the social protests continued to increase, especially those of the peasants, students, and workers (Archila, 2000). However, Betancur diagnosed the crisis in a different way. He considered that the crisis and its main expression, violence, had objective and subjective causes. The former had to do with the lack of presence of the state in vast areas of the national territory and their lack of integration into the national market. In order to face up to this cause, Betancur developed a national integration plan, that consisted basically of public investment in physical and social infrastructure in said regions. The subjective causes, were due to the perception among new generations of Colombians that had grown up in the shadow of the National Front that they had no space in which to participate in the political, economic and social life of the country. To confront this situation, the Betancur government developed two policies: a peace process to seek the reinsertion of guerrilla groups into civil life, and a "political opening" or process of democratization of the political regime (Bejarano, 1990). This process included measures like the popular election of mayors, so that the demobilized guerrilla groups would find spaces for political participation (Orjuela, 1992).

The guerrilla groups with the exception of the Revolutionary armed forces of Colombia, FARC, received the peace negociations with skepticism. This group entered negotiations with the government and to test the regime's determination regarding 
democratization, decided to create a legal political movement, the Patriotic Union. Nonetheless, the peace negotiations failed due, among other reasons, to the systematic extermination of the members of that political group, including several presidential candidates, at the hands of paramilitaries and anonymous forces of the extreme right, to the point that in the past two decades around 3,000 members of these movements have been assassinated. This situation was the result, in part, of the ambiguous position of the FARC regarding legal political action, that led them to "combine all forms of struggle." It also derived from the lack of a real will to democratization and tolerance on the part of the Colombian political regime.

In general terms, it can be said that the Betancur government had a clear vision of the need to integrate Colombia politically, territorially and economically, and to oxygenate and democratize the political regime. Nonetheless, the structural factors of the Colombian political and social crisis, and the lack of vision of the ruling class, meant an obstacle for Betancur's political project. In the end, Betancur was abandoned by the Conservative party, his own party, who called him "communist", and by a large part of the Liberal party. Furthermore, the intransigence of the M19 guerrilla group, was the straw that broke the camel's back. This group's 1985 assault on the Supreme Court of Justice, with its violent ending in which many of the Justices died, weakened the government even more.

In practice, the popular election of mayors was the only reform instituted by the Betancur government that was relatively successful. By establishing a bond of 
accountability between the mayor and the local community, it has contributed to democratize the political regime to some degree and to relegitimate the state. Nevertheless, this reform has also contributed to strengthening clientelism and corruption. Only a few municipalities have elected mayors who are "outsiders" or civic leaders who have tried to positively transform political and social life at the local level.

The Liberal government of Virgilio Barco (1986-1990), sought to revitalize and relegitimate the bipartisan regime by means of a scheme to end the connivance between liberalism and conservatism, through the institutionalization of a scheme of relations of "government party and opposition party." However, given the profound socioeconomic transformations that have taken place in Colombia during the second half of the twentieth century, which have resulted in a more diversified and complex society, solutions to the crisis based on the continuity of bipartisanship are doomed to failure or to contribute to aggravate the crisis itself. Due to the conviction that the bipartisan scheme had been exhausted, the Barco government opted for two different strategies. The first consisted of newly exploring the possibility of a political agreement regarding the reinsertion of guerrilla groups, which was only possible with the M19; and the second, of reforming the political constitution, in response to the clamor of certain key sectors in the formation public opinion in the country.

To carry out the the constitutional reform, Barco proposed convoking the citizens to a plebiscite, in order to derogate a norm of the Constitution of 1886 , introduced by the National Front pact, that prohibited reforming the constitution by means of direct 
participation of the primary constituent power, i.e., the people. If the plebiscite was approved, the government would proceede to call elections for a constitutional assembly with popular participation. However, this initiative failed due to the strong opposition of the Conservative party and of various sectors of the ruling class. Given this opposition, president Barco was obliged to make an agreement with the Conservative party, desisting from the plebiscite and committing himself to carry out the reform through the Congress. But the Congress' decision to include a norm that favored drug-traffickers in the reform by prohibiting the extradition of Colombians, caused the constitutional reform to abort.

The late eighties linked all the factors of the political crisis in such a way as to produce a situation of anomie and increased violence, the catalyst of which was the violence exercised by the drug-traffickers. The victims of the hard and bloody war that they unleashed against Colombia's weak state and society included judges, the police, important public officials, common citizens and, between 1989 and 1980, three presidential candidates. It was then that a group of university students, interpreting the feeling of Colombian society, led a movement that diverse social sectors later joined, to reform the political regime and Colombia's public institutions. This led, during the Liberal government of Cesar Gaviria (1990-1994), to the election of a Constitutional Assembly in December of 1990.

There was broad representation in this Assembly which included not only the traditional political parties, but also those on the left, some guerrilla groups that 
demobilized during the Barco and Gaviria governments' peace processes to participate in it $^{16}$, entrepreneurs, and diverse sectors of Colombian society. If, as defined in the theoretical framework of this dissertation, the political regime is not simply the sum of institutions and norms that regulate the relations between the political parties and the state, but also the relations between the social classes and between them and the state, then the Constitutional Assembly was an attempt to broaden the Colombian political regime, to make room for the social sectors that have never been included in it.

\subsection{The Societal Project of the Constitution of 1991: Legitimacy, Democracy and Equity}

The main objective of the Constitutional Assemably of 1991 was to resolve Colombia's political crisis. To achieve this purpose, the Assembly introduded a series of reforms in six major areas: a) the quest for peace, b) the expansion of democracy and of the economic, political and social rights of citizens, c) the strengthening and relegitimation of the state and the political regime, and d) the modification of the economic regime to introduce elements of equity.

The Constitution of 1991 can be considered a societal project that sought to integrate and democratize Colombian society. The quest for social integration manifested, among other things, in the fact that the political and social forces that promoted that project were very heterogeneous since they covered everything from traditional bipartisanship and drug-trafficking elements to university students and

\footnotetext{
${ }^{16}$ The M19, the Popular Liberation Army (EPL), the Socialist Renovation Current (CRS), the armed indigenous movement "Quintin Lame", and the Revolucionary Workers Party (PRT).
} 
progressive intellectuals, as well as indigenous groups, social movements, nongovernmental organizations and various radical left-wing political groups that wanted to explore a peaceful and democratic path to change.

The idea that the new Constitution was considered by its main promoters to be a societal project is noted in the a posteriori disenchantted reflection of an analyst who, referring to participative democracy, introduced by the new constitution, affirmed:

\begin{abstract}
the expectations, perhaps utopian and messianic that we had about what could be achieved through them and ask ourselves whether on this horizon of the invention of a new country, we can change - without being fully conscious of the fact - the citizen who really exists, or at least tries to do so, in a context of multiple tensions and inequalities, for the elusive image of an imaginary citizen in the face of whom the former is pathetically deficient, definitely precarious and lacking in civic virtues. (...) It is necessary to recognize that the dramatically intensified war in the past ten years has significantly contributed to closing the spaces for participation; that the increased poverty in the cities and the displacement in rural zones has turned the different fundamental rights established in the constitution of 1991 into simply virtual and rhetorical realities (Uribe, 2001: 143).
\end{abstract}

\title{
4.2.1. The Quest for Peace
}

At the beginning of the nineties in Colombia, leaving aside common crime, which is comparatively one of the highest in the world, there were two great focal points of violence: the guerrilla groups and the drug-trafficking cartels.

In relation to guerrilla violence, it is necessary to say that the idea of reforming the Constitution by means of a constitutional assembly elected by popular vote generated a process of demobilization of armed groups, due to the expectation of participating in it and of being actors in important transformations in the country's 
political, economic and social structure. This characteristic differentiated the peace processes of the nineties with respect to previous ones. While the processes of the eighties were, in the strict sense, processes of insertion of armed groups in the social order, which remained intact, the peace processes of the nineties have been the opportunity for these groups to abandon the armed struggle on the condition that they participate, in an active way, in the transformation of society for institutional ways. That is to say, the peace processes, since the nineties, have increasingly been the scenario in which to reconstruct or to refound the state and civil society in Colombia.

Throughout the eighties, the armed conflict had been aggravated due to the strengthening of the military capacity of the different armed actors, due to the abundant financial resources available to them, flowing from the illegal narco-trafficking business, extorsion, and kidnapping. At the end of the eighties, it became increasingly clear that a peace proposal based on the surrender of the armed groups or on their unconditional reinsertion into the existing order, was not possible. The demand of the armed groups increasingly aimed at a reform of the political regime and the economic and social structure of the country.

For this reason, the possibility of adopting a new political constitution was presented in 1991 by the Gaviria government (1990-1994) as a peace pact with certain guerrilla groups. The negotiation process with the National Liberation Army (EPL), culminated in the signing of an agreement in March 1991, to participate in the Constituent Assembly. The same thing occurred with the Revolutionary Workers' Party 
(PRT), and the insurgent Manuel Quintín Lame Indigenous Movement. The M19 movement that had demobilized since the end of the previous government, also participated in the Constitutional Assembly, with an electoral success that was unprecedented for any guerrilla group, which enabled them to exercise importamt leadership in the Assembly's deliberations. The strongest guerrilla groups as well as the ones with the greatest destabilizing capacity, the Revolutionary Armed Forces of Colombia (FARC) and the National Liberation Army (ELN), did not want to participate in the constitutional process.

With most of the guerrilla groups demobilized and participating in the Constitutional Assembly, the Gaviria government considered this situation as a good argument for delegitimating the non-demobilized guerrilla groups. On the one hand, Gaviria considered that after the reforms the new constitution would establish, there would no longer be reasons for credible guerrilla actions. One the other hand, the FARC and the ELN, strengthened financially and militarily, did not have sufficient political vision and assumed an ambiguous position regarding the constitutional process. Nonetheless, the government made several attempts to approach these groups to negotiate peace. But with both radicalized positions, the negotiation process ended in a strong armed confrontation. The government undertook a military offensive against the guerrilla the same day that elections were held to elect the representatives to the Constitutional Assembly. This led the FARC to radicalize even more its offensive and militaristic position that it continues to hold to this day. With this, the possibilities of a new constitution as an instrument for achieving peace in the country were limited. 
With respect to the relationship between the Constitutional Assembly as a scenario of peace and drug-trafficking violence, it must be said that throughout the eighties drug- traffickers became "narcoterrorists", due to the articulation of various factors. In the first place, the antinarcotics policy of the U.S. Government, who defined the problem of drug-trafficking as a national security issue, gives priority to a repressive strategy to deal with the problem. This translated into pressures on the Colombian government to deal repressively with the drug-traffickers and to ensure their extradition to the United States. However, this position of the U.S. government ignored the weak nature of the Colombian state, so that the political pressures to confront drug-trafficking with repression only contributed to further increasing its weakness (Tickner, 2001). The drug-traffickers on the other hand confronted the Colombian state with a multiple strategy: assassination of important political and social figures of the country, the use of terror against civil society, the infiltration of illicit money in political campaigns and in institutions of popular representation, and open war on the state, under the slogan "we prefer a tomb in Colombia to a jail cell in the United States." In the second place, the linking of the drug-trafficking mafias to paramilitary groups permitted the strengthening of the military capacity of these group, since they had the money to acquire arms and training. This relationship between drug-traffickers and paramilitaries has been one of the main factors in the violation of human rights and the weakening of authority and justice in Colombia. 
The drug-traffickers' strategy of combining terrorist actions with political actions makes it possible to think that they sought legitimacy and acceptance among social sectors that thought the state was incapable of ending leftist subversion. Therefore, one can sustain the thesis that, as of the late eighties, the drug-traffickers were an important part of a politico-military project of the extreme right. This is confirmed by the rise of the Movement for National Restoration (MORENA) in August of 1989. According to general Miguel Maza Márquez, the director of the Administrative Departament of Segurity (DAS) at that time, that political movement was

the culminating point of a symbiosis between drug-traffickers, self-defense groups, and the groups of paid assassins trained by agricultural entrepreneurs fed up with constant harassment by the guerrilla (...) In the context of this accelerated metamorphosis, one perceives the influence of the drug cartels and the laxity of certain private agencies that, confused by the volume punishable facts attributed to those who have risen up in arms, have finally decided to subtly align themselves with the opposite block, without paying attention to the fact that their procedures and barbarism are equally condemnable (El Tiempo, August 24, 1989, p. 10C).

Some government measures were finally able to contain the advance of this extrem right political project; but it is possible to conclude, with president Barco, that at the end of the eighties the war against drug trafficking should be understood not only as a struggle of the law against organized crime, but as an effort to permit "the survival of democratic institutions and public liberties" (Barco, 1989: 137-138).

However, the weak Colombian state was in no condition to confront an enemy strengthened by such an enormous amount of illicit financial resources. For this reason, the drug cartels subjected the country to one of the worst waves of terrorism in its entire history. There was no other way out than to change the strategy and try to negotiate 
with the drug cartels. In any case, the policy against that phenomenon was ambiguous throughout the eighties and oscillated between repression and dialogue (Orjuela, 1990). The change to a clear negotiation against drug-trafficking occured during the Gaviria government (1990-1994). This distinguished between drug-trafficking and drugtrafficking related violence. The former, was considered a transnational phenomenon the treatment of which surpassed the limits of national politics and required international cooperation. The latter was considered to be a national problem and, therefore, the Colombian government had sufficient autonomy to manage it. The Gaviria government thus developed a policy of bringing the drug cartels to justice, in exchange for not extraditing them to the United States. This implied making the negotiations of previous years with the cartels explicit and public, not so as to legitimate it, but rather to find a basis on which to elaborate more realistic policies for dealing with it.

The Constitutional Assembly was the scenario in which to legalize this policy. As mentioned above, the violence associated with drug-trafficking was the straw that broke the camel's back, and led the Assembly to seek a solution to the Colombian political crisis. During the deliberations the bombs and the indiscriminate assaults against civil society ceased; but the drug-traffickers kidnapped well known journalists in order to exert pressure on the Constitutional Assembly. Despite the reticence of some of its members, it approved an article that prohibited the extradition of Colombians. One of the delegates to the assmbly summed up Colombian society's posititon on the matter in a single phrase:

as the lovers of peace that we are, we have the intimate conviction that we will never achieve it while and arbitrary and unconstitutional decree of a state 
of seige continues to allow the extradition of Colombians (Gaceta Constitucional, No. 39: 10).

The constitutional prohibition of extradition served to return tranquility to Colombian society and made possible the surrender of Pablo Escobar, head of the Medellin cartel. However, this prohibition was derogated during the Samper government (1994-1998), partly due to the pressures of the U.S. government, and partly to president Samper's need to legitimate himself before the national and international community, given the accusations of having received money from drug cartels in his electoral campaign.

\subsubsection{The Introduction of a Social Democracy}

Given the restricted nature of Colombian democracy, Constitutional Assembly of 1991 proposed making the political system more inclusive and representive. In this sense, the first article of the new Constitution establishes the character of the Colombian state as democratic. participatory and pluralistic. The second article establishes that one of the essential purposes of the state is to "facilitate the participation of all in the decisions that affect them in economic, political, administrative and cultural life of the nation". In addition to the vote, it also established a series of mechanisms for direct political participation such as the plebiscite, the referendum, popular consultation, the open town council meeting, the legislative initiative of citizens, and the recall or revocation of mandate of political representatives by the citizens.

The rights to social participation include traditional right to free association, but it also includes new rights such as community participation in health services and education, in decisions that can affect the environment, worker participation in 
management of enterprises, and participation of ethnic, social, economic, cultural and ecological sectors in the National Planning Council, etc. In fact, the Constitution of 1991 establishes that the professional, labor union, social and sports associations should be democratic, and assign the state the role of "fostering democratic practices for learning the principles and values of citizen participation" (article 41).

Furthermore, it established the popular election of governors (that of mayors had already been established in 1986); the local administrative boards for popular representation of the diverse zones of the municipalities; the indigenous communities' right to govern themselves through their own authorities, in accordance with their culture and traditions; and the popular election of judges of the peace to deal with minor conflicts among citizens. In synthesis, it can be said that, at least formally, the new Constitution broadly established direct participation of citizens, to the point that one of the members of the Constitutional Assembly pointed out that "the ideology of democratic participation became the cement of the whole structure of the new Political Charter" (Fals Borda, 1991: 53).

The Constitutional Assembly considered the old constitution to be very poor in matters of human rights and that, in addition to the exclusionary nature of the bipartisan regime, social exclusion and the violation of human rights were two of the main factors of the Colombian political crisis. For this reason, it was decided to place the emphasis on the recognition of three generations of human rights, i.e., individual political rights and civil liberties; socioeconomic and cultural rights; and collective rights like the right 
to a healthy environment. The first are the traditional and universally known ones such as the right to life, habeas corpus, and freedom of conscience. Among the second, the Constitution of 1991 established the right to social security and health, decent housing, education, the rights of minorities and disadvantaged or discriminated persons such as children, women, the elderly and the handicapped. Among the third are the right to public space, to quality public goods and services, and the right to enjoy a healthy environment. The emphasis on socioeconomic inclusion is noted from the very first article of the Constitution of 1991, which defines Colombian state as a "social state of law".

The Constitution of 1991 also established a series of judicial mechanism and institutions for the exercise and effectiveness of these rights, such as the Constitutional Court, the Defender of the People, the injunctive action named tutela, and popular actions. These mechanisms, as will be seen further on, have been considered by the community to be really effective for demanding their rights with respect to the state and public administration, which have often been characterized by arbitrary treatment and ineffectiveness. According to the Colombian Commission of Jurists, with very few exceptions, Colombian judges did not know and did not apply norms regarding these three generations of human rights,

whereas, under the protection of the Constitution of 1991, constitutional justice has been vigorous in the protection of the rights of persons and minorities, as well as in its intention to control the abuses by the authorities and the powerful (Uprimmy, 1991: 99). 
The constitutional recognition of these three generations of human rights means the concretion of the quest for greater social justice on the part of progressive political and social forces. In this respect, one of the Justices of the new Constitutional Court, which has led the crusade for the recognition of these rights and social justice, points out that

the Constitution, in synthesis, proposes two strategies of justice. The first, respect for the person, regardless of their differences. The second, respect for the person, taking their historic particularities into account, to maintain the difference, to suppress it or to discount disadvantages and inequities, according to each case (...) The Constitution has begun to recognize subjects who require special protection (minors, women, the elderly, the handicapped, homosexuals, prisoners, indigenous people, and indigents, etc.) The accent of the [new constituional] regime protection of social rights, indicates that their interests were not usually duly articulated by the democratic political process, which certainly cannot be maintained indefinitely (Cifuentes, 2000: 268269).

For this reason, the constitutional mechanisms that have really been effective in the recognition and guarantee of these rights in recent years have generated the biggest legal, political and economic controversies that Colombia has experienced in the second half of the twentieth century. That debate will be analyzed further on.

\subsubsection{Strengthening and Relegitimation of the State and the Political Regime}

As has been pointed out in the theoretical framework, the state is an essential element in the production of the social order, in producing the cohesion of society and the integration of the territory through the regulation, the coordination of the different social subsystems, and the legitimate use of force. Furthermore, the third chapter showed how the Colombian state has suffered such deterioration in recent decades that it is in no condition to produce a social order. This situation has translated into violence and 
anomie, in the incapacity of the public authorities to guarantee even the most elementary rights of citizens, and in the degradation with which Colombian society assumes the diversity, the disagreement, and the demand for their rights.

For this reason, in the last three decades, a series of reforms have been introduced, without much success, in the administration of justice in aspects such as the computerization of information and decongestion of court dockets, organization of the judicial career, technical and professional development of criminal investigation agencies, and the physical modification and decongestion of prisons, among other things. (Escallón, 1998). But it was the Constitutional Assembly of 1991 that adopted a somewhat more profound reform of the judicial branch through the creation of new institutions such as the Superior Council of the Judicature, the General Prosecutor's Office, and the adoption of the accusatory system in the criminal justice, and the creation of constitutional justice with the Constitutional Court as its highest tribunal.

The administration of the judicial branch was assigned to the Superior Council of the Judicature. This function corresponded to the Ministry of Justice in the past, and its performance was very inefficient. It is necessary to emphasize that in addition to elaborating and executing the budget of the judicial branch, the Superior Council of the Judicature must supervise the performance of the judicial offices.

With the adoption of the accusatory system, the judges are relieved of the function of investigating crimes, which now becomes a function of the General 
Prosecutor's Office, whose actions are governed more by the technical criteria of criminal investigation than by the procedural formalism of the function of judgment. In this respect, one analyst pointed out that the investigation of crimes had erroneously been attributed to the judges in Colombia, which was incompatible with the nature of their function, since they are not trained to investigate the facts, but to analyze them in law (Giraldo, 1993). With this technical separation of functions, the Constitutional Assembly hoped to achieve a significant increase in the effectiveness of criminal justice and a notable reduction of impunity.

It is significant to point out the fact that there had been an attempt to introduce the idea of a General Prosecutor's office and the accusatory system into Colombia in 1979 , but the authoritarian bias of the government at that time prevented its virtues of effectiveness from being known to the public. At that time, various associations of judges and lawyers, non-governmental organizations, and academics, considered that judicial reform to be the repressive instrument of the regime and called the Colombian state a police state. In this respect, it was said that:

there are, thus, sufficient symptoms to think that the concentration of investigative functions under a General Prosecutor whose designation will correspond practically to the executive, was not due to reasons unrelated to the unstable balance of the social struggles characteristic of recent years and tries to project the broadening of police function of the executive into the judicial field. For this purpose, there will now be an institution which, like the general prosecutor's office gives the state sufficient flexibility to criminally repress, under the protective appearance of a normal judicial process, anyone who the conditions of reproduction of the capitalist system point to as undesirable or unbearable" (Rojas, 1980: 157-158).

Two decades later, in the face of the achievements of the General Prosecutor's Office, it is becoming clear to the different social forces, even those on the left, just how great a 
degree of deterioration the basic order in Colombia has reached. Although the established order ultimately constitutes society asymmetrically and permits the exercise of class domination, it is also what makes it possible, as $\mathrm{O}^{\prime}$ Donnell says, for "the multiple social relations [to be carried out] on the basis of [a minimum of] stable expectations" (1992: 10).

Finally, in relation to the topic of the reform of justice, it is necessary to point out that part of the violence that Colombian society suffers is generated in economic and social disputes among its citizens, due to the impossibility of dealing institutionally with disagreements and conflicts, because of the congestion of civil, commercial and familylaw cases in the courts. Therefore, effectiveness of the administration of justice in civil matters has also been sought through the direct participation of citizens in the solution of conflicts by institutionalizing the process and creating non-judicial mechanisms for the resolution of conflicts, such as conciliation, arbitration tribunals, and justices of the peace elected by the community. The purpose is to see that the judges will only have to deal with conflicts to which the community has not found a solution. This is because, according to one expert, the congestion in the courts is due in part to the progressive process of judicialization that consists of taking every type of conflict arising between citizens to the judges to decide, regardless of the transcendence or the degree of commotion it causes in the community (Giraldo, 1993). Thus, the legitimacy of the state requires the solution of its lack of effectiveness in the administration of justice, which in turn requires the participation of the community in the solution of their conflicts, within institutional frameworks. 
Another important aspect of the search for legitimacy of the state, has been the creation of the Constitucional Court, which has been assigned the task of constitutional control of the law, which previously corresponded to the Supreme Court of Justice. But the most important function of the Constitutional Court has been that of being the supreme human rights tribunal. This is exercised through the revies of judicial decisions related to the injuctive action, which is the instrument by means of which citizens can make use of their fundamental rights before any authority that refuses to recognize them.

Due to its decisions, the Constitutional Court has been the institution that has become the symbol of the quest for social justice, and has therefore played a fundamental role in the re-legitimation of the state. From the beginning, the Court has been very clear in pointing out the normative and political importance of the new definition of the state as a "social state of law". In a 1992 decision, this entity affirmed that the social state is not a mere rhetorical formula but one that implies a great responsibility of judges in the recognition of constitutional and social rights of citizens (Uprimmy, 2001).

This function of recognition of fundamental rights, not only in the political field but in the social and econmic fiels as well, has caused the Constitutional Court to be accused of politicizing and usurping the legislative and executive functions of designing economic policy, given the decisions that have been taken in the field of hounsing finance and the right to health and education, among other things. These accusations 
and the conflicts between the Constitutional Court and the functionaries in charge of handling economic policy will be analyzed in the last chapter of this dissertation. For the moment, one must say that it is not a question of the political character the Constitutional Court, but rather that the issues on which it has decided have acquired a notable political character, given the Colombian context of profound social inequality. The political character of these judicial decisions are also derived from the new place that the 1991 Constitution attributed to the Court in the political system, that puts it in direct relation with the social and economic conflicts that have not been resolved in the instances of political decision, due to deficiencies in political representation, to a lack of political will of the ruling class and to the weakness of civil society. The Constitutional Court was created to "ensure that the democratic 'opening' initiated by the constitutional movement would be maintained" (Cepeda Manuel José, 2000: 519). This democratic spirit had a text: the new Constitution, but not, as Cepeda says, a context, or, rather, it lacked another context, because "on the social plane, the need to put an end to arbitrariness was as great as the conceptual vacuum [that the Court] had to fill (Ibidem: 553). In general terms, one can say that the Constitutional Court has been the state institution that symbolizes the spirit of democratization and equity that animated the constellation of progressive forces that promoted the constitutional movement. From this viewpoint, the Court has tried to keep open the institutional and legal possibilities for social reform and effective political participation of minorities and the socially least advantaged. 
In relation to re-legitimizing the regime, it is necessary to start by saying that the Constitutional Assembly revoked it in a polemic decision, the mandate of the Congress at that time. It was a decision with more of a symbolic character than a real one, but it demonstrated the desires of the new social and political forces represented in the Assembly to make a "tabula rasa" out of the "ancien regime", and create a new political regime in Colombia. For this, the Constitutional Assembly established a series of mechanisms and institutions to broaden the political representation of the minorities and forces other than the traditional bipartisanship, to reduce clientelism and corruption, and to increase citizens' control over the activity of the state, especially in relation to the allocation and use of public resources.

Political participation was broadened at the municipal level with the creation of the local administrative boards and with popular election of mayors at the departmental or state level. At the national level, participation was broadened through the creation of national circumscription for election the senate, in order to favor political minorities. Although in the first congressional elections following approval of the new Constitution, held in October 1991, the traditional political class obtained a majority of the votes once again, despite the fact that its mandate had been revoked by the Constitutional Assembly, the new norm showed its virtues since $18 \%$ of the seats in the senate corresponded to new political forces different from the traditional bipartisanship (Restrepo, 1993: 233). Nevertheless, the bipartisanship again regained lost ground in the 1994 elections, which shows the enormous weight of the rusty structure of the old 
Colombian political regime even after the introduction of these reforms. However, a gap was openned up which third forces could take advantage of.

For the representation of ethnic minorities, a special seat was created in the Senate for the indigenous communities, and one in the lower house for the black communities. Furthermore, in recognizing the indigenous territories as políticoadministrative entities of the state, their dialects as official languages in that territories, and the right of indigenous people to govern themselves through their own authorities, according to their own customs and traditions, Colombia is inscribed in the worldwide tendency toward recognition of multiculturalism, that poses to contemporary political orders the challenge of constructing political unity on the basis of recognition of ethnic and cultural diversity (Taylor, 1994; Kymlicka and Wayne, 2000).

In relation to the system of checks and balances, the Constitutional Assembly was concerned with reestablishing the equilibrium between the executive and the legislative, which had been altered since 1968 in favor of the former. For this reason, the new Constitution granted the legislative branch faculties and mechanisms for exercising greater political control over the executive, such as the motion of censure of ministers, the congressional power to modify certain executive decrees, prohibition of codes issued by the executive, and the return to the legislative branch of certain powers in economic matters. 
In order to "purifiy" Congress and political activity and to "eradicate" practices such as clientelism and corruption, the Constitution introduced a series of limitations and prohibitions, such as revocation of the mandate of mayors and governors, and the loss of office for members of Congress, which is produced by violation of the severe criteria of disqualifications and incompatibilities established for those who wish to hold a seat in Congress. For instance, since the new Constitution was approved in October 1991, the Council of State has received 298 petitions for loss of investiture, of which 35 have been decided positively (Colprensa, December 11, 2001). The loss of investiture means political death since whoever is dispossessed of a seat in Congress can never again hold any elected public office of popular representation.

Furthermore, the so-called auxilios parlamentarios, i.e. financial "aids" given by the government to congressmen, were eliminated, at least on paper. Those "aids" are the funds the government included in the national budget in favor of members of the Congress, in exchange for their approval of the bills it submits to Congress. However, this practice continues to be used by the executive, who has considered it to be the only way to carry out its policies of economic restructuring. This situation illustrates the hybrid character of Latin American political regímes in which the old clientelist political practices are combined with the technocratic needs of economic restructuring, as pointed out by Gamarra (1994).

In relation to the political parties, the new Constitution established the right of all citizens to found parties and movements, state financing of political campaigns, and 
equality of access to public communications media, which favors political minorities and tries to compensate them with respect to the weight of bipartisanship. Finally, the new constitution strengthened the state's agencies of control such as the Offices of the Procurator and the Comptroller, and created the Office of the Defense of the People to ensure that human and other rights are respected.

In synthesis, the Constitutional Assembly attempted to solve Colombia's long political crisis through strengthening, relegitimation, and democratization of the state and the political regime. The international context and the new global actors have also contributed to this task. The pressure of the U.S. State Department and of the American NGO, Human Rights Watch, for Colombia's Government, Armed Forces, and subversive groups to respect human rights has contributed to the process of reinstitutionalizing the state and society in Colombia (US Department of State, 2000; Tickner, 2001). Likewise, the United Nations, with its Delegate Office for Human Rights in Colombia, has contributed as a global force, to create a more democratic society in the country. The new agencies of global governance such as the World Bank operate in the same sense and its demands for state reform and, while emphasizing privatization and economic restructuring of the state, also ask for its democratization and institutional improvement. However, this combination of exogenous and endogenous factors is far from fluid and is full of tensions and contradictions.

\subsubsection{The Quest for Equity}

In very general terms, it can be said that the concept of the economy written into the Constitution of 1991, can serve as the foundation for both a policy of state intervention 
in the economy and a free market policy and internacionalization of the economy. This ambiguity is the result of the convergence in the Constitutional Assembly of forces that represent the two economic ideologies and the role played in the Assembly by the government of Cesar Gaviria (1990-1994), whose economic role and development plan were clearly neoliberal (Presidency of the Republic, National Planning Departament, 1991). From this point of view, in 1991 two different societal projects confronted each other: one led by the progressive and leftist social forces that wanted an economy sensitive to the social needs of the great majority of the Colombian population, and another led by the Gaviria government and its technocratic economic group, that tried to carry out its neoliberal restructuring project both within the Constitutional Assembly and outside of it, in the institutions in charge of managing the economic policy.

Nonetheless, the predominant trait of the new Constitution in economic matters, and from which it has derived its meaning in the ten years that have passed since its approval, has been the emphasis on equity and the great number of socioeconomic rights established in it. The concern for equity appears, among others, in article 1, which defines the Colombian state as a social state of law, and in article 334 , which establishes that the state is in charge of directing the economy and that it should seek the equitable distribution of opportunities and the benefits of development, full employment of human resources, and ensure that all persons, particularly those with the lowest income, have effective access to basic goods and services. 
The new Constitution also established that the state would promote the access of all Colombians to rural and urban property, foment the participation of workers in the companies they work for, and encourage associative and solidary forms of management of property. It also established the social function of private property and enterprises (article 333), and leaves open the possibility that they be expropriated when they do not fulfill this function, even by an administrative process with no judicial process for expropriation (article 58). This decision was highly criticized for its effects on the economic liberalization model, since it is argued that it could frighten foreign investment away.

In relation to the planning of economic and social development, the Constitution establishes the possibility of ample participation of the entrepreneurial, social, cultural, political ecological sectors in the National Planning Council.

But the Constitution also contains norms of neoliberal inspiration such as those that establish the independence of the Central Bank and, therefore, of monetary, credit and international exchange rate policy, with which it recognized the global tendency in these matters (Maxfield, 1997 and 1999). Economic freedom is guaranteed in article 333, which establishes that the state "will impede the obstruction or restriction of economic freedom and will avoid or control any abuses by persons or enterprises of their dominant position in the national market". The privatizing neoliberal spirit is manifest in the articles that establish that the private sector could participate in offering public services, and that the government could sell or liquidate state enterprises or grant private 
firms the right to fulfill their functions when the former do not do so efficiently" (article 336).

Given this ambiguity, in which interventionist welfare-state norms are blended with neoliberal norms, the Constitutional Court has taken charge, through its decisions, of emphasizing the social and equitable nature of the new political charter. This is one of the reasons why it can be considered the garantor of the progressive spirit of the new constitution and the creator of a viable context for applying its norms.

But the proliferation of socioeconomic rights is undoubtedly the principal characteristic of the Constitution of 1991 in economic matters. This is due to the fact that, traditionally, the social policy of the state was always the last priority and was never translated into significant financial resources to make it viable. At the first inflationary or fiscal obstacle, the social policy was abandoned. The Constitution tried to modify this situation by establishing that social spending would no longer be a residue of the economic policy but rather the main obligation of the state. As has already been shown, many norms show a clear intention to intervene in the functioning of the economy and to orient public spending to guarantee its citizens, especially the poorest sector, effective enjoyment $c$ ' socioeconomic human rights. Thus, for example, one of the most controversial norms for the partisans of a neoliberal economic policy are articles 356 and 357 , which establish a series of constitutionally obligatory transfers of resources from the national budget to the departments and municipalities to attend the basic needs of education and health of its poorest citizens. 
At present, these transfers represent about $45 \%$ of the current revenue of the central government. This situation has generated three points of confrontation between the model of social liberalism, established by the constitution, and the neoliberal model proposed by the government. In the first place, the promoters of the neoliberal model argue that the transfers of resources have generated rigidity in the assignment of public spending, which clashes with neoliberal ideas of flexibilizing the allocation of resources and also produces "fiscal laziness" in local governments and communities with respect to generating their own resources (Departamento Nacional de Planeación,1981; Presidencia de la República-Departamento Nacional de Planeación, 1992). In the second place, liberalization of the economy has implied the dismounting of tariffs on foreign commerce, which were one of the main sources of fiscal resources for the state for many years. Therefore, there is a need to seek new sources of fiscal income to finance the above-mentioned social spending obligations established by the new constitution which add up approximately to 400 billion pesos and represent $2 \%$ of the GDP (Sarmiento Palacios, 1992). Nevertheless, it is not easy to obtain new fiscal resources for covering the new public expenditures mandated by the 1991 Constitution due, among other reasons, to the structural limitations imposed by the neoliberal economic model, which implies reducing the fiscal deficit and, as far as possible, avoiding increases in taxes. There is, therefore, a conflict between the demands of the new constitution and the postulates of the new economic model. Thirdly, it is argued that the resources transferred from the cemtral government to the departments and municipalities are wasted or improperly allocated, due to clientelist practices and corruption. Although there is much truth to this argument, the remedy to these problems cannot be the reduction of resources 
for the social policy of the state. Furthermore, this situation clearly shows the cultural conflict generated between the features of political pre-modernity introduced by the regime and the demands for full modernization imposed by the new constitution, the

neoliberal model and the global context. In the fourth place, the agreement on fiscal adjustment signed by the Pastrana government (1998-2002) and the International Monetary Fund in 2000 demands, among other things, the reduction and rationalization of the above-mentioned transfers to the regions. With this, it is not only the confrontation between the two societal projects that becomes more evident, but the influence of exogenous factors on domestic policies as well.

\subsection{The Balance of the New Constitution: A Societal Project without Consensus}

As shown above, the Constitution of 1991 is a project that seeks to re-establish the Colombian state and society and overcome the political and social crisis through the quest for peace and reduction of violence, the broadening of democracy and human rights, the strengthening and relegitimation of the state and the political regime, and the search for equity. However, after ten years of attempts to strengthen this constitutional project, the political crisis has not only not been solved, it has indeed worsened.

In fact, the armed conflict has intensified, despite the fact that the Constitution was conceived as a pact of peace among Colombians. Nevertheless, the agreement was not possible due to the fact that the significant actors in the armed conflict, such as the guerrilla groups FARC and ELN, the military, and the paramilitary, did not participate in it. Furthermore, the armed conflict is due in part to the lack of agrarian reform and modernization and technical development of agricultural production. However, neither 
the peasants nor the large landholders participated in the Constitutional Assembly either. And although the Constitution established the social function of property, until now it has not been possible to carry out an agrarian reform, due to the limitations imposed by the power structure in Colombia, where vested interests linked to large rural landholders still wield significant weight.

Despite the General Prosecutor's successes in combatting organized crime, the administration of justice, not only in criminal matters, but in civil, labor and family matters as well, continues to be very deficient (Giraldo, 1996). Criminality and impunity still run very high. Violations of human rights persist, although some progress was made in terms of their recognition and judicial protection.

In relation to the opening of the political regime and its democratization, it can be said that the Constitution laid the foundations for making the transition from bipartisanship to a multi-party system, but the new political forces are still too weak and fragmented to dispute the place of the traditional political parties. Nevertheless, significant spaces were opened up for ethnic and political minorities, and progress was achieved in terms of conscientization and citizenship formation. However, the new channels for direct political participation have not been fully utilized as yet, due to the weakness and fragmentation of civil society and its poor capacity to organize autonomously, which hinders its participation in the decision-making process as a strong interlocutor of the state.

Clientelism and corruption still typify the political regime. The traditional political class has attempted to dismount the reforms introduced by the new constitution, 
or has managed to evade the restrictions it imposed in order to legitimate Congress and political activity. The fact that the Pastrana government (1998-2000) and the independent political forces have attempted, unsuccessfully, to reform both Congress and the electoral system in the past three years despite the reforms introduced by the Constitution of 1991 , shows the limited transforming power that legal norms or "formal institutions", as North denominates them (1990), have had in these matters. According to North, historic change is the result of the interplay between formal institutions which can be modified by the intentional actions of actors, and the resistance opposed by informal norms constituted by the culture, which resists all attempts at intentional modification. From this point of view, it can be said that the new constitution's efforts to modify clientelism and corruption have been precarious indeed since they are the expression of a pre-modern political culture that has existed for centuries. The conflict between the traditional political class and the new constitution, as noted by Fernán González, "demonstrates the lack of congruence between the more modernizing regulations and the concrete functioning of the institutions that operate in a more traditional world" (1993: 18).

On the other hand, the progressive and modernizing forces that gave rise to the constitutional process did not manage to consolidate either their predominance over the traditional political forces or the unity needed to obtain sufficient power to become an alternative of change in the following stage. Suffering from a lack of popular roots, internal conflicts, or victims of the violence itself, they became weakened or fragmented politically, as in the case of the M19, EPL, and the Movement for National Salvation. As Manuel José Cepeda has said, although the Constitutional Court has attempted to 
maintain the reforming spirit of the Constitutional Assembly, "it has been the victim of the context. It lacked something that it could not create: a configuration of political forces similar to those that gave birth to the Constitution de 1991 (2000: 526).

Finally, despite the Constitutional Assembly's attempt to make Colombian society more equitable, social inequality has increased, as will be seen in the next chapter, as a result of the neoliberal economic reforms.

In recent years there have been several different interpretative attempts to explain the "failure" of the Constitution of 1991. Some of them, like that mentioned by González (1991), emphasize the limitations of the legal norms to transform society in depth. Other interpretations attribute the failure to the weakness of the state and to the fact that the Constitution fell short of fulfilling its goal of democratizing the political regime, especially with respect to internal democratization of the political parties (Bejarano, 1994). Other interpretations consider the time factor and maintain that ten years is a very short lapse of time for new institutions to mature and become consolidated. Finally, a recent interpretation has argued that the Constitution of 1991 increased the ungovernability of the political system, due to the great number of institutions that it created and, especially, to an excess of socioeconomic rights and transfer of resources to the regions that it stipulated. All of this has generated expectations that the government cannot fulfill, obstacles to economic growth, and impediments and conflicts in the relations among state authorities (Alesina, Kluger y Rosental, 2000).

Nevertheless, the thesis presented in this dissertation is that the Colombian Constitution of 1991 did not succeed in putting an end to the country's political crisis, not 
merely because of its insufficiencies or excesses, but because it is a project to create an equitable society which has entered into sharp confrontation with another societal project of neoliberal inspiration. And to date, neither of the two has obtained sufficient consensus to impose itself due to their contradictons, the weakness of the state, the fragmentation of the elites, the weakness of civil society, and the limitations imposed by globalization.

The global context also contributes to making the new constitution ambiguous because, on the one hand, it reinforces the democratizing tendencies and respect for human rights (elements of the new worldwide political agenda) but, on the other hand it reinforces neoliberal tendencies which reduce, at the domestic level, the margin for manoevering of governments and political forces to undertake and demand social reforms, since they require what neoliberalism denies: orientational activity of the state in the economy, strong social spending, and progressive taxation.

\section{Chapter 5}

\section{Colombian Societal Project II: Neoliberal Restructuring}

In this chapter I will provide an intial reflection upon the prior socioeconomic context in which neoliberal reforms were inserted (5.1). Next I will describe the composition of the business groups which have been affected by changes in the Colombian economic model (5.2), and discuss their diverse reactions to this process (5.3). I will also analyze the dynamics and contradictions of such a process (5.4 and 5.5), and the way in which it 
contributed to political regime change and to the fragmentation of the economic elite's groups. Finally, I will refer to the way in which transformations in the economic model implied the breakdown of political agreements with the labor class and the reduction of benefits obtained by it during the hey days of import substitution industrialization (ISI), which also signified a change in the political regime (5.6).

\subsection{Economic Liberalization: An Adequate Societal Project?}

As shown in the theoretical framework, the new global technological, economic, and political conditions have led, in Latin America in general, and in Colombia in particular, to a series of modifications of economic and state structures that, in turn, modify the relations among society, the economy and politics. From the national point of view, neoliberal reforms are also due to the decisions of the Colombian technocratic elite. This restructuring, as already mentioned, revolves around the points of the Washington consensus, i.e., a) reducing the state's size by reducing public expenditures and privatizing public enterprises; b) decentralizing the state's activity and transferring the responsibility for providing and financing public services to local governments; c) liberating prices and interest rates from state control, and deregulating economic activity; d) introducing regressive taxation; e) reducing tariffs and barriers to foreign trade; and e) making the labor force market more flexible.

These reforms were introduced in Colombia towards the end of the Barco government (1986-1990) and during the Gaviria government (1990-1994), for the purpose of making the transition from the import substitution industrialization (ISI) 
economic model to one of liberalizing and internationalizing the economy. These two governments, and the Gaviria administration in particular, based their economic policy on the Washington Consensus' common diagniosis for all Latin American economies, i.e. that the excessive protectionism of the old ISI model is one of the main causes of reduced productivity and the slow growth of the national economy (Presidency of the Republic, 1991; Montenegro, 1991). However, it is necessary to point out two things regarding this diagnosis. In the first place, the economic liberalization policy in Colombia was not the result of a need for severe economic adjustment programs in Colombia because, unlike other Latin American economies, Colombia had a lower level of foreign debt and therefore suffered less from the debt crisis of the eighties and had managed to maintain a moderate, stable economic growth rate and avoid hyperinflation. In fact, the average inflation in Colombia between 1970 and 1995 oscillated around $22 \%$, and the economic growth rate fluctuated between $3 \%$ and $6 \%$ during the 1950 1990 period (Misas, 2001: 115-116). According to some economists, this was thanks to the fact that economic policy during the second half of the twentieth century has been managed with prudence, pragmatism, gradualism and stability, as a result of political and institutional agreements. If, as has already been mentioned, these agreements gave rise, from a political and social viewpoint, to a hybrid regime that blends elements of premodernity and modernity (in terms of the coexistence of agrarian and industrial interests, along with clientelism and political rationality), from the economic viewpoint, it was expressed in a stable exchange rate, moderate inflation, and moderate fiscal and balance of payments deficits (Ocampo, 1992; Flórez, 2001). 
In the second place, various economists, historians, and political scientists have pointed out that both industrialization and state interventionism were very weak in Colombia due, among other things, to the weight of agrarian interests and agricultural production in the country's economic activity (Gómez Buendía, 1976; Palacios, 1980b; Ocampo 1992). Therefore, neither state protectionism nor the inward development model is the cause of the Colombian economy's structural problems. In this respect, Ocampo affirms that

protectionism clearly preceded industrialization but was incapable in itself of inducing dynamic industrial development. Furthermore, once the industrialization process was initiated, protection performed a secondary role, if compared with the effects of the expansion of the internal market induced by the coffee bonanza at the beginning of the twentieth century, the external economies generated by the integration of coffe market into the international market, the effects of that integration on the traditional internal domestic economic structures, and the strong fluctuations in the real exchange rate generated by the coffee cycle (. . .) the country made an early transition to a mixed model that combined the substitution of imports with the promotion of exports (. . .) the serious problems of industry in terms of productivity, structural dynamism and financial fragility only began in the mid-seventies when any import substitution strategy had been abandoned (. . .) already lacking any strategic concept of its role in the development process, industry became very vulnerable to diverse external and internal shocks" (Ocampo, 1992: 19).

But despite the fact that the country maintained a positive economic growth rate, without great traumatisms in the second half of the twentieth century, except for the past four years, during which the economy has experimented the worst recession of the century, its growth dynamic was not sufficient to integrate a large part of the population, redistribute income, or modernize its productive structure. This situation was due to various factors, including a symbiosis of the agrarian and commercial elites in the formation of the industrial entrepreneurial class, the small size of the internal market and the limited expansion of the salary relationship. This led to slow growth of the internal 
demand, and determined the formation of scarce, poorly diversified industries, specialized in the production of non-durable consumer goods, which suffered an early process of oligopolization. All of this created little need for enterprises to increase their installed capacity or to incorporate technological advances in order to increase work productivity (Misas Arango, 2001). When, at the beginning of the sixties, the Colombian state attempted to undertake a second, more intensive phase of the industrialization process, characterized by the production of intermediate goods, Colombian industrialists firmly opposed it. Only

the action of the state - very small when compared with the rest of Latin America - and the association with certain multinational suppliers, made it possible to introduce the petrochemical industry, the chemical industry, and other producers of intermediate inputs into the country (Misas Arango, 2001: 120 ).

If the Colombian state, despite its weakness, was the promoter of this process, then excessive state interventionism in the Colombian economy cannot be blamed for the country's economic stagnation, but rather the fact that more of this type of intervención was needed. In any case, the productivity of the Colombian economy has fallen drastically in the past three decades, and compared with other Latin American economies, it suffers from a technological lag of more than twenty years, its production has concentrated on the internal market, and it is in no condition to take advantage of the opportunities the economic opening has provided for it to become integrated into the world market (Garay, 1998). This situation shows that, despite the supposedly wise and prudent management of economic policy by the economic and political elite, there has been neither leadership, nor clarity, nor vision of the future to orient the country's 
socioeconomic development. This affirmation is corroborated by Garay when he affirms that

Colombian society has traditionally been a society characterized by a culture adverse to investment and capital accumulation, and more prone to consumption and negative savings. In the past thirty years the rates of savings and private investment has never surpassed a very moderate average level ( . . .) in contrast with economies that have had to significantly increment (triple or quadruple) their levels of savings with respect to the gross domestic product, in a period of two or three decades, in order to develop (1999: 148).

Thus, what Max Weber called the "spirit of capitalism", i.e., the accumulation of capital based on the values of productive work and investment and the "ascetic life", i.e., savings with foresight for the future, has been absent in Colombia, and adoption of the neoliberal model of economic liberalization has contributed to making this evident.

Therefore, it can be deduced that the ISI and state interventionism per se di not cause the lack of dynamism and growth in the Colombian economy, but rather a complex articulation of historic factors. Hence, the desirable societal model in Colombia, from the economic and social viewpoint, would be the strengthening of the productive structure through the incorporation of new technologies, expansion of the internal market, and incorporation of large sectors of the population that have been excluded from the market and the opportunity to consume. Nonetheless, global tendencies have imposed the articulation of the Colombian economy with the world economy. This explains why the policy makers of the Gaviria government, ignoring the history of the Colombian economy, assumed the inadequate diagnosis of the Washington Consensus, and made the decision to change the economic model. This resulted in a paradox since in order to change the country's political-institutional structure by means 
of the Constitutional Assembly, there was an ample consultation process with the participation of almost all the political and social forces, the adoption of the neoliberal development model was done unilaterally and with no consultation, which simply reinforced the confrontation between the those who favored one or the other of the two different societal projects.

\subsection{The Main Colombian Business Groups}

In this section I will sketch out the main economic interests that exist in Colombian society, in order to provide basis for understanding the distinct positions of the business sector facing changes in the accumulation model.

The interests of large farmers and landholders are represented by the Sociedad de Agricultores de Colombia (Colombian Farmers Society), SAC, founded intially in 1871 and refounded in 1904, and by the Federación de Ganaderos (Confederacy of Cattle Raisers), FEDEGAN, founded in 1963. Until the first half of the XXth century, SAC had a significant influence upon the economic policy; in the second half, however, it progressively lost its power (Urrutia, 1981). Nevertheless, its interests, as well as those of FEDEGAN, are over-represented in the Congress of the Republic (Hartlyn, 1985) due to the fact that such an institution, even today, largely represents the interests of the rural elite, in spite of the increasing urban composition of the Colombian population. Given that agrarian production received significant state protection and subsidies, this sector has been one of the most affected by the adoption of the free market model. 
The Federación Nacional de Cafeteros (National Confederacy of Coffee Growers), FEDECAFE, founded in 1927, represents, as its name indicates it, the interests of coffee growers and exporters. Until the 1980s, it was Colombia's most powerful business organization, given the importance of coffee exports for the growth of the economy. The coffee economy also established the bases for capital accumulation that enabled the development of the country's industrialization as of the $1930 \mathrm{~s}$. FEDECAFE controls more than the $50 \%$ of Colombian coffee exports; fulfills not only private but also a serie of state functions, such as the administration of the National Coffee Fund; owns a myriad enterprises and investments in the financial, agroindustrial, and air and maritime transportation sectors; and is the head of a series of socioeconomics institutions in the Colombian coffee regions. For this reason, FEDECAFE has been described for the analysts as "part business organization, part public company, and part industrial and financial conglomerate" (Urrutia, 1981: 143). However, FEDECAFE's power has decreased notoriously, as it will be discussed below, due to the new political and economic national and international conditions, especially the breakdown of the International Coffee Agreement .

The Country's industrialization and increased state interventionism which developed since the 1930s gave rise to the diversification of social interests and to multiple organizations for representing new economic interests. Such change was presented in this manner by one Colombian analyst:

"private interests began increasigly to organize in a business-like way, to take advantage of the economic intervention of the state, and to be able to influence its decisions. At the same time these busineess groups served as a cohesive force to face the new social order, giving way, especially after 1938 , to a kind of corporative economy" (Bejarano, 1985: 214). 
So farmers, cattle raisers and caffee growers had to share their power with a new business group, the Asociación Nacional de Industriales (National Industrialists Association), ANDI, founded in 1944. It represents the interests of large national industries. The interests of small and medium industries are represented by the Asociación Colombiana Popular de Industriales (Colombian Popular Association of Industrialists), ACOPI, founded in 1951. Given that these two sectors produce mainly for the internal market, they have been seriously affected by economic liberalization.

The interests of merchants are represented by the Federación Nacional de Comerciantes (National Confederacy of Merchants), FENALCO, founded in 1945. The financial sector is represented by the Asociación Bancaria de Colombia (Colombian Banking Association), ASOBANCARIA, founded in 1936, and by the Asociación Nacional de Instituciones Financieras (National Association of Financial Institutions), ANIF, founded in 1974. Both of these sectors have been benefited from the politics of commercial liberalización and financial globalization.

As of the 1970 there has been a proliferation of business sectors guilds. From 22 existing business groups in 1950, the Colombian business community grew to 81 organizations in 1981, 106 in i 980 and 200 in the 1990s (Urrutia, 1981; Rettberg, 2000).

At the beginning of the 1980s and 1990s, the diverse guilds of the business sector tried to unify in a common organization, in order to strengthen themselves as interlocutors of the State, to fill the gap left by political parties, and to better face the 
country's political and economic crisis. This common organization was the Frente Gremial (the Business Front), created in 1981, whose existence was short-lived; and the Consejo Gremial Nacional (the National Business Counsel) created in 1991, that still exists but has failed in agglutinating the business community, given that of 200 guilds, it only represents 15 organizations. With the exception these efforts, it can be affirmed that the business community's interest representation is highly disperse, given its incapacity to unify, which makes it weak and dependent upon the state. At the same time, the state's stability depends in great part upon the business sector support, which gives to the political regime a certain corporativist character. However, it is an "ad hoc corporativism" (Gallón, 1982) given that it does not evidence a stable structure, and the economic rules of the game are negotiated for short periods, and sector by sector. Until the end of the 1980s, FEDECAFE and ANDI had, within such a state-businnes sector relations framework, a privileged position for negotiating their interests. Proof of this is the fact that ANDI occupied a seat on the board of trustees of nearly 60 state entities (Osterling, 1989: 206). However, this privileged position was displaced in the 1990 s by the Colombian four largest business conglomerates.

The largest entrepreneurial groups began to form in Colombia in the the 1970s, by means of fusions, acquisitions of some enterprises by others, and horizontal and vertical integration among them. These groups can be defined as "related firms held together through interlocking directorates, holding companies, cross-financing, and often continued family ownership" (Maxfield and Schneider, 1997: 45). At the end of the 1970 s there were ten of these groups in Colombia (Silva, 1978), and there are about 
twenty at present. Nevertheless, the most significant and powerful groups in Colombian economy and politics are the so-called "big four". These are: a) the "Antioquia Sindicate", composed of 118 firms that cover the following sectors, among others: financial (20 firms), food products (18 firms), textiles (10 firms), insurance ( 9 firms), cement ( 9 firms), investments ( 7 firms), and commerce (4 firms); b) The Bavaria Entrepreneurial Group, which originated in the country's oldest and largest brewery. It is made up of 80 firms in the following sectors: investments (11 firms), beverages (10 firms), telecommunications and means of communication ( 9 firms), air transport (4 firms), and services, among others; c) the Aval Group (Luis Carlos Sarmiento Angulo Organization), which includes 51 firms mainly in the financial sector (24 firms), investments (12 firms), industrial (6 firms), construction (5 firms), and telecommunications, among others; and d) the Ardila Lülle Organization, which originated in the soft drink industry and now includes 46 firms in the following sectors: textile (12 firms), investments ( 9 firms), sugar ( 7 firms), telecommunications and means of communication ( 5 firms), financial ( 4 firms), beverages ( 2 firms), among others.

Together, these four large entrepreneurial groups own more that 295 of the country's enterprises, and reported 1,900,000 dollars in utilities in 1997 (Semana, May 4, 1998, p. 83-90), which is equal to more than $2 \%$ of the GDP. This means that these four large groups constitute the main motor of economic growth in Colombia. These groups have benefited from the economic opening and liberalization policy, as it will be discuss subsequently. 
Finally, it is important to reiterate that economic stabilization and restructuring processes in America Latina have taken place not only due to the changes in the technology and in the world economy, but also to the rise of new coalitions of national interests. An important expression of such a phenomenon has been the growing influence of technocrats in the decision-making process (Centeno and Silva, 1998). The importance of teams of economic experts in Latin American governments increases to the extent in which they displace traditional politicians in the decision-making processs, political controls upon their activities are weakened, and their social insulation grows. This situation guarantees the autonomy of such teams, since the the content of economic restructuring programs can be justified as the result of technical decisions. Therefore, in this decision-making style, political negotiations and ideological fights tend to be displaced by criteria of scientific rationality. In point 3.3 I showed how this phenomenon was produced gradually in Colombia since the mid-20 century. The technocratic elite has been, therefore, one of the main actors of changes in the accumulation model in Colombia, and its appearance on the political stage has fragmented, still more, the Colombian elite. But far from being a unified actor, state economic teams also exhibit splits and confrontations, as will be illustrated subsequently.

\subsection{The Early Stage of Economic Liberalization: Ambiguities and Oppositions}

The economic liberalization model had already been adopted during the government of López Michelsen (1974-1978), who wanted to turn Colombia into the "the Japan of South America." But at that time, the country's industrial structure was not prepared to 
face the competition of external industries that competed on the international market in prices and quality, by virtue of technological advances (Misas Arango, 1994 and 2001). Years later, the Barco government's (1986-1990) development plan again referred to the need to adopt a model of liberalizing and internationalizing the economy. The Barco government intended to iniciate the process in mid-1989, but decided to postpone the decision, due to the crisis of the coffee economy, produced by the rupture of the International Coffee Pact, and the need to concentrate efforts and resources on the war on drug-trafficking which was then at its most intense level.

At the end of February 1990, the government officially announced the implementation of its economic liberalization policy through a report to the head of the National Planning Department to the mass media, who affirmed that economic liberalization was a fact that was "unpostponable, imminent and irreversible" (La República, February 19, 1990, p. 1B). The basis of the liberalization policy was a document (Conpes-DNP, 1990) that took up the recommendations of a study of the Colombian economy, done by the World Bank, which called attention to the need to turn the external sector of the economy into the motor force of development, by means of liberalization of the economy that will allow the country's full insertion into the world market (World Bank, 1987). That document was based on the Washington Consensus' diagnosis for all Latin American economies, according to which the ISI protectionist development model had been exhausted and had not generated any significant economic growth, nor any competitive participation of the Colombian economy in international markets. The recommendations made by the study in mention 
included liberation of the exchange rate as a major instrument for regulating foreign commerce, the reduction of tariffs, and the replacement of the pre-importation license by a more flexible mechanism. The Barco government accepted, without question, this diagnosis and considered that the protectionist model had produced a distortion in relative prices, and had not generated incentives for national industry to introduce new technologies, which was manifested in low levels of efficiency and productivity. In order to initiate the process, the government announced measures such as the provision of financial resources for the technological modernization of industry, the reduction of tariffs, and the gradual and selective transfer of goods that could not be imported under the previous importation regime to a regime of free importation. that measures were to enter into effect within a period of five years.

The government's decisions generated a great debate about the scope and the opportuneness of the economic liberalization policy. The Colombian Association of Small and Medium-sized Industries, ACOPI, through its president, Juan Alfredo Pinto, has expressed its concern and confusion with respect to what it considered to be a lack of clarity on the part of government regarding a decision as important as the change of economic model and did still not understand why the decisions on a topic of such great transcendence should be made known by means of a mere report. ACOPI called for a clear official pronouncement, made by the President of the Republic or the Minister of Economic Development and not just "any functionary who thinks him- or herself authorized to talk about the subject" (La República, February 19, 1990, p.1B). The Minister of Development, María Mercedes Cuellar, tried to tranquilize businessmen by 
telling them they would not be affected by the new foreign exchange policy, since the resources for financing the economic opening, coming from foreign loans, would be granted in pesos in the country and not in dollars, and there would be ample deadlines for payment.

ACOPI considered the economic liberalization to have been imposed by the International Monetary Fund, which demanded the adoption of that policy as a condition for granting foreign loans. Furthermore, it asked the government to revise the criteria with which it assigned the quotas of funds for importing, since the way they were designed negatively affected small industry (La República, May 5, 1990, p. 1A-2A), and the elimination of all regulatory and political obstacles that the state imposed on the country's entrepreneurial and productive activity (El Colombiano, May 20, 1990, p.7A). Despite these requests, ACOPI did not reject the opening on principle; on the contrary, it affirmed that "one would have to be blind not to see that the opening is a necessity in Colombia" (La República, February 19, 1990, p. 1B). According to that association, it was the only alternative for achieving GDP growth rates higher than 6\%. Nevertheless, ACOPI feared that the policy adopted by the government, with the support of the World Bank, would lead to the bankruptcy of a large number of firms, and the subsequent development of a modernization policy for those that manage to survive.

The National Association of Industrialists, ANDI, on the other hand, was openly opposed to the economic opening policy. Its president, Fabio Echeverri Correa, affirmed that it was a policy imposed by the World Bank that could lead to the bankruptcy of 
many Colombian firms, produce unemployment rates of $18 \%$ or $19 \%$, and favor the occupation of Colombian workers in countries like Venezuela, Korea, Taiwan and the United States. The ANDI demanded clarity from the government in its formulation of economic policy and steps to achieve a common accord with the private sector, so that the economic liberalization would not affect its interests (La República, February 12, 1990, p. 10A). For the ANDI, the economic liberalization should be gradual and selective and the country's transport and communications infrastructure should be improved as a prerequisite. Furthermore, the vice president of the ANDI, Jorge Bustamante, pointed out that it was not so clear that the ISI model had been exhausted since there had been no studies that demonstrated the fact (El Tiempo, February 12, 1990, p. 5A). The ANDI also indicated that in order to deal with economic liberalization, it was necessary to carry out a series of labor law reforms, in order to reduce the costs of the labor force and flexibilize the labor market. In exchange, the industrialists proposed the creation of unemployment insurance for workers who lost their jobs because of the liberalization (El Espectador, April 23, 1990, p.p 1A, 7A). In the economic liberalization policy, entrepreneurs now saw the opportunity to concrete a series of demands regarding reduction of the costs of contracting workers and flexibilizing the labor market, that they had been presenting to the government since the early eighties (Orjuela, 1984). The ANDI, which represents the interests of big industries, criticized the accelerated pace at which foreign commerce was being liberalized. Big industry aspired to contain the free importation of products that threatened national production, and to maintain certain levels of protective tariffs ( $\mathrm{La}$ República, July 4, 1990, p.p. 1A-2A). In relation to the opportuneness of the decision to 
open the economy, ANDI president Fabio Echeverri, indicated that it did not take account of the situation of national industry, or the country's lack of adequate infrastructure to face international competition. Therefore, Echeverri demanded resources to achieve technological modernization, in order to increase productive efficiency, reduce costs, and make Colombian exports competitive in the international market (La República, April 27, 1990, p. 1A). Finally, the ANDI demanded that the government reach a serious agreement with entrepreneurs and workers before permitting the intervention of international financial agencies (El Tiempo, May 20, 1990, p. 12B). Workers supported these petitions (El Siglo, May 2, 1990, p. 1B).

The National Federation of Merchants, FENALCO, was initially in favor of economic liberalization and shared the government's diagnosis that it was the only option to respond to the exhaustion of the ISI model, which manifested itself in the scarce growth rate of the GDP and industrial exports. With the reduced growth rates of the Colombian economy, FENALCO president, Sabas Pretelt de la Vega, said that the country would take 50 years to achieve the GDP of Argentina, 80 years that of México, 60 that of Venezuela, and 600 to reach that of Germany (El Colombiano, February 11 , 1990, p.9A), Nonetheless, FENALCO considered that many more financial resources would be needed to develop the economic liberalization policy and proposed that the government adopt measures to legalize the nationalization of Colombian capital deposited in the international financial system. According to its calculations, there were 18 billion dollars that could returned to the country and used to finance the opening, modernize the productive structure, and conquer external markets. In any case, FENALCO emphasized the need to provide diverse types of support for the economic 
actors and to open the economy gradually and selectively. Failure to do so would be counterproductive for business (El Tiempo, April 15, 1990, p. 1A, 8C).

Jorge Méndez Munévar, president of FEDEMETAL, the metalworks industry association, also affirmed that the internationalization of the economy was due to the demands of the international economic agencies that were willing to offer loans of 500 million dollars to Colombia if it reduced its tariffs. The industrialists of the metalworks sector affirmed that the liberation of imports could end protectionism, which they considered the last hope for Colombian industry. FEDEMETAL also rejected the unilateral and non-consulted way in which the Barco government adopted the economic opening policy, without considering the opinion of the nation's entrepreneurs (La República, July 18 de 1990, p. 1A-3A).

Land transport entrepreneurs, associated in COLFECAR, pointed out that for the opening to be possible, it was necessary to modernize the ports and construct a much more technified and modern highway network to integrate the country's diverse transport systems. They also requested resources and incentives for the replacement of old vehicles through low-interest loans and reduced taxes (La República, April 16, 1990, p. 3A).

In turn, ANDIGRAF, the association of graphic industry entrepreneurs, expressed its concern over the radical character the government was giving to the policy of liberalizing and internationalizing the economy and criticized its acceptance of the 
guidelines handed down by the international finance agencies. It pointed out that the economic opening should be selective, i.e., limited to goods that are not exported or to productive sectors that are not linked to external markets (El Tiempo, April 19, 1990, p. $5 B)$.

CAMACOL, the construction industry association, which benefited from state plans for the construction of housing and infrastructure, warned about the dangers to the construction industry implicit in a policy to cut social spending in order to contain inflation, produced by the accelerated devaluation by means of which the state sought to increase the competitiveness of Colombian exports. CAMACOL also expressed its concern over the World Bank's demand that the Colombian government adopt more radical measures in the economic opening process, as a condition for the disbursement of loans already contracted with that entity. According to CAMACOL, that would represent a threat both to the stability of public investment and to the general dynamics of the economy (El Colombiano, May 10, 1990, p. $7^{\mathrm{A}}$ ).

Eliseo Restrepo, president of the Agricultural Society of Colombia, SAC, indicated that the Colombian economy was not yet in condition to undertake such an opening, since it had great technical deficiencies, produced at high costs, and was not prepared to meet the demands of the external market (El Espectador, May 1, 1990, p. 7A). The SAC and the National Federation of Cattlemen, FEDEGAN, considered that the lack of protection for the agricultural sector would expose them to disadvantageous competition from the subsidized production of the highly developed countries (La 
República, February 15,1990 , p. 10A). Therefore, the SAC considered it necessary to adopt an agricultural modernization program that would make it possible to compete internationally, to introduce mechanisms for more efficient commercialization of its products and to establish more adequate tariffs than those that had been in effect until then (El Tiempo, February 23, 1990, p. 10A).

The Barco government's Minister of Finance, Fernando Alarcón Matilla, was emphatic in rejecting accusations that the economic opening policy was a demand of the international finance agencies, and affirmed that the government was autonomous in defining economic policy. He explained that Supplement VIII of the "Challenger" contract with the IMF, to accede to multilateral credit resources, only implied the normal annual visit that the Fund makes to every member country and which results in an internal report that is binding for rich and poor countries alike. Furthermore, the Minister pointed out that the economic opening should not be understood as a simple liberalization of import, but rather as an effort to modernize the country's productive structure, in order to achieve higher growth rates. Nonetheless, he made it clear that the government could not say how far it would advance in this regard. (La República, February 12,1990 , p. 7A). But the Barco government, which was about to leave office, decided to leave the task of developing and deepening the initiated process of opening and internationalizing the economy to its successor.

The Gaviria government (1990-1994) continued broadening the politics of opening and internationalizing the economy, on the basis of the Washington Consensus 
diagnosis. Therefore, the government also argued the change of economic model was a consequence of the loss of dynamism of growth and the low productivity of the Colombian economy due to the obsolescence of the national productive infrastructure (Montenegro, 1991). Gaviria's government adopted a series of deregulatory policies which, while aimed at increasing the efficiency of state administration and the economy, resulted in social exclusion. These policies included: a) the flexibilization of the labor market through the reduction of workers' benefits like elimination of indefinite- term contracts and privatization of the state social security system; b) reduction of import taxes and duties, and the establishment of regressive taxation in which the consumption tax replaced the income tax as the principal source of financing of state activity; c) privatization of public enterprises in the fields of maritime ports, airports, railroads, telecommunications, and social security which resulted in the loss of thousands of jobs in the public sector and d) the political, administrative and fiscal decentralization process through which a great number of the central government's functions were transferred to municipalities and their fiscal responsibility was increased.

Labor organizations took a stand against the economic opening policy and affirmed that it was an imposition of the World Bank and the International Monetary Fund, that it would have negative effects not only on production but on the living conditions of the workers, and announced the creation of a "common front" to oppose the policy of flexibilizing the labor market and liberation of imports. Public employees were especially affected by the policy of privatizing state functions and enterprises. This meant the firing of around 30,000 workers, according to the National Government, and 
more than 77.000 according to the Unitary Central of Workers, CUT (Archila, 1995: 263). Regarding the privatization policy, the National Federation of Workers in the Service of the State, FENALTRASE, manifested that it "eliminates institutions that have have performed important public tasks in order to transfer them to the private sector, which endangers social function fulfilled by these institutions." They also manifested that the measures taken by the government ignored "all social and labor rights" (El Tiempo, December, 30, 1992, 8A).

There were two tendencies in the Gaviria government's economic team: those in favor of total, accelerated opening, led by the Minister of Finance, Rudolf Hommes and the Director of the National Planning Department, Armando Montenegro; and those in favor of a gradual, selective opening, led by the Minister of Economic Development, Ernesto Samper. President Gaviria did not take sides publicly but was in favor of accelerated opening. Business associations and workers supported the gradualist position of Minister Samper, with whom they identified regarding the inadvisability of abruptly exposing national production to foreign competition. Only FENALCO, the merchants' association, supported the government's decision for total, accelerated opening. FENALCO's only objection was related to the exchange rate, because it considered the pace of devaluation to be too fast (La República, August 24, 1990, p. $3 \mathrm{~A})$. This position was due to the fact that the merchants would benefit from the elimination of the restrictions on foreign commerce, but could not take advantage of it because a high rate of devaluation would increase the price of imports, which would diminish the volume of its associates' operations. 
A significant difference between the Barco and Gaviria governments is that the latter decided to apply the opening policy to the entire agricultural sector as well. In fact, the Gaviria government announced that the protection of this sector would be by means of variable, automatic tariffs based on international prices, and not as had been done previously, by means of quotas and import licenses. Thus, the private sector would have a broader field in which to commercialize imported agricultural products, which would make it possible to privatize a state agency, the Agricultural Marketing Institute, IDEMA, the function of which was to guarantee sustained prices for agricultural producers, regardless of the costs and risks, which were assumed by this institute. Sustained prices would therefore gradually lose their importance, and the costs and risks would be assumed directly by the producers and investors, as in any other private activity. Credit for fomenting the agricultural sector would be granted only to finance commercialization infrastructure and transfer of technology (El Tiempo, August, 23, 1990, p.p. 1A, 7A and 8A).

Associations of agricultural entrepreneurs like the SAC and FEDEGAN, and peasant organizations such as the National Association of Non Proprietary Peasants, ANUC; $y$ the National Agrarian Federation, FANAL, among others, united to demand that the government change its agricultural policy. These associations considered that the sector should not be exposed to the international competition of farm products that are highly subsidized by the industrialized countries, and that the farm sector could not be expected to bear the weight of the government's anti-inflationary policy, one of the 
mechanisms of which was massive importation of food products to contain the generalized rise in consumer prices. (El Tiempo, August 30, 1990, p.p. 1A y 6A).

The government's position regarding these claims was ambiguous. On the one hand, President Gaviria, in a speech before the National Agricultural Congress, attended by more than 1500 delegates from 80 agricultural associations, promised to compensate the sector for forty years of abandonment by the government, and for the negative effects of the economic policy. For this purpose, he announced that the economic opening policy would be gradual and without traumatisms for the agricultural sector. On the other hand, in the same congress, the Minister of Agriculture, María del Rosario Sintes, detailed the President's generic affirmations in affirming that the development of the agricultural sector would be done on the basis of "the options offered by the international market," and that the objective of the agricultural policy was to achieve a higher level of income for the producers, on a sound basis that would guarantee the consolidation and broadening of agriculture in Colombia (El Tiempo, September 20, 1990 , p. 12A). However, the Minister manifested that so as not to affect agricultural production, the pre- importation license and taxes on imported agricultural products would be eliminated gradually, in such a way as to establish a certain level of protection, for the medium term, and a variable system of tariffs, for the long term, the purpose of which would be to achieve a progressive adjustment of the costs of national production to the real costs of the international market (El Tiempo, November 3 de 1990, p. 13B). This mechanism was not clear to the agricultural producers, who indicated that the government only emitted "signs of disconcert" (El Tiempo, November 20, 1990, p. 7A). 
For the associations within the agricultural sector, the above-mentioned positions meant that the government abandoned the goal of achieving alimentary self-sufficiency in the country, that noncompetitive sectors would be sacrificed, and that the nation's agriculture should become specialized in those products in which the country could take advantage of the possibilities of the external market.

On the other hand, the Minister of Development, Ernesto Samper, trying to respond to the numerous objections to the economic opening policy, affirmed, within the framework of the First Mixed Foreign Commerce Commision, that the economic opening would not be done behind the back of the entrepreneurs (El Espectador, September 26, 1990, p. 7A) and that there would be foreign credit resources, in the amount of 1,100 million dollars to finance technological renovation and industrial relocation projects to foment exports and promote small and medium-sized industry. Furthermore, the National Planning Department announced programs to develop transportation and communications infrastructure. That announcements were received with skepticism by the producers, since they considered the amount announced by the Minister of Development to be insufficient, given that the mere renovation of equipment for the textile sector alone to enable it to compete in the international market would cost 500 million dollars, and the cost of industrial renovation projects in their entirety amounted to 4,500 million dollars (Revista Negocios, March, 1990, p. 26) 


\subsection{The Deepening of the Economic Liberalization}

During 1991, three facts characterized the development of the Gaviria government's economic opening policy: a) the creation of the National Gremial Council on the part of the business sector, b) the tensions and contradictions between the the policy to reduce inflation and the policy to stimulate the growth of the economy and exportations, and c) the acceleration of the policy of liberalizing internationalizing the economy.

The creation of the National Gremial Council was the result of an initiative of the Gaviria government's Minister of Development, Ernesto Samper, who sought to create an institution that would group together the business sector, in order to more effectively concert and discuss the measures of the new economic model and the initiatives for economic integration with other countries of the region (Cepeda Ulloa, 1994, and Pretelt de la Vega, 1994). For the entrepreneurs, the organization had, in addition, a double purpose: on the one hand, as mentioned in a previous chapter, they sought to fill the gap left by the political parties in relation to the need to deal with the problem of the deterioration of the social order, and on the other hand, they sought to achieve the unification of forces to face the government, in order to better confront the economic opening policy and defend themselves from it. The Council was integrated by fifteen of the most representative entrepreneurial associations, such as the National Association of Industrialists, the Agricutural Society of Colombia, the National Cattlemen's Federation, the Sugar-Growers Association, the National Association of Exporters, the Colombian Association of Flower Exporters, and the Banking Association, among others. However, 
this number is very small if one considers that the country has more than one hundred entrepreneurial associations.

In relation to the industrial sector, the economic opening policy included, in addition to the liberation of imports, promotion of export development, technological modernization of the productive structure, and the foment of new productive sectors with possibilities of technological development. These objectives were assumed by common accord with the private sector. Furthermore, two funds were created: one to finance new investment projects, and another destined to help workers who were fired, in order to grant them anticipated pensions, temporary unemployment aids, retraining programs, and credit for the creation of micro-enterprises (El Tiempo, July 9, 1991, p. 8A). Nevertheless, the policy of financial support for technological modernization of enterprises and of construction and improvement of the transportation and communications infrastructure of the country was scarcely developed.

To initiate the policy of support for technological modernization of Colombian industry so that it could compete in the international market, the government defined seven basic industrial sectors: iron and steel, automobile, metalworks, leather, textiles, and clothing manufacturing industries. Tributary stimuli were established for these industries, reduced tariffs on the importation of capital goods and raw materials, and internal and external credit, the latter in the amount of one billion dollars El Tiempo, March 6, 1991, p.14B). One of the most significant measures was that related to the automobile industry. In fact, this industry had been highly regulated by the state in 
relation to the models and the number of cars that could be assembled in the country, and it was in the hands of just a few firms that dominated the national market, thanks to the very high protective tariffs on the importation of foreign cars. However, consumers did not benefit in terms of options, quality or prices, compared with the international market. To correct this situation, the government decreed total freedom for the establishment of automobile-producing and -assembling companies, and substantially reduced tariffs on imported spare parts (El Tiempo, May, 16, 1991, p. 8A).

An exogenous factor that had an influence on accelerating the opening and the making of the above-mentioned decisions, was the series of negotiations for the commercial integration of Colombia, Mexico and Venezuela, in order to form the "Group of the Three". In fact, as a result of these negotiations the elimination of tariffs was accelerated in the metalworks, automobile, steel, and petrochemical industries. These sectors suffered, in the short lapse of eight months, the process of eliminating tariffs on foreign commerce, which was supposed to be carried out over a period of four years. This caused conflicts between the Minister of Development, Emesto Samper, who defended slow and gradual opening, and the industrial associations, despite the fact that the former was considered by the latter to be the defender of their interests within the government. According to the Association of Steel Industrialists, NNACERO, the elimination of tariffs was harmful to the country, since many metalworks companies would have to close, with the following social effects, since that sector generated 700,000 direct jobs and 350,000 indirect jobs (El Tiempo, April 1, 1991, p. 7B). Other trade associations such as the ANDI and ANALDEX, and the plastic producers 
criticized these negotiations since they considered it inadvisable to enter into agreements with a country like Mexico, which had a much stronger and more developed economy and infrastructure of ports, roads, and communications than Colombia (El Tiempo, June 25,1991, p. 10B). It could be said that in this case the integrating tendencies of the "geoeconomy" prevailed over domestic interests.

In relation to the agricultural sector, the Gaviria government sought to stimulate the production of goods in short supply and great demand in the international market, promote the creation of associations of cultivators to strengthen their national and international competitiveness and reduce tariffs on cereals from $30 \%$ to $20 \%$ within a lapse of six months. This measure was severely criticized by farmers, who considered that six months was too short a period to prepare the sector to face international competition, and demanded a greater degree of gradualism in the process of eliminating tariffs on foreign commerce (La República, July 6, 1991, p.8B). The Minister of Agriculture, Maria del Rosario Síntes, announced that the main objective of the agricultural policy was to incorporate this sector into the economic opening and to introduce market mechanisms into it and, therefore, the subsidized credit and the sustained prices, guaranteed by the state, would end and would be left at the level of international prices. Furthermore, tariffs on the importation of agricultural supplies would also be eliminated in order to help to reduce production costs. The Minister said that the agricultural sector's efficiency would not increase if the producers did not try to make greater investments and to modernize the technologyused in agricultural production (La República, July 10, 1991, p.p. 1A, 8A). 
These announcements were criticized by agricultural producers' associations, who manifested that Colombia's agricultural production was not yet in any condition to compete on the international market and, therefore, it was necessary to maintain sustained prices and tariff protection for somewhat longer (El Tiempo, October 10, 1991, p.p. 1A, 3A; and Novembre 28, 1991, p.6C), and to achieve this, they were ready to strongly oppose the government. According to Gustavo Cano, president of the National Farmers Association, the government was proceeding unilaterally by not consulting farmers on the policies relating to the agricultural sector. According to Cano, the planting of wheat and barley was suspended due to the lack of favorable conditions, while the government stimulated the importation of food products (El Espectador, January 16,1991, p. $8 \mathrm{~A}$ ). In the meantime, Darío Bustamante, manager of the Agricultural Marketing Institute, IDEMA, a state agency, speaking in the name of the government, denied the lack of support for the agricultural sector and said that DEMA was willing to buy the crops at sustained prices. At the same time, he affirmed that the government had the right to formulate an agricultural policy based on the free market, as a mechanism for determining prices (El Tiempo, January 22, 1991, last p. section A).

But the plans and programs for modernizing the agricultural sector were not well developed and did not produce greater technical development or increased productivity. According to data from the Foreign Commerce Institute, INCOMEX, farm machinery purchases decreased by 28 million dollars between January and September of 1991, which meant the greatest fall in recent years, despite the radical tariff reduction on 
imported machinery and the elimination of many administrative obstacles (El Tiempo, November 13, 1991, p. 12A). According to agricultural sector entrepreneurs, this situation was explained by the fact that they were not willing to make investments while there was economic uncertainty and problems of violence and public order (Ibidem). This position was not accepted by the government and President Gaviria referred to the fact in the annual assembly of the SAC. For Gaviria, the signs of recession were transitory and the measures adopted to internationalize the agricultural sector were fully justified. Furthermore, stabilization of the opening process would open broad horizons for investment and productive development of the agricultural sector (El Tiempo, November 28, 1991, p. 6C).

In response to the criticism from the agricultural sector, the Minister of Agriculture indicated that farmers could not continue justifying their low competitiveness with the argument of the subsidies that the most industrialized countries grant their agricultural products, and that they were not taking advantage of the benfits the government was offering them to acquire technology and supplies, a fact that was reflected in their inefficient production (El Tiempo, July 6, 1991, p. 8B). But the most important point in the confrontation between the government and the agricultural producers was with the cotton-growers, when almost two hundred of them carried out a protest that included the blocking of an important national highway. The cotton-growers demanded that the government intervene to improve their situation caused by the high costs of supplies, decreased demand due to the fact that the textile industry was using synthetic fibers, and low prices of natural fiber in the national market. In response to the 
cotton-growers, the Minister of Agriculture insisted on the need to modernize agricultural production and accepted that it was necessary to adopt measures to improve the situation of the sector, but the decisions regarding the economic opening policy were beyond the reach of the Ministry of Agriculture (El Tiempo, July 9, 1991. p. 9B).

As can be observed, positions regarding the economic opening policy were very polarized and, for that very reason, given the lack of spaces for agreement, and ambiguity on the part of the government, the adoption of new measures generated confrontations among the actors. The new Minister of Agriculture, Alfonso López Caballero, seemed to grasp this situation and, upon assuming office, announced that he would continue the process of economic liberalization in the agricultural sector, but "without academic rigidity" and with the spirit of listening to the agricultural sector's concerns, in order to make the restructuring process as little traumatic as possible (El Tiempo, July 9, 1991. p. 9B).

\subsubsection{Tensions between Anti-Inflation and Liberalization Policies}

In 1991 the economic situation was characterized by a vacillating opening policy that was highly confronted by the business sector; a decrease in international reserves, and an annual inflation rate of $32 \%$, the highest in recent decades. In order to reduce inflation, the government adopted monetary measures that restricted credit, controlled demand, and permitted the accumulation of foreign currency by attracting capital from abroad (Giraldo Samper, 1993). This situation originated a contradiction between two objectives of the Gaviria government's economic policy: the objective of achieving 
general economic stability, sought by the Minister of Finance, the National Planning Department, and the Monetary Board, and the objective of achieving greater economic growth of the different productive sectors which the Ministries of Economic Development, Labor, and Agriculture pursued more directly.

The monetary policy decisions adopted by the Ministry of Finance were oriented to preventing increased inflation, but they made credit more expensive, which worked against the entrepreneurs' need for an adequate flow of resources to finance their production. Furthermore, the lower rate of devaluation, which in practice amounted to a progressive reevaluation of the peso with respect to the dollar, was considered by exporters to be an obstacle to the success of the economic opening policy, if it was indeed to be understood as an effort to substantially increase Colombian exports, and not just as greater freedom for importation. This fact was percieved by industrialists and farmers as a grave situation of uncertainty for the economy, and as an abrupt, unilateral change in the rules of the game that the government had announced at the start of the economic opening process.

The government's decision to control inflation by reducing the prices of imported goods was highly criticized by exporters, who were the most affected by this measure. Jorge Ramirez Ocampo, president of the National Association of Exporters, ANALDEX, manifested that that measure meant a revaluation of the peso and a denial of the economic opening policy and that, if it were not possible to advance in this objective in an inflationary environment, reduced inflation could not be achieved at the cost of the 
producers; nor did they consider valid the government's argument to justify that measure, according to which it was now necessary to revaluate the peso because the devaluation of previous years had been excessive (La República, July 2, 1991, p. 8A). According to the vice-president of the ANALDEX, Javier Díaz, the government had changed the rules of the game for exporters, to the degree that it had revaluated the peso, reduced tax stimuli such as the reimbursement of taxes on exports, and increased interest rates on loans from the Fund for the Promotion of Exports, PROEXPO (El Tiempo, July 11, 1991, p. 14A). Furthermore, the Federation of Metalworks Industries, FEDEMETAL, pointed out that the exchange measures threatened fulfillment of the economic integration agreements particularly those relating to the Andean Pact. This was due to the fact that the adjustments generated by the exchange policy increased the price differences among the member countries (El Mundo, November 8, 1991, p. 4A) and exposed Colombian products to disadvantageous competition in the sub-regional market. On the other hand, the Confederation of Chambers of Commerce, the Colombian Chamber of Book Publishers, the Graphic Industries Association and the Clothing Manufacturing Industries Association, indicated that the revaluation of the peso with respect to the dollar, generated by the anti-inflationary policy, created an environment favorable to the increase of speculative activities, which was harmful to the economy as a whole (El Tiempo, I November 11, 1991, p. 4C, and November 15, 1991, last p.A).

Despite the industrialists' protests the government's priority was to curb inflation, the increase of which threatened the stability of the economy in general, and it was 
determined to do so, even at the cost of affecting private sector interests and generating uncertainty in the short term. The Director of PROEXPO, Carlos Caballero Argáez, expressed himself in this sense in defending the government's anti-inflationary policy. Caballero accepted that the anti-inflation measures had generated high costs for exporters, but considered that this situation would be transitory. He affirmed that the first thing to seek was price stability, but recognized that without the stimulus of the exchange rate, the objective of fomenting exports would not succeed (El Espectador, July 20, 1991, p. 7B).

Industrialists joined exporters in their criticism of the anti-inflationary and exchange policy. The National Association of Industrialists, ANDI, for example, pointed out that there were great contradictions between the economic opening and technological modernization policy and the short term objectives, aimed at counteracting the inflationary tendencies. The effects of that contradiction were not the best: credit cuts and the consequent increase in interest rates (on both commercial credit and credit to foment exports), revaluation of the peso, and reduction of tax incentives such as the reimbursement of taxes for exports. The ANDI argued that it was impossible to fulfill the economic opening policy objectives in these conditions, and therefore necessary to adopt a series of measures to permit a return to a balance between the monetary policy and the exchange policy, without hurting exports (El Tiempo, August 19, 1991 p. 12A).

The Association of Financial Institutions, ANIF, pointed out that the government's restrictive measures had produced negative effects, such as $\$ 450,000$ 
million cut in investment, an increase in banks' lists of defaulting debtors, that was growing at an annual rate of $13 \%$, and a reduction in savings deposits. This situation partly explained the avalanche of dollars that were entering the country and that had produced an increase in foreign currency reserves of more than $\$$ one billion dollars in just seven months. All of this meant that, given the lack of credit in the country, businessmen were resorting to foreign financing (La República, August 13, 1991, p. 2B).

As far as the Banking Association is concerned, its president, Florángela Gómez, considered it necessary to eliminate the marginal reserve requirement in order to normalize the flow of commercial credit, which had fallen $\$ 200,000$ million during 1991 , as a consequence of the anti-inflationary measures. It was evident that it was very important for the banks to have access to the resources taken out of circulation through the reserve requirement, in order to undertake a larger number of brokering operations. But the banks also realized that the scarcity of credit resources could cause a dangerous increase in the defaulting debtors' lists (La República, August 24, 1991, p.p. 1A, 4A).

Merchants supported the financial sector's request that the government modify its anti-inflationary policy, so as to consolidate the commercial opening and promote economic growth. Therefore, they proposed that the government adopt measures, such as eliminating the marginal reserve requirement, reducing tariffs on the importation of capital goods, eliminating exchange certificates as a form of payment to exporters, permitting Colombians to hold bank accounts in dollars within the country, establishing 
stimuli for firms that modernize their technology, and fully promoting the privatization process (El Tiempo, August 26, 1991, p. 2B).

The Gaviria government's economic team was not unanimous in its opinion regarding the advisability of the measures to combat inflation. That, as mentioned above, was due to the existence of two different focuses on the economic liberalization and internationalization policy: that of Finance Minister, Rudolf Hommes, and that of Development Minister, Ernesto Samper. The latter requested the former to modify the anti-inflationary policy, since it negatively affected fundamental industries for the economic opening process, and to abolish the ninety-day period established for converting the Exchange Certificates into pesos ${ }^{17}$, in order to provide greater liquidity to exporters (El Tiempo, August 12, 1991, p.p. 1A, 8A). The Finance Minister responded that the export-related exchange measures would not be modified, arguing the inadvisability of that decision (La República, August 13, 1991, p.p. 1A, 12A). In this way, the disagreement within the government's economic team was made evident.

On the one hand, the Minister of Development, Ernesto Samper, made his antimonetarist and gradualist position clear and proposed a reduction of the marginal reserve requirement of $10 \%$, a percentage which, in his opinion, would permit adequate management of an anti-inflationary policy (El Tiempo, August 28, 1991, p. 1A). Such a decrease would imply the release of 400,000 million pesos, which would be an important flow of resources for investment in industry (El Tiempo, August 29, 1991, p.

\footnotetext{
${ }^{17}$ A market money instrument representative of foreign currency, issued by the state to exporters, which could not be cashed in until after ninety days.
} 
9A). This position was supported by Roberto Junguito Bonnet, member of the board of directors of the Bank of the Republic, who considered it necessary to modify the monetary policy, since in his opinion it was already showing signs of exhaustion as an anti-inflationary mechanisms and had negative effects on economic growth and on the credit flow to the productive sector. Junguito thought it evident that the weight of the monetary stabilization efforts had fallen excessively on the control of productive credit. Furthermore, control of the expansión of the means of payment through open market operations, on the part of the state, caused fiscal deficit, since it obliged the government to cover the high cost of these operations with public resources. Junguito concluded that the monetary control policy exerted excessive pressure, causing interest rates to rise, affecting productive investment, and leading to the massive entry of capital from abroad. (El Tiempo, August 29, 1991, p. 9A). Finally, the pressures, both internal and external, led the government to propose to the Board of Directors that the Bank of the Republic release $\$ 175,000$ million pesos through the gradual dismounting of the marginal reserve requirement, so as not to affect the objectives of the economic opening policy (El Tiempo, August 30, 1991, p. 13A).

It is necessary to emphasize the Board of Directors of the Bank of the Republic's opposition to the Ministry of Finance's monetary policy, since both entities have traditionally acted in common accord on this topic. This significant fact, together with the confrontations between the Bank and the Constitutional Court mentioned above, 
originated in the autonomy the Constitution of 1991 granted the central bank in relation to the management of monetary policy.

In synthesis, during the second semester de 1991, there was great tension between the two objectives of the economic policy; the objective of consolidating the commercial opening, and the objective of achieving macroeconomic stability. To guarantee the former, the government should offer industrialists favorable conditions, including an adequate flow of financial resources at acceptable interest rates, that would permit investment in productive projects. It was also necessary to increase the competitiveness of national industry in the international market, which would require resources to finance projects for the technological modernization of industry, and a favorable exchange policy for farmers, industrialists, exporters and merchants. Within the government, this position was represented by the Minister of Development and, partially, by the Minister of Agriculture. However, the Minister of Finance and the National Planning Department were in favor of a macroeconomic stability policy of a monetarist type, that advocated the reduction of inflation through control of the money supply, even if this policy affected national producers in the short term. The acceleration of the opening, which took place in the second semester of 1991, meant the defeat of the gradual opening position, defended in the government by the Minister of Development, Ernesto Samper, and the definitive triumph of the more radical positions, defended by the Minister of Finance and the Head of the National Planning Department. 


\subsubsection{Acceleration of Liberalization}

Despite the fact that in July of 1991 the government had rejected the Monetary Board's recommendations to carry out a more radical liberalization, and had affirmed that it would not modify either the taxes on exports, or the exchange and foreign trade policy before January 1994 (El Tiempo July 26, 1991, p. 13A), in August of 1991 the Minister of Finance announced acceleration of the economic restructuring process. Thus, the measures that were not supposed to enter into effect until 1994 were introduced ahead of time, and national products entered into open competition with imported goods. The decision to accelerate the opening implied a substantial tariff reduction, a decrease of two points in the surtax on imports, increased devaluation and agilization of privatization programs and the modernization of ports and of the highway network. Tariffs were also eliminated on the importation of supplies, raw materials, and capital goods for industry. The agricultural sector was also included in the government's decision to open the market.

Among the reasons the government adduced to accelerate the economic opening, was, in the first place, the stagnation of exports, which businessmen attributed to the general uncertainty created by the lack of definition and clear direction in the opening policy; in the second place, the need to increase the supply of imported goods, since the government thought that it would have a rapid and positive effect in reducing inflation its main objective- and thus reduce the annual inflation rate to $22 \%$. The substantial reduction in investment and production costs due to the reduced of tariffs on imported raw materials and capital goods would also contribute to this objective. The government 
considered that the decision to accelerate the opening would clarify the rules of the economic game. The policy was supported immediately by exporters. But the National Association of Industrialists, ANDI, considered that the decision introduced new factors of uncertainty into productive activity, because it affected the planning of production processes that were already underway, which had been undertaken with the criteria and deadlines pointed out previously by the economic authorities. The ANDI considered that the decision to accelerate the opening had been made unilaterally by the government, without consulting with the private sector, and requested a return to the previous tariff policy. Furthermore, they considered that the increase in international reserves was due not just to less dynamic exports but also, mainly, to the restrictive monetary policy that had prevented greater economic growth and propitiated the entry of speculative capital, stimulated by the high interest rates (El Tiempo, August 27, 1991, p. 13A).

The industrialists were joined by the construction industry firms, organized in the Colombian Chamber of Construction, CAMACOL, who thought that acceleration of the opening would have only negative effects on the Colombian economy. For CAMACOL, the government measures generated uncertainty in business, deteriorated the credibility of the economic policy, reduced the expectations of project investors, produced ups and downs in the planning of business firms and traumatisms in the modernization process (El Espectador, September 3, 1991, p. 8D). Given the force of the facts, the industrialists could only express, once again, their intention to oppose the national government. According to the president of the ANDI, Juan Guillermo Angel, the 
industrialists at least had the right to request real and effective participation in the decision-making process that affected their activity, and that right had been violated by the government. Furthermore, the business community demanded coherence and continuity in government policies, as well as clear and stable rules of the game to permit the long-term planning and realization of their economic activities, and to avoiding be subject to fluctuations that made it impossible to create a climate favorable to productive investment.

Finally, in relation to the role of the Congress, the whole series of economic reforms needed to adopt the free market model in internationalization of the economy, was approved with very little opposition. This is explained by the following facts: in the first place, the scarce interest in economic or, more precisely, macroeconomic matters in the Congress. Given the clientelist nature of the Congress, an economic law is approved if it implies an allocation of associated public funds to the regions or the interests of the congressmen. In the second place, the Congress was threatened with revocation of its mandate on the part of the Constitutional Assembly of 1991 at the time of adoption of the new economic model. Given this situation, the Congress, in approving the main economic projects of the government, hoped to gain the support of President Gaviria, who had arisen through the rank and file of clientelism. In the third place, the approval of the new constitution and the winds of democratization that it introduced, contributed to creating a climate that appeased the potential opposition within the Congress among the representatives of the social sectors that would be affected by the adoption of the new economic model (Cepeda, 1994). Although the reforms that affected workers were 
approved, due to the reasons mentioned above, to the lack of representatives of the working class in Congress, and to the weakness of organized labor since union membership consists of less than $6 \%$ of the Colombian labor force (Urrutia, 1994).

The government of Cesar Gaviria was followed by that of Ernesto Samper (19941998). Consequent with the position he had assumed as Minister of Development during the former government regarding adoption of the new economic model, Samper tried to introduce gradualism in adopting the model and to make it more equitable in nature. With respect to industry, he designed a policy aimed at fomenting technological development and the formation of human capital. In relation to the agricultural sector, he developed programs to moderate the effects of the commercial opening and to promote rural development. He also attempted to improve the country's transport and telecommunications infrastructure. To make the objectives of reducing inflation and improving the situation of the social sectors most affected by the new economic model compatible, Samper propitiated a reapprochement among producers, workers and consumers, so as to reach an agreement on prices, salaries and productivity. Nevertheless, the scandal of the filtration of a considerable amount of drug-traffickers' contributions into his presidential campaign funds, produced a chain of events that polarized the country politically and gravely affected its governability, to such an extent, that none of his proposals actually developed significantly. From this point of view, the Samper government can be considered Colombia's lost quadrennium. 
In the academic world and the "think tanks" there has also been a debate on the advisability of adopting the model of liberalization and internationalization of the economy, that led to the same polarization observed within the government and between it and the business sector. On the one side, there are the academics who sustain that to solve the problems of Colombian economy "it would be enough to follow the policies suggested in the Washington Consensus" (Echavarria, 2000: 122). Nonetheless, this analysts argue that "in most fields the reforms were not profound and became stagnated during the Samper administration (1994-1998) that opposed his 'social model' to the 'neo-liberal' policies of the previous government" (Ibidem: 123). On the other side were those who considered the crisis and the economic imbalances to be due precisely to the adoption of the policies recommended by that consensus, since the commercial opening contributed to the systematic deterioration of national industry. Instead of an industry that is competitive in the international market, "sectors have arisen that are highly dependent on imports and have little capacity to generate employment. Furthermore, their possibilities of expanding are limited" (Sarmiento Palacios, 2000: 51).

In synthesis, practically all the workers, businessmen from the different sectors of production, and certain academic sectors expressed their reservations and fears regarding the neoliberal economic policy. All of this belied the affirmation of some comparative-politics analysts to the effect that individual interests had lobbied in favor of the neoliberal policy of restructuring the economy, and confirmed the conclusions of Geddes (1995) in the opposite sense. It is clear that the liberalization and internationalization of the economy had to affect individual economic interests 
negatively, since half a century of implement of the inward development model, had meant a series of advantages and benefits, the abrupt abandonment of which would affect them profoundly and negatively. Failure to take this structural background into account is what leads many analysts to overestimate the strategic decisions of the actors. On the contrary, a "rational actor" would seek a strategy to avoid measures that affect their vested interests, or a very slow supression of the old economic structures, in order to mitigate the negative effects.

\subsection{From Optimism to Crisis}

Prior to the adoption of the new model of free market and internationalization of the economy, there were a series of economic conditions in Colombia that fomented speculation, such as: a) the production and commercialization of cocaine; b) the massive entry of dollars resulting from the commercialization of cocaine abroad and facilitated now by the flexibilization of foreign currency exchange and the deregulation of foreign trade; c) the laundering of illegal dollars through the importation of luxury consumer goods, the construction of housing, and the purchase of landholdings; and d) speculation with the assets of existing enterprises, which led to a lack of real, new investment in the productive sector (Misas, 1994) and to a lack of technological renovation in the productive structure of Colombian firms. If to this we add the already mentioned structural difficulties associated with the introduction of the new model, which made its implementation slow and difficult, it can be said that, in practice, the new economic model degenerated into a promotion of speculative capital, with financial and 
commercial systems, both legal and illegal, that became the new source of capital accumulation.

This dependence with respect to speculative activity gave the Colombian economy certain characteristics and a dynamism that it maintained until 1995, and that would otherwise be inexplicable, such as relatively high growth rates for a Latin American country; accumulation of foreign currency despite the fact that Colombia became more of an importing country than an exporting one; exportation of capital; revaluation of the peso at the same time that domestic production was too weak to compete in the international markets; increased public and private spending due to the availability of cheap credit, and a simultaneous decrease in internal savings. In synthesis, the economic model in fact became a tacit model of accelerated accumulation of money capital in the short term, that did not benefit the productive sectores and was therefore condemned to an ephemeral and conjunctural life.

In fact, as of 1996, the first recessive symptoms began to appear in the economy. All the above-mentioned factors generated a series of macroeconomic imbalances, increased importations with respect to exports, and an unemployment rate that reached $20 \%$ in the year 2000 (Sarmiento Palacios, 2000). The abundant capital that entered from abroad generated a "dance of millions" that was channeled through the banking system by means of the offer of cheap credit, and towards importations, superfluous consumption, and the purchase of housing (Flórez, 2001). But when the interest and unemployment rates increased, the result could not have been clearer: companies deeply 
in debt or en bankruptcy, homeowners unable to pay their mortgages, and increased lists of defaulted debtors in the banks, above tolerable levels. The Bank of the Republic, which should have acted as a "monetary policeman", given the autonomy granted it by the new Constitution, adhered to the will of the government, and thus also contributed to creating the conditions of liquidity needed for the the above-mentioned expansion of spending and the revaluation of the currency in the first half of the nineties (Flórez, 2001). The economy began to show recessive symptoms since 1996, for which reason the government introduced a series of measures to detain the crisis and recover the real exchange rate that, as already mentioned, had been strongly reevaluated in the first half of the nineties.

The end of the "dance of the millions" revealed the vulnerability of the economic measures of the first five years of implementation of the new economic model. The growth rate of the economy plummeted and the construction and manufacturing sectors entered into crisis. This situation worsened in 1998, when the economy experienced the effects of the Asian and Russian crises, examples of external shocks that have multiplied and have become more intense through the effects of globalization. These effects were: deterioration of the country's terms of exchange, with adverse implications for national income; restriction and the increased cost of foreign financing; the flight of capital; and strong pressures to increase exchange rates and interest rates. Towards the end of 1998 , the Pastrana government (1998-2002) found it necessary to declare an economic emergency to confront the crisis of the financial sector, due to the increased number of 
defaulting debtors, particularly in the housing-financing system, whose users could not continue to meet their payments when interest rates increased.

The above provided ground for homeowners to create an organization to pressure the government to reform the housing-financing system, which had become very onerous. For this purpose, they questioned the legitimacy of the housing law before the Constitutional Court, which decided in their favor, invoking the fundamental right to housing, established in the Constitution of 1991. Given this double pressure, the government had to intervene in favor of the users, which led to a serious confrontation between the Bank of the Republic economists and the government's economic team on the one hand, and the Constitutional Court Justices and the defenders of the new constitution on the other. This confrontation will be the subject of analysis in the next chapter.

In 1999, financing possibilities, both external and internal, became even more restricted. The private sector's demand was reduced significantly and the economic growth rate fell abruptly. Whereas between 1993 and 1995 the GDP grew at a rate of 5\% annually, between 1996 and 1998 it was only 2\% per year, and in 1999 it was negative by $4 \%$ (Flórez, 2001: 48). Due to the above circumstances, the Pastrana government had to sign a formal agreement with the International Monetary Fund (IMF), aimed at recovering macroeconomic stability, gaining credibility in international markets, and achieving support to obtain new external credit resources. This agreement with the IMF also implied a confrontation with some of the norms of the Constitution of 1991. As 
mentioned earlier, this established a series of transfers of the central state's resources towards the regions and municipalities, to finance educational and health services. These transfers amount today to almost $50 \%$ of the state's current revenue. One of the points of the agreement with the IMF was the elimination of those transfers of resources, with which the confrontation between the two societal projects becomes even more evident, which will be analyzed in the next chapter.

\subsection{The Effects of the Change of Economic Model on the Political Regime}

As already mentioned in the theoretical framework, the adoption of the neoliberal accumulation model also implied a transformation of the political regime. The Analysis of this phenomena requires seeing this model as something more than a series of macroeconomic policy measures and to consider it as a "societal project". This is understood as the model of accumulation from the perspective of the conception of relations among the state, civil society, and the economy on the part, of the social sector or sectors that aspire to lead the process of social transformation. This conception implies, in turn, a redefinition of the rules of the game among the different social classes, and between these and the state, which constitutes a modification of the political regime. It thus requires surpassing the traditional definition of political regime as an ensemble of rules and institutions that regulate the struggle for political power, and the relations between the different branches of public power. From the perspective of this dissertation, an important function of the political regime is to act as an element of articulation between the state and the accumulation model, generating the possibility 
of establishing alliances among different social sectors, in order to orient the social process.

The above-mentioned concepts of regime and economic model as societal projects, also have consequences for the concept of "autonomy of the state." In its traditional conception (Poulantzas, 1969; Skocpol, 1979 and 1985), thar autonomy has been understood as the state's capacity of the state to distance itself with respect to partial interests of civil society. On the contrary, the existence of a societal project demands that state action be the result of a combination of internal strength of state institutions and their articulation with key sectors of civil society that aspire to lead the process of social transformation (Evans, 1995). In this sense, the political regime is the link between the state and the accumulation model, and makes it possible to present the latter as a societal project or to impede or obstruct its implementation.

To elaborate that concept of political regimes as the organizing principle of society, it is necessary to base it on Antonio Gramsci's concept of hegemony. From his perspective, the ruling class not only execises domination but a "moral and intellectual leadership" in society as well $(1971$, p. 57), i.e., it is a question of trying to exert domination not just by means of force but of consensus as well. Max Weber's (1968) works also contribute to structuring the concept of political regime, to the degree that for this author, the process of capital accumulation demands a series of cultural conditions relating to an ethic of the ruling class without which no development is possible. These 
leadership and consensus should be obtained through compromises and reforms in which the interests of different social groups should be taken into account.

From the previous perspective, the change of change of economic model renders inoperative the old agreements between the elites and social classes, which sustained and made possible the functioning of the previous model of industrialization for substitution of imports, and imposed the need to generate new agreements that express the new correlation of social forces. In the Colombian case, the magnitude of that change and the difficulty of achieving these new agreements has been pointed out by Carlos Caballero Arguéz, one of the most renowned technocrats in the economic teams of the governments of the nineties, and defender of the adoption of the neoliberal model, when he affirmed that

in Colombia it has taken us great effort to understand the implications of the changes that took place in the world in the past decade and, naturally, those of the process we call 'opening', initiated in the early nineties in this country. It was not simply a question of opening the economy to trade and foreign investment - commercial opening and financial liberalization - but something much more profound. Namely, the management of politics and of economy in the world at the end of the twentieth century (. . .) But change involved and still involves risks. In this specific case, it affected traditional politicians, that had seen their power and capacity to do favors, and to collect on favors, dwindle. They were equaly obliged to modify their way of acting. Likewise, productive enterprises and economic groups faced the need to redesign their strategies, to redefine the sectors where they should be, to increase investment to compete and open up to the world. The change was also difficult to transmit and to sell to people, because it generated nostalgia for the past (El Tiempo, July 24, 1998, p. 5A).

\subsubsection{Fragmentation of Economic Elite}

In Colombia, the possibilty of achieving these new agreements, consensus and leadership has been limitated for two reasons. In the first place, because, in addition to the division 
between the political and economic elites mentioned above (Chapter III), it is necessary to mention the division between the economic elites themselves, due to the model of opening and internationalizing the economy. These elites have been dividided into those that have incorporated technological advances and have been connected to the world's productive and financial circuits, and less competitive ones that act on the basis of the national market. While the former advocate free trade and internationalization of the economy, the latter are in favor of protectionism or gradual opening. In the second place, through the exclusion of subordinated social sectors due, among other things, to the reduction of public social spending, state subsidies, and labor rights and guarantees, and to increased unemployment. Both dimensions of the economic restructuring process limited the possibilities of the elites to make alliances among themselves and with other social sectors, in order to democratically construct new rules of the game that regulate the relations between the social and political actors.

From the above-mentioned perspective, the opening of the Colombian economy to the international market, not only signified a profound reformulation of the development model in effect until 1990 , but a regime change as well, to the extent that the political agreements to maintain the prudence and gradualism on which management of the ISI-model economic policy had rested were broken. Prior to economic liberalization, the business sector had exerted a significant influence on the state institutions in charge of formulating economic policy. The state dispensed benefits to entrepreneurs and protected them from foreign competition and, in turn, the economic elites offered their unconditional support for the state action. The elites therefore 
established agreements to divide the markets and share the public resources that the state transferred to them through production subsidies and tax exemptions. Furthermore, control of the mass media, financing of election campaigns, and the permanent flow of leaders of different business sectors to high government positions, especially to the institutions responsable for managing economic policy, enabled the entrepreneurial elite to design economic policy in accordance with their interests. However, as already mentioned, the low growth and investment rates, the growing pressure of international agencies, and the inevitable tendency of economic globalization, made continuity of the old economic model and the political agreements that sustained them, impossible.

To all of the above must be added the 1990 election of Cesar Gaviria, in circumstances of increased violence and anomie in the country, which gave his government great autonomy in relation to the economic and political elites. Gaviria and his economic team were convinced of the need for and the advisability of opening and deregulating the nation's economy, as was being done or had been done by other Latin American governments, and the autonomy they enjoyed because of the circumstances mentioned, gave them a margin to maneuver to change the economic model, to isolate themselves from social and political pressures, and to assume the political cost it represented.

The decision to change economic policy also aggravated the institutional fragmentation of the state's decision-making process. This fragmentation was manifest in the primacy of the technical instances such as those of the Ministry of Finance, the 
National Planning Department, and the Bank of the Republic, and the subordination of other entities such as the Ministries of Development, Agriculture, Labor, and Foreign Trade, which, regardless of the political weight of those who headed them, should submit to the decisions adopted by the dominant decision-making institutions.

The change of economic model took the business sector by surprise, which was very fragmented, without a single instance of articulation or representation of their interests and, consequently, lacking the force needed to impose itself as interlocutor of the government. The entrepreneurial sectors played only a reactive role and did not have any long-term proposed goal, accustomed as they were to negotiating with the government, sector by sector, on the specific aspects of economic policy that affected each sector. Therefore, when, due to adoption of the new economic model, the rules of the game changed abruptly, the private sector's associations to unite in the National Gremial Council, but did not manage to formulate general proposals and limited themselves to requesting a slowing-down of the liberalization and internationalization of the economy, an extention of the deadlines for the elimination of protective tariffs, and the continuity of production subsidies.

Furthermore, the new economic model produced a fragmentation of the country's entrepreneurial ruling class. Traditionally, it had been divided between the big business sector, represented by the National Association of Industrialists (ANDI), and the small and medium-sized business sector, represented by the Colombian Association of Small Industrialists, ACOPI. In the nineties, However, big business has become divided 
between the sector of the so called "big four economic conglomerates", whose interests are linked to the internationalization of the economy, and the sector that represents national industry, which is being affected by the internationalization itself. This fact thus explains the distancing that has occurred in the past four years between the ANDI and the National Gremial Council, on the one hand, and the big four largest economic conglomerates on the other. This fragmentation is documented in Gabriel Misas' study on national industry (1994). He argues that the most outstanding characteristic of capital accumulation in Colombia in the past three decades has been the formation of large financial-economic groups and the accelerated growth of financial savings. These two phenomena show that the logic of accumulation has not focused on expanding manufacturing production, i.e., Those groups have dedicated themselves to acquiring the property of existing enterprises rather than to generating new real assets. Thus arose an entrepreneurial sector with large financial surpluses, situated in a position of control with respect to a great number of national enterprises and that benefits from a policy of economic opening and privatization of state functions, above all in realtion to the financial, telecommunications, electric energy, and exploration for and refining of oil.

All four groups, but especially the Bavaria Group, the Ardila Lülle Organization and the Luis Carlos Sarmiento Organization, have benefited from the economic opening policy since they have taken advantage of new conditions to make investments in Europe and the United States, especially in the brewery, soft drinks, and financial sectors. They have likewise benefited from the privatizing of state functions, especially 
from the sale of state banks and from liberalization of the telecommunications sector and TV transmission sector, which were highly controlled by the state until 1991.

Furthermore, as an analyst of the Colombian industrial sector has pointed out, the main assets of these groups are concentrated in non-tradeable goods, i.e., those that cannot be provided by external suppliers. For the Colombian case, goods like beer, soft drinks, sugar, cement, and processed foods, behave as if they were non-tradeable goods, and they constitute the main manufacturing production of the great groups mentioned above. In relation to non-tradeable goods, such as textiles, these groups

had managed to articulate themselves favorably with the international market, and therefore the policies implemented have not affected them very unfavorably. In brief, the opening and its related policies could not negatively affect the enterprises that produced non-tradeable goods and, on the contrary, it offered them great possibilities of benefits (Misas, 1994: 186-187).

With respect to the industrial sector that acts on the basis of the national market, represented mainly by the ANDI and the National Gremial Council, one can say that it has been subordinated to the "four big" economic groups, strongly affected by the economic opening, since it was in no condition to compete on the international market, and has lost power in relation to the orientation of macroeconomic policy. A study by Luis Jorge Garay (1998) has shown that the productivity of the Colombian economy has fallen drastically and presently that, in comparative terms, it is suffering from a technological lag of twenty years, in which national production has concentrated on the internal market and has not taken advantage of the opportunities the economic opening has offered for it to become inserted into the world market. This fact would indicate that despite the supposedly prudent and intelligent handling of the economy on the part of 
the technocratic elite in decades prior to 1990 , there was no accord or any clarity to orient the country's economic development.

Economic opening has also affected the agrarian sector, both that which produces for the internal as well as for the external market. The most dramatic case is that of the coffee sector, which represented $80 \%$ of the country's exports in the fifties and fell to simply $18 \%$ in the nineties (Misas, 1994: 188). Therefore, the drastic reduction in agricultural sector's participation in generating foreign currency has simultaneously signified, for this sector as well, a considerable loss of power in the orientation of macroeconomic policy and at, the same time, this situation is affecting its capacity of political influence and social mobilization.

The above-mentioned division of the Colombian entrepreneurial elite, became evident in 1996, on the occasion of the crisis of the government of Ernesto Samper (1994-1998), due to accusations that his presidential campaign had received large sums of money from the drug-trafficking mafias. On January 22, 1996, Defense Minister Fernando Botero admitted in a television interview that President Samper did know about the entry of that funds into his campaign chest. The following day, given the evident destabilization, the political parties' inability to find solutions to the crisis, the polarization of society, Colombia's decertification by the United States, and the fear that the U.S. would impose economic sanctions on the country, the Nacional Gremial Council demanded the president's resignation. However, the four major entrepreneurial groups publicly expressed their disagreement with the Council's demand, supported the 
President, and applied pressure to produce a reconciliation between the two sides, as a result of which Samper was strengthened and was able to finish his mandate (Rettberg, 2001). Thus, the four major economic conglomerates became a new factor of power in Colombia and showed that a fragmentation of the economic elites exists, in displacing the country's traditional economic-sector associations that, although they filled the vacuum left by the political parties, saw their power and leadership dimininished, due to the internal divisions, loss of affiliations and credibility, and the weakening produced by the model of liberalization and internationalization of the economy.

\subsubsection{The Breakdown of Labor Agreements}

Adoption of the neoliberal accumulation model has also implied breaking the agreements among the state, the entrepreneurs, and the working class, which had made it possible to develop a national market, and guaranteed workers minimal basic living conditions, rights and job stability, however precarious.

These labor guarantees and rights first developed in the mid-thirties, when liberal president Alfonso López Pumarejo (1934-1938) assumed power with the support of the working class, to develop a project of political and economic modernization and industrialization of the country. Labor legislation arose, thus, in that period amidst of an environment of strong state intervention, protection for incipient national industy, formation of a national market, and constitution of citizens and consumers (Tirado, 1989). Protection for workers, the right to a minimum wage and a maximum workday, and the regulation of collective labor relations by means of institutionalization of the 
right to union membership and the right to strike, were examples of the new attitude assumed by the state, given the practically non-existence of salary relations in the Colombian economy and the repressive treatment of labor conflicts on the part of employers and governments at that time. As Archila affirms,

in those years workers' desires to construct an organization to have a presence in the public scenario, coincided with the liberal governments' intention of having an ally in its modernizing projects. With the institutionalization of the labor conflict, the working class obtained its citizenship papers. The type of identity constructed during those years referred basically to the imaginary horizons of the factory worker (1995:257258).

Thanks to this labor legislation, workers, at least in the formal sector of the economy, achieved a series of rights and benefits such as overtime pay; extra charge night work; 15 working-days paid vacation each year; a bonus of a half month's salary each semester; the right to severance pay, which consisted of one month's salary for each year of work, liquidated retroactively according to the worker's last salary, which was to be paid when the work contract finalized, or before, in case the worker required it to finance the purchase of a home or for higher education; employer's payment of $12 \%$ annual interest on the funds accumulated for workers' severance pay, entrepreneurs' contributions to the social policy system, distributed as follows: $12.3 \%$ of workers' salary for social security, 3\% for the Family Welfare Institute, $4 \%$ for Family Compensation Funds, and 2\% for the National Labor Training Service. Altogether, these benefits and contributions represent about $45 \%$ of the workers' basic salary. In enterprises where workers were organized in unions, these benefits increased and were broadened through additional benefits. Over time, and especially in the second half of the twentieth century, union action was directed to the defense of these rights and labor 
stability, especially in what refers to maintenance of indefinite term labor contracts, and retroactivity of severance pay, which, in the opinión of the entrepreneurs, rigidified both the legislation and the labor market.

Nonetheless, the dynamics of relations among the state, the entrepreneurs, and the workers began to be transformed in the eighties and, more clearly, at the beginning of the nineties. The globalization process, the effects of technological changes in production and the adoption of the new neoliberal accumulation model, required flexibilization of the labor market and labor relations, all of which affects stability in the work place, the systems of labor remuneration based on fixed social benefits, and allowances oriented toward workers' welfare, that tend to be replaced by labor relations schemes based on increases in work productivity.

The Gaviria government and the legislators at the beginning of the nineties responded to these new economic, productive, and labor conditions, with Law 50 of 1990, which sought to flexibilize the labor market. This law eliminated retroactivity in calculating the amount of severance pay, flexibilized labor contracts, and introduced the possibility of paying an integral salary (with no social benefits or allowances) above a certain salary level (Arenas, 1991). Law 100 of 1990 modified the social security system to broaden its coverage, but also to privatize it and to introduce market mechanisms in the offer of retirement pensions and health services. The arguments of policy-makers at that time were based on the fact that the previous labor law was too rigid and prevented the flexibility firms needed to be able to respond to a more open and 
competitive economy, both in the domestic and the international spheres, and to the new technological conditions that required highly qualified workers. In synthesis, labor law, which had been an instrument of protection for worker, becomes a means of regulating the labor market based on the needs of the enterprises. At the present moment, amidst the country's economic crisis, the government and the business sector have proposed an even greater flexibilization of labor legislation to permit payment of the minimum wage without social benefits, the elimination of overtime payments, and extra pay for night work, among other things. They have also proposed suppressing the so-called "parafiscal" contributions that weigh upon the payment of salaries, such as the percentages for the Family Welfare Institute and for the National Labor Training Service.

The result of all of this is the loss of influence of the working class in general, and organized labor in particular, in national politics and economics, especially in what refers to the capacity to maintain its standard of life and employment stability. It is a lesser power in relation to the orientation of social policy, business administration, the labor environment and productive processes. Organized labor is no longer a valid interlocutor before the state and the the business sector.

The Unions and the large centralized labor organizations (the Unitary Central of Workers, CUT, and the General Confederation of Democratic Workers, CGTD) are not prepared nor have they acquired sufficient force to effectively oppose the abovementioned restructuring processes and to offer viable alternatives. Although the level of 
union membership has traditionally been low in Colombia, the growing informalization of labor relations, the flexibilization of legislation and the labor market, the privatization of the state and the dismounting of social policies have aggravated this tendency even more. While in $197016 \%$ of the economically active population was unionized, the percentage fell to $8.24 \%$ in 1984 , to $7.9 \%$ in 1990 , and to $7.7 \%$ in 1994 (Archila, 1995). Despite this weakness, thel labor centrals unions and the strongest unions (those of state workers, teachers, and oil-industry workers) carried out 41 general strikes between 1997 and 1999 in protest against the economic and social policy of the neoliberal governments (Cambio, August 30,1999, p. 24). The strike carried out in 1999 , involved not only workers but other social sectors as well, such as defaulted debtors in the housing financing system purchases, transporters, peasants, rice-growers, and bank employees, amongst others.

Nonetheless, these protests have not been strong enough to modify the government's economic and social policy, or to give workers and the popular sectors a better negotiating position in the neoliberal restructuring process. This has led workers and organized unions to seek direct political participation through party and parliamentary action. Thus, for the congressional and presidential elections of 2002 , the organized workers' movement and other social sectors organized the "Social and Political Front", whose presidential candidate was Luis Eduardo Garzón, the former leader and president of the CUT. With one year of its existence, that movment has had unprecedented success for the left, since its congressional candidate, former Constitutional Court Justice Carlos Gaviria, obtained one of the highest votes, and his 
presidential candidate, Luis Eduardo Garzón, has obtained the support of the main independent and leftist congressmen and voters. This will probably give the Social and Political Front more than a million votes in the presidential elections at the end of May 2002. Although it is not possible for Luis Eduardo Garzón to presidential elections, his political movement is already taking shape as an important social-democratic force, with great possibilities of constituting an alternative to the neoliberalism that has predominated in the country throughout the nineties. This also contributes to eroding bipartisanship and to further democratizing Colombian political regime.

\section{Chapter 6 \\ The Conflict between \\ Project I and Project II: \\ Legitimacy versus Efficiency}

In this final chapter, an analyis will be done of some of the main contradictions resulting from the two societal projects that were undertaken simultaneously in Colombia since the beginning of the nineties: the Political Constitution of 1991 and the process of neoliberal economic restructuring. These contradictions, as will be seen farther on, are associated with attempts to reduce public spending versus an increase in the size of the state $(6.1)$, to the attempts to improve and legitimate political representation versus fragmentation of the political forces and the survival of old clientelist practices (6.2), to the attempts to strengthen and extend the markert as coordinator of social relations versus the social, economic, and political heterogeneity of Colombian 
society $(6.3,6.4$ and 6.5$)$, and to the disagreement between the two societal projects regarding the criteria for distributing social goods (6.6 and 6.7).

The evaluation of said reforms has polarized analysts, decision makers, and the social actors, which, in itself, is already first evidence of the degree of sharpening of the social fragmentation to which the reforms of the nineties had led. With respect to the Constitution of 91 , chapter IV showed that opinion was divided three ways: in the first place, those that considered that the constitutional norms alone were unable to transform society (González, 1993); secondly, those who considered that the Constitution fell short in its purpose of democratizing society and the political regime (Bejarano, 1994); and finally, those who considered that the Constitution increased the ungovernability of the political system (Alesina, Kluger y Rosenthal, 2000) or compromised the economic stability and functioning of the free market (Kalmanovitz, 2001; Clavijo, 2001).

With respect to economic restructuring, opinions became radicalized around two positions. On the one hand, there were those who considered that the internationalization and liberalization of the economy were based on adequate diagnoses and criteria, but the negative effects were due to the fact that this process was not carried out in the necessary depth, or with the necessary speed or skill (Echavarría, 2000). On the other hand, there are those who consider that the assumptions on which the economic liberalization policy is based are mistaken and have been the cause of the economic crisis that the country has suffered since the mid-nineties (Sarmiento, 1998 and 2000). Other positions (González, 2001; Misas, 2001; Flórez, 2001) considered that the cause 
of the problem was not to be found in liberalization or in economic opening as such, but in the way in which it was justified and the context in which it was implanted, which led to a very biased and partial consideration of the effects of industrialization for substitution of imports model, in order to provide evidence of the need to adopt an open market model. According to González (2001), since adoption of the industrialization for substitution of imports model began, its success was believed to depend on the development of an exporting dynamics that would permit the generation of foreign currency reserves needed to modernize national industry. Furthermore, as of 1968 , with the program to promote exports and achieve Colombia's entry into the Andean Pact, it was considered that the local production of final and intermediate goods should be directed not only to the domestic market, but to the international market as well. Nonetheless, the country did not manage to increase its export capacity significantly, due to structural limitations, which is different from saying that the substitution of imports was synonimous of a closed and inefficient economy (González, 2001: 402), as the Gaviria government would have us believe.

It is common practice to measure the success or failure of political, economic and social reforms by the degree to which they managed to advance in achieving the purpose and the rationality of their authors. Thus, for example, if the objective was to reduce the size of the state and it was not reduced, it is considered that this was due to the deficient or insufficient application of the measure in question. However, in this dissertation I assume a position that goes beyond said focus. As I pointed out in the chapter corresponding to the theoretical framework, the dynamics of the social processes surpass 
the intention of the actors, or go even farther beyond. It is the context of forces and social structures in which action is inscribed that determines their destiny. The economic reforms, such as the change of accumulation, or political models, such as the Constitution of 1991, are based on postulates of rationality that are not necessarily fulfilled in social reality. It is not possible to determine ahead of time the consequences that a decision would unleash; as Herbert Simon has said,
in an important sense, all decision is a matter of compromise. The alternative that is finally selected never permits a complete or perfect achievement of objectives, but is merely the best solution that is available under the circumstances. The environmental situation inevitably limits the alternatives that are available, and hence sets a maximum to the level of attainment of purpose that is possible (1947: 6).

Individuals make decisions that may or may not be rational, but society, understood not as the sum of the individuals but as the ensemble of individual interactions, generates forces that wind up limiting the individual's field of action. As Marx said, "men make their own history, but not of their own free will in circumstances they have chosen, but in circumstances they encounter directly, that exist and are a legacy of the past"(1973: 408). From this perspective, decisions taken by actors who propelled the economic liberalization policy found a limit in decisions taken by those who promoted the Constitution of 1991 and vice versa. In turn, contexts of structural heterogeneity and fragmentation that characterize Colombian society, and of globalization processes in which it is inscribed, affected the course of both societal projects.

\subsection{Reduction Versus Increased Public Spending}

As has been established in previous chapters, one of the objectives of the neoliberal restructuring was to reduce the size of the state, whereas the objectives of political 
restructuring was its strengthening and re-legitimization, increasing and improving the channels of political representation and the party system, and increasing and improving guarantees of fundamental rights of citizens. The interaction of both processes produced an interesting result: the size of the state, measured in terms of public spending as a proportion of the GDP, increased from $20.4 \%$ in the 1990 to $37.7 \%$ in 2000 (table 1).

Table 1

Public Sector Spendig as Proportion of GDP

\begin{tabular}{cccccc}
\hline Year & $\begin{array}{c}\text { Central } \\
\text { Government }\end{array}$ & $\begin{array}{c}\text { Social Security } \\
\text { System }\end{array}$ & $\begin{array}{c}\text { National Decentralized } \\
\text { Sector and Public } \\
\text { Enterprises }\end{array}$ & $\begin{array}{c}\text { Regional and Local } \\
\text { Governments }\end{array}$ & Total \\
\hline 1990 & 5.4 & 2.6 & 4.3 & 8.1 & 20.4 \\
1991 & 6.4 & 2.7 & 4.5 & 8.1 & 21.6 \\
1992 & 7.5 & 2.7 & 4.8 & 8.1 & 23.1 \\
1993 & 6.6 & 3.3 & 5.7 & 8.8 & 24.3 \\
1994 & 6.6 & 3.9 & 6.0 & 9.5 & 26.1 \\
1995 & 6.8 & 4.7 & 6.9 & 9.7 & 28.1 \\
1996 & 7.7 & 5.6 & 7.6 & 11.8 & 32.7 \\
1997 & 8.2 & 6.1 & 7.3 & 12.4 & 34.1 \\
1998 & 8.2 & 6.8 & 6.7 & 12.3 & 33.9 \\
1999 & 8.9 & 7.7 & 5.8 & 14.2 & 36.6 \\
2000 & 10.7 & 6.5 & 6.9 & 13.6 & 37.7 \\
$(\mathrm{pr})$ & & & & & \\
\hline
\end{tabular}

Source: DNP, CONFIS, Banco de !a República, Cordi (1998)

Pr: preliminar

One could think that the Colombian state's tendency to grow was due to insufficient or deficient application of neoliberal policies of privatization, deregulation, 
and reduction of state functions and personnel. However, although that could be comparatively true ${ }^{18}$, this tendency is similar to that of practically all states throughout the world. In fact, neither the United Kindgom nor the United States could escape it during the governments of Margaret Thatcher (1979-1991) and Ronald Reagan (19801988), which were the governments that most attempted to reduce state intervention in their countries. In England, the public spending share of GDP rose from $31 \%$ from 1961 to 1973 to $40 \%$ between 1981 and 1990 . In the United States, said proportion rose from $29.5 \%$ to $34.9 \%$ in the same period (Institut Francaise des Relations Internationales, 1991: 401-407). Graph No. 2, taken from the World Bank (1997: 22), presented the worldwide tendency to increase the size of the state between 1960 and 1994. As can be observed, this tendency held constant throughout the second half of the twentieth century, for the developed as well as the developing countries. For the former, the public spending share of GDP rose from $25 \%$ between 1970 and 1974 , to $37 \%$ between 1990 and 1994, which was precisely the period of most profound application of neoliberal policies. For the latter, the tendency is less pronounced but also on the increase, rising from $21 \%$ to $27 \%$ in the same periods. While the increase in public spending has been constant in developed countries, a slight decrease has been observed between 1990 and 1994 in developing countries, but there has been a clear tendency to increase during the 34 años taken into consideration. In Latin America and the Caribbean, the tendency is similar to that of developing countries, but while for the

\footnotetext{
${ }^{18}$ If the Economic Freedom of the World Index, of the Fraser Institute is considered as an indicator of the degree of economic liberalization, which is measured on a scale of 0 a 10 , Colombia has a ranking of 92 , with an index of 5.6, below Chile's ranking of 15 and index of 7.5, Argentina's ranking of 30 and index of 7.2, Peru's ranking of 45 and index de 6.9, Bolivia's ranking of 51 and index of 6.7, and Venezuela's and Brazil's ranking of 82 and index of 5.8 (Fraser Institute, 2002).
} 
latter, considered altogether, the size of the state has increased by $27 \%$ between 1990 and 1994, for the Latin American region that increase has been a slightly lower $23 \%$ in the same period.

\section{Graph 1}

Central Government Spending by World Regions (\% GDP)

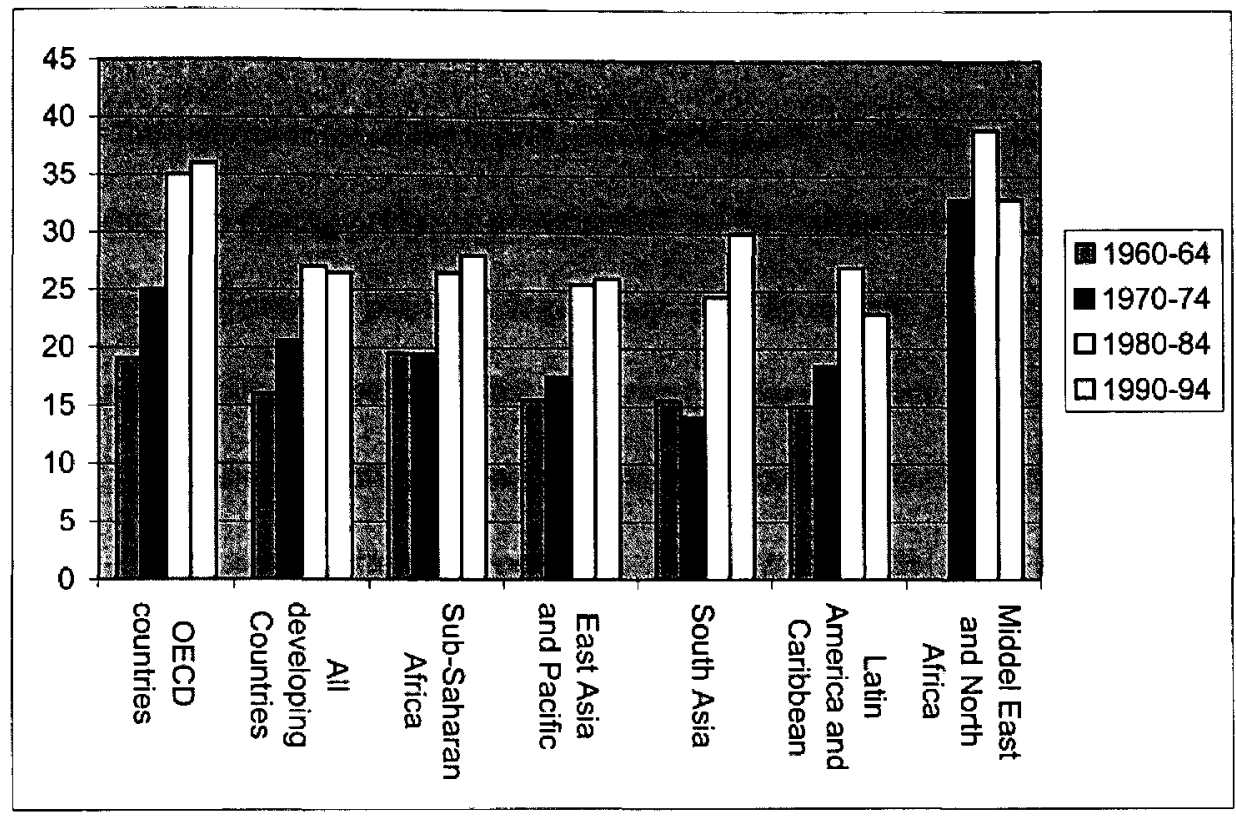

Source: World Bank (1997: 22)

Three conclusions can be reached from analysis of the above figures: in the first place, developed countries, despite the fact that they had adopted neoliberal policies to reduce the size of the state, have not been able to limit growth of public spending nor to dismount the welfare state. Secondly, in Latin America and the Caribbean there has been a relatively greater tendency to reduce the size of the state in comparison with other regions of the Third World. In contrast, southeast Asia, which has achieved greater 
economic and technological development in comparison with the rest of the Third World, has not shown any tendency to reduce the size of the state. Thirdly, multinational finance agencies, in order to achieve a global market economy, have pressured Third World countries to reduce the size of their public sector, a policy that has not yet functioned in the developed capitalist countries.

More than the insufficient application of free market policy, the explanation of the fact that throughout most of the world, neoliberal governments have increased public spending more than during previous governments of Keynesian orientation, is rooted in the contradiction between political legitimacy and economic efficiency. In fact, legitimacy and efficiency are the most important factors of state activity ( $\mathrm{O}^{\prime}$ Connor, 1973; Offe, 1993) and determine the state's capacity to integrate society and distribute its resources. This contradiction is rooted in the fact that the state has to try to simultaneously fulfill
the conditions in which profitable accumulation is possible [and] to maintain or create the conditions for social harmony. A capitalist state that openly uses its coercive forces to help one class accumulate capital at the expense of other classes loses its legitimacy and hence undermines the basis of its loyalty and support. But a state that ignores the need to assist the process of capital accumulation runs the risk of drying up the sources of its own power, the economy's surplus production capacity, and the taxes drawn from it for this surplus. (. . .) Because of the dual and contradictory character of the capitalist state, nearly every state agency is involved in the accumulation and legitimization functions, and nearly every state expenditure has this twofold character" (O'Connor, 1973: 6 and 7).

Much government spending has a positive effect on the process of capital accumulation, in reference to reducing the cost of labor and increasing the productivity of capital in general. In relation to the former, the state socializes costs that, in absence of a social 
policy, would have to be assumed directly by entrepreneurs, such as medical attention, labor training, social security etc. In relation to the latter, state spending on education, research and development; energy, transport and telecommunications infrastructure, and the search for markets and investment opportunities contribute to reducing the investment costs for private investors and to increasing the productivity of the economy as a whole. Therefore, it is incorrect to think that this activity of the state, although it be only indirectly productive, is onerous for the economy as a whole. These functions explain the impossibility of drastically reducing public spending, together with the fact that the provision of collective services by the state is institutionalized and converted into citizen's rights, which, in turn, influences their perception and acceptance of the social order. Therefore, the suppression of state spending and services has a high social cost in terms of the erosion of legitimacy of the state.

Given that the costs of production are socialized and social needs increase, while the funds needed to finance them are private (rate of profit, income, salary, etc.), the need for political representation arises: "No taxation without representation" was the slogan that fostered parliamentary government in the western world. Therefore, the principle of public representation is fundamental for the legitimacy of the state's extraction of resources needed for fulfillment of the public functions of contribution to the accumulation of capital and production of a legitimate social order. Thus the demand for quality and effectiveness of the function of political representation. 
In the Colombian case, the contradiction between legitimacy and effectiveness is the result of three factors. In the first place, the interaction between the political and economic elements of restructuring the state; i.e., of the contradiction between a new constitutional order that demands "more state" as a condition for overcoming the crisis of legitimacy of the state and integration of society, and a new model of economic development that requires "less state" in order to permit the free allocation of social resources by the market. In the second place, of the contradiction between the deficient quality of the function of political representation and the neoliberal demands for effective and transparent institutions. And in the third place, of the contradiction between a state that does not effectively guarantee the political and socioeconomic rights of its citizens and an exclusionary economic system, on the one hand, and a government that needs to reduce public spending and deregulate the market on the other. While the Gaviria administration (1990-1994) privatized state enterprises and attempted to reduce public spending, the new constitution increased the number of institutions and turned equity, distribution, and democracy into the cornerstone of the new political and economic order.

The neoliberal objective of reducing public spending was affected by the great importance attributed by the Constitutional Assembly to the policy of strengthening the state, broadening democracy and achicving equity by means of a policy of increasing and descentralizing public spending, especially in education and health. Due to the demands of the Constitution of 1991, the participation of social spending in GDP increased from $8 \%$ in 1990 to $15 \%$ in 1997 (World Bank, 2002: 68). 
But despite the efforts of the Constitutional Assembly of 1991 to strengthen the state and increase its legitimacy, which was translated into increased public spending, among other things, the Colombian state is still very weak in its function of providing cohesion for society, integrating the territory and providing security and justice for its citizens. The problem does not derive solely from the possible deficiencies of the Constitution of 1991, but rather, as already mentioned in previous chapters, from the incapacity of the political and economic elite to conceive and undertake a project of social integration, colonization, and socioeconomic development of the national territory as a whole, and from the fragmentation of power resulting from the different fractions of the dominant class to constitute a hegemony. The reason for this, as already mentioned, is the strong tradition of autonomous regional powers which, from the beginning of independent political life at the start of the nineteenth century, produced a rejection of any attempt to impose a central hegemony or strong national power. Over the years, this trait of Colombian politics became one of the pillars of the political regime and one of the principal causes of the weakness of the state.

\subsection{Political Representation Improvement Versus Political Forces Fragmentation}

Political exclusion, the deficient quality of the legislative function, corruption and the clientelism of the Colombian congress, have affected not only the legitimacy of the state itself but the functioning of the Colombian economy as well. According to institutional economic theory (North, 1990), the market economy functions due to formal and informal institutions, which reduce the uncertainty and the costs of information and transaction.

The institutions orient and regulate the behavior of the agents, establish property rights, 
facilitate contracting, offer information on prices and, in general, create a social environment that can favorably or unfavorably influence economic development. The most important of formal institutions is the law. Thus the parliament and its legislative activity are essential in the constitution of a market economy.

For the above reasons, the Constitutional Assembly of 1991 sought to legitimize and improve the channels of political representation but, paradoxically, the result was the sharpening of the fragmentation of the system of parties and representation, and an increase in the ungovernability of the Colombian political system. As mentioned in Chapter IV, the Constitutional Assembly of 1991 was based on a diagnosis, according to which the restrictions of the system of representation and the negative effects of the long predominance of bipartisanship, had led to the exclusion of other political and social forces, and stimulated the formation of subversive political organizations. Therefore, the Constitutional Assembly proposed opening the system of representation to the political forces excluded by the bipartisan agreement.

Although the purpose of eradicating the liberal and conservative hegemony, and of incorporating new social and political forces into the state's system of representation was positive, this was done not only by means of the establishment of spaces for the participation ethnic and political minorities, but also through the establishment of a lax normativity to permit the founding of political parties and movements, and much greater opportunity to postulate candidates for elections. Due to that constitutional norms and their legal developments (Political Constitution, articles 103, 107-108; law 130 of 1994), the 
number of political parties increased from 8 in 1990 to 80 in 1998, and that of political movements rose to 64 . Likewise, between 1986 and 1998 the number of lists inscribed for Senatorial and Congressional elections rose from 202 and 330 to 319 and 692 respectively (Pizarro, 2001: 102). The result has been an atomization of the political forces and a consequent increase of fragmentation of the political system, since the aggregation of interests, the formation of significant majorities and minorities, and the formation of solid political support for the government, or a solid opposition, is impossible. In the parliamentary sphere and in the Colombian political process in general, the traditional and third forces are not an instrument of aggregation of collective demands and interests today, but an instrument of de-aggregation of social interests. No party, force or political movement represents a social sector, a classs, or a significant class fraction in Colombia today. The fragmentation of political forces is such that for the congressional elections of 1998 there were 222 lists that did not obtain a single seat, despite the fact that they obtained a total of 2,540,000 votes altogether (Pizarro, 2001: 103). This fragmentation even works against the objective of obtaining a more effective and profound democracy, since it does not favor third forces that have arisen as alternatives to bipartisanship, given that they have been divided into a diversity of small, weak parties and movements of the most diverse political, religious, ethnic and regional nature.

\subsection{Implementation of Neoliberal Economic Model Versus its Unintended Consequences}

As mentioned in Chapter 5, from the beginning of the nineties Colombia has adopted a series of measures to introduce the free market model. They include the following: a) commercial opening and internationalization of the economy, b) elimination of currency 
exchange control, c) flexibilization of the labor market, d) adoption of indirect and regressive taxation that is displacing progressive taxation, e) privatization of some public enterprises, especially in the area of telecommunications, f) political. administrative, and fiscal decentralization, for which a great number of financial functions and resources of the central government were transferred to the municipalities, and g) the policy of reducing the fiscal deficit in order to diminish the "size of the state." The purpose of said reforms was to increase the competitiveness of national production, accelerated economic growth, and greater economic and social well-being for the population. Nevertheless, eleven years after its adoption, the neoliberal economic model has not managed to improve the country's development conditions as a whole. To the contrary, the growth of the economy has fallen annually over the past six years, culminating in 1999 with a negative rate of $4.2 \%$.

\section{Graph 2}

\section{The Fall of the Economic Growth Rate (\%)}

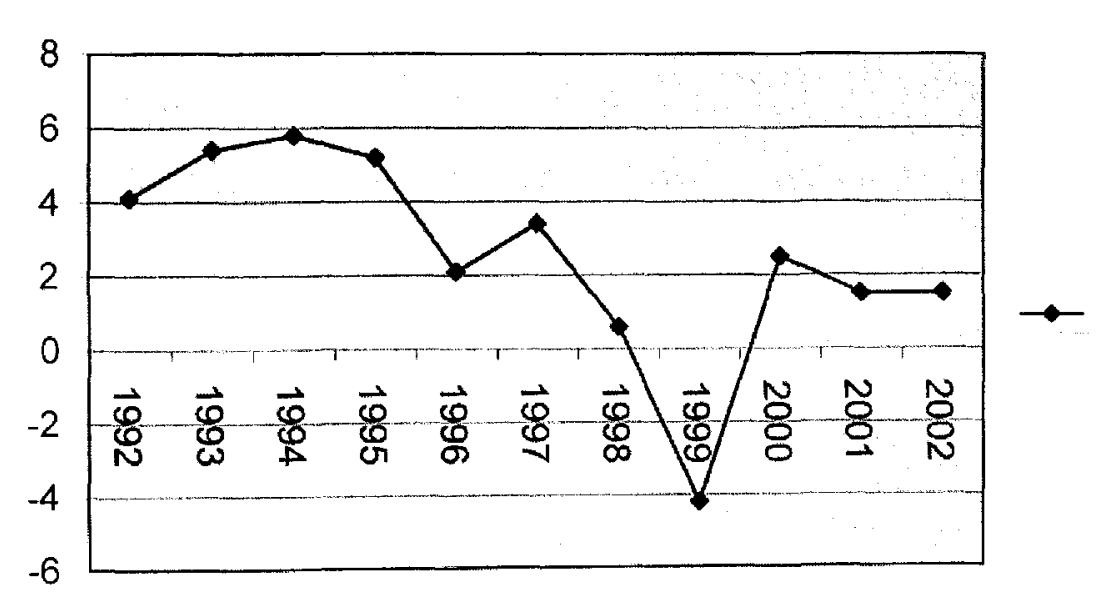

Source: Banco de la República - DNP 
According to the logic of the neoliberal model, commercial and financial liberalization should be accompanied by a decrease or at least a stabilization of real salaries and a severe reduction of spending, in order to generate surpluses for foreign trade. However, as will be shown now, the Colombian economy was opened up to the world market at the same time that both public and private spending as well as real salaries increased. The increase in public spending, as already mentioned, is associated with the provisions of the Constitution of 1991 , to the extent that it created new state institutions, increased social spending, and established new socioeconomic rights for citizens. Public spending also increased due to the servicing of the foreign debt, as will be seen below, above all since 1995 .

Liberalization of foreign trade was significant in Colombia, since the average tariff descended from $33.4 \%$ in 1980 to $11.8 \%$ in 2000 and imports subject to the restriction of quotas went from $73.8 \%$ in 1992 to $1.7 \%$ in 1998 (Echavarría, 2001: 64). These figures are similar to those for other Latin American and Asian countries in the same period (Fraser Institute, 2002).

But the liberalization of foreign trade is done not only to increase imports but also to increase the exports that would generate the growth of the economy. This did not occur, however, since at the start of the opening, in 1993, imports grew $48 \%$ while exports grew 3\% (Misas, 2001: 116) and during the entire decade of the nineties, exports grew at an annual pace of $30 \%$ while exports grew at $13 \%$ annually. But although Colombian exports have grown and diversified, $66.4 \%$ of them still consisted of 
agricultural and mining products (Sarmiento 2000: 53). The result has been a loss of economic dynamics, which led to a severe recession in the second half of the nineties. According to economic analysts, this lack of dynamics was also due to the contradiction between commercial and currency exchange liberalization, and the type of goods that Colombian industry produces.

\section{Graph 3 \\ Average annual Growth Rate of Exports}

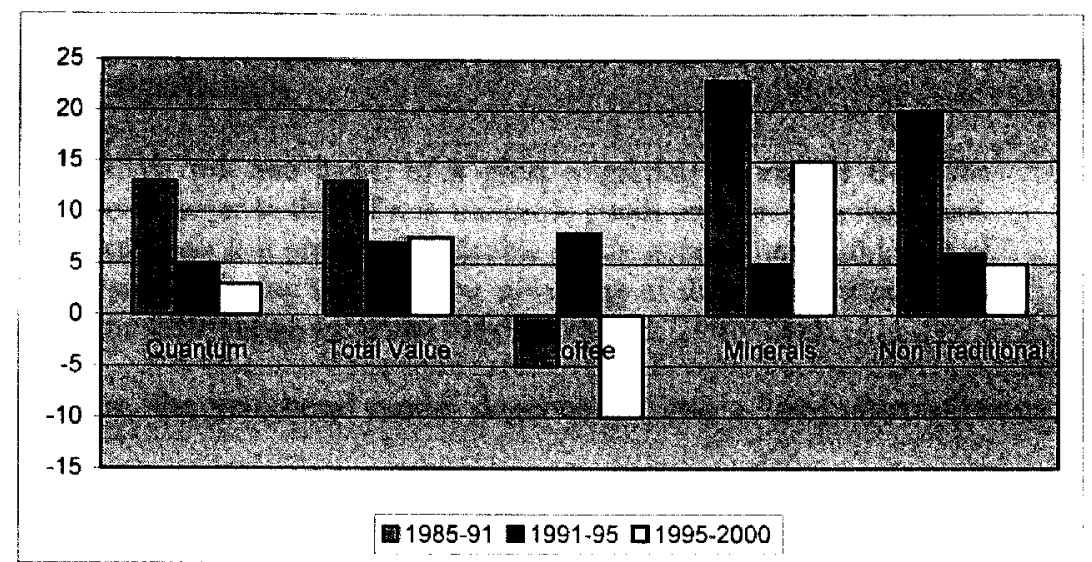

Source: Banco de la República, DNP, ECLAC

In relation to the goods produced by Colombian industry, it is necessary to say that the economic restructuring was done on the basis of the the idea that opening up to foreign competition would oblige domestic producers to adopt new technologies and to produce with the current standards in force in the international economy. This conduct was supposed to correspond to the rationality of the actors, since to act otherwise would imply losing competitiveness in the world market. But in this aspect, the decision makers failed in not taking account of the specific context in which the free market 
model was implanted: in Colombia, around $50 \%$ of all industrial goods are non-tradeable or behave as such (Misas, 1994). Non-tradeable are goods or services that cannot be replaced or substituted by external suppliers, for which reason the incidence of external competition is minimum or nil; therefore the commercial liberalización did not produce the expected results in Colombia. On the contrary, the production of tradeable goods were negatively affected by both external competition and the revaluation of the Colombian peso, which was the cause of the fact that these products could not compete with those coming from abroad. The profitability rates of the production of tradeable goods were reduced significantly

giving place, on the one hand, to a great migration of capital from the tradeable goods sector to that of non-tradeable goods and, on the other hand, to the fact that firms that produced tradeable goods stopped producing part of them and began importing them, taking advantage of their knowledge of the market and the distribution networks they had (Misas, 2001: 117).

Therefore, in practice, the neoliberal model degenerated into a "de-industrialization" of the Colombian economy, since industry's participation in the GDP fell from $23 \%$ in 1985 to $18 \%$ in 1995 (Florez, 2001b: 163).

The Constitution of 1991 was based on a supposed autonomy of the state in the management of monetary and fiscal policy. But at the same time, Gaviria's economic team opened the capital account and liberated both foreign trade and the currency exchange rate, which implied a reduction of the autonomy of the state in the management of these policies, since the latter began to depend on external factors. To carry out these two openings simultaneously is considered a mistake by diverse analysts (Edwars, 1998; Misas, 2001). In the Colombian case, it generated two negative effects: in the first place, the greater pace 
of the growth of imports as compared to exports led to a large deficit in the trade balance. In the second place, the opening of the capital account increased the entry of capital, largely of illicit origin, into the country. Because of this, the international reserves grew by $68 \%$ between 1991 and 1992 (Misas, 2001). All of the above led to the fact that between 1990 and 1998 the Colombian peso would suffer a revaluation of around $20 \%$, in real terms. This revaluation also contributed to increasing imports, lowering the growth rate of exports, and orienting investment toward the non-transable goods sector. All of the above, together with the increased fiscal deficit that reached $5 \%$ in 1999, forced the Bank of the Republic to adopt a financial restriction policy, which led to the present economic recession. The interest rates were raised to try to slow down the flow of capital but this, too, produced the opposite effect. In turn, the increased capital flow produced an expansion of credit, with the consequent inflationary pressure, which obliged the monetary authorities to change their policy as of 1994. In the second half of the nineties, the recession and the crisis of the private sector exploded, due to the indebtedness produced in the first half of the decade. Thus, the opening of trade and of the capital account required state capacity to generate a fiscal superavit in order to avoid inflationary pressures and the flight of capital, a capacity that the Colombian state simply did not have. As far as the Gaviria government is concerned, it underestimated the effects of the fiscal imbalance, due to its confidence in the abundance of recourses that would result from the exportation of the country's large oil reserves. Supposedly, these resources would make it possible to balance both the commercial and the fiscal deficits, but it eventually became known that these reserves were not as large as they had been believed to be and the resources never arrived (Misas, 2001: 118). 
According to the postulates of the neoliberal model, as has been mentioned, commercial liberalization and internationalization of the economy are incompatible with increases in real salary. In this field there was also a contradiction between the Constitution of 1991 and economic restructuring, since the increase of state institutions, together with revaluation of the exchange rate and the increased demand for skilled labor, required by an economy that experienced a certain degree of technological development, although slight, induced an increase in salaries in Colombia. Between 1990 and 1998, real salaries in the public sector grew 50\% (partly due to Constitutional Court decisions, as will be seen further on), and those of the industrial sector grew $44 \%$ for employees and $13 \%$ for workers (Echavarria, 2001: 170). One of the manifestations of the economic crisis is the high rate of unemployment which rose from $10.6 \%$ in 1991 to $20.5 \%$ in 2000 . For some analysts, the lack of flexibility of the labor market and the increased real salaries have been the causes of unemployment (Echavarría, 2001: 72). Other analysts, argue that employment has increased in commerce and services, sectors that form part of the nontransable goods group, whereas in industry, mining and agriculture it has diminished and, therefore, the cause of unemployment must be sought not in real salaries but in reduced demand (González 2000).

In synthesis, in decision making regarding liberalization of the economy, the magnitude of the influx of foreigh capital that would enter the country was not taken into account. This effect was foreseeable, given the highly speculative nature of the Colombian economy and the significant weight ot the illegal activities that link the economy to illegal 
international activities. Given these circumstances, the commercial opening should have been done first and the capital account opening later, in order to avoid phenomena like revaluation, speculation and indebtedness. However, external forces did not leave any margin to manoever and, instead, simultaneously implanted all the points of the "Washington Consensus"; the particular context in which they would be put in place was ignored, and this produced "unintended consequences."

\subsection{The Neoliberal Model Versus Economic and Social Heterogeneity}

The neoliberal model has resulted in a notable increase of social inequality and in the sharpening of enormous differences in the population's access to the market. This clearly shows that the contradiction between the two societal projects underway in Colombia since the beginning of the nineties: while the Constitution of 1991 tried to democratize society politically and socially, the neoliberal model excluded ample sectors of the population from the benefits of economic development.

The neoliberal reforms seriously affected the distributive function of the state which, in turn, affected its capacity to reconcile the interests of the different social actors. This situation gave rise to a distributive conflict and growing polarization of society. This is very serious if one considers the fact that Colombia has been a characterized by highly concentrated income. Recent data show that this tendency has sharpened with the introduction of the neoliberal economic model, since the Gini inequality coefficient rose from 0.467 en 1988 to 0.510 in 1997 (graph 4). In fact, in the early eighties, considered by economic analysts to be the era of greatest equity, the $20 \%$ richest portion of the 
population received $49 \%$ of the national income, while the poorest $20 \%$ received $6.6 \%$; whereas in 1996 the richest $20 \%$ of the population received $54 \%$ of the income, while the poorest $20 \%$ obtained only $6 \%$ (Fedesarrollo/Ser, $1997: 42$ ).

\section{Graph 4 \\ Evolution of Gini Coefficient}

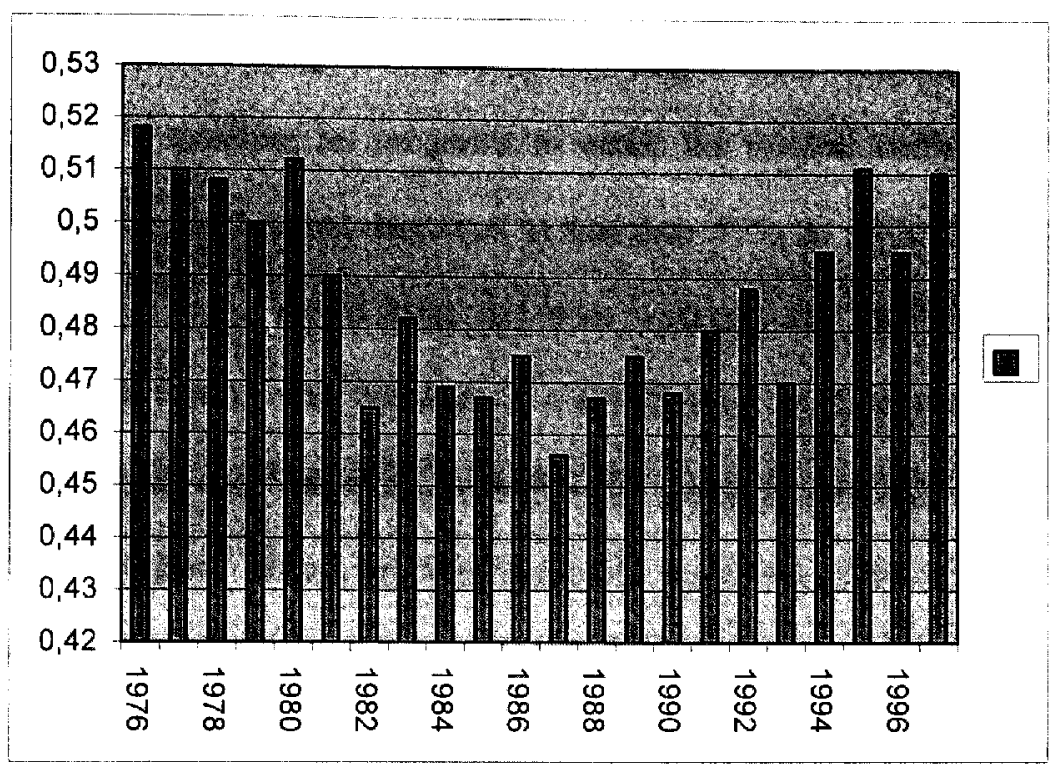

Source: DANE, DNP

From the viewpoint of income, the economic reforms of the nineties signified decreased pay for labor and a broadening of the breach between skilled and unskilled workers' salaries, this being one of the main causes of the deterioration in income distribution (Núñez y Sánchez, 1998). The unemployment rate rose from $8.7 \%$ in 1995 to $20 \%$ in 2001 . If the fact that subemployment has increased by $23 \%$ in the past decade is added to this, it can be said that $43 \%$ of the Colombian population is either unemployed or underemployed (Sarmiento Palacio, 2000a). 
The poverty level increased from $60 \%$ in 1995 to $64 \%$ in 1999 (World Bank, 2002). If one considers that poverty had been decreasing from $80 \%$ in 1978 to $65 \%$ in 1988 and to $60 \%$ in 1995 , it can be said that in the last six years there has been a worsening of the living conditions of more than half the Colombian population, caused by the economic structural adjustments and, specifically, by the recession that has existed since 1996, induced by those adjustments, despite the fact that they sought to improve the growth conditions of the economy and the well-being of the population. Despite the increased poverty, the central government's spending on programs to assist the poorest sectors, remained around $1 \%$ during the nineties and decreased to less than $0.7 \%$ in 2000 (World Bank, 2002: 10). According to the World Bank, this is an extremely low level of spending if one compares it with that of other countries in a similar stage of development, such as Mexico, Peru, Uruguay and Venezuela, and with the needs of specifically vulnerable groups that do not have access to key social-aid programs (Ibidem). In these circunstances, the World Bank considers that for Colombia to decrease its poverty to the level of 1995 , the economy should grow to at a rate of at least $4 \%$, as the minimum goal for the year 2010 (Ibidem). However, it is not likely that the Colombian economy will reach that level of growth. After the negative growth rate $(-4.2 \%)$ of 1999 , the GDP growth rate has been less than the population growth rate, since it was $1.5 \%$ in 2001, and a growth rate of less than $2 \%$ is foreseen for 2002 (Fedesarrollo, 2002)

The above figures make it possible to conclude that the neoliberal reforms do not confirm the neoclassic economic postulate, according to which free competition in the 
market leads to neutral solutionss with respect to equity; "on the contrary, the greatest effects against income distribution occurs in the section with the greatest differences in participants' possibilities [in the market]" (Sarmiento Palacios, 2000: 329). This indicates that if the state wanted to increase its legitimacy it would have to implement a sound policy to redistribute income. However, the margin for manoever is very small. With diminished resources, the state has less capacity to respond to social pressures. In the present circumstances, there are three reasons why it has been difficult for the country to carry out an income distribution policy. In the first place, Colombia has a low imcome tax-paying rate. This is partly due to the fact that since the end of the eighties, as an effect of adoption of the neoliberal model, an indirect and regressive taxation has been introduced (taxing consumption rather than income) which represented $62 \%$ of all state revenue in 2002 . In the earl of 1970 s the progressive or direct taxation (income tax) represented $51 \%$ of total revenues. (Garay, 2002: 686). This generated inequitable effects in the distribution of income, since it concentrates tax payment on the whole population and not on the highest income sectors. In the second place, the economic crisis makes it difficult for the state to obtain resources through a tax reform, in order to direct them toward social investment, since the business sector is in no condition to pay more taxes. Furthermore, the armed conflict not only obliges the national government to seek new resources, but to channel part of the already existing ones to security and defense. In fact, spending on defense and security, as a proportion of the national government's spending, has increased from $10 \%$ in 1985 to $12 \%$ en 1995 ; and the intensification of the conflict due to the breakdown of peace negotiations between guerrilla groups and the Pastrana government (1998-2002), made it possible to foresee that this increase would accelerate in the coming years until it reached 
$15 \%$. One of the priorities of the Uribe government (2002-2006) is to convince the members of congress and the business sector of the need to approve and subscribe the socalled "war bonds" that are to provide additional resources to combat subversion. In the third place, an income redistribution policy would require a coalition of progressive political forces to support and promote it. However, the formation of this coalition is not possible in the present situation in Colombia. On the one hand, the exacerbation of the armed conflict has contributed to creating a more conservative and authoritarian climate, prone to trying to solve things by the use of force, that does not favor mobilizations of social sectors in favor of vindicating socioeconomic rights. Social movements and the labor movement have been victims of the violence of different armed actors. On the other hand, the progressive forces are a minority in the Congress and, as shown above, they are very fragmented, which makess the formation of coalitions difficult. Furthermore, the Congress as a whole will concentrate its attention, in the next two years at least, on two of the main policies of the new government of President Alvaro Uribe: the search for new taxes to increase resources in order to deal with the armed actors, and reform of the political system, which includes, among other things, the elimination of one chamber of congress and the possible revocation of the mandate of the current members of congress, which does not generate a propitious environment for discussing great social reforms in the quest for equity.

In synthesis, in the late nineties, the neoliberal model presented adverse results: a slow-down in economic growth, crisis of the productive sector, massive unemployment, increased economic informality, and increased social inequality. The economic benefits 
and the market opportunities remain concentrated in the high income sector of the population. This reduces the possibilities of increasing demand and, therefore, the possibility of generating a positive effect in terms of growth and production. Instead of increasing access to the market and income, the neoliberal adjustment has increased the requirements and makes access more difficult for the majority of the population. This results in the exclusion or the unstable insertion of the population in the economic process and the impossibility of achieving sustained growth based on productivity, technological innovation, and better employment of the country's human resources. But, instead of greater productivity, innovation and equity, new spaces arose for speculation and commercial and financial intermediation, patrimonialist appropriation of social benefits, and opportunism and clientelism in contracts in both the public and the private sectors.

This is not an attempt to sustain a reductionist thesis that blames neoiberalism for all of the country's problems. As has been shown throughout this dissertation, the change of constitutional norms, the weakness of the state, the armed conflict, the drug trafficking, the heterogeneity and the fragmentation of Colombian society have also been factors in the political and social crisis. Nonetheless, what is underscored here are the unintended consequences of the application of neoliberal measures in a context of heterogeneity and fragmentation. From this perspective, the problem has not been caused only by the economic model per se, but also by its incapacity to modify the conditions of heterogeneity and assymetry existing in Colombia's society, market, and productive structure, at the time of its adoption. Given the lack of structural correctives, 
the neoliberal adjustment induced a type of development that contributed to making the country's political, economic, and social conditions even more heterogeneous. Therefore, the decision makers failed in applying the neoliberal model since they basically and implícitly assumed that Colombia's society and economy were homogeneous and structurally symmetrical. This supposition of homogeneity led the policy makers to adopt policies based on the principle of neutrality regarding the divergent conditions of the agents who participate in the market.

Instead of opting for a selective and gradual insertion of the Colombian economy into the global economy, that would prepare national production to face external competition, the Gaviria government (1990-1994) opted for an internationalization of the economy that opened the domestic market to foreign products, with the consequent negative effect on domestic capital and labor. The multinational companies introduced their intermediate components and products into the country for them to be assembled in the national market. In fact, as shown in Table No.2, the average annual growth of direct foreign investment (DFI) in Colombia increased from $12 \%$ in the $1990-1994$ period to $27 \%$ in the $1995-1996$ period (Fedesarrollo, 1998: 145).

Table 2

\section{Average Annual Growth of Direct Foreign Investment} in Colombia (\%)

\begin{tabular}{ccccccc}
\hline Year & $1975-79$ & $1980-84$ & $1985-89$ & $1990-94$ & 1995 & 1996 \\
\hline Total DFI & 10.5 & 12.8 & 13.8 & 12.1 & 23.3 & 26.9 \\
US DFI & 12.1 & 14.3 & 20.2 & 8.3 & 12,6 & 9.5 \\
\hline
\end{tabular}

Source: Fedesarrollo (1998) 
The consequence of this opening was, as already mentioned, that imports increased and exports did not increase, due to the fact that Colombia has certain comparative advantages in the production of goods for which there is no demand in the world market (Misas, 2001), a fact that contributed to generating the economic recession. In the Samper government (1994-1998), the manifestations of the crisis were already notorious: growing deficit in the current balance of payments account, revaluation of the peso, high interest rates, increased foreign debt, etc. But although said government recognized the gravity of the problem (Presidency of the Republic-DNP, 1994 and 1995), it did not take the necessary measures to correct the structural imbalances, because it did not have either the necessary legitimacy or the margin needed to manoever, due to the crisis generated by accusations that the Samper campaign had received large amounts of money from the drug lords, and the great political, social, and international pressures the President had to face as a result. During the Pastrana government (1998-2002), efforts were concentrated on trying to reduce unemployment, but above all, on developing the agreements reached with the International Monetary Fund regarding reduction of the fiscal deficit, reform of the pension and retirement system, and reduction of tranfers of fiscal resources from the central government to departmental and municipal governments. However, the only area in which the Pastrana administration had any success was in achieving the last of these reforms, as will be shown below.

In these conditions of indiscriminate opening, the industrial sectors that had traditionally been the leaders of national production such as textiles, clothing, leather, 
and certain capital goods, had clearly come to a standstill, and even entered into a retrocession due to their technological backwardness, their inability to compete in the international market, and their displacement from the domestic market by foreign products. The difference between exports and imports was financed with foreign credit obtained at interest rates of over $10 \%$. At the end of the nineties, the economic situation worsened because, in addition to the foreign trade imbalance, the interest payments on the foreign debt amounted to $6.5 \%$ of the GDP in 1998 (Sarmiento, 2000a: 53). As Sarmiento has pointed out, the neoliberal economic model led to results that were the opposite of the goals it pursued, since it implied

a large balance of payments deficit financed with foreign credit at interest rates higher than the economic growth rate, which provoked growing indebtedness. At present, it amounts to $50 \%$ of the GPD and, as in Argentina, it has reduced the country's access to international markets (El Espectador, June 2, 2002: 13A). 


\section{Graph 5
Colombian Foreign Debt (\%)}

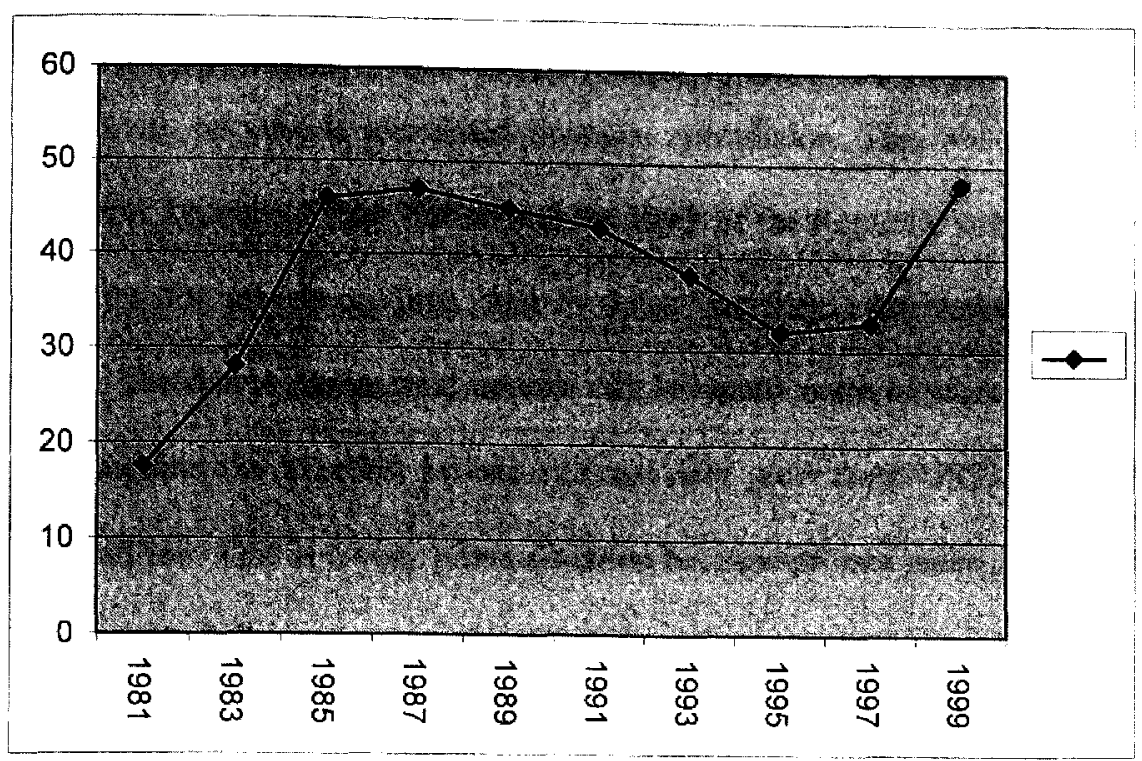

Source: Contraloría general de la República

The internal public debt also increased as an effect of neoliberal policies, especially as an effect of the monetarist emphasis of this economic model. During the nineties, the Bank of the Republic gave priority to reducing the amount of money in circulation in order to decrease inflation. The emission of internal debt bonds was the mechanism the bank used for that purpose. To the extent that the balance owing on the internal debt increased, the interest increased as well. Therefore, the resources obtained from later emissions of bonds to take money out of circulation had to be used to pay the interest on earlier emissions, to the point that by the mid-nineties, close to $96 \%$ of the value of the new emissions went to servicing the debt (Contraloria General de la Republica, 1996). Thus the government was not going into debt to invest in works of 
infrastructure, foment productive activities or pay public employees, but to respond for previous debts that were largely originated by a monetary policy of a contractionist type. In addition to the high fiscal cost, the internal debt also had a negative impact on economic activity because it stimulated financial speculation. This was due to the fact that the General Treasury of the Nation and the Bank of the Republic competed with the financial sector for private savings, and in doing so, they contributed to increasing interest rates. The rise in the internal interest rate led many entrepreneurs to go into debt abroad. Throughout the nineties, private external debt grew from US $\$ 2,000$ million to US $\$ 16,000$ million. This is a very grave situation because private enterprises contracted this debt when the dollar was worth $\$ 1,000$ Colombian pesos and now they must pay it with the dollar values at closer to $\$ 3,000$ pesos. In synthesis, this management of the internal public debt produced three negative consequences: a) it increased the fiscal deficit, a problem aggravated by the fact that the resources obtained had not served to increase public investment; b) it stimulated the speculative tendency of the economy; and c) it stimulated the external indebtedness of the business sector.

\subsection{Strengthening of Social Hybridation Social}

All of the above factors have reinforced the political, economic, and social amalgamation of rationalities and both traditional and modern patterns of legal and illegal behavior that characterized Colombian society throughout the past decade. Traditional patterns refer to the existence of privileges, clientelism and patrimonialism in economic activities, in both the public and the private sector. Modern patterns refer to the limited conditions of competition in the market and of technological innovation, and 
to the displacement of unskilled labor by skilled labor. The illegal patterns refer to the presence of illegal funds in Colombian economic and social activities, and to their erosive effect on the productive culture and Colombians' relation to the law and the public sphere. Thus, instead of becoming democratized, the economic process remains in the hands of those who are in condition to benefit from the assymetries and the economic and social heterogeneity, i.e., in the hands of the four major national economic groups, multinational enterprises, and the illegal economy. In fact, in the previous chapter it was shown that one of the characteristics of Colombian industry in the nineties was the formation of four large economic conglomerates (the Bavaria, Ardilla Lulle, Aval and Sindicato Antioqueño entrepreneurial groups), which currently control the 295 largest firms in the country, a fact that allows them to obtain annual profits that represent a little more that $2 \%$ of the GDP. This control permitted these conglomerates to place themselves in conditions to make strategic alliances with transnational capital and enterprises (Misas 2001:128).

Another characteristic of the Colombian economy over the past twenty years, has been the growth of the illegal economy (Thoumi, 1994: 98) and, given its clandestine nature, it has been very difficult to calculate its size and economic impact. The few available studies have calculated that the illegal economy represented $8.7 \%$ in 1985 (Ibidem). However, it is possible to think that illegal activities in the Colombian economy have increased in the nineties due to the liberation of trade and foreign currency exchange. The situation described above has been clearly described by Luis Jorge Garay, who affirms that 
in Colombia, the prevailing productive culture does not correspond to a true capitalist culture, but rather a culture that has inclined to a certain extent to the search for profit and the satisfaction of selfish exclusionary objectives in favor of certain groups, achieved by means of the use of individual privileges related to their position in the country's political, economic and social structure. Even more, this culture manifests typically rent-seeking traits; i.e., practices through which the dominant groups privilege their obtention of profits as a result of their position in the social structure rather than as the fruit of work, savings, investment, innovation and risk (1999:24).

For this reason, in order to overcome the rent-seeking nature of the economy and its harmful effects in Colombian society, it is necessary acclimatizing an entrepreneurial culture that will make it possible to advance toward modernization and efficiency of the productive apparatus so as to generate true social wealth and to set the bases for economic growth accompanied by distributive justice. This will require, as a group of Colombian scholars led by Garay asserted recently, Colombian entrepreneurs and all agents involved in the productive process to assume

greater responsibility and an active commitment ... that is not just limited to the fulfilment of their tax-paying and labor responsibilities, but must also include decisive actions to improve productive conditions and to assume collective responsibilities for systemic competitiveness, so as to propitiate the participation of other social groups in the definition and implantation of actions that will guarantee greater social inclusión(Garay, 2002: 35).

In synthesis, the Colombian social and economic amalgam consists in the fact that the precariousness of the country's industrial and market development, the exclusion, and the old clientelist and patrimonialist practices are not eliminated by the new forms of economic action and their corresponding regulatory institutions, but are instead juxtaposed beside the former. This is the main characteristic of Colombian society: the dichotomies of tradition-modernity, development-underdevelopment, and inclusion-exclusion, which have been strengthened by the adoption of the neoliberal model. 
On the other hand, neoliberal adjustment has produced a disconnection between economic and social policy that has contributed to fragmenting social relations even more. The new economic policy has not considered social heterogeneity either, or its effects on income redistribution. The deterioration of the latter has sharpened the social integration crisis, which is manifested in the existence of ample sectors of the population excluded from both the market and socioeconomic development, or that have been precariously inserted into them. Indicators of this exclusion and precarious insertion are: in the first place, the unemployment rate that, as has been mentioned several times, began to increase in 1995 until it reached a level of $20 \%$ in 2001 . Secondly, the informal sector of the economy and the underemployment that represent about $50 \%$. Thirdly, the Gini inequality coefficient which rose from 0.467 en 1988 to 0.510 in 1997 . And finally, the poverty rate which, as has already been mentioned, reached $64 \%$ in 1999 . If the social situation did not worsen even more in the nineties, it was thanks to increased public spending in education and health, propitiated by the Constitution of 1991. However, as will be seen in the following section, the agreement the Pastrana government signed with the International Monetary Fund reduced public spending in these very sectors. In synthesis, the excluded population has no possibilities of contributing to the formation of social wealth because they are unemployed or contribute in a precarious way because they are underemployed or because they do not have the necessary level of education or vocational training, due to the fact that the Colombian process of capital accumulation is characterized by a socialization of costs and a limited 
or concentrated appropriation of social benefits. This contributes to increasing the social fragmentation and the detonating elements of the political and economic crisis.

This precarious insertion of the majority of the population into the economic process, has also affected the process of building citizenship, by imposing limits on the expansion and on the maximization of human capacity since, as shown above, it is under-utilized for economic and social development, which does not favor increased production, social wealth, and human development. It is therefore necessary to seriously consider the problems derived from the insufficient demand, which not only constitute a source of restrictions for the continued growth and socioeconomic development, but also for the process of constructing and extending citizenship. The construction of citizenship requires not only the political recognition of the social actors and their rights, it also requires the development of an active policy to generate employment and income, broadening of social security, formation of human resources and redistribution of income and wealth. And it is precisely these policies that have least reached the most unprotected sectors, which presently constitute a large proportion of the population. Therefore, when mechanisms of competition are introduced into the economy without correcting the preexisting asymmetries in social relations, the discriminatory tendencies of the market are sharpened and the economic possibilities of the majority of the population are reduced. The effects of modernization in the functioning of the economy are thus concentrated in the privileged sectors of society. On the one hand, a very reduced sector of individuals and enterprises (the above mentioned Four Large Economic Groups: Bavaria, Ardila Lulle, Aval and Sindicato Antioqueño) receive the 
concentrated benefits of economic activity and change generated by the new model while, on the other hand, the political, economic, and social fragmentation of the country is increased.

The exclusion or precarious insertion of the majority of the population into the economic process, aggravated by the neoliberal model, is one of the obstacles to the rise of "infrastructural power" of the state, defined as its capacity to implement decisions, penetrating civil society with infrastructures by means of which the it extracts resources and provides resources (Mann, 2002: 3). This is a characteristic that Colombia shares with the rest of the Latin American states. According to Michael Mann, the main challenge of the states of the region

remains essentially the same as it was almost 200 years ago as they achieved their independence. It is how to incorporate their diverse populations into a genuine citizenship, which can sustain infrastructurally powerful states, which can become finally democratic. The biggest obstacle is not political conflict between ethnic or religious groups fighting over whose state it is (..) Rather, it is essentially the level of domestic inequality existing between classes that generates the main problem (Mann 2002: 22).

\subsection{Disagreement over the Criteria for Distributing Social Benefits}

The fragmentation of Colombian society has been aggravated by the inability of the diverse social actors to reach a consensus on the fundamental elements of social order. In this respect, the societal project arising from the Constitution of 1991 competes with that arising from the neoliberal economic model. The former was promoted by progressive socialdemocratic forces, while the latter has been promoted by the forces of globalization and by the new Colombian technocratic elite. These two projects have advanced in a parallel manner since 1991 and neither of the two has achieved enough of 
a consensus to impose its will. In the initial euforia of democratization resulting from the Constitutional Assembly, Colombian society did not realize that there were great contradictions in terms of concepts and practical application between the two projects and that they would therefore lead to the present situation due to the impossibility of reaching an agreement on the fundamental elements of social order and the criteria for distributing social resources.

The Constitution of 1991 introduced the series of changes that were mentioned in Chapter 4, but it also introduced others of which Colombian society has been less aware, such as the introduction of criteria of distributive justice and social liberalism in the allocation of social resources, and a new concept of law, less formal and rigid than that which had predominated in the country until then, where the interpreter of the law has an active role in creating law. Given the ambiguous relationship that Colombian society has traditionally had with the law (Gómez Buendia, 1999; Kalmanovitz, 2001), this new concept gave greater weight to law in structuring society and in guaranteeing individual rights, broadening its coverage to areas that traditionally had escaped it, such as the economy and Colombian citizens' relations with the public sphere. This new concept of law has required the support of a constitutional jurisprudence more commited to the culture of democracy and human rights than that which had predominated in the Supreme Court of Justice before 1990 .

As already mentioned, the Constitutional Court was conceived by the Constitutional Assembly as an entity with the power needed to develop the content of 
social justice of the Constitution of 1991. This power altered the traditional balance of power between the different state institutions and gave rise to a new configuration of the political system. This explains the confrontations produced in the past decade between the different state institutions and especially between the Constitutional Court and the Bank of the Republic and the members of Gaviria's economic team.

The new criteria for the allocation of social resources, resulting from the political agreement of a socialdemocratic nature were expressed in the Constitution of 1991, the law, and the jurisprudential decisions of the Constitutional Court. Driven by this and by the injuctive actions interposed by citizens, the new constitution's societal project has struggled to develop. Nevertheless, it has not achieved enough consensus to become consolidated, because the neoliberal societal project harbors social forces and global tendencies that are adverse to it.

In its function of preserving the social-liberal character of the Constitution of 1991, the Constitutional Court has proferred a series of controversial decisions, including the following: a) the Bank of the Republic's obligation to include production and employment among its objectives, rather than just monetary policy and control of inflation, as had been the case previously, b) modification of the mortgage system and permanent control of interest rates on home loans, in order to guarantee the right to housing; c) prohibition of bonos pensionales in private schools (by means of which a membership fee is charged for admission); d) equality of salaries in the public and private sectors, and the indexation of the minimum wage and the salary of state 
employees, and e) state health system coverage for so-called "catastrophic illnesses" which involve high costs for those who suffer from them.

These decisions, according to the critics, are opposed to the full operation of the "laws of the market", which are the only criteria the neoliberal accumulation model accepts for allocating social resources. Therefore, the above-mentioned decisions on economic and fiscal affairs have been rejected by the government's economic team, the Board of Directors of the Bank of the Republic, the economists of the "thinks tanks" that advise the government on economic matters, the financial sector, and some membes of the business sector. In contrast, these decisions have found an echo among the minorities, the working class, and the disgruntled middle class.

The argument of those who are against the decisions of the Constitutional Court is that they generate macroeconomic instability and that they are both costly and inefficient. Co-Directors of the Bank of the Republic, such as Salomon Kalmanovitz (2001) and Sergio Clavijo (2001), have advocated that economic principles such as scarce resources, budget restrictions, normative restriction, transparence, and supply and demand should determine the allocation of social resources. In this regard, Kalmanovitz demands that the Constitutional Court assume

fiscal responsabilities when it is deciding about the services of the Colombian state, of which it is a key part, and whose viability it should defend. It should recognize that there are budget restrictions and that the assignment of spending should be rationalized, which leads to greater justice in distribution (Kalmanovitz, 2001: 158). 
The authors mentioned have criticized the Constitutional Court for recognizing social benefits for specific persons, in order to preserve the abstract equality of a generic right of citizenship, as if this were not made concrete in the demand for real economic and social rights. Many economists' criticisms of the Constitutional Court have to do with the decisions that go against the above-mentioned principles. In this respect, Sergio Clavijo complains that

the basic task of economic and social development in Colombia is seriously threatened due to the so-called 'juridical instability', aggravated now by the activism of the Constitutional Court, particularly during the 1994-2000 period. In fact, the Constitutional Court decided to alter the interpretation of the laws sanctioned years before and to accomodate principles of a populist nature to diverse articles of the Constitution of 1991, understood as those that order increased public spending without considering the negative macroeconomic effects. In this sense, it is not surprising that the main state unions and political parties with populist inclination have supported the decisions of the court that imply greater public spending. These decisions will impede adequate re-dimensioning of the Colombian state, while they seriously debilitate the separation of powers through which the ordering of public spending was delegated in the congress. (Clavijo, 2001: ix-x).

Nevertheless, the technical dressing assumed in the neoliberal economists' critiques fails to conceal the ideological nature of the debate between the defenders of each of the two different societal projects. This is seen not only in the term "populist" that Clavijo uses to describe Constitutional Court decisions, but also in demands that the Court be modified to make it more "pluralistic". In this sense, one critic considers that

the Court requires a better process for selecting its members and their ways of making decisions. It would be advisable to have a more interdisciplinary and pluralistic membership (which is clearly not the case today due to [the presence of] so many laborists and socialdemocrats) (Revista Dinero, November 10, 2000: 120. Emphasis added).

On the other hand, E. Sarmiento, an economist who is one of the most outspoken critics of the neoliberalisml, comes to the defense of the Constitutional Court in affirming that 
it is not that the justices interfere with the dictates of the economic model, but that the economic model interferes with the Constitution. A retrospective glance is enough to see that the Court's most controversial decisions have been oriented to avoiding further aggravation of the inequitable effect of the present model. The use of fiscal resources to compensate for losses in the financial sector was rejected, the mortgage system that expropriated the homes of a broad range of Colombians was declared unconstitutional, the Bank of the Republic's practice of lowering inflation at the cost of unemployment was severely criticized and now the economic adjustment based on salary repression is denied. (El Espectador, October 29, 2000).

The high-ranking officials of the government and the Bank of the Republic do not take into account the fact that the Constitution of ' 91 took up the principles of distributive justice, which are based on allocation criteria that are not economic but extra-economic, i.e. political, as opposed to the principles of commutative justice, which are proper to the market. This, of course, affected public spending, but that is the consequence of a collective foundational decision, in which the criteria and the priorities to be applied in allocating social resources were decided politically. Macroeconomic stability is a basic condition for the growth of the economy, but it should not be allowed to obstruct society's political agreements, if it is to be democratized by providing effective access to the basic benefits of socioeconomic development to the entire population.

Therefore, the Constitution of 1991 asigned the Constitutional Court the function of overseeing the decisions of both the government and the central bank, especially in social, salary, monetary, fiscal, and currency exchange matters, to ensure that they adhere to the underlying principles of the new political pact. For this reason, the decisions of the Constitutional Court transcend the juridical sphere, they surpass the 
logic of the market, and they have political and economic effects since, by recognizing or assigning rights from a social democratic perspective, they alter the previous balance of power. Thus it has been understood by the Constitutional Court which, through one of the justices, has said that

the country has not yet understood the function of a constitutional tribunal. The Court's decisions have not yet been assimilated sufficiently: decisions that have been made in law but which necessarily have political and economic consequences. And this does not mean that we the judges or justices of the Court are usurping the functions of any other entity, but rather that our function necessarily has consequences of this type. It is said that the Court should not interfere in economic matters. But the fact is that economic legislation is not removed from the control that the Court must exercise over all laws, regardless of the topic they relate to. The decision, of course, produces economic effects. And at times these economic effects can cause problems. (Gaviria and Uprimny, 2000: 10).

\subsection{The Agreement with the IMF and the Dismounting of the Constitutional Sources of Social Public Spending}

As mentioned, the Constitution of ' 91 increased public spending, especially that of a social nature in education and health, by means of strengthening political, administrative, and fiscal decentralization. Fiscal decentralization began in Colombia in 1983, through modernization of the municipal tax system and the increase of transfers of resources from the central government to local governments, since the municipalities had either lacked resources entirely or had only scarce resources until that year, a situation that did not allow local governments to adequately attend the needs of the community. Political decentralization began in 1986, with the popular election of mayors, who had been appointed by governors until that year, who, in turn, were appointed by the president. The Constitution of 1991 introduced the popular election of governors and permitted community participation in the management of municipal affairs through the election of Local Administrative Boards. Administrative 
decentralization also began in 1986 with the transfer to local governments of a large number of functions that had previously been the responsibility of the central government. These covered a variety of different fields such as the construction and endowment of schools, contracting and payment of teachers, construction and endowment of hospitals, construction of roads, aqueducts and sewerage systems, basic environmental improvement, agricultural technical assistance, elaboration of economic and social development plans at the local level, etc. However, the great problems with decentralization were the insufficient resources, the local governments' lack of technical and administrative capacity, and the low level of social participation. (Orjuela, 1992). For this reason, the Constitutional Assembly of 1991 proposed improving the decentralization process through increased fiscal resources so that the departments and municipalities could extend the coverage of education and health services, and through political participation at the local level. This was intended to increase the legitimacy of the state, by facing the country's enormous inequalities and the need to deepen democracy, especially at the local level. Generally speaking, from the perspective of relations among the three levels of government, it can be said that the constitution propitiates a process of redistributing powers, functions and resources of the central government, in favor of greater autonomy and leadership for the departments and municipalities and more direct community participation in the allocation of resources and management of local public affairs.

To achieve this purpose, the Constitution of ' 91 , in articles 356 and 357 , established a series of transfers of resources from the national budget to the departments 
and municipalities to finance the provision of education and health services, especially for the poorest sectors of the population. At present, this transfers represent $46.5 \%$ of the nation's current income. Due to this constitutional obligation, social public spending increased from $8.2 \%$ of the GDP in 1990 to $14.4 \%$ in 1998 ; i.e., 6.2 percentage points, a figure that slightly surpasses the growth of total public spending (National Planning Department, 2000). This increased social public spending made it possible to extend the coverage of education and health services, as a result of which the former rose from $68 \%$ in 1993 to $80 \%$ in 1997 , and the latter increased from $24 \%$ to $55 \%$ in the same period, and to $65 \%$ in 1999 (DNP - PNUD, 2000). Coverage of water and sewerage services also increased. As a result, the population with unsatisfied basic needs was notably reduced from $37 \%$ in 1993 to $26 \%$ in 1999 (lbidem).

\section{Graph 6 \\ Reduction in Unsatisfied Basic Needs (\%)}

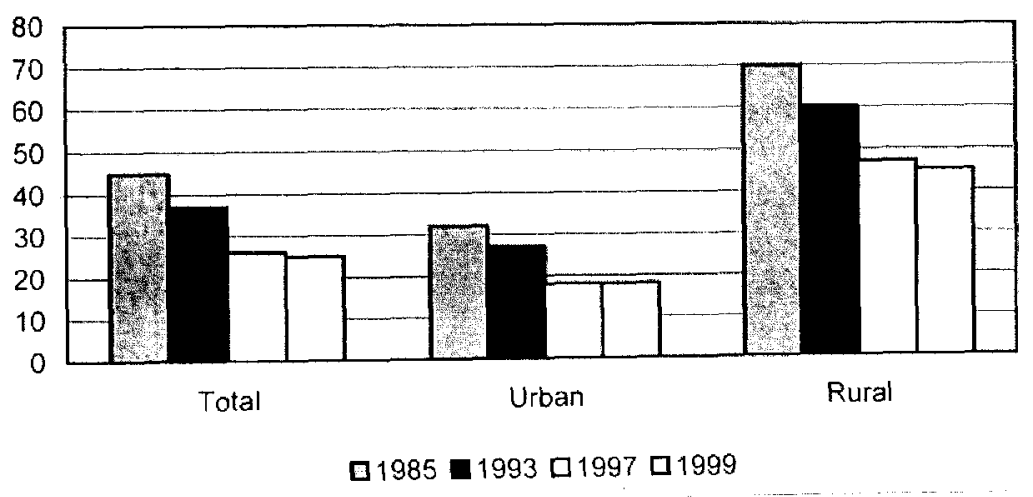

Source: DNP 
Despite the above-mentioned advances, the decision makers on the government's economic team considered that articles 356 and 357 of the Constitution, which permitted financing progress in social matters, constituted "a true drain on public finances" (Ministerio de Hacienda, 2000) and one of the main causes of the state's fiscal deficit, which is $5 \%$ of the GDP today. Therefore, one of the points of the fiscal adjustment agreement that the Pastrana government (1998-2002) signed with the International Monetary Fund in 2000 was the reduction and rationalization of the abovementioned transfers to the departments and municipalities (Banco de la República Ministerio de Hacienda, 1999). For this purpose, the government presented a bill to reform the Constitution, Legislative Act 012, which was approved by the Congress in August 2001. This reform generated a series of protests on the part of mayors, governors, the teachers' union (FECODE) and students. But despite the protests and the regressive nature of the reform, it was approved by the Congress, due to the fact that the national government resorted to the traditional practice of distributing "parliamentary aids, i.e., money from the national budget given by the government to the politicians to "invest" in their own regions in exchange for their approval of the government's proposals.

Given that the Constitution linked those transfers to the growth of the Cnetral Government's current revenues (consisting of tributary and non-tributary revenue, except for capital resources), the reform consisted of unlinking them from that parameter and linking them to the annual increase in inflation over a 7 -year period, with which a significantly lower increase of transfers is achieved. 
With the above-mentioned reform, the Central Government sought to reduce the fiscal deficit by saving 7 billion pesos and, at the same time, recovering the flexibility of its revenues since the old scheme of calculating the transfers limited the national government's possibilities of obtaining fiscal resources through a profound tax reform, since almost half of the resources obtained this way would have to be transferred to the departments and municipalities. However, the transfers could not be blamed for the increase in the fiscal deficit since the national government's effective spending increased by $8.3 \%$ of the GDP between 1990 and 1999 , while transfers to departments and municipalities represented only $2.2 \%$ of that increase. The remaining $6.1 \%$ was due to the growth of foreign debt servicing, which amounted to more than $40 \%$ of the national budget in 2001, and to the increased operating expenses of the central government (Contraloría General de la Republica, 2001). Therefore, the transfers do not represent even one third of the fiscal deficit, so the argument that they caused the imbalance in the state's finances is not well founded.

The constitutional reform of the transfers not only has quantitive effects, in producing a decrease of 7 billion pesos in financing for social policy, but qualitative effects as well, to the extent the future growth of the economy and state income will not translate into significant increases of resources for social policy in the regions and municipalities, as established by the progressive social forces that approved the Political Constitution of 1991. The reform of the transfers will slow down the growth of the education and health sectors, since the reform was conceived in such a way that, 
according to the experts, the growth of transfers will be inversely proportional to the growth of the economy, i.e., the greater the growth of the economy, the smaller the increase of the transfers. According to Jaramillo (2001: 7), it is not true that the reform is only for seven years, as "the government sold the idea", for this would be unacceptable to the IMF. The design of the legislative act will make it possible for the transfers to be linked to the Central Government's current revenues once again in 2008, but percent-wise these transfers will no longer be $46.5 \%$ of the Central state's current revenues, but only $36 \%$ or even as low as $30 \%$, so that even if economic growth improves, the percentage of income transferred to departments and municipalities will be lower. As a consequence of that reform, at the end of the seven years, there will be a reduction of around 870,000 places for students in primary education, and 1.9 million impoverished Colombians will have no access to public health care. (Jaramillo, 2001: 7).

In synthesis, what the confrontation between the neoliberal and the socialdemocrat societal projects are showing is that no fundamental agreement exists regarding the essential elements of the social order in Colombia, nor about whether the assignment of freedoms, goods, and social opportunities should be done on the basis of political criteria and legal norms, or on the basis of the laws of the market and the principles of economic science. 


\section{Chapter 7}

\section{Conclusions with Some Hints for Latin America}

In these pages I have proposed to characterize the present Colombian situation as a crisis of political and social integration. In order to surpass the actor-centered focuses that have prevailed in contemporary political science, especially in the United States, I have established a structural relationship among three dimensions that I consider fundamental: a) the weakness of the state; b) the tensions between the tendencies toward integration and disintegration of society; c) the tensions and contradicition between political and social democratization which is inclusionary, and the neoliberal economic adjustment model which is exclusionary.

Likewise, I have proposed to go beyond the minimalistic and procedural concepts of democracy that predominate in political science and reduce its conception and practice to purely electoral and representative aspects. Nevertheless, beyond the technical problems posed by the election of those who are to govern lie the problems that constitute the essence of politics: collective and public deliberation regarding the distribution of resources, freedoms and social opportunities. The traditional concepts of democracy leave its social and economic dimensions aside precisely at the moment in which neoliberal economic restructuring has transferred the function of distributing social resources from the state to the market and limited the state's possibilities of producing a more egalitarian social order in societies like those of Latin America which are characterized by a high degree of concentration of income and wealth. 
For analytical purposes, I have defined society as an ensemble of social interactions resulting from the permanent tension between cooperation and conflict. For this reason, all societies present a tendency to a certain degree of disintegration, so that it is never possible to consider society as absolutely integrated. The integration crisis presents itself when profound social changes distort the relations among the different spheres that constitute the societal pattern (politics, economics, and culture), in such a way that the inter-systemic coordination of society, and the relations among the different social actors become difficult or even impossible. Based on the concept of societal pattern, I have attempted to express the mutual determination of politics, culture, and economics in the constitution of social relations and institutions. This focus is intended to provide an alternative to focuses based on the actor and its agency, that predominate today in the social sciences and neglect the structural aspects of social phenomena and unsought effects of individual decisions.

On the basis of said framework, I have shown that the crisis which Colombian society has suffered during the past ten years is a result of the convergence of tendencies toward political and social disintegration. The former were expressed, in the first place, in the violence which is the manifestation of a state that has not yet completed its formative process, and that has a limited capacity to regulate social relations, institutionalize conflicts, integrate the nation's territory, and distribute its social resources. Secondly, in the exacerbation of clientelism and the persistence of traditional forms of social relationships, which make the transition from a type of conduct guided by personal loyalties and inclinations to one prescribed by general and impersonal norms 
very difficult. The social integration crisis is expressed in the ruling classes' inability to elaborate and agree upon a societal project broad enough to articulate diverse social interests; in social exclusion, in the fragility of the social fabric, and in the degradation of the ways of assuming conflict, diversity, and disagreement.

This two-fold integration crisis worsened in the nineties due to the confrontation between two different societal projects: that which arose from the Constitution of 1991 , and that which arose from the neoliberal economic development strategy. Whereas the former was promoted by the progressive forces in the Constitutional Assembly, the latter has been promoted by the forces of globalization and by a new domestic technocratic elite. These two projects have advanced in parallel form since 1991, and neither one has achieved enough of a consensus to impose itself. In the initial euforia of democratization caused by the Constitutional Assembly, Colombian society did not realize that there were great contradictions between these two projects, and that they affected the possibilities of achieving an agreement regarding the fundamental elements of the social order and the criteria for the distribution of social resources.

The neoliberal model has advocated the development of a market logic in the allocation of resources and the insertion of the economy in the world market, all of which is reinforced by the imperatives of the globalization process, and has implied a loss of sovereignty and autonomy of the state in favor of the supranational regulatory agencies. However, adoption of the neoliberal strategy has sharpened the social fragmentation by introducing market mechanisms in a society like that of Colombian, 
characterized by a lack of territorial integration which, in turn, has prevented the full constitution of a national market, and by strong tendencies of social exclusion that have not permitted complete constitution of the social actors as "consumers and citizens".

The economic model has also led to a division among the economic elites, and it is exclusionary in nature due, among other things, to cuts in public social spending and state subsidies, and to the generation of unemployment. These elements have limited the elites' possibilities of forming alliances among themselves and with other social sectors, for the purpose of constructing new rules of the game to regulate social relations democratically.

The situation described above aggravated the old division of the country's ruling class, which had been split since the sixties into a political elite and an economic elite, with opposing interests. This in turn led to a fragmentation of state institutions: while the political elite expressed itself through the congress and the non-technical institutions, the economic elite did so through the technical institutions responsible for designing economic policy. The Constitution of 1991 also contributed to sharpening the political and social fragmentation, in altering the balance between the three branches of government, atomizing the system of parties and representation, and introducing nonmarket criteria in the allocation of social resources, which were in contradiction with those established by the neoliberal reforms, 
The way in which the neoliberal development strategy was adopted in Colombia contributed to generating a severe economic recession and a high degree of social exclusion. And for this reason, it entered into contradiction with the advances in matters of political and social democratization produced by the Constitution of 1991. The adoption of the neoliberal model was done behind society's back and behind the back of the political institutions that articulate and aggregate interests, a fact which demonstrated the growing divorce between the mechanisms for the generation of consensus and legitimacy and the mechanisms for the formation and implementation of macroeconomic policies. Consequently, in excluding participation from the sphere of macroeconomic policy, which is precisely where the foundations can be laid for a society that is not only democratic but a just society as well, the path was opened in Latin America in general, and in Colombia in particular, to a type of legitimacy of a technocratic and efficiencyfocused nature that is displacing political legitimacy. Nonetheless, the fact that it has not been possible to achieve ample participation in the formulation of macroeconomic policies is also due to the fragmentation and weakness of the progressive forces and the lack of representativeness of the traditional Liberal and Conservative parties.

In synthesis, in Colombia, in the past decade, all of the factors mentioned above converged to produce an inconclusive process of economic modernization, but without political modernity, expressed in an ambiguous attitude on the part of society with respect to democracy, a lack of interconnection between politics, the economy, ethics and culture, and a relative and very partial social integration that generates, in itself, the social conditions for its own undoing. 
The focus developed in this dissertation for the Colombian case can be applied to the analysis of other Latin American societies. The adoption of neoliberal restructuring processes throughout the region, and their convergence with the democratization process, have given way to contradictions between inclusion and exclusion, and are sharpening the fragmentation and the heterogeneity of Latin American societies. Albert Hirshman said, over a decade ago, "never has Latin America been lectured and advised as insistently as in the last few years on the virtues of the free market, privatization, and foreign private investment" (1987: 30-31), and never, for the same reason, had Latin America ever suffered such an economic and social crisis as the one it is suffering now. At the beginning of the nineties, Washington Consensus' recipes predicted growth rates of between $4 \%$ and $6 \%$ for the economies of the region. After twelve years of severe fiscal, monetary and currency exchange adjustments, the situation could not be worse: in 2001 Latin America barely grew $0.5 \%$ and the prognostic for this year is $0.7 \%$. Even Chile, which had been presented as the ideal model of a market economy, has not grown since 1996. The free market also promised to rescue the region from underdevelopment and poverty. However, the number of the poor has grrown to over 210 million, increasing by one million each year, and 87 million are indigent (IDB, 1999). Of the 44 million people in the region that were incorporated into the labor force in the past ten years, 20 million are employed in the informal sector or are underemployed and 10 million are unemployed. This social regression is the region is further aggravated by the fact that the foreign debt grew from 450,000 million dollars to 740,000 million dollars in the course of the past decade. 
Most Latin American countries have very large deficits in their balance of payment current accounts, which limit their possibilities of growth and threaten financial and currency exchange stability. This is aggravated by the effect of the "interconnectedness" of globalization, in virtue of which the enormous current account deficits of the Asian countries implied strong devaluation and a sharp fall in the prices of basic products. In 1998 Colombia registered deficits equivalent to $6 \%$ of the GDP, Brazil had a deficit of $4.5 \%$, and Argentina and Mexico had deficits of $3 \%$. In this field, the most illustrative case is, again, Chile, which has been presented as the model to follow, and now faces current account deficits of $6 \%$ of its GDP (Cepal, 2001).

In synthesis, the region's economies have been exposed to structural balance of payments deficits which increase with economic growth and their correction is subject to substantial devaluations that imply a fall in real salaries. All of the above makes it possible to question those analysts who, despite the evidence, considered that "the politics of economic adjustment" was undergoing a series of stages characterized as periods of "crisis, painful measures, monetary stability, recovery (stability and some growth); investment and sustainable growth" (Acuña and Smith, 1994, Joan Nelson). In even the best of cases, this scheme may have only precarious validity in terms of reducing inflation in Latin American countries.

The social deterioration and economic imbalances described above have led in many countries of the region to an increase in the fragmentation and anomie that are 
characteristic of Latin American societies. Mexico is divided is split into two societies: the modern and prosperous society of the NAFTA and the premodern, indigenous, poor society of the Zapatista Movement; Venezuela is politically and socially polarized around the figure of Chávez; Ecuador faced a profound political destabilization that led to the overthrow of two presidents following strong protests and social uprisings; Peru also overthrew a president but did not manage to overcome the high poverty levels of the population. Argentina is the last country in the region to explode socially and economically, with sharp manifestation of social anomie.

The crisis in which most Latin American countries find themselves immersed today has unleashed a wave of criticism against the International Monetary Fund and the World Bank. This comes not only from the transnational anti-globalization movements but from the Congress of the United States and from the Nobel Prize winner in economics and former vice-president of the World Bank, Joseph Stiglitz, as well. Stiglitz not only questions the International Monetary Fund's technical capability and knowledge of Third World reality, but its role in the deterioration of democracy as well. According to Stiglitz,

in theory, the Fund supports democratic institutions in nations it attends. In practice, it undermines the democratic process through the imposition of policies. Officially, of course, the $\mathrm{MF}$ imposes nothing. It simply 'negotiates' the conditions for receiving aid. But all the power is on one side in the negotiations -that of the IMF- and the IMF rarely concedes enough time to achieve an ample consensus or even extensive consultations with the congress or civil society. At times the IMF dispenses with pretending to be totally transparent and negotiates secret pacts. (2001:2). 
The Meltzer Commission expressed itself along the same lines in its report to the Congress of the United States which pointed out that the actions of the IMF not only did not bring about economic development in the countries that signed agreements with it, but that its programs actually impoverished the nations that received its aid, and its influence in domestic policy in fact undermined national sovereignty and often negatively affected the development of democratic institutions in the countries that applied its economic recipes (Anif, 2002: 7). In addition to these criticisms, some voices have been raised in favor of reconsidering development theory, the problems of poverty in the Third World, and the inclusion of greater concern for political institutions, cultural aspects, and social cohesion (Birdall and Londoño; Naim, 1999). However, this has not sufficed to change the formula, to judge by the IMF's demands of Argentina following the recent debacle. To these exogenous factors must be added other endogenous factors characteristic of Latin America such as economic and social inequality, clientelism and comuption, drug trafficking and violence. The region's economic calamity is due as much to these factors as to the international financial agencies' refusal to accept the lack of realism of its diagnoses and the error of their economic policy demands. Despite the clear evidence that the reforms they demand have not produced the expected results, their promoters and defenders justify maintaining them with the argument that protectionism is the worst option.

To the contrary of what some comparative political analysts have attempted to show, what has become clear is that there is no relationship between structural economic 
adjustment and democracy. Instead, there has been a progressive weakening of democracy since the beginnings of the nineties, and not just in Latin America but throughout the rest of the Third World as well, which manifests itself in many ways, among them: the loss of sovereignty of states in favor of supranational institutions that act without democratic control. The growing freedom of action that transnational and financial firms have acquired, the transnationalization of culture that homogenizes and dissolves all possibility of cultural and ideological diversity, the technocratization of political life and the corresponding generalization of a discourse on economics and political economy that defines them as spheres in which citizens' participation and political and ideological debate have no place. All of this is a clear expression of the fact that "neoliberal politics" has brought with it less democracy, reduced the decisionmaking capacity of citizens, and sharply limited the power of the least advantaged sectors of the population to influence the course of social affairs.

Therefore, the decade of the nineties has not only been "another lost decade" for Latin America, but one of sharpened social and political fragmentation as well. To lay the foundations for a better future, the countries of the region will have to build social and political institutions that promote social cohesion, and economic institutions that promote savings, investment, especially in the development of human capital and scientific and technological development. The historical evidence shows that there are no common recipes nor any one single development model that is equally valid for all who undertake this task. Economic development has taken place in societies with very diverse political and economic institutions. Countries like South Korea and Taiwan are an example of this fact. 
Therefore, counting on a "check list" of reforms, like that of the Washington Consensus, which are expected to be carried out unfailingly simply does not help at all. On the contrary, the reality of the facts and the social analysis suggests that these inadequate theories should be reconsidered and substituted by others that are more representative of the particular realities of diverse societies. It is not a question of switching back from neoliberalism to "cepalism" but rather of designing a model of one's own, that is more adequate and dictated by a long dureé historical perspective and a more structural and systemic focus which overcomes the deficiencies of those based on voluntarism and methodological individualism. Latin America has to construct institutions that are adequate to its historical particularities, the aspirations of its peoples, and the nature of its economic policy.

Institutions matter, of course, but so does the nature of the socioeconomic system in which they are immersed. In societies like those of Latin America, characterized as they are by endemic discrimination and inequality, it is almost impossible to achieve social stability in the long run unless the institutions provide opportunities for participation and decisionmaking capacity to those who have been excluded. Reduction of the undesireable effects of the economic process, such as inequity and poverty, depends on the political power structure within the society. Therefore, economic growth tends to reduce poverty only if the poorest sectors of the population have enough political power and access to education and to decisive institutions to be able to benefit from it. 
Therefore, the analyses traditionally used in comparative politics would do well in attempting to overcome their minimalistic concepts of democracy in order to achieve a better understanding of reality, at least with respect to the Third World countries, since that reality has shown that formal democracy can co-exist with profoundly anti-democratic social and economic practices. Democracy is an integral concept: political, economic, and social. 


\section{Bibliography}

\section{Books and Journals}

Acuña, Carlos H. and Smith, William C. (eds.), 1994a, "The Political Economy of Structural Adjustment: the Logic of Support and Opposition to Neoliberal Reform", in: Smith, William C., Acuña, Carlos H. and Gamarra Eduardo A., Latin American Political Economy in the Age of Neoliberal Reform. Theoretical and Comparative Perspectives of the 1990s, Coral Gable:, North-South Center, University of Miami, p.p. 17-66.

Agüero, Felipe and Stark, Jeffrey, 1998, Fault Lines of Democracy in Post-Transition Latin America, Coral Gable: North-South Center Press, University of Miami.

Ahumada, Consuelo, 1996, El Modelo Neoliberal y su Impacto en la Sociedad Colombiana, Bogotá: El Ancora Editores.

Alesina Alejandro, Kluger Maurice, and Rosental, Howard, 2000, "División de Poderes: una Estimación de la Separación Institucional de los Poderes Públicos en Colombia", Documentos de Trabajo, No. 17, Bogotá: Fedesarrollo.

Anif, 2002, Carta Financiera, No. 121, febrero/abril

Archila, Mauricio, 1995, "Tendencias Recientes de los Movimientos Sociales", in: Leal Buitrago, Franciso (comp.), En Busca de la Estabilidad Perdida. Actores Politicos y Sociales en los Años Noventa, Bogotá: Tercer Mundo Editores- IEPRI_Colciencias, p.p. 252-301

Archila, Mauricio, 1997, "Protesta social y Estado en el Frente Nacional", in: Controversia, No. 170, mayo, 1997, p.p. 9-55

Archila Mauricio, 2000, "Las Luchas Sociales en el Post-Frente Nacional (1975-1990)", in: Controversia, No. 176, abril. 2000, p.p. 9-37

Arenas Monsalve, Gerardo, 1991, "La Reforma Laboral: ¿Un Nuevo Marco Normativo para las Relaciones de trabajo en Colombia?", in: Politeia, No. 8, 1991, p.p. 95-102

Axelrod, Robert M., 1984, The Evolution of Social Cooperation, New York: Basic Books.

Baco de la República - Ministerio de Hacienda y Crédito Público, 1999, Acuerdo Extendido de Colombia con el Fondo Monetario Internacional, Bogotá. 
Barco, Virgilio, 1989, Realizaciones del Programa de Cambio: El Gobierno Cumple con Colombia. Informe del Presidente de la República, Virgilio Barco, al Congreso Nacional, Bogotá: Presidencia de la República.

Bates, Robert H. and Krueger, Anne O. (eds.), 1993, Political and Economic Interactions in Economic Policy Reform: Evidence from Eight Countries, Cambridge, Mass.: Basil Blackwell.

Bejarano Ana María, 1990, "Estrategias de Paz y Apertura Democrática: un Balance de las Administraciones Betancur y Barco", in: Leal Buitrago, Francisco y Zamosc León, 1990, Al Filo del Caos. Crisis Politica en Colombia en los Años Ochenta, Bogotá: Tercer Mundo Editores/Instituto de Estudios Políticos y Relaciones Internacionales, Universidad Nacional, p.p. 57-124

Bejarano, Ana María, 1994, "Recuperar el Estado para Fortalecer La Democracia", in: Análisis Político, No, 22, mayo-agosto, 1994, p.p. 47-79

Bejarano, Ana María y Segura, Renata, 1996, "El Fortalecimiento Selectivo del estado Durante el Frente Nacional, in: Controversia, No. 169, noviembre, 1996, Cinep, Bogotá, p.p. $9-35$

Bejarano, Jesús Antonio, 1985, Economia y Poder, Bogotá: SAC/CEREC

Birsdall, Nancy and Londoño, Juan Luis, "Asset Inequality Matters: An Assessment of the World Bank's Approach to Poverty Reduction", in: AER Papers and Proceedings, Vol. 87, No. 2, May, 1997

Bolivar, Ingrid Johanna, 1999, "Sociedad y Estado: La Configuración del Monopolio de la Violencia", in: Controversia, No. 175, diciembre, 1999, p.p. 11-39

Bresser Pereira, Luiz Carlos, Maravall, Jose María and Przeworki, Adam, 1994, "Economic Reforms in New Democracies: A Social-Democratic Approach", in: Smith, William C., Acuña, Carlos H. and Gamarra Eduardo A., Latin American Political Economy in the Age of Neoliberal Reform. Theoretical and Comparative Perspectives of the 1990s, Coral Gable; North-South Center, University of Miami, 1994, p.p. 181-212

Borón, Atilio, 1995, State, Capitalism and Democracy in Latin America, Boulder: Lynne Rienner.

Borón, Atilio, 1998, "Faulty Democracies? A Reflection on the Capitalists "Fault Lines" in Latin America", in: Agüero, Felipe and Stark, Jeffrey, 1998, Fault Lines of Democracy in Post-Transition Latin America, Coral Gable: North-South Center Press, University of Miami.

Brew, Roger, 1977, El Desarrollo Económico de Antioquia, desde la Independencia hasta 1920, Bogotá: Banco de la República. 
Buzan, Barry, 1991, People, States and Fear. An Agenda for International Security Studies in the Post-Cold War Era, Boulder: Lynne Rienner Publishers.

Calderón, Fernando and Dos Santos, Mario R., 1995, Sociedades sin Atajos. Cultura, Política y Reestructuración Económica en América Latina, Buenos Aires: Ediciones Paidós.

Cavarozzi, Marcelo, 1992, "Beyond Transitions to Democracy in Latin America", in: Journal of Latin American Studies, Vol 24, No. 2.

Centeno, Miguel Angel, and Silva Patricio (editors), 1998, The Politics of Expertise in Latin America, Amsterdam: Centrum voor Studie en Documentatie van Latijns Amerika / Palgave Macmillan

Cepal, 1990, Transformación Productiva con Equidad. La Tarea Prioritaria del Desarrollo en América Latina y el Caribe en los Años Noventa, Santiago: Cepal.

Cepal, 1994, Panorama Social de América Latina, Santiago: Cepal

Cepeda, Fernando, 1977, Debate sobre la Constituyente, Bogotá: Universidad de los Andes.

Cepeda, Fernando, 1994, Dirección Política de la Reforma Económica en Colombia, Bogotá: Fonade - DNP.

Cepeda, Manuel José, 2000, "La Ubicación de la Corte Constitucional en el Sistema Político", in: Jurisdicción Constitucional de Colombia. La Corte Constitucional 19922000. Realidades y Perpectivas, Bogotá: Corte Constitucional / Consejo Superior de la Judicatura / Escuela Judicial Rodrigo Lara Bonilla, Konrad Adenauer Stiftung, 2000

Cifuentes Muñoz, Eduardo, 2000, "Sujetos de Especial Protección en la Constitución Politica de Colombia", in: Jurisdicción Constitucional de Colombia. La Corte Constitucional 1992-2000. Realidades y Perpectivas, Bogotá: Corte Constitucional / Consejo Superior de la Judicatura / Escuela Judicial Rodrigo Lara Bonilla, Konrad Adenauer Stiftung, 2000

Clavijo, Sergio, 2001, Fallos y Fallas de la Corte Constitucional, Bogotá: Alfaomega / Cambio.

Cohen, Youssef, 1994, Radicals, Reformers, and Reactionaries. The Prisoners's Dilemma and the Collapse of Democracy in Latin America. Chicago: The University of Chicago Press.

Collier, David and Levitsky, Steven, 1997, "Democracy with Adjectives. Conceptual Innovation in Comparative Research" in: World Politics, Vol. 49, No. 3, April 1997 
Colombia: Descentralización y Federalismo Fiscal. Informe Final de la Misión, 1992, Bogotá: Presidencia de la República / Departamento Nacional de Planeación.

Commission on Global Governance, 1995, Our Global Neighbourhood: The Report of the Commission of Global Governanace, Oxford: Oxford University Press.

Conaghan, Catherine and Malloy, James M., 1994, Unsettling Statecraft. Democracy and Neoliberalism in the Central Andes, Pittsburgh: Pittsburgh University Press.

Confecámaras, Fundación Corona, Cipe, 2000, Probidad: La Lucha Anticorrupción de los Empresarios en los Negocios con el Estado, Bogotá: Confecámaras, documentos de coyuntura No. 5

Conpes - DNP, 1990, Programa de Modernización de la Economía Colombiana, Bogotá: Departamento Nacional de Planeación, Documento 2465J

Contraloría General de la República, 1996, Informe Financiero, Diciembre

Contraloría General de la República, 1999, La Recuperación de la Confianza. Infrome del Contralor General Carlos Ossa Escobar al Congreso y al Presidente de la República, Bogotá: Contraloría General.

Contraloria General de la República, 2001, Informe Financiero, Marzo.

Cordera, Rolando, 1996, "Nuevas Reformas y Funciones del Estado en América Latina", en: Loaeza, Soledad (comp.), 1996, La Reforma del Estado y la Democracia en América Latina, México: El Colegio de México.

Cordi Galat, Angela, 1998, "El Tamaño del Estado Colombiano. Indicadores y Tendencias, 1973-1995", in: DNP, Planeación y Desarrollo, Vol. XXIX, No. 3, julioseptiembre, 1998

Coser, Lewis, 1964, The Functions of Social Conflict, New York: Free Press.

Cox, Robert W., 1987, Production, Power and World Order: Social Forces in the Making of History, New York: Columbia University Press.

Crozier, Michel, Huntington, Samuel and Watanuki, Joji, 1975, The Crisis of Democracy. Report on the Governability of Democracies to the Trilateral Comission, New York: New York University Press.

Dahl, Robert, 1971, Polyarchy. Participation and Opposition, New Haven

Dahl, Robert, 1989, Democracy and its Critics, New Haven 
Dahrendorf, Ralf, 1972, Class and Class Conflict in Industrial Society, London: Routledge and Kegan Paul.

Departamento Nacional de Planeación, 1981, Finanzas Intergubernamentales en Colombia. Informe Final de la Misión, Bogotá.

Departamento Nacional de Planeación, 2000, Coyuntura Económica e Indicadores Sociales, Boletín No. 26, Julio, Bogotá: SISD.

DNP (Departamento Nacional de Planeación) - PNUD (Programa de las Naciones Unidas para el Dedsarrollo), 2000, Informe de Desarrollo Humano para Colombia, Bogotá: Tercer Mundo Editores.

Diamond, Larry; Linz, Juan and Lipset, Martyn Seymour, 1989, Democracy in Developing Countries: Latin America, Boulder: Lynne Rienner.

Diamond, Larry; Linz, Juan and Lipset, Martyn Seymour, 1995, Politics in Developing Countries: Comparing Experiences with Democracy, Boulder: Lynne Rienner.

Dugas, John, 1993, La Constitución de 1991: Un Pacto Politico Viable ?, Bogotá: Departamento de Ciencia Política, Universidad de los Andes.

Dugas, John; Ocampo, Angelica; Orjuela Luis Javier and Ruiz, German, 1992, Los Caminos de la Descentralización: Diversidad y Retos de la Transformación Municipal, Bogotá: Universidad de los Andes.

Echandia Castilla, Camilo, 1999, El Conflicto Armado y la Manifestaciones de Violencia en las Regiones de Colombia, Bogotá: Presidencia de la Reública de Colombia, Oficina del Alto Comisionado para la Paz, Observatorio de Violencia.

Echavarría, Juan José, 2000, "Neoliberalismo y Reformas Estructurales en el Trópico", in: Coyuntura Económica, Septiembre 2000

Edwards, Sebastian, 1998, "Openness, Productivity and Growth: What Do We Really Know?, in: Economic Journal, No. 108, March, 1998, p.p. 383-398

Elias, Norbert, 1987, El Proceso de la Civilización: Investigaciones Sociogenéticas y Psicogenéticas, Mexico: Fondo de Cultura Económica.

Elias, Norbert, 1998, "Los Procesos de Formación del Estado y de Construcción de la Nación", in: Revista Historia y Sociedad, No. 5, Diciembre, 1998

Elster, Jon, 1992, El Cemento de la Sociedad: Las Paradojas del Orden Social, Barcelona: Gedisa. 
Escallón Nuñez, María del Pilar, 1998, Acceso a la Justicia: Politicas Estatales y Estudios Académicos Durante los Años Ochenta y Noventa, Tesis de Grado, Bogotá: Uni Versidad de los Andes, Facultad de Derecho.

Escobar Tello, María Paula, 1995, Fedecafé y Estado: Historia, Coyuntura y Transformación de una Relación Paraestatal, Tesis de Grado, Bogotá: Universidad de los Andes, Facultad de Ciencias Sociales, Departamento de Ciencia Politica.

Evans, Peter, 1992, "El estado Como Problema y Como Solución: Rapacidad, Autonomía Contextualizada y Cambio Estructural", en: Haggard, Stephan y Kaufman, Robert (comps.)1992, La Politica de Ajuste Económico. Las Restricciones Internacionales, los Conflictos Distributivos y El Estado, Bogotá: Cerec, p.p. 175-225

Evans, Peter, 1995, Embedded Autonomy: States and Industrial Transformation, Princeton: Princeton University Press.

Evans, Peter; Reuschemeyer, Dietrich and Skocpol, Theda (eds), 1985, Bringing the State Back In, Cambridge: Cambridge University Press.

Falk, Richard, 1995, On Humane Governance: Toward a New Global Politics, Pennsylvania: Pennsylvania University Press.

Fals Borda, Orlando, 1991, "La Accidentada Marcha hacia La Democracia Participativa en Colombia", in: Análisis Político, No. 14, 1991

Fanelli, Jose Maria; Frenkel Roberto and Rozenwurzel, Guillermo, 1994, "Growth and Structural Reform in Latin America; Were We Stand ?", in: Smith, William, Carlos H. and Gamarra Eduardo A., Latin American Political Economy in the Age of Neoliberal Reform. Theoretical and Comparative Perspectives of the 1990s, Coral Gable: NorthSouth Center, University of Miami.

Fedesarrollo and Instituto Ser de Investigación, 1992, Revista Coyuntura Social, Julio, No. 6 .

Finanzas Intergubernamentales en Colombia. Informe Final de la Misión, 1981, Bogotá: Departamento Nacional de Planeación.

Flórez, Luis Bernardo, 2001a, "Colombia tras Diez Años de Reformas Políticas Económicas", in: Cuadrenos de Economia, No. 34, 2001, p.p. 31-55

Flórez, Luis Bernando, 2001b, "Tendencias del Ahorro, la I)nversión y el Crecimiento en Colombia", in: Misas Arango, Gabriel, 2001; Desarrollo Económico y Social en Colombia. Siglo XX, Bogotá: Universidad Nacional de Colombia, p.p. 147-201

Fraser Institute, 2002, Economic Freedom of the World: 2002 Annual Report, in: http://www.fraserinstitute.org 
Friedman, Milton, 1982, Capitalism and Freedom, Chicago: University of Chicago Press.

Frühling, Hugo, 1998, "Judicial Reform and Democratization in Latin América", en: Agüero, Felipe and Stark, Jeffrey, 1998, Fault Lines of Democracy in Post-Transition Latin America, Coral Gables: North-South Center Press at the University of Maimi.

Fukuyana, Francis, 1995, Trust: The Social Virtues and the Creation of Proeperity, New York: The Free Press.

Gaitán, Fernando, 1995, "Una Indagación sobre las Causas de la Violencia en Colombia", in: Dos Ensayos sobre la Violencia en Colombia, Bogotá: Fonade/DNP, 1995.

Galtung, Fredrik, and Pope, Jeremy, 1999, "The Global Coalition Against Corruptión: Evaluating Transparency International", in: Schedler, Andreas, Diamond, Lary, and Plattner, Marc, 1991, The Self-Restraining State. Power and Accountability in New Democracies, Boulder, Co.: Lynne Rienner Publishers.

Gallón, Gustavo, 1982, "Concertación Simple y Concertación Ampliada" in: Controversia, No. 105, Bogotá: Cinep

Gamarra, Eduardo A., 1994, "Market Oriented Reforms and Democratization in Latin America: Challenges of the 1990s" in: Smith, William, Carlos H. and Gamarra Eduardo A., Latin American Political Economy in the Age of Neoliberal Reform. Theoretical and Comparative Perspectives of the 1990s, Coral Gable: University Of Miami, North-South Center.

Garay, Luis Jorge, 1998, Colombia: Estructura Industrial e Internacionalización 19671996, Bogotá: DNP-Colciencias-CEC-Mincomex-Minhacienda-Procxport.

Garay, Luis Jorge, 1999, Globalización y Crisis ¿Hegemonía o Corresponsabilidad?, Bogotá: Tercer Mundo Editores / Colciencias.

Gargarella, Roberto, 1997, "Recientes Reformas Cosntitucionales en América Latina: Una Primera Aproximación", en: Desarrollo Económico, Vol. 36, No. 144, eneromarzo, 1997

Geddes, Barbara, 1994, Politician's Dilemma: Building State Capacity in Latin America, Berkeley: Universitiy of California Press.

Gedded, Barbara, 1995, "The Politics of Economic Liberalization”, in: Latin American Research Review, vol. 30, No.2, 1995, pp. 195-214 
Giddens, Anthony, 1984, The Constitution of Society: Outline of the Theory of Structuration, Berkeley: University of California Press.

Giddens, Anthony, 1993, Consecuencias de la Modernidad, Madrid: Alianza.

Giddens, Anthony, 1997, La Nuevas Reglas del Método Sociológico: Crítica Positiva de las Sociologías Comprensivas, Buenos Aires: Amorrortu.

Giraldo Angel, Jaime, 1993, "La refroma Constitucional de la Justicia", in: Dugas, John, 1993, La Constitución de 1991: Un Pacto Político Viable?, Bogotá: Departamento de Ciencia Política, Universidad de los Andes.

Giraldo Angel, Jaime, 1996, "El Fracaso de la Reforma Constitucional de la Justica", in: Coyuntura Social, No. 15, Noviembre, 1996, p.p. 103-117

Giraldo Samper Marcela, 1993, Reportaje a la Economía Colombiana, Bogotá: Ediciones Aurora.

Gold, David, Clarence, Lo and Wright, Erik Olin, 1975, "Some Recent Developments In Marxist Theories of the State", in: Monthly Review, vol. 27, No. 5-6

Gómez Buendia, Hernando, 1976, "Los Grupos Industriales en el Desarrollo Económico: Conjeturas e Interpretaciones", in: Coyuntura Económica, diciembre, 1976, p.p.

Gómez Buendía, Hernando (comp.), 1999, ¿Para Dónde Va Colombia?, Bogotá: Tercer Mundo Editores/Colciencias.

González, Cesar, 1997, "Los Muertos que vos Matáis. . ." in: Poder \& Dinero, No. 50, Septiembre de 1997, p.p. $75-76$

González, Fernán, 1993, "Tradición y Modernidad en la Política Colombiana", in: Delgado, Oscar, et. al., 1993, Modernidad, Democracia y Partidos Políticos, Bogotá: Fidec / Fescol.

González, Fernán, 1997, Para Leer la Politica. Ensayos de Historia Política Colombiana, Bogotá: Cinep, dos volúmenes.

González, Jorge Iván, 2000, "Flexibilización Salarial y Politica Monetaria", en Nómada, marzo, 2000

González, Jorge Iván, 2001 "Entre la Sustitución de Importaciones y la Apertura", in: Misas Arango, Gabriel, 2001; Desarrollo Económico y Social en Colombia. Siglo XX, Bogotá: Universidad Nacional de Colombia, p.p. 399-425. 
Gramsci, Antonio, 1971, Selections from the Prison Notebooks, New York: International Publishers.

Habermas, Jürgen, 1987, Teoría de la Acción Comunicativa. Volumen II: Critica de la Razón Funcionalista, Madrid: Taurus.

Habermas, Jürgen, 1989, Problemas de Legitimación del Capitalismo Tardio, Buenos Aires: Amorrortu.

Habermas, Jürgen, 1996, Between Facts and Norms. Contribution to a Discourse Theory of Law and Democracy, Cambridge, Ma.: The MIT Press.

Habermas, Jürgen, 1999, La Inclusión del Otro. Estudios de Teoria Politica, Barcelona: Paidós.

Haggard, Stephan, 1990, Pahtways from the Periphery: The Politics of Growth in the Newly Industrilizing Countries, New York: Cornell University Press.

Haggard, Stephan y Kaufman, Robert (comps.)1992, La Politica de Ajuste Económico. Las Restricciones Internacionales, los Conflictos Distributivos y El Estado, Bogotá: Cerec,

Haggard, Stephan and Kauffman, Robert, 1995, Political Economy of Democratic Transition, Princeton: Princeton University Press.

Hagopian, Francis, 1993, " After Regime Change: Authoritarian Legacies, Political Representation and the Democratic Future of South America", in: World Politics, Vol. 45, No. 3, April 1993.

Hartlynn, Jonathan, 1985, "Producers Associations and Politics in Colombia", in: Latin American Research Review, Vol. 20, No. 3

Hartlynn, Jonathan, 1988, The Politics of the Coalition Rule in Colombia, New York: Cambridge University Press.

Hartlyn, Jonathan, 1989, "Colombia: The Politics of Violence and Accommodation", in: Diamond, Larry, et. al., op cit.

Hegel, Georgwe, W. F., 1955, Filosofia del Derecho, Buenos Aires: Editorial Claridad.

Hirshman, Albert, 1987, "The Political Economy of Latin Américan Development: Seven Exercises in Retrospect", in: Latin American Research Review, No. 22, March, 1987

Hobbes, Thomas, 1987, Leviatan, México: Fondo de Cultura Económica. 
Institut Francaise des Realtions Internationales, 1991, Ramses 92: Rapport Annuel Mondial sur le Systeme Economique et les Strategies, Paris: Dunod.

Instituto Geográfico Agustin Coddazzi, 1996, Diccionario Geográfico de Colombia, Bogotá

James, E, 1996, International Monetary Cooperation since Bretton Woods, New York: Oxford University Press.

Jaramillo Pérez, Ivan, 2001, "Impacto del Acto legislativo 012. Goles a la Política Social", in: UN Periódico, No. 25, Agosto 19, 2001.

Kalmanovitz, Salomón, 2001, Las Instituciones y el Desarrollo Económico en Colombia, Bogotá: Grupo Editorial Norma.

Kymlicka, Will, and Wayne, Norman (eds.), 2000, Citizenship in Diverse Societies, Oxford: Oxford University Press.

Keohane, Robert O. and Nye, Joseph S., 1989, Power and Interdependence, Harper Collins Publishers.

Korzeniewicz, Roberto Patricio and Smith, William C., 1996, Latin America in the World Economy, Coral Gable: North-South Center Press, University of Miami.

Korzeniewicz, Roberto Patricio and Smith, William C., 2000, "Poverty, Inequality, and Growth in Latin America: Searching for the High Road to Globalization", in: Latin America Research Review, Vol. 35, No, 3, 2000.

Leal Buitrago, Francisco, 1977, "La Crisis Politica Colombiana: Alternativas y Frustraciones", in: Analisis Politico, No. 1, mayo-agosto, 1987, p.p. 76-88

Leal Buitrago, Francisco, 1989, Estado y Politica en Colombia, Bogotá: Siglo XXI Editores.

Leal Buitrago, Francisco, y Dávila Ladron de Guevara, Andrés, 1991, Clientelismo: El Sistema Politico y su Expresión Regional, Bogotá: Tercer Mundo Editores/ Instituto de Estudios Políticos y Relaciones Internacionales, Universidad Nacional de Colombia.

Lechner, Norbert, 1982, "El Proyecto Neoconservador y la Democracia", in: Crítica y Utopía, No. 6, 1982

Lechner, Norbert, 1986, La Conflictiva y Nunca Acabada Construcción del Orden Deseado, Madrid: Centro de Investigaciones Sociológicas / Siglo XXI Editores.

Lenin, 1978, El Estado y la Revolución, Moscú: Editorial Progreso. 
Linz, Juan and Stepan, Alfred, 1996, Problems of Democratic Transitions and Consolidation: Southern Europe, South America and Post-Communist Europe, Baltimore: John Hopkins University Press.

Linz, Juan and Valenzuela Arturo, 1994, The Failure of Presidential Democracy, Baltimore: the John Hopkins University Press.

Lipietz, Alain, 1987, Mirages and Miracle: The Crisis of Global Fordism, London: Verso.

Lipset, Seymour Martin, 1959, "Some Social Requisites of Democracy: Economic Development and Political Legitimacy", in: American Political Science Review, No. 53, p.p. $69-105$

Lipset, Seymour Martin, Kyoung-Ryung, Seong, and Torres, John Charles, 1993, "A Comparative Analysis of the Social Requisites of Democracy", in: International Social Science Journal, No. 136,

p.p. $155-175$

Londoño, Juan luis y Székely, 1997, Oersistent Poverty and Excess Inequality: Latin AméricDuring 1970-1995, Washington: BID, 9.

Mainwaring, Scott and Scully, 1995 Timothy (eds.), Building Democratic Institutions, Stanford:

Stanford University Press.

Malloy, James M. and Seligson Mitchel A. (Eds.), 1987, Authoritarians and Democrats: Regime Transitions in Latin America, Pittsburgh: Pittsburgh University Press.

Mann, Michael, 1993, The Sources of Social Power, Cambridge: Cambridge University Press.

Martz, John D., 1997, The Politics of Clientelism: State and Democracy in Colombia, Transactions Publishers.

Marx, Karl, 1987, El Capital Crítica de la Economia Politica, México: Fondo de Cultura Económica.

Marx, Karl, 1973, El Dieciocho Brumario de Luis Bonaparte ,Moscú: Editorial Progreso.

Marx, Karl, 1973, "La Ideología Alemana", en: Karl Marx y Friedrich Engels, 1973, Obras Escogidas, Moscú: Editorial Progreso. 
Mason, Ann, 2001, "La Crisis de Seguridad en Colombia: Causas y Consecuencias Internacionales de un Estado en Via de Fracaso", en: Colombia Internacional, No. 4950 , febrero, 2001 , p.p. $82-102$

Maxfield Sylvia, 1997, Gatekeepers of Growth: The International Political Economy of Central Banking in Developing Countries, Princeton: Princeton University Press.

Maxfield, Sylvia, 1999, "A Brief History of Central Banks Independence in Developing Countries", in: Schedler, Andreas, Diamond Larry, and Plattner, Marc F., 1999, The Self Restraining State, Boulder: Lynne Rienner Publishers.

Maxfield, Sylvia and Schneider, Ben Ross, 1997, Business and the State in Developing Countries, Ithaca: Cornell University Press.

Mettenheim, Kurt, Von and Malloy, James (eds.), 1998, Deepening Democracy in Latin America, Pittsburgh: University of Pittsburgh Press.

Migdal, Joel S., 1988, Strong Societies and Weak States. State-Society Relations and State Capabilities in the Third World, Princeton: Princeton University Press.

Miliband, Ralf, 1970, El Estado en la Sociedad Capitalista, México: Siglo XXI.

Misas Arango, Gabriel, 1994, "Elementos para una Política de Desarrollo para la Industria Colombiana", in: Bernal A. Jorge A., 1994, Integración y Equidad. Democracia, Desarrollo y Politica Social, Bogotá:Viva La Ciudadanía / Corporación S.O.S. Colombia, p.p. 185-201

Misas Arango, Gabriel, 2001, "De la Sustitución de Importanciones a la Apertura Económica. La Difícil Consolidación Industrial", in: Misas, Arango Gabriel, 2001 Desarrollo Económico y Social en Colombia. Siglo $X X$, Bogotá: Universidad Nacional de Colombia, p.p. 111-1134

Mittelman, James H. (ed.), 1996, Globalization: Critical Reflections, Boulder: Lynne Rienner.

Montenegro, Armando, 1991, "Lineamientos del Nuevo Plan de Desarrollo", in: Anif, Subsiste el Futuro: Constitutción Política y Económica, Bogotá.

Montenegro Armando, 1994, "Justicia y Desarrollo Económico", in: Planeación y Desarrollo, vol. XXV, julio, 1994, Departamento Nacional de Planeación, Bogotá.

Montenegro Armando, Posada, Carlos Esteban, and Piraquive Gabriel, 2000, "Violencia Criminalidad y Justicia: Otra Mirada desde la Economia", in: Coyuntura Económica, Vol. XXX, No. 2, junio 2000, Fedesarrollo. 
Moore, Barrington, 1966, The Social Origins of Dictatorship and Democracy, Boston: Beacon Press.

Morley, Samuel A., 1995, Poverty and Inequality in Latin America: The Impact of Adjustment and Recovery in the 1980s, Baltimore: The John Hopkins University Press.

Munk, Gerardo, 1996, "Disaggregating Polítical Regime: Conceptual Issues in the Study of Democratization", in: Kellog Institute Working Paper, No. 228.

Nelson, Joan (ed.), 1990, Economic Crisis and Policy Choice: The Politics of Adjustment in the Third World, Princeton: Princeton University Press.

Naim, Moises, 1999, "Fads and Fashions in Economic Reforms: Wahington Consesus or Washington Confusion?" in: IMF Conference on Second Generations Reforms, Washington, 1999

North, Douglass, 1990, Institutions, Institutional Change, and Economic Performance, Cambridge: Cambridge University Press.

Nozick, Robert, 1990, Anarquia, Estado y Utopía, México: Fondo de Cultura Económica.

Núñez, Jairo, and Sánchez, Fabio, 1998, Educación y Salarios Relativos en Colombia, 1976-1995", Bogotá: Departamento Nacional de Planeación, Archivos de Macroeconomía, No. 74

Ocampo, José Antonio, Reforma del Estado y Desarrollo Económico en Colombia", in: Análisis Político, No. 17, septiembre-diciembre, 1992, p.p. 5-40

O'Connor, James, 1973, The Fiscal Crisis of the State, New York: Saint Martin Press.

O'Donnell, Guillermo, 1973 Modernization and Bureaucratic-Authoritarianism: Studies in South American Politics, Berkeley: Institute for International Studies, University of California.

O'Donnell, Guillermo and Schmitter, Philippe C. (Eds.), 1986, Tentative Conclusions About Uncertain Democracies, Baltimore: John Hopkins University Press.

O'Donnell, Guillermo, 1992, On the State, Various Crisis and Problematic Democratizations (Preliminary Draft). Notre Dame: Hellen Kellog Institut for International Studies, University of Notre Dame / CEBRAP.

O'Donnell, Guillermo, 1996, "Illusions About Consolidation", in: Journal of Democracy, Vol. 7. No. 2, April, 1996 
Offe, Claus, 1993, Contradictions of the Welfare State, Cambridge, Mass.: The MIT Press.

Oquist, Paul, 1978, Violencia, Conflicto y Política en Colombia, Bogotá: Instituto de Estudios Colombianos.

Orjuela, Luis Javier, 1990, "Narcotráfico y Política en la Década de los Ochenta: Entre la Represión y el Diálogo", in: Arrieta, Carlos G., et. al., Narcotrafico en Colombia: Dimensiones Politicas, Económicas, Jurídicas e Internationales, Bogotá, Tercer Mundo Editores/Ediciones Uniandes.

Orjuela, Luis Javier, 1992, "La Descentralización en Colombia: Paradigma para la Eficiencia y la Legitimidad del Estado", en Dugas, John, Ocampo, Angélica, Ruíz Germán, y Orjuela, Luis J., 1992, Los Caminos de la Descentralización. Diversidad y Retos de la Transformación Municipal, Bogotá: Universidad de los Andes, Departamento de Ciencia Política.

Orjuela, Luis Javier, 1984, "Reflexiones en Torno a la Reforma Laboral", in: Controversia, No. 120, octubre, 1984, p.p. 67-89

Oslak, Oscar, 1981, "The Historical Formation of the State in Latin America: Some Theoretical and Methodological Guidelines for its Study", in: Latin American Research Review, vol., XVI, No. 2, 1981, p.p. 3-29

Osterling, Jorge, 1989, Democracy in Colombia: Clientelist Politics and guerilla Warfare, New Brunswick: Transaction Publishers

Oxhorn, Philip D. y Ducatenzeiler, Graciela, 1998, What Kind of Democracy? What Kind of Markets? Latin America in the Age of Neoliberalism, Pennsylvania: Pennsylvania State University Press.

Palacios, Marco, 1980a, "La Fragmentación de las Elites Regionales en Colombia: una Perpectiva Histórica", in: Revista Mexicana de Sociología, vol. XLII, No. 4, 1980. p.p.1663-1687

Palacios, Marco, 1980b, Coffee in Colombia, 1850-1970, an Economic, Social y Political History, Cambridge, MA.: Cambridge University Press.

Palacios, Marco, 1995, Entre la Legitimidad y la Violencia: Colombia 1875-1994, Bogotá: Grupo Editorial Norma.

Pecaut, Daniel, 1987, Orden y Violencia: Colombia, 1930-1953, Vol. I, Bogotá: Cerec/Siglo XXI.

Peeler, John, 1985, Latin American Democracies: Colombia, Costa Rica, Venezuela, Chapel Hill: University of North Carolina Press. 
Petras, James and Leiva Fernando I., 1994, Democracy and Poverty in Chile: the Limits to Electoral Politics, Boulder: Westview Press.

Pizarro, Eduardo, 2001, "La Reforma Política: El Dilema entre la Incorporación y la Ingobernabilidad", in: Revista Foro, No. 41, junlio 2001. p.p. 99-110

Poulantzas, Nicos, 1979, Estado, Poder y Socialismo, México: Siglo XXI.

Prealc, 1990, América Latina, Inversión y Equidad, Santiago de Chile.

Presidencia de la República de Colombia, Departamento Nacional de Planeación, 1991, La Revolución Pacífica: Plan de Desarrollo Económico y Social 1990-1994, Bogotá.

Presidencia de la República de Colombia, Departamento Nacional de Planeación, 1992, Colombia: Descentralización y Federalismo Fiscal. Informe Final de la Misión para la Descentralización, Bogotá.

Presidencia de la República- DNP, 1994, El Salto Social. Bases para el Plan de Desarrollo, 1994.1998, Bogotá.

Presidencia de la República- DNP, 1995, El Salto Social. Plan Nacional de Desarrollo, 1994-1998, Bogotá.

Pretelt De La Vega, Sabas, 1994, Apertura y Desarrollo. Elementos Para el Debate, Bogotá: Editorial Linotipia

Przeworski, Adam, 1991, Democracy and the Market: Political and Economic Reforms in Eastern Europe and Latin America, New York: Cambridge University Press.

Przeworski, Adam and Limongni, Fernando, 1993, "Political Regimes and Economic Growth", in: Journal of Economic Perspectives, No. 7, p.p. 51-57

Pulecio, Jorge Reinel, 1991, La Apertura en Colombia, Bogotá: Fescol.

Rawls, John, 1971, A Theory of Justice, Cambridge, Ma: The Belknap Press of Harvard University Press.

Remmer, Karen, 1990, "Democracy and Economic Crisis: The Latin American Experience", in: World Politics, Vol. 42, p.p. 315-335

Remmer, Karen L., 1991, "New Wine or Old Bottlenecks? The Study of Latin American Democracy", in: Comparative Politics, Vol. 23, No. 4, July, p. 479-495.

Remmer, Karen L., 1992, "The Process of Democratization in Latin America", in: Studies in Comparative International Development, vol. 27, No.4, p. 3-24. 
Restrepo, Luis Alberto, 1993, Síntesis 93 Anuario Social, Politico y Económico de Colombia, Bogotá: Tercer Mundo / IEPRI, Universidad Nacional.

Rettberg, Angelika, 2001, "Dos Crisis, Dos Desenlaces: Retos y Realidades del Empresariado Organizado Colombiano en los Años Cincuenta y Noventa", in: Revista de Estudios Sociales, No. 8, enero, 2201

Reyes, Alejandro, et. al., 1978, Estatuto de Seguridad, Derechos Humanos, Democracia Restringida, Bogotá: Cinep, Serie Controversia, No. 70-71

Rosenau, James N. 1990, Turbulence in World Politics: A Theory of Change and Continuity, Princeton: Princeton University Press.

Rosenau, James N. and Czempiel, Ernst-Otto (eds.), 1992, Governance Without Government: Order and Change in World Politics, Cambridge: Cambridge University Press.

Rojas Fernando, 1981, El Estado Colombinano en los Ochenta: un Régimen Policivo? Bogotá: Cinep, Serie Controversia, No. 82-83

Rubio, Mauricio, 1999, "La Justicia en una Sociedad Violenta", in: Deas, Malcom, and Llorente, Maria Victoria (comp.), Reconocer la Guerra para Construir La Paz, Bogotá: Cerec/Ediciones Uniandes, 1999

Rueschemeyer, Dietrich; Huber Stephens, Evelyn, and Stephens, John D., 1992, Capitalist Development and Democracy, Chicago: University of Chicago Press.

Sarmiento Palacios, Eduardo, 1992, "La Constitución y la Economía: el Modelo por Armar", in: Parra E., Nestor Hernando, 1992, Los Cambios Constitucionales. Bogotá: Sociedad Económica de Amigos del País.

Sarmiento Palacio Eduardo, 1998, Alternativas a la Encrucijada Neoliberal. Mercado, Narcotráfico y Descentralización, Bogotá: Ediciones ECOE /Academia Colombiana de Ciencias Económicas / Editorial Escuela Colombiana de Ingenieria.

Sarmiento Palacio Eduardo, 2000, Cómo Construir una Nueva Organización Económica. La Inestabilidad Estructural del Modelo Neoliberal. Elementos para un Estado Estratégico, Bogotá: Editorial Oveja Negra /Academia Colombiana de Ciencias Económicas / Editorial Escuela Colombiana de Ingeniería.

Sassen, Saskia, 1996, Losing Control? Sovereignty in an Age of Globalization, New York: Columbia University Press.

Scholte, Jan Aart, 2000, Globalization. A Critical Introduction, New York: St. Martin's Press. 
Seligson, Mitchel A., 1987, "Democratization in Latin America: The Current Cycle", in: Malloy, James M. and Seligson Mitchel A. (Eds.), 1987, Authoritarians and Democrats: Regime Transitions in Latin America, Pittsburgh: Pittsburgh University Press.

Schedler, Andreas, Diamond Larry, and Plattner, Marc F., 1999, The Self Restraining State, Boulder: Lynne Rienner Publishers.

Silva Colmenares, Julio, 1978, Los Verdaderos Dueños del País, Bogotá: Editorial Suramericana

Simon, Herbert, 1947, Administrative Behavior. A Sudy of Decision Making Process in Administrative Organization, New York: The MacMillan Company.

Skocpol, Theda, 1979, States and Social Revolutions: A comparative Analysis of France, Russia and China, Cambridge, Mass.: Cambridge Universiry Press

Skocpol, Theda, 1985, "Bringing the State Back in" Evans, Peter; Reuschemeyer, Dietrich and Skocpol, Theda (eds), 1985, Bringing the State Back In, Cambridge: Cambridge University Press.

Smith, William C., Acuña, Carlos H. and Gamarra, Eduardo A., 1994, Latin American Political Economy in the Age of Neoliberal Reform. Theoretical and Comparative Perspectives of the 1990s, Coral Gables: North-South Center, University of Miami.

Smith, Wiiliam C., Acuña, Carlos H. and Gamarra, Eduardo A. (eds.), 1994b, Democracy, Markets, and Structural Reform in Latin America: Argentina, Bolivia, Brazil, Chile and Mexico, Coral Gable: North-South Center, University of Miami.

Smith, William C. and Korzeniewicz, Roberto Patricio, 1997, Politics, Social Change, and Economic Restructuring in Latin America, Coral Gable: North-South Center Press, University of Miami.

Sola, Lourdes, 1994, "The State, Structural Reform and Democratization in Brazil", in: Smith, Wiiliam C., Acuña, Carlos H. and Gamarra, Eduardo A. (eds.), 1994b, Democracy, Markets, and Structural Reform in Latin America: Argentina, Bolivia, Brazil, Chile and Mexico, Coral Gable: North-South Center, University of Miami.

Stiglitz Joseph, 2001, "Lo que Aprendi de la Crisis Económica Mundial", in: Lecturas Dominicales, 26 de agosto de 2001

Stallings, Barbara, 1992, "La Influencia Internacional en las Políticas Económicas: Deuda, Estabilización y Reforma Estructural, en: Haggard, Stephan y Kufman, Robert, 1992, La Politica de Ajuste Económico. Las Restricciones Internacionales, los Conflictos Distributivos y el Estado, Bogotá: Cerec, 1992 
Taylor, Charles, 1994, "The Politics of Recognition", in: Gutmann, Amy (ed.), Multiculturalism, Princeton: Princeton University Press.

Thoumi, Francisco, 1994, Economia, Política y Narcotráfico, Bogotá: Tercer Mundo Editores.

Tickner, Arlene, 2001, "Tensiones y Contradicciones en los Objetivos de la Politica Exterior Estadounidense en Colombia: Consecuencias Involuntarias de la Politica Antinarcóticos de Estados Unidos en un Estado Débil, in: Colombia Internacional, No. 49-50, 2001, p.p. 39-61

Tilly, Charles, 1992, Coercion, Capital and the Europen States, AD 990-1992, Princeton: Princeton University Press.

Tirado Mejía, Alvaro, 1989, "López Pumarejo: La Revolución en Marcha",in: Nueva Historia de Colombia, Tomo I, Historia Politica 1886-1946, Bogotá: Editorial Planeta

Uprimmy, Rodrigo, "Constitución de 1991, Estado Social de derecho y Derechos Humanos: Promesas Incumplidas, Diagnósitcos y Perpectivas", in: Seminario de Evaluación. Diez Años de la Constitución Colombiana 1991-2001, Bogotá: Universidad Nacional de Colombia, Facultad de Derecho, Ciencias Políticas y Sociales/ILSA, junio, 2001

Uribe, María Teresa, 2001, "Las Promesas Incumplidas de la Democracia Participativa", in: Seminario de Evaluación. Diez Años de la Constitución Colombiana 1991-2001, Bogotá: Universidad Nacional de Colombia, Facultad de Derecho, Ciencias Políticas y Sociales / ILSA, junio, 2001

Uribe de Hincapie, María Teresa, and Alvarez, Jesús Maria, 1987, Poderes y Regiones: Problemas en la Constitución de la Nación Colombiana 1810-1850, Medellín: Universidad de Antioquia.

Urrutia Montoya, Miguel, 1981, Gremios, Politica Económica y Democracia, Bogotá: Fdesarrollo/Fondo Cultural Cafetero.

Urrutia Montoya, Miguel, 1984, Los de Arriba y los de Abajo: las Distribución del Ingreso en Colombia en las últimas Décadas, Bogotá: Cerec/ Fedesarrollo.

Urrutia Montoya Miguel, 1994 "Colombia”, in: Williamson John, 1994, The Political Economy of Policy Reform, Washington D.C.: Institute for International Economics

US Department of State, 2000, Infrome sobre Derechos Humanos. Colombia 1999, Bogotá: USIS, Marzo.

Vacs, Aldo C., 1994, "Convergence and Dissension: Democracy, Markets and Structural Reform in World Perspective, in: Smith, William C., Acuña, Carlos H. and 
Gamarra, Eduardo A., Latin American Political Economy in the Age of Neoliberal Reform. Theoretical and Comparative Perspectives of the 1990s, Coral Gable: NorthSouth Center, University of Miami, 1994

Van Parijs, Philippe, 1992, ¿Qué es una Sociedad Justa?Introducción a la Práctica de la Filosofia Politica, Buenos Aires: Ediciones Nueva Visión.

Wang, Hongying, and Rosenau, James N., 2001, "Transparency International and Corruption as an Issue of Global Governance", in: Global Governance, vol. 1. No. 7, Jan-Mar., p.p. 25-49

Waterbury, John, 1992, “¿El Meollo del Asunto? La Empresa Pública y el Proceso de Ajuste", en; Haggard, Stephan y Kaufman, Robert (comps.)1992, La Política de Ajuste Económico. Las Restricciones Internacionales, Los Conflictos Distributivos y El Estado, Bogotá: Cerec, p.p. 226-268

Weber, Max, 1997, Economia y Sociedad, Bogotá: Fondo de Cultura Económica.

Williamson, John, 1990a, The Progress of Policy Reform in Latin America, Washington D.C.: Institute for International Economics.

Williamson, John, 1990b, Latin American Adjustment: How Much Has Happened?, Washington D.C.: Institute for International Economics.

World Bank, Commercial Policy Survey, 1983-1987, Washington

World Bank, 1997, World Development Report. The State in a Changing World, New York: Oxford University Press.

World Bank, 2002, Colombia Poverty Report, in: http://www.worldbank.org/co

\section{Magazines and Newspaper}

Cambio

El Colombiano

El Espectador

El País

El Siglo

El Tiempo

La República

Semana 
VITA

\section{LUIS JAVIER ORJUELA}

September 24, 1954

Born, Medellin, Colombia

Educational Background

1998- 2004

Ph. D. Candidate, Political Science

Florida International University (Miami, Fl.)

1995-1997

M.A., Political Science

Florida International University ( Miami, Fl.)

1985-1987

Master Public Administration

Hochschule für Verwaltungswissenschaten

Speyer,Germany

1974-1979

Law Degree (Lawyer)

Universidad Santo Tomás, Bogotá, Col.

Professional Experience

Since 1998

Asociate professor, Poltical Science Department Los Andes University, Bogotá, Col.

1991- 1995

Docent and researcher, Political Science Department, Los Andes University, Bogotá, Col.

1990-1991

Advisor to the Office of Modernization of the State Presidency of the Repúblic of Colombia.

$1980-1985$

Researcher in Social Science, Centro de Investigación y Educacion Popular, CINEP, Bogotá.

Publications

Luis Javier Orjuela E., "Las Transformaciones Contemporáneas de lo Político y sus Problemas de Legitimación", en: Revista Internacional de Filosofia Politica, No. 22, diciembre, 2003.

Ann Mason y Luis Javier Orjuela (editores), La Crísis Politica Colombiana. Más que un Conflicto Armado y un Proceso de Paz, Bogotá: Uniandes- Facultad de Ciencias SocialesDepartamento de Ciencia Política-Ceso-Fundación Alejandro Angel Escobar, 2003 
Luis Javier Orjuela E, Colombia: "Dos Proyectos de Sociedad Enfrentados", en: Ann Mason y Luis Javier Orjuela (editores), La Crisis Politica Colombiana. Más que un Conflicto Armado y un Proceso de Paz, Bogotá: Uniandes- Facultad de Ciencias SocialesDepartamento de Ciencia Política-Ceso-Fundación Alejandro Angel Escobar, 2003, p.p. 123-141

Luis Javier Orjuela y Sergio De Zubiría, "Colombia en la Década de los Noventa: Crisis de Integración Politica y Social", en: Ecuador Debate, No. 53, agosto de 2001, Quito, Ecuador, p.p. 125-144, ISSN: 1012-1498

Luis Javier Orjuela E., "La Debilidad del Estado Colombiano en Tiempos del Neoliberalismo y el Conflicto Armado", en: Colombia Internacional, No. 49-50, febrero de 2001, Bogotá, Universidad de los Andes, Centro de Estudios Internacionales.

The anterior article was also published in the United States as "The Weakness of the Colombian State in the Age of Neoliberalism and Armed Conflict", in: David Myhre (editor), Colombia: Civil Conflict, State Weakness, and (In)Security, Princeton: Princeton University, Program in Latin American Studies, PLAS Cuadernos, Number 7, 2003. p.p. 64-84

Luis Javier Orjuela E., "El Estado Colombiano en los Noventa: Entre la Legitimidad y la Eficiencia", en: Revista de Estudios Sociales, No. 1, agosto, 1998, Bogotá, Universidad de los Andes, Facultad de Ciencia Sociales/ Fundación Social, ISSN: 0123-885X

"La Economía Política de la Reforma del Estado Colombiano", en: Dos Aproximaciones a la Reforma del Estado en Colombia. Documentos de Trabajo, No.1, Enero de 1995, Bogotá, Universidad de los Andes, Departamento de Ciencia Política

"Hacia una Nueva Configuración de Estado Colombiano en la Década de los Noventa", en: Política Colombiana, Vol. II, No. 2, 1992, Bogotá, Contraloría General de la República. 